\title{
Long-term effects of timber management on forest breeding songbirds in the central Appalachians
}

\author{
Douglas Becker \\ West Virginia University
}

Follow this and additional works at: https://researchrepository.wvu.edu/etd

\section{Recommended Citation}

Becker, Douglas, "Long-term effects of timber management on forest breeding songbirds in the central Appalachians" (2010). Graduate Theses, Dissertations, and Problem Reports. 3188.

https://researchrepository.wvu.edu/etd/3188

This Dissertation is protected by copyright and/or related rights. It has been brought to you by the The Research Repository @ WVU with permission from the rights-holder(s). You are free to use this Dissertation in any way that is permitted by the copyright and related rights legislation that applies to your use. For other uses you must obtain permission from the rights-holder(s) directly, unless additional rights are indicated by a Creative Commons license in the record and/ or on the work itself. This Dissertation has been accepted for inclusion in WVU Graduate Theses, Dissertations, and Problem Reports collection by an authorized administrator of The Research Repository @ WVU.

For more information, please contact researchrepository@mail.wvu.edu. 


\title{
LONG-TERM EFFECTS OF TIMBER MANAGEMENT ON FOREST BREEDING SONGBIRDS IN THE CENTRAL APPALACHIANS
}

DOUGLAS BECKER

\author{
Dissertation submitted to the \\ Davis College of Agriculture, Natural Resources and Design \\ at West Virginia University \\ in partial fulfillment of the requirements for the degree of
}

\author{
DOCTOR OF PHILOSOPHY \\ in \\ FOREST RESOURCES
}

\author{
Petra Bohall Wood, Ph.D., Chair \\ James T. Anderson, Ph.D. \\ Gerald R. Hobbs, Ph.D. \\ Patrick D. Keyser, Ph.D. \\ Michael P. Strager, Ph.D.
}

Division of Forestry and Natural Resources

\author{
Morgantown, West Virginia \\ 2010
}

Keywords: timber management, clear-cut, partial harvest, songbird, threshold, Canada Warbler, bird-habitat relations 


\section{ABSTRACT \\ LONG-TERM EFECTS OF TIMBER MANAGEMENT ON FOREST BREEDING SONGBIRDS IN THE CENTRAL APPALACHIANS}

\section{DOUGLAS BECKER}

Multiple-use demands on forests often lead to compromises among human benefits from timber harvesting and maintaining habitat for wildlife and ecosystem function. Timber harvests are economically important throughout the central Appalachians; at the same time, many species of neotropical migrant bird species have been declining, including mature forest and early successional species. Past research has primarily been short-term, focused on single harvest types or single harvesting events, overlooking the complexity of long-term, continued forest management using multiple harvesting methods, which this study addresses.

I conducted 50-m fixed radius point counts and monitored nests at the Wildlife and Ecosystem Research Forest (WERF) and Panther Run Tract in Randolph County, WV, from 2007-2009 and incorporated previous research using the same techniques from 1996-1998 and 2001-2003. I digitized annual landcover, dividing the cover classes into five categories: mature deciduous, mature mixed, clear-cut, light partial harvest, and heavy partial harvest. From each yearly landcover, I calculated the area by landcover type and landscape metrics at two scales: landscape and local. The study area was divided into three elevational blocks (Panther Run was a block and the WERF was divided in two), which each represented a landscape. I used a 100-m radius around each point count and nests to calculate local scale landcover and metrics for chapters two and three and a 300-m radius for chapter four..

In chapter two, my objectives were to identify temporal abundance and nest success trends and identify landscape-scale disturbance thresholds for species and habitat guilds using a variety of harvests. Early successional species increased in relative abundance, while interioredge and forest-interior guilds peaked in relative abundance mid-study, after which the forestinterior guild declined. Of 44 analyzed species, 9\% declined, 36\% increased, and 32\% peaked in abundance mid-study. Forest-interior and interior-edge guilds exhibited thresholds, a disproportionate response in bird abundance relative to a small change in habitat results, at $28 \%$ of the landscape, $10 \%$ harvesting by clear-cuts, and $18 \%$ harvesting by light partial harvests, after which abundances declined. Thresholds for the early successional guild were greater for 
total harvests (42\%), similar for harvesting by clear-cuts $(11 \%)$, and smaller for light partial harvests(10\%), for which relative abundances increased after surpassing thresholds except for a reduction in the rate of increase for clear-cuts. Even though abundance of most species (82\%) did not decline as the area affected by timber management increased, implementing management at or below our approximate harvest thresholds for forest-interior and interior-edge guilds would reduce the number of declining species by half.

In chapter three, my objective was to use the broader spectrum of habitat conditions resulting from long-term management to categorize bird species into habitat groups, identify habitat commonalities between group members, and determine habitat conditions associated with successful nests. Using non-metric multidimensional scaling (NMDS), I identified four habitat groups: mature forest, disturbed-canopy low elevation, disturbed-canopy high elevation, and early succession. Early successional species increased in abundance with greater amount of clear-cuts, heavy partial harvests, and edge density. The two disturbed-canopy groups (divided based on elevation) had no consistent metrics among species, but included variables representing different aspects of disturbed mature forests. Mature (undisturbed) forest species declined in abundance with increased clear-cuts, core early succession habitat, and habitat intermixing and reduced shape complexity. Nest success models had high error due to small sample sizes; still, they suggested different conditions are required for successful breeding than for high abundance. My results highlight the need to reconsider the classification of bird species with respect to habitat created by timber management. Group members shared many habitat commonalities and model error was improved over traditional habitat guilds, but variation remains among most species within these groups.

In chapter four, my objectives were to evaluate the response of Canada Warbler (CAWA) abundance and nest success to habitat characteristics as they changed due to forest management practices. According to the Breeding Bird Survey (BBS), the abundance of this declining species has been stable in the Appalachian Bird Conservation Region (BCR), suggesting this region may make important contributions to the species' conservation; however, off-road point count results indicate that CAWA relative abundance decreased on the WERF and the Appalachian BCR, but at lower yearly rates on the WERF. Early in the study, relative abundance was greater closer to roads, but as timber harvest became more common, it was positively related to area of light partial harvests at the local scale. Overall, relative abundance responded positively to all three 
types of timber harvests. Nest success did not differ between 1996-1998 and 2007-2009. Nests in 2007-2009 had less intermediate canopy cover and residual trees but more green cover, woody debris, and pole trees than nests in 1996-1998. Successful nests had more low cover, less vertical diversity, more woody debris, more saplings, and greater edge density than unsuccessful nests. My research finds preliminary support for use of timber harvests management tool for Canada Warblers in the southern portion of their range with the need for long-term monitoring of abundance and nest success to confirm successful management. 


\section{ACKNOWLEGMENTS}

I first thank all the members of my graduate committee: Dr. Petra Wood, Dr. Jim Anderson, Dr. Michael Strager, Dr. Gerry Hobbs, and Dr. Pat Keyser. I appreciate their guidance, helpful edits and suggestions, and unique viewpoints without which I would not have been able to successfully complete this dissertation. I am grateful to Dr. Petra Wood for her support and advice. Her door was always open when I needed to discuss my research and helped guide me in the right direction. I thank Dr. George Merovich and Matt Shumar for their statistical help and guidance in using Program R. Lastly, I thank Becky Nestor who was vital behind the scenes, taking care of the endless bureaucracy and paperwork.

I thank the National Council for Air and Stream Improvement (NCASI), the MeadWestvaco Corporation, the West Virginia Cooperative Fish and Wildlife Resource Unit, and the West Virginia University for funding my research. Special thanks go to Dr. T. Ben Wigley, of NCASI, and Dr. Joe McNeel of the WVU Division of Forestry and Natural Resources.

I am also thankful for all the technicians who assisted me in my research: Jessica Harmening, Matthew Strassburg, Michael Capon, Patience Falatek, Tiffany Grade, Veronica Coptis, Sara Miller, Wendy Schalk, Sara Josenhans, Scott Mitchell, Sandy Taylor, Russ McClain, Alisha Morey, Mitchell Banach, and Amber Swicegood. This research would not be possible without their many hours climbing mountains and walking through overgrown timber harvests filled with green brier and Rubus.

I am grateful to Penn Virginia and Meadwestvaco Corporation, especially Aaron Plogher and Larry Jackson, for allowing my field crew to stay in the bunkhouse in Cassity and providing us with access to their properties. I also thank the employees of the timber companies who were willing to move their equipment so we could pass through their active logging zones and the local residents of Cassity for making everyone feel at home in their community and assisted with removal of the large pine tree that fell on one of the field vehicles, blocking the driveway at the bunkhouse.

Last but not least I thank my family. My parents have always supported and encouraged me to achieve my goals. This dissertation is a result of their love and care. 


\section{TABLE OF CONTENTS}

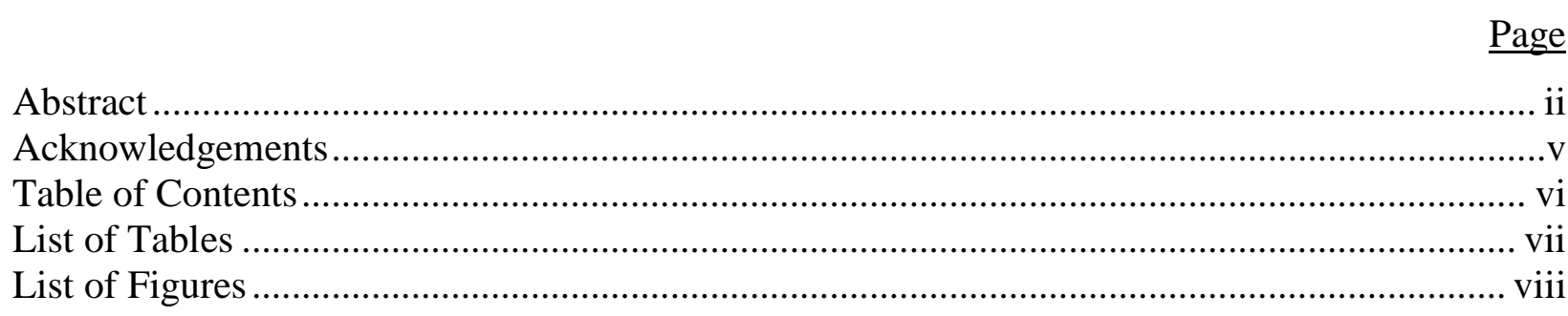

\section{CHAPTER 1: INTRODUCTION}

Introduction

$\underline{\text { Page }}$

Chapter Overview

Literature Cited

Figures

CHAPTER 2: THRESHOLD RESPONSES OF SONGBIRDS TO LONG-TERM TIMBER MANAGEMENT ON AN ACTIVE INDUSTRIAL FOREST

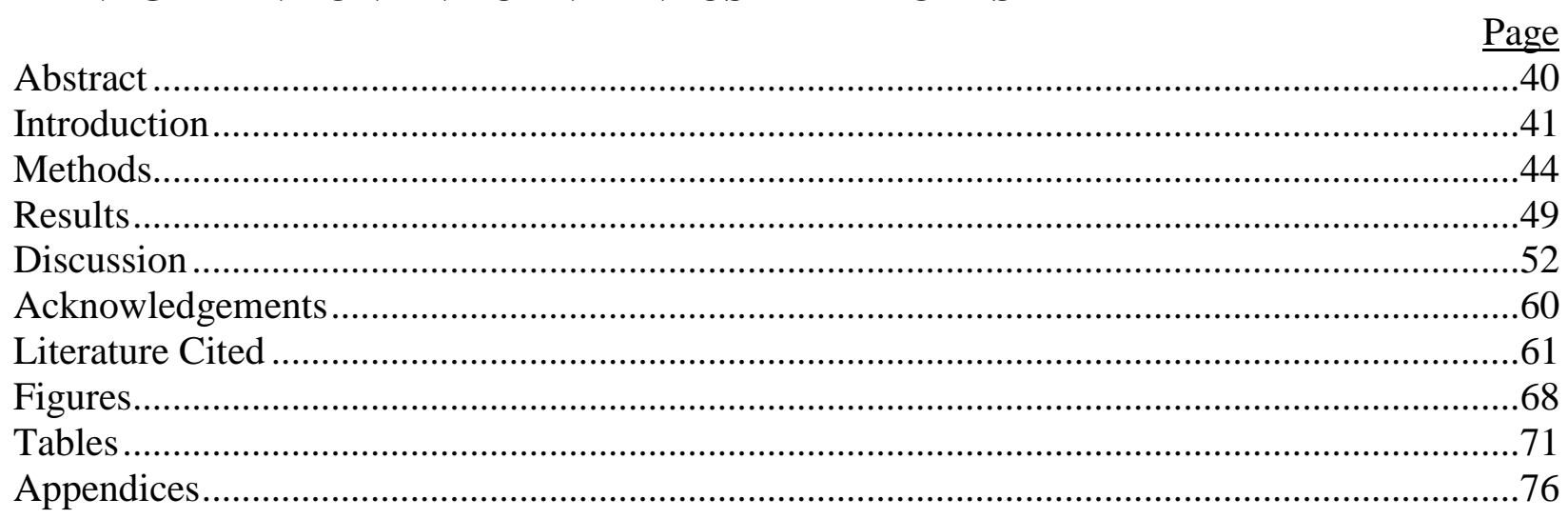

\section{CHAPTER 3: REASSESSING FOREST SONGBIRD HABITAT ASSOCIATIONS: INFLUENCE OF DISTURBANCE ON RELATIVE ABUNDANCE AND NEST SUCCESS ON A MANAGED LANDSCAPE IN THE CENTRAL APPALACHIANS}

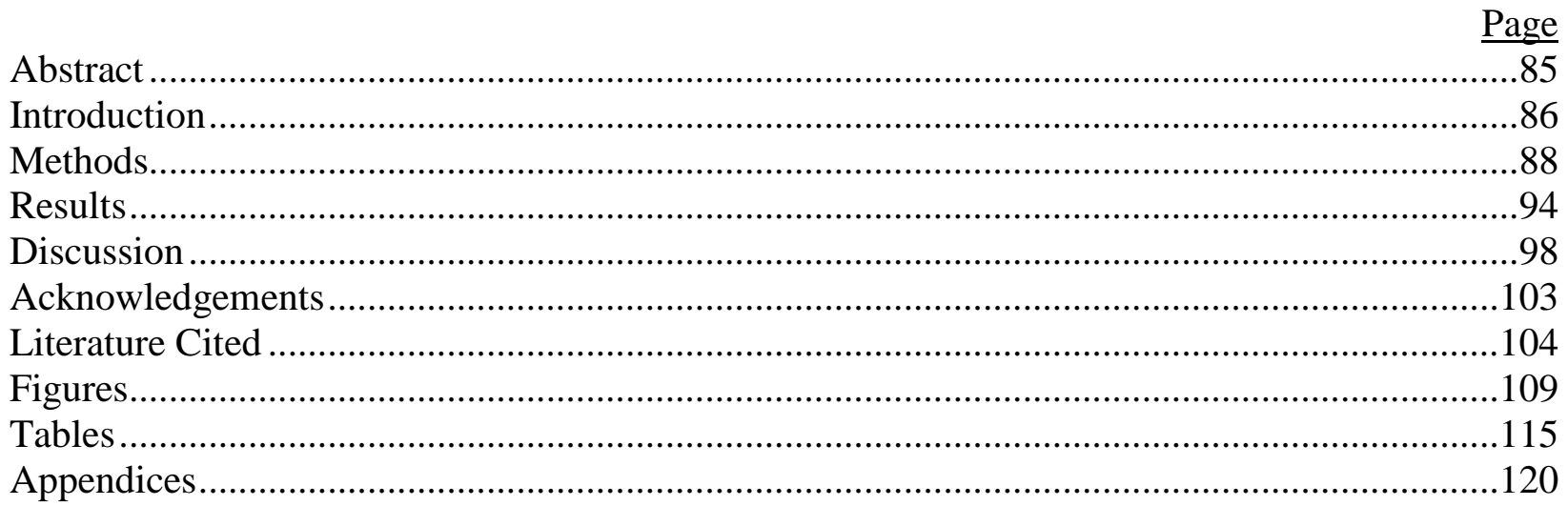




\section{CHAPTER 4: RESPONSE OF CANADA WARBLERS (WILSONIA CANADENSIS) TO CHANGING FOREST CHARACTERISTICS IN THE SOUTHERN PORTION OF THEIR RANGE}

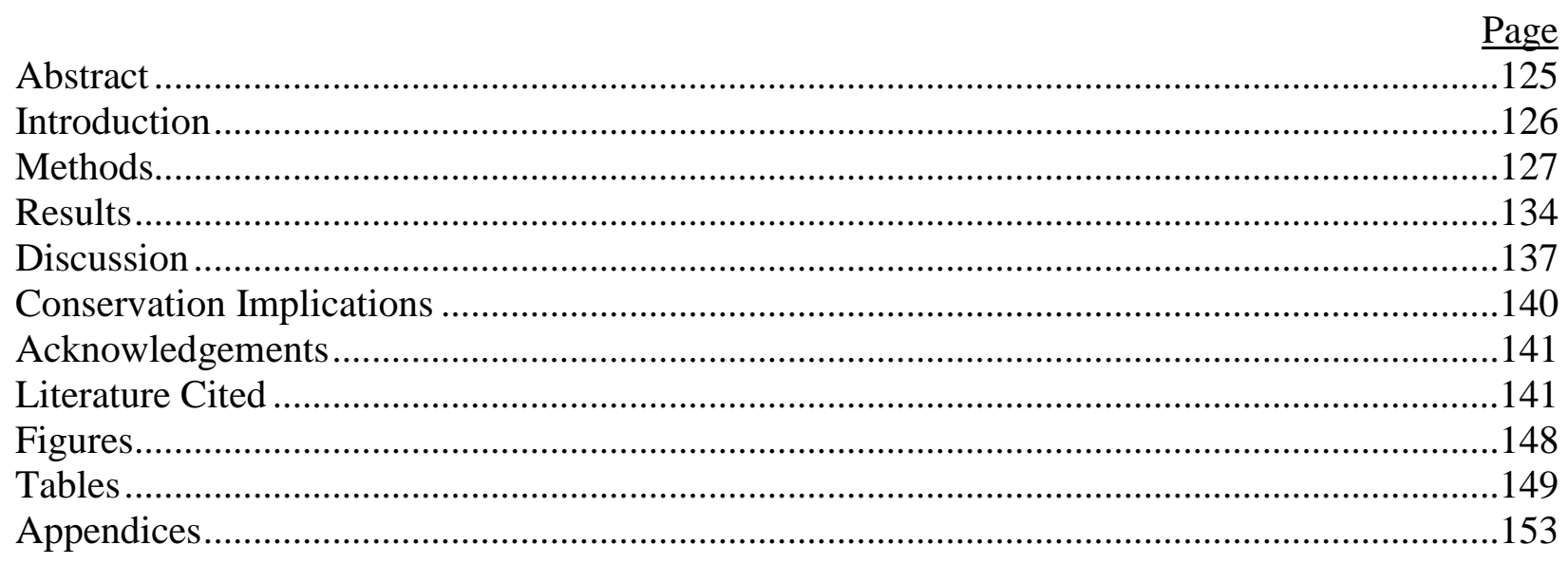

\section{LIST OF TABLES}

\section{CHAPTER 2:}

Table 1. Annual amounts of landcover (ha) at the Wildlife and Ecosystem Research Forest, 1996-2009

Table 2. Average relative abundance of bird species and guilds among 3-year periods at the Wildlife and Ecosystem Research Forest, WV, 1996-2009.

Table 3. Thresholds (\%) in relative abundance for total harvests, clear-cut harvest, and light partial harvests at the Wildlife and Ecosystem Research Forest, WV, 1996-2009.

Table 4. Nest success (surv) for focal species during each three-year period at the Wildlife and Ecosystem Research Forest, WV, 1996-2009.

\section{CHAPTER 3:}

Table 1. Regression tree results identifying landscape pattern metrics and landcover types influencing a change in relative abundance of traditional habitat guilds and NMDS ordination habitat groups at the Wildlife and Ecosystem Research Forest from 1996-2009.

Table 2. Regression tree results identifying landscape pattern metrics and landcover types influencing a change in relative abundance of focal bird species at the Wildlife and Ecosystem Research Forest from 1996-2009. 
Table 3. Classification tree results identifying landscape pattern metrics and landcover types distinguishing successful and unsuccessful nests of NMDS ordination habitat groups at the Wildlife and Ecosystem Research Forest from 2001-2009..

\section{CHAPTER 4:}

Table 1. Annual values for landscape metrics and landcover on the Wildlife and Ecosystem Research Forest, 1996-2009.

Page

Table 2. Landcover and landscape metrics retained in regression trees of Canada Warbler relative abundance during each three year time period (1996-1998, 2001-2003, and 2007-2009)

at the Wildlife and Ecosystem Research Forest.

Table 3. Variables retained in classification trees comparing Canada Warbler nests found in 1996-1998 $(n=9)$ and in 2007-2009 $(n=17)$ and comparing successful $(n=15)$ and unsuccessful nests $(n=11)$ in 1996-1998 and 2007-2009 for microhabitat and successful $(n=$ 11 ) and unsuccessful nests $(n=7)$ in 2007-2009 for landscape metrics at the Wildlife and Ecosystem Research Forest.

Table 4. Mean (\#/pt/yr) and SE for landcover and landscape metrics at point count stations $(n=1000)$, stations with Canada Warblers present $(n=266)$, and nest sites $(n=19)$ at the Wildlife and Ecosystem Research Forest, 1996-2009.

\section{LIST OF FIGURES}

\section{CHAPTER 1:}

Figure 1. The upper inset map shows the location of West Virginia within the black boundary of the Appalachian Bird Conservation Region. The black star locates the study area within West Virginia.

Figure 2. Point count locations at the Panther Run Tract, 2002-2003 and 2007-2009. The number indicates the elevational block.

Figure 3. Nest plot locations at the Panther Run Tract. Solid lined plots are the original plots and plots with dashed lines were shifted to that location due to changing landcover. The number indicates the elevational block.

Figure 4. Point count locations at the Wildlife and Ecosystem Research Forest in A) 1996-1998

and B) 2001-2003 and 2007-2009. The numbers represent the elevational blocks.

Figure 5. Nest plot locations at the Wildlife and Ecosystem Research Forest. Red lines are the nests plots in 1996-1998 and black lines are plots in 2001-2003 and 2007-2009. Plots with dashed lines represent plots that were shifted to that location due to changing landcover. The numbers represent the elevational blocks. 
Figure 6. Aerial photo of the Wildlife and Ecosystem Research Forest and surrounding landscape in 2007.

Figure 7. Aerial photo of the Wildlife and Ecosystem Research Forest and surrounding landscape in 2007 with the annual landcover layer overlayed.

Figure 8. New clear-cut harvest at the Wildlife and Ecosystem Research Forest.

Figure 9. Approximately 2-year old clear-cut harvest with early vegetative regeneration at the Wildlife and Ecosystem Research Forest. .36

Figure 10. New heavy partial harvest at the Wildlife and Ecosystem Research Forest.

Figure 11. Approximately 2-year heavy partial harvest with early vegetation regeneration harvest at the Wildlife and Ecosystem Research Forest.

Figure 12. Light partial harvest in a mature deciduous stand at the Wildlife and Ecosystem Research Forest.

Figure 13. Light partial harvest in a mature mixed forest stand at the Wildlife and Ecosystem Research Forest.

\section{CHAPTER 2:}

Figure 1. Bird diversity among 3-year periods using species richness (species/pt) and Shannon diversity at the Wildlife and Ecosystem Research Forest from 1996-2009. All 3-year periods for both diversity metrics are significantly different $(\alpha=0.05)$ according to the Dunnett-TukeyKramer multiple comparison test.

Figure 2. Percent total harvests of the landscape (range) for the 3-year period or periods with the largest relative abundance for each forest-interior species at the Wildlife and Ecosystem Research Forest from 1996-2009.

Figure 3. Percent total harvests of the landscape (range) for the 3-year period or periods with the largest relative abundance for each interior-edge species at the Wildlife and Ecosystem Research Forest from 1996-2009.

Figure 4. Percent total harvests of the landscape (range) for the 3-year period or periods with the largest relative abundance for each early successional species at the Wildlife and Ecosystem Research Forest from 1996-2009. 


\section{CHAPTER 3:}

Figure 1. Landscape blocks and nest searching plots (dashed plots were shifted due to timber harvests) within the Wildlife and Ecosystem Research Forest (lower) and Panther Run Tract (upper left), WV.

Figure 2. Local-scale boxplot results at point count locations $(\mathrm{n}=1270)$ for $\mathrm{A})$ elevation and $\mathrm{B})$ degree slope and within 100m of plot center for C) area-weighted mean shape index, D) contrastweighted edge density, E) interspersion-juxtaposition, F) Shannon diversity index, and G) the area of five landcover types (mature deciduous, mature mixed, clear-cut, light partial harvest, and heavy partial harvest) at the Wildlife and Ecosystem Research Forest and Panther Run Tract (combined) for entire study period, 1996 - 2009. The central line of the boxplot measures the median for each variable, while the ends of the box are the first and third quartiles. The whiskers on each boxplot extend to 1.5 times the interquartile range with dots representing values further than this cutoff..

Figure 3. Landscape-scale boxplot results for A) area-weighted mean shape index, B) contrastweighted edge density, C) interspersion-juxtaposition, D) Shannon diversity index, E) the area of core mature forest and core early succession, and F) the area of five landcover types (mature deciduous, mature mixed, clear-cut, light partial harvest, and heavy partial harvest) at the Wildlife and Ecosystem Research Forest and Panther Run Tract (combined) for entire study period, 1996 - 2009. The central line of the boxplot measures the median for each variable, while the ends of the box are the first and third quartiles. The whiskers on each boxplot extend to 1.5 times the interquartile range with dots representing values further than this cutoff.

Figure 4. Groupings of selected bird species A) early succession, B) low elevation disturbance, C), high elevation disturbance D), mature forest as a result of NMDS $(k=3)$ at the Wildlife and Ecosystem Research Forest and Panther Run Tract

Figure 5. Linear vector fitting for landscape pattern metrics and landcover on the first two axes of NMDS ordination ( $k=3)$ at the A) local and B) landscape scales. Variables with $p \leq 0.05$ are plotted..

Figure 6. Smoothed curves on the NMDS ordination $(\mathrm{k}=3)$ for non-linear metrics and landcover at the local scale (A) light partial harvest, B) mature deciduous, C) contrast weighted edge density, and D) Shannon diversity] and at the landscape scale [E) mature deciduous, F) clear-cut, $\mathrm{G})$ contrast-weighted edge density, and H) interspersion-juxtaposition. Arrows point from higher values to lower values.

\section{CHAPTER 4:}

Figure 1. Relative abundance (number of individuals/pt/year) of Canada Warblers by year at point counts on the Wildlife and Ecosystem Research Forest (WERF) and throughout the entire Appalachian Bird Conservation Region, 1996-2009. 
CHAPTER 1 INTRODUCTION 
Due to the "deepening biodiversity crisis" forest managers have begun implementing broader forest management approaches such as ecosystem management and sustainable forestry (Grumbine 1994, Haulton 2008), which have been adopted by many resource agencies (Brown and Marshall 1996, Thomas 1996). These approaches generally strive to sustain ecological integrity by maintaining viable populations, ecosystem representation, ecological processes, and evolutionary potential while accommodating human use (Grumbine 1994). Multiple-use demands on forests by humans and wildlife, often lead to compromises by forest managers and landowners when making management decisions. Therefore, economic benefits from timber harvesting and related wood products are often balanced against maintaining habitat for wildlife and ecosystem function and other human uses such as recreation, aesthetic beauty, and improved air and water quality.

As of 2000, West Virginia was the third most heavily forested state (78\%) in the United States with over 4.8 million ha of forest. Of these forested areas, $98 \%$ are available for timber harvesting (USDA Forest Service 2000) and all counties have a significant component of timberland (Childs 2005). Timber harvesting and related wood products are important economically for West Virginia, ranking ninth in share of total state employment and fourth in total gross state product (West Virginia Department of Commerce 2010). In 2008 approximately 9.5 million $\mathrm{m}^{3}$ of timber were harvested in West Virginia (Widmann et al. 2010) and when combined with other wood products, resulted in approximately 45,000 jobs (West Virginia Department of Commerce 2010) and contributed \$4 billion annually to the state (Childs 2005). The economic value of timber and wood products extends beyond West Virginia within the central Appalachian region. In Kentucky, forest industries provide 37,500 jobs and ship products worth $\$ 6.4$ billion annually (Thomas et al. 2007). In Tennessee, forests and forest products accounted for $6.6 \%$ of the state's economy, $\$ 21.7$ billion in economic output, and approximately 180,000 jobs (Young et al. 2007). Pennsylvania is the leading U.S. producer of hardwoods, over 1 billion board feet annually, and produces over $\$ 5.5$ billion of forest products yearly (Pennsylvania Forest Products Association 2004). Therefore, timber harvests are economically valuable throughout the region.

At the same time, many species of neotropical migrant bird species have been declining in West Virginia and other parts of the eastern United States (Askins et al. 1990, Peterjohn et al. 1995, Rich et al. 2005). Many factors have influenced this decline including habitat loss and 
degradation (Faaborg et al. 1995) and forest fragmentation (Robinson et al. 1995). Researchers have noted declines in species that require mature, minimally disturbed forests (Robbins et al. 1989, Hoover et al. 1995, Rosenberg et al. 1999) as well as disturbance-dependent shrub species (Hunter 2001, Dettmers 2003). Because West Virginia remains heavily forested compared to many other eastern states, the state has a unique opportunity to play a key role in forest bird conservation. Therefore, to ensure the long-term persistence of many bird species' populations while maintaining economically important timber harvest, research is needed to determine how to optimize harvesting goals and the habitat requirements of forest songbirds.

Because most research on the responses of birds to timber management has been shortterm, lasting only 1-2 years (Sallabanks et al. 2000), a need exists for long-term research to include not only the initial bird response but the continued response to future vegetative change. Further, this research should include multiple scales as different bird species respond to different scales of habitat management (Brennan and Schnell 2005).

\section{Silviculture-Habitat Change}

Timber harvests change the composition of forest habitats for bird species via the selection of specific trees. Further, type and size of the harvest can modify both the horizontal and vertical structure of the remaining habitat.

For forest-interior species, harvests may reduce the overall quantity of forested habitat and the overall quality of the remaining habitat by reducing patch size and increasing edge. Smaller, more fragmented stands experience higher nest predation rates (Yahner and Scott 1988, Hoover et al. 1995), and increased competition for resources from edge species (Wilcove and Robinson 1990), reducing nest success within the stands (Bollinger and Linder 1994). Smaller fragments also support less prey biomass for ground foraging bird species (Burke and Nol 1998) and gap formation and harvesting can depress arthropod availability (Duguay et al. 2000, Kilgo 2005). Although greater Brown-headed Cowbird, Molothrus ater, parasitism can be a problem in some landscapes (Brittingham and Temple 1983, Robinson 1992), it generally is not in heavily forested areas where cowbird abundance is relatively low (Annand and Thompson 1997, Duguay 2001, Rodewald and Yahner 2001, Moorman et al. 2002). Similarly, many other edge effects may be limited in more heavily forested areas (Rudnicky and Hunter 1993). 
At the same time, harvests increase the availability of early successional habitats, thereby, increasing the abundance of early successional specialist and generalist species (Drapeau et al. 2000, Duguay et al. 2001). Currently, many early successional species are declining as their habitats are advancing to later successional states following human-induced forest changes earlier in the century (Hagan 1993, Hunt 1996). Early successional species often decline from 6-15 years post-harvest depending on the type of harvest (McDermott 2007, McDermott and Wood 2009). Forest-interior bird species and their young also do not strictly rely on mature forest but use early successional habitats post-breeding (Vega Rivera 1998, Pagen et al. 2000, Marshall et al. 2003, Dellinger 2007, McDermott and Wood 2010). While artificial gap creation may cause declines in abundance of forest species, it does not always increase predation and parasitism (Germaine et al. 1997, Gram et al. 2003). Therefore, in a forestdominated landscape, harvesting might be an important management tool to support a broad array of bird species.

\section{$\underline{\text { Silviculture-Bird Response }}$}

Silvicultural treatments can increase overall avian diversity and abundance (Baker and Lacki 1997, King et al. 2001) by creating younger stands and a greater heterogeneity of landscape ages (Loehle et al. 2005). Due to past clear-cutting of a majority of eastern forests, many mature forests are approximately 100 years old and characterized by a dense overstory and open subcanopy, reducing vertical diversity. Timber harvests increase vertical diversity, which has a positive linear relation with bird diversity (Karr and Roth 1971) and was found to be an important local factor in bird abundance changes (Holmes and Sherry 2001). Higher diversity and abundance of birds in treated stands does not imply that logging is beneficial to the entire bird community. Individual species' abundances may be increased, but the treatments alter the composition of the bird community (Anderson and Crompton 2002). The effects of harvesting are beneficial to shrub-scrub species through habitat creation while negatively affecting interior forest species (Baker and Lacki 1997, Germaine et al. 1997, Duguay 2001, McDermott and Wood 2009). Avian response to disturbance can differ between natural and human disturbance regimes with generally greater effects on habitat availability from human disturbance (Klaus et al. 2005). However, research suggests that to maintain bird communities, management practices should simulate levels of natural disturbance (Drapeau et al. 2000). 


\section{$\underline{\text { Silvilcultural- Treatment Differences }}$}

Uneven-aged treatments include partial harvest techniques such as thinning, diameterlimit cutting, and single-tree selection (Smith 1962). Trees are selected based upon age, diameter, vigor, form, and species to maintain a relatively consistent stand structure (Thompson et al. 1995). Uneven-aged techniques retain a mix of age and size classes by selective harvest of individual trees or small groups (Nyland 1996) and often resemble natural disturbance such as ice and wind storms (Greenberg and Lanham 2001, Faccio 2003). As a result, uneven-aged treatments often have little effect on species composition and abundance of forest bird species (Thompson et al. 1995, Robinson and Robinson 1999, Weakland 2002, Gram et al. 2003, Campbell et al. 2007, Holmes and Pitt 2007), and increase the relative abundance of gapspecialist species (Brawn et al. 2001), but may not create suitable habitat for early successional species requiring large areas (Costello et al. 2000, DeGraaf and Yamasaki 2003). Uneven-aged treatments have little effect on nest survival (Robinson and Robinson 2001, Gram et al. 2003, King and DeGraaf 2004) including nest predation and cowbird parasitism (King et al. 2001, Clawson et al. 2002, Moorman et al. 2002, Gram et al. 2003) as long as the reduction of overstory canopy closure does not make the stand unsuitable. Over time, conditions remain beneficial for late-successional species, but wane within 15-20 years for early-successional ones (DeGraaf and Yamasaki 2003, Campbell et al. 2007).

In contrast, even-aged cuts remove a large percentage of the canopy cover and result in uniform patches of even-aged trees (Nyland 1996). Examples of even-aged treatments include clear-cuts, two-age harvests, and shelterwood cuts. Even-aged patches often have almost complete avian species turnover (Franzreb and Ohmert 1978). Following tree removal these patches are colonized by early successional bird species and late-successional, mature forest birds are rare until a new closed canopy forms through regeneration (Thompson et al. 1996, Baker and Lacki 1997, Duguay et al. 2001, Gram et al. 2003, Bulluck and Buehler 2006, Hanowski et al. 2006, Wallendorf et al. 2007). The size of the harvest also is important as most studies suggest some degree of area-sensitivity by early-successional species (Lent and Capen 1995, Costello et al. 2000, Gram et al. 2003, Brito-Aguilar 2005, Rodewald and Vitz 2005, Askins et al. 2007), although Krementz and Christie (2000) found no effects of even-aged harvest patch size. Though not suitable breeding habitat for mature forest birds, even-aged harvests are used post-breeding and during migration (Vega Rivera 1998, Pagen et al. 2000, 
Marshall et al. 2003, King et al. 2005, Vitz and Rodewald 2006, McDermott and Wood 2009) due to favorable foraging (Keller et al. 2003, McDermott and Wood 2009) and denser vegetative cover. Even-aged treatments also often lead to lower nest success for forest-interior species due to increased nest predation and parasitism (Robinson et al. 1995, Flaspohler et al. 2001, Manolis et al. 2002) but some research has found similar or greater nest survival rates in regenerating stands compared to nests within mature forest (Hanksi et al. 1996, Weakland 2000, Duguay et al. 2001, Gram et al. 2003). Compared to uneven-aged treatments, even-aged treatments vary primarily in the scale and the intensity of the disturbance (Brawn et al. 2001).

On a landscape scale, removing the same volume of tree basal area with either method results in the same total area of regeneration, because the amount of trees removed would be equal, but differs in the size and distribution of the disturbances (Shifley et al. 2000). Even-aged treatments result in landscape mosaics of different aged stands, while landscapes from unevenaged treatments are less heterogeneous but stands are composed of a range of tree sizes (Brawn et al 2001).

Clear-cutting is a type of even-aged treatment in which all trees from a selected stand are harvested at the same time however residual trees often are left standing (Smith 1962). Harrison and Kilgo (2005) found that compared to silvicultural clear-cuts, patch-retention harvests, an alternative to silvicultural clear-cutting in which the residual trees are left in a clumped distribution, had greater bird species abundance and richness and that forest-interior bird species recolonized these sites faster. Residual trees are important for retention of forest bird species following clear-cutting. Brawn et al. (2001) found that some canopy breeding species such as Scarlet Tanager, Piranga olivacea, and Great-crested Flycatcher, Myiarchus crinitus, will continue to breed within clear-cuts if residual trees are retained. Dellinger et al. (2007) found that three thrush species [Veery (Catharus fuscescens), Wood Thrush (Hylocichla mustelina), and American Robin (Turdus migratorius)] nested in clear-cuts stands often near residual canopy trees.

Shelterwood cuts vary from clear-cuts in that the harvest occurs in a series of two or more cuts (Smith 1962). Some trees are left uncut to provide protection and a partial canopy for the establishment of the new stand following harvest. Once the new stand is well developed, the remaining trees are harvested. Compared to clear-cuts, shelterwood cuts will favor regeneration of more shade-tolerant tree species (Brawn et al. 2001). While the responses of many bird 
species are similar to clear-cuts, some species show strong relations with the denser, vertical cover provided by shelterwood cuts (Annand and Thompson 1997, Brashear 2006, Augenfeld et al. 2008).

Two-age harvests, or deferment cuts, are even-aged harvests intermediate between clearcuts and shelterwood cuts. Two-aged harvests are created by removing at least half of the stand each half rotation, resulting in two distinct age classes (Marquis 1989). Compared to silvicultural clear-cuts, two-age cuts have greater vertical complexity and canopy cover (Weakland 2000). Where clear-cutting is not an acceptable practice, two-age management provides an acceptable conservation alternative when cowbird parasitism is not a concern (Duguay et al. 2001). Further, as compared to clear-cuts, the more complex canopy structure of two-aged stands supported almost a 5 times greater abundance of Cerulean Warblers (Dendroica cerulea), a species of conservation concern, in the Allegheny Mountains of West Virginia (Wood et al. 2005). Finally, many consider two-age harvests to have more aesthetic value than clear-cut harvests (Miller 1993).

Of the studies that have compared bird response to different even-aged and uneven-aged silvicultural treatments, few have found differences among harvesting treatments and some have contradictory results. At the stand scale, Baker and Lacki (1997) and Duguay et al. (2001) found no differences in overall bird abundance between clear-cuts and two-aged cuts, although Harrison and Kilgo (2004) found greater diversity and bird densities. Clawson et al. (2002) and King et al. (2001) found no differences in nest success of early successional species between group selection cuts and clear-cuts. Morrison (1992) found higher abundances of birds in uneven-aged stands, but suggested that managing for tree species diversity in even-aged stands could minimize these differences.

On a landscape scale, Thompson et al. (1996) modeled differences between even- and uneven-aged treatments and again found no difference for mature forest species, only differences in composition of early successional species caused by the availability of different size gaps in clear-cuts compared to selective cuts. Results examining the effects of landscape configuration were conflicting, as Drolet et al. (1999) found that birds did not respond to different mature forest configurations, while Mitchell et al. (2006) found that species richness was strongly related to the availability of and configuration of the landscape. 


\section{$\underline{\text { Study Scale }}$}

To effectively manage bird populations, a species' habitat relations must be examined on scales from local to landscape. Different bird species respond to different scales of habitat management, requiring multi-scale analysis for effective management of all species (Brennan and Schnell 2005). The best explanatory models of species richness and community similarity often include both local-scale measures of habitat structure and heterogeneity and also landscape-scale measures of the environment (Cleary et al. 2005). Further, vegetative landscape models based on the surrounding habitat matrix more accurately measure bird distribution than vegetative cover models based on the vegetation at the sampling site, highlighting the gains in predictive ability achieved by incorporating landscape patterns (Seoane et al. 2004). Optimal design of landscapes for bird conservation should include multiple scales (Will et al. 2005). Initially, the amount and conditions of habitat types at the landscape-scale should be characterized including their ability to support and sustain bird populations to develop population-based habitat objectives and identify landscapes of conservation priority. Patch characteristics and landscape configuration should be included in this landscape assessment. Next, to assess, predict, and monitor bird population response to landscape change and management activities, models should be created relating micro-scale vegetation to bird abundance and productivity. These models would predict the effects of stand level change such as the amount of edge, patch size, predator density, and vegetative structure. Finally, models at both scales, along with an assessment of the opportunity costs of conservation, are combined to create an optimal management solution.

The scale at which variables are measured also can influence bird-habitat relations. Small-scale data better explain variation in bird abundance, while landscape factors better explain the presence/absence of species (Cushman and McGarigal 2004). Finally, only using local factors in analysis limits the applicability of research because local factors can be misleading when used to predict the impact of forest management on larger regional scales (Drapeau et al. 2000).

\section{Need for Long-term Research using Multiple Harvest Types}

Long-term research is needed to investigate the response of bird communities to active timber management practices. Past research has been short-term in nature lasting only 1-2 years 
(Sallabanks et al. 2000). Short-term studies increase the likelihood that observed changes in bird abundance are due to yearly variability not related to the management practices under consideration by the study or that they reflect only the immediate response to habitat changes (Sallabanks et al. 2000, Collins 2001). Long-term research encompasses not only the initial change in habitat but the continued successional vegetative response.

Further, avian temporal response to landscape habitat change often is not linear in nature (Betts et al. 2007, Betts and Villard 2009), but can incorporate thresholds, during which a small change in habitat results in a disproportionate response in bird abundance and nest success. Theory has predicted the occurrence of landscape thresholds (With and Christ 1995, Fahrig 2003), but until recently few statistical techniques were available to identify them (Guenette and Villard 2005, Haggett 2005). Swift and Hannon (2010) suggest four possible explanations for thresholds: habitat configuration, allee effects, time lags, and habitat loss. Empirical tests for landscape thresholds remain uncommon (Homan et al. 2004, Radford and Bennett 2004) but are becoming more frequent in bird research including both simulation (Carlson 2000, Flather and Bevers 2002, Schrott et al. 2005) and empirical landscape studies (Carlson 2000, Imbeau and Desrochers 2002, Cushman and McGarigal 2003, Radford and Bennett 2004, Lindenmayer et al. 2005, Radford et al. 2005). Thresholds have been more commonly identified in agricultural landscapes than forest ones (Mönkkönen and Reunanen 1999), but this may be due to greater difficulty in identifying the distribution of habitat across a forest gradient (Wiens 1994). Thus, identifying timber harvesting thresholds would be of great value in management decisions.

Landscapes also typically consist of multiple owners, which often have different objectives and use different management practices. Thus, research needs to consider a diversity of timber management practices including both even-aged and uneven-aged methods. To date, most research has focused on avian response to different types and methods of timber harvests including those that compared the effects of even-aged and uneven-aged management to unmanaged forests (Weakland et al. 2002, Duguay et al. 2001, Augenfeld et al. 2008), the differences between harvest types (Annand and Thompson 1997, Baker and Lacki 1997, Duguay et al. 2001, Dellinger et al. 2007, McDermott and Wood 2009), and the effects of modifying existing harvesting techniques, for example retaining residual trees in clear-cuts (Brawn et al. 2001, Harrison and Kilgo 2004). However, most such studies have been short-term or have only focused on bird community response following initial harvest (Keller et al. 2003, Campbell et al. 
2007). Therefore, research is needed to determine the response to continual, long-term timber management using a variety of harvest types.

\section{Detection Probability}

Point counts, the most common method used to acquire the relative abundances of birds, assume equal detectability among both species and individuals, an assumption commonly violated. Variation in detectability can be caused by many factors that influence singing rate and activity including the time of day or season (Skirvin 1981, Amrhein et al 2004), breeding stage (Wilson and Bart 1981, Gill 2003), geographic region (Kroodsma et al. 1999), developmental differences (Titus et al. 1997), mate quality (Moller 1991, Otter et al. 1997), and food and/or water availability (Gottlander 1987, Rashotte et al. 2001). Further, point counts fail to account for differences in observer skill and training (Sauer et al. 1994, Diefenbach et al. 2003) or habitat acoustical properties that influence the degree to which singing birds can be heard (Richards 1981, Waide and Narins 1988). As a result, relative abundances include inherent bias which limits their value for comparing between species, for individual species across different habitats, or across other factors such as year or observer.

To overcome this limitation a variety of techniques have been proposed to determine detection probabilities such as removal models (Farnsworth et al. 2002), double-observer (Nichols et al. 2000), capture-recapture (Karr 1981), and distance sampling (Burnham et al. 1980, Buckland et al. 1993). To account for detectability within this study, I performed two different removal model analyses to determine differences between experienced and inexperienced observers and yearly differences. First, across all nine years of data, I calculated removal model detection probabilities using three time intervals (0-3min, 4-5, and 5-10). I found no observer or year differences, and the null model was selected for most species that failed to incorporate heterogeneity in detection among individuals within species. Second, I calculated removal models using the final 3-years of data collected from 2007-2009 using seven intervals (0-2min, $>2-3,>3-4,>4-5,>5-6,>6-7$, and >7-10). I did detect some observer and year differences in the detection probability per minute; however, these differences were negligible when calculated over the entire 10-min duration of the count.

Johnson (2008) found that no effective method of adjustment has yet been designed for large-scale, multi-species surveys, a classification under which this study falls, which is further 
supported by Efford and Dawson (2009) who also found that "no existing method allows effective estimation of population size from point counts". Based on the previous two studies and a lack of differences from the removal model results, I chose not to correct the count results but to use relative abundances for analyses within the study. I limited as many sources of bias as possible through training of observers, only conducting counts from 0600-1000 in favorable condition (no rain, minimal wind), and using 50-m fixed radius. The 50-m fixed radius counts should limit habitat differences as compared to a larger or unlimited radius count.

\section{$\underline{\text { Statistical Techniques }}$}

Within this dissertation, I have used some less familiar techniques in analyzing my results to account for the inherent messiness of ecological data. Therefore, I provide more detailed background about these techniques to provide a better understanding of their selection and use.

\section{Classification and Regression Trees}

De'ath and Fabricius (2000) suggested using this modern statistical technique (Breiman et al. 1984) to find ecological patterns from data that are complex, unbalanced, contained missing data, include non-linear relations, and high-order interactions. Trees explain the variation of a single response variable (relative abundance or nest success in my case) using one or more explanatory variables (e.g. landcover, landscape metrics, microhabitat) to split the response variable into homogenous groups. Classification trees are performed on categorical response variables and their final groups are characterized by the distribution of the response variable; whereas, regression tree are performed on numerical response variables and their groups are characterized by the mean.

The tree is constructed using an iterative splitting process such that each split follows a single rule: a single explanatory variable is used to split the response variable into two mutually exclusive groups that are as homogenous as possible. The split is represented as $>$ or $<$ the value for the single explanatory variable that maximized the homogeneity of the resulting two groups. Homogeneity is measured using either the information index, Gini index, or the twoing index for classification trees and the sum of squares about the group means or sum of absolute deviations about the median for regression trees (Breiman et al. 1984). Each successive group is then split again using the same rule. In selecting the final tree, the goal is to partition the response 
variables into as homogenous groups as possible while keeping the size of the tree (number of groups) reasonably small. The process of selecting the best tree involves building an overly large tree and finding ways to reduce its size (pruning). To select the best tree size, crossvalidation is used to estimate the true (prediction) error for any given tree size. These estimates are then plotted against the tree size, and the best tree is often selected as the one with the minimum relative error or alternatively within $1 \mathrm{SE}$ of the minimum.

To assess fit for each tree, the relative error (the inverse of the variance explained by the model) and the cross-validation error are calculated. Values close to zero are perfect predictors while values close to one are poor predictors (De'ath 2002). Cross-validation error better represents the predictive abilities of trees using new data.

De'ath and Fabricius (2000) identified five advantages of classification and regression trees: 1) flexibility to handle a broad range of response types, 2) invariance to transformation of explanatory variables, 3) ease and robustness of construction, 4) ease of interpretation, and 5) ability to handle missing data.

\section{Non-metric Multidimensional Scaling}

Non-metric multidimensional scaling (NMDS; Kruskal 1964) is a visual ordination technique that represents objects in space based proportionally on a dissimilarity or distance matrix based on some attribute. In my study, avian survey locations are the objects and they are related in a distance matrix based on their species composition. McCune and Grace (2002) identified NMDS as the ordination method of choice for characterizing most ecological community structure, and Minchin (1987) described this technique as the most robust unconstrained (based on species data not constrained by environmental variables) ordination technique in community ecology. NMDS differs from other metric ordinations, in that it deals with ordinal not ratio or interval data (Kruskal 1964). Also, NMDS does not explain variation such as eigenvector techniques [principal component analysis (PCA), discriminant function analysis (DFA), or canonical correspondence analysis (CCA)] only displaying gradients or structure in species composition (Holland 2008). The advantage is that NMDS makes few assumptions about the nature and distribution of the data so that it can be used for non-normal, skewed, and non-linear data. Any distance metric (i.e. Euclidean, Manhattan, Bray-Curtis) can 
be used to determine the dissimilarity matrix by NMDS unlike other techniques which specify specific measures such as covariance or correlation in PCA (Holland 2008).

Generally, complex data sets include relations in many dimensions (n-dimensional space), but ordinations serve as data reduction techniques to reduce them to a manageable number. For NMDS, the number of dimensions is defined and then the ordination iteratively seeks a solution that maximizes the rank order correlation between distances in the dissimilarity matrix and the distance in the reduced dimensional space, stopping once an acceptable solution is found. The difference between the true distance in the n-dimensional space and the distance in the reduced dimensional space is measured as stress (Kruskal 1964). To avoid being trapped in local minima, multiple random starts are performed in the iterative process to find the global minimum (Holland 2008). To understand this need for multiple starts, think of the ordination as a flat surface with a many minor depressions and one large deeper depression and the iterative process as a ball. Dropping the ball at a single point increases the likelihood that the ball may come to rest in a smaller depression, not the best solution, but by repeated dropping the ball in different locations eventually the ball will come to rest in the deeper depression, the best solution. This process is repeated for higher dimensions to see if stress is appreciably reduced and the best solution is selected. Species can be added to the final solution as a weighted average of their position in the ordination.

The axes of the NMDS ordination do not represent and are not interpretable as a gradient; therefore, to represent the ordination in terms of environmental variables, the entire ordination is correlated with the independent variables using vector fitting. Vector fitting assumes a linear relation between the environmental variable and the ordinations using an arrow to represent the direction of the gradient and the length of the arrow to represent the strength (Oksanen 2010). In the case of non-linear relations, the environmental variables can be fit using smoothed curves (Roberts and Oksanen 2010).

\section{$\underline{\text { Study Area }}$}

We conducted our research at the Wildlife and Ecosystem Research Forest (WERF), located in Randolph County, West Virginia in the unglaciated Allegheny Mountain and Plateau region from 1996-1998 (Weakland 2000), 2001-2003 (Dellinger 2005), and 2007-2009 (Fig. 1). This 3,413 ha forested area was established in 1994 by Westvaco Corporation to study relations 
between commercial forest management practices and ecosystem wildlife processes. In 2002, we added the 1,705 ha Panther Run Tract (PRT), also owned by Westvaco Corporation, located $16 \mathrm{~km}$ north of the WERF. Both properties were sold to Penn Virginia in the winter of 2007. Each year of the study, we conducted 50-m fixed radius point counts to quantify the avian relative abundance and monitored nests within nest-searching plots to quantify nest success. The study area was divided into three elevational blocks (Panther Run the lowest elevation; block 1: mean $=750 \mathrm{~m}$, range $=596-905 \mathrm{~m}$ ) and the WERF divided into two block of approximately equal area along the elevational gradient (block 2: mean $=902 \mathrm{~m}$, range $=696-1107 \mathrm{~m}$; block 3: mean $=955 \mathrm{~m}$, range $=816-1094 \mathrm{~m}$; Figs 2-5).

Regional topography consists of narrow valleys with small, high-gradient streams, and steep slopes topped by broad ridges that generally run in a south-southwest to north-northeast direction. The sites receive high annual average precipitation, more than $160 \mathrm{~cm}$, with snow common throughout the winter resulting in a cool and humid environment. Soils are acidic and well-drained inceptisols and ultisols.

Vegetation communities on the study areas vary by elevation. Red spruce (Picea rubens) and eastern hemlock (Tsuga canadensis) characterize stands above $1000 \mathrm{~m}$. Northern hardwoods including red maple (Acer rubrum), American beech (Fagus grandifolia), and black cherry (Prunus serotina) dominate at 850-1000 m. Below $850 \mathrm{~m}$, cove hardwood and mixed mesophytic plant communities occur with species such as northern red oak (Quercus rubra), black birch (Betula lenta), and tulip poplar (Liriodendron tulipifera) dominating the canopy. Xeric oak-hickory communities dominated by black oak (Quercus velutina), scarlet oak (Quercus coccinea), and hickory (Carya spp.) also occur at low elevations. Communities of eastern hemlock, red spruce and rhododendron (Rhododendron spp.) are found in the riparian areas.

Although primarily mature forest at the study's inception, the WERF is currently a mixture of harvested and mature forest stands as a result of timber management (Fig 6-7). In 2002, PRT had comparable proportions of clear-cuts to the WERF, but slightly higher proportions of light partial harvests and total harvests. Forest management was classified into three types: silvicultural clear-cuts (Figs. 8, 9), heavy partial harvests including shelterwood cuts and deferment cuts (Figs. 10,11), and light partial harvesting via group selection and high-grade harvests of mature sawtimber (Figs. 12, 13). 


\section{Objectives and Hypotheses}

The purpose of this study was to evaluate the demographic responses of songbird species and habitat guilds to landscape habitat change in an actively managed forest. In turn, this will enable the development of forest management guidelines allowing maintenance of bird communities in managed landscapes. Specific objectives were:

1) Measure the change in landscape metrics over the course of the study and the effects of these changes on songbird nest success, relative abundance, and community structure.

Determine which metrics have the strongest relations to demographic changes and which species and guilds are most affected by landscape change.

$\mathrm{Ho}_{1}$ : Landcover and landscape metrics will not vary temporally.

$\mathrm{Ho}_{2}$ : Songbird abundance, nest success, and community structure will not change in response to landscape change.

$\mathrm{Ho}_{3}$ : All metrics will evenly affect changes in nest success, relative abundance, and community structure as a response to landscape changes.

Ho4: The responses of all bird species and guilds to landscape changes will be the same. $\mathrm{Ho}_{5}$ : Early successional, interior-edge, and forest-interior species will respond similarly to landscape changes.

2) Identify threshold levels of disturbance from different harvest types after which bird abundance increased or decreased.

$\mathrm{Ho}_{6}$ : All species and guilds will respond linearly to landscape change.

$\mathrm{Ho}_{7}$ : Bird response to landscape change will be the same for all harvest types.

$\mathrm{Ho}_{8}$ : Thresholds will be the same for early successional, interior-edge, and forest-interior species.

Ho9: Thresholds will be the same for habitat guilds and species within the guilds.

3) Evaluate breeding bird-habitat relations among a wide gradient of disturbance levels in a managed landscape by developing empirically-derived habitat groups for forest-breeding birds, 
for which we compared their habitat relations to traditional habitat guilds and among bird species within habitat groups.

$\mathrm{Ho}_{10}$ : Traditional habitat guilds best classify bird species in relation to disturbance from timber management.

$\mathrm{Ho}_{11}$ : All metrics will evenly affect changes in relative abundance and nest success for empirically-derived habitat groups.

$\mathrm{Ho}_{12}$ : The metrics will influence the empirically-derived habitat groups and species within these groups the same.

$\mathrm{Ho}_{13}$ : The metrics will influence relative abundance and nest success the same for each empirically-derived habitat group.

4) Determine the response of Canada Warbler abundance and nest success to changing forest characteristics at multiple spatial scales as a result of forest management practices including clear-cut and partial harvests.

$\mathrm{Ho}_{14}$ : Canada Warbler relative abundance and nest success will not respond to landscape change.

$\mathrm{Ho}_{15}$ : The response of Canada Warbler relative abundance to landcover and metrics will not vary over time.

$\mathrm{Ho}_{16}$ : Microhabitat and landscape metrics will be the same at nests found early in the study (1996-98) versus nests found late in the study (2007-09).

$\mathrm{Ho}_{17}$ : Microhabitat and landscape metrics will be the same at successful and unsuccessful nests.

$\mathrm{Ho}_{18}$ : Habitat used by Canada Warblers will be the same as available habitat.

\section{Chapter Overview}

This dissertation has been written in the form of four chapters. The first chapter provides an introduction and justification for my research. The second chapter examines the temporal response of forest breeding songbirds to continuous, long-term timber management. The third chapter evaluates breeding bird-habitat relations among a wide gradient of disturbance levels in a 
managed landscape. The fourth chapter examines the response of Canada Warbler abundance and nest success to timber management and the conservation implications of timber management for this species. The last three chapters are written in the style of, and will be submitted to the following scientific journals:

Chapter 2-Forest Ecology and Management

Chapter 3-The Auk

Chapter 4-The Wilson Journal of Ornithology 


\section{Literature Cited}

Amrhein, V., P. K. Kunc, and M. Naguib. 2004. Seasonal patterns of singing activity vary with time of day in the nightingale (Luscinia megarhynchos). Auk 121:110-117.

Anderson, S.H., and B.J. Crompton. 2002. The effects of shelterwood logging on bird community composition in the Black Hills, Wyoming. Forest Science 48: 365-372.

Annand, E.M., and F.R. Thompson III. 1997. Forest bird response to regeneration practices in central hardwood forests. Journal of Wildlife Management 61: 159-171.

Askins, R.A., J.F. Lynch, and R. Greenberg. 1990. Population declines in migratory birds in Eastern North America. Current Ornithology 7: 1-57.

Askins, R.A., B. Zuckerberg, L. Novak. 2007. Do the size and landscape context of forest openings influence the abundance and breeding success of shrubland songbirds in southern New England? Forest Ecology and Management 250:137-147.

Augenfeld, K.H., Franklin, S.B., and D. H. Snyder. 2008. Breeding bird communities of upland hardwood forest 12 years after shelterwood logging. Forest Ecology and Management, 255:1271-1282.

Baker, M.D., and M.J. Lacki. 1997. Short-term changes in bird communities in response to silvicultural prescriptions. Forest Ecology and Management 96: 27-36.

Betts, M.G., Forbes, G.J. and Diamond, A.W. 2007. Thresholds in songbird occurrence in relation to landscape structure. Conservation Biology 21: 1046-1058.

Betts, M.G., and M. Villard. 2009. Landscape thresholds in species occurrence as quantitative targets in forest management: generality in space and time? in Villard, M., and B.G. Johnson, eds. Setting Conservation Targets for Managed Forest Landscapes. Cambridge University Press, New York, NY.

Bollinger, E.K. and E.T. Linder. 1994. Reproductive success of neotropical migrants in a fragmented Illinois forest. Wilson Bulletin 106: 46-54.

Brashear, K. 2006. Variation in bird communities among three silvicultural treatments in northern hardwood forests. Powerpoint presentation. Michigan Society of American Foresters Feathers in the Forest Technical Conference, Sault Sainte Marie, Michigan, 1011 May 2006. http://michigansaf.org/Tours/Feathers/PowerPoints/4-Brashear.pdf

Brawn, J.D., S.K. Robinson, and F.R. Thompson III. 2001. The role of disturbance in the ecology and conservation of birds. Annual Review of Ecological Systems 32: 251-276.

Breiman, L., J.H. Friedman, R.A. Olshen, and C.G. Stone. 1984. Classification and Regression Trees. Wadsworth International Group, Belmont, CA. 
Brennan, S.P., and Schnell G.D. 2005. Relationship between bird abundances and landscape characteristics: the influence of scale. Environmental Monitoring and Assessment 105: 209-228.

Brito-Aguilar, R. 2005. Effects of even-aged forest management on early successional bird species in Missouri Ozark Forest. MS Thesis, University of Missouri-Columbia. 47 pp.

Brittingham, M., and S. Temple. 1983. Have cowbirds caused forest songbirds to decline? Bioscience 33:31-35.

Brown, R.S., and K. Marshall. 1996. Ecosystem management in state governments. Ecological Applications 6:721-723.

Buckland, S. T., D. R. Anderson, K. P. Burnham, and J. L. Laake. 1993. Distance Sampling: Estimating Abundance of Biological Populations. Chapman and Hall, New York.

Bulluck, L.P., and D.A. Buehler. 2006. Avian use of early successional habitats: Are regenerating forests, utility right-of-ways and reclaimed surface mines the same? Forest Ecology and Management 236:76-84.

Burke, D.M. and E. Nol. 1998. Influence of food abundance, nest site habitat, and forest fragmentation on breeding ovenbirds. The Auk 115:96-104.

Burnham, K. P., D. R. Anderson, and J. L. Laake. 1980. Estimating density from line transect sampling of biological populations. Wildlife Monographs 72.

Campbell, S. P., J. W. Witham, and M. L. Hunter, Jr. 2007. Long-term effects of group selection timber harvesting on abundance of forest birds. Conservation Biology 21:12181229.

Carlson, A. 2000. The effect of habitat loss on a deciduous forest specialist species: the whitebacked woodpecker (Dendrocopes leucotos). Forest Ecology and Management 131: 215221.

Childs, R.A. 2005. West Virginia's forests: growing West Virginia's future. West Virginia Division of Forestry Report. http://www.wvforestry.com/Economic\%20Impact\%20Study.pdf

Clawson, R.C., J. Faaborg, W.K. Gram, and P.A. Porneluzi. 2002. Landscape level effects of forest management on bird species in the Ozarks of southeastern Missouri. Pp. 147-160 In: Shifley, S.R. and J.M. Kabrick eds. Proceedings of the second Missouri Ozark forest ecosystem symposium: post treatment results of the landscape experiment. USDA Forest Service General Technical Report NC-227. St. Paul, MN.

Cleary, D.F.R., M.J. Genner, T.J.B. Boyle, T. Setyawati, C.D. Angraeti, and S.B.J Menken. 
2005. Associations of bird species richness and community composition with local and landscape-scale environmental factors. Landscape Ecology 20: 989-1001.

Collins, S.L. 2001. Long-term research and the dynamics of bird populations and communities. Auk 118:583-588.

Costello, C.A., M. Yamasaki, P.J. Pekins, W.B. Leak, and C.D. Neefus. 2000. Songbird response to group selection harvests and clearcuts in a New Hampshire northern hardwood forest. Forest Ecology and Management 127:41-54.

Cushman, S.A., and K. McGarigal. 2003. Landscape level patterns of avian diversity in the Oregon Coast Range. Ecological Monographs 73: 259-281.

Cushman, S.A., and K. McGarigal. 2004. Patterns in the species-environment relationship on both scale and choice of response variables. Oikos 105: 117-124.

De'ath, G., and K.E. Fabricius. 2000. Classification and regression trees: a powerful yet simple technique for ecological data analysis. Ecology 81: 3178-3192.

De'ath, G. 2002. Multivariate regression trees: a new technique for modeling speciesenvironment relationships. Ecology 83:1105-1117.

DeGraaf, R.M., and M. Yamasaki. 2003. Options for managing early successional forest and shrubland bird habitats in the northeastern United States. Forest Ecology and Management 185:179-191.

Dellinger, R. 2005. Nesting success and nest site characteristics of four thrush species on a managed forest. PhD dissertation. West Virginia University, Morgantown, West Virginia. 98 p.

Dellinger, T.A. 2007. Post-fledging ecology and survival of neotropical migratory songbirds on a managed Appalachian forest. M.S. Thesis. West Virginia University, Morgantown, West Virginia. 122 p.

Dellinger, R.L., P.B. Wood, and P.D. Keyser. 2007. Occurrence and nest success of four thrush species on a managed central Appalachian forest. Forest Ecology and Management 243: 248-258.

Dettmers, R. 2003. Status and conservation of shrubland birds in the northeastern U.S. Forest Ecology and Management, 185:81-93.

Diefenbach, D. R., D. W. Brauning, and J. A. Mattice. 2003. Variability in grassland bird counts related to observer differences and species detection rates. Auk 120:1168-1179.

Drapeau, P., A. Leduc, J.F. Giroux, J.P.L. Savard, Y. Bergeron, and W.L. Vickery. 2000. 
Landscape-scale disturbances and changes in bird communities of boreal mixed-wood forests. Ecological Monographs 70: 423-444.

Drolet, B., A. Desrochers, and M.J. Fortin. 1999. Effects of landscape structure on nesting songbird distribution in a harvested boreal forest. Condor 101: 699-704.

Duguay, J.P., P.B. Wood, and G.W. Miller. 2000. The effects of timber harvests on invertebrate biomass and avian nest success. Wildlife Society Bulletin 28: 1123-1131.

Duguay, J.P., P.B. Wood, and J.V. Nichols. 2001. Songbird abundance and avian nest survival rates in forests fragmented by different silvicultural treatments. Conservation Biology 5: 1405-1415.

Efford, M.G., and D.K. Dawson. 2009. Effect of distance-related heterogeneity on population size estimates from point counts. Auk 126: 100-111.

Faaborg, J., M. Brittingham, T. Donovan, and J. Blake. 1995. Habitat fragmentation in the temperate zone. Pages 357-380 in T.E. Martin and D. M. Finch eds., Ecology and management of neotropical migratory birds. Oxford University Press, New York and Oxford.

Faccio, S.D. 2003. Effects of ice storm-created gaps on forest breeding bird communities in central Vermont. Forest Ecology and Management, 186:133-145.

Fahrig, L. 2003. Effects of habitat fragmentation on biodiversity. Annual Reviews of Ecology and Systematics 34:487-515.

Farnsworth, G.L., K.H. Pollock, J.D. Nichols, T.R. Simons, J.E. Hines, and J.R. Sauer. 2002. A removal model for estimating detection probabilities from point-count surveys. Auk 119: 414-425.

Flaspohler, D. J., Temple, S.A., and R.N. Rosenfield. 2001. Species-specific edge effects on nest success and breeding bird density in a forested landscape. Ecological Applications $11: 32-46$.

Flather, C.H., and M. Bevers. 2002. Patchy reaction-diffusion and population abundance: the relative importance of habitat amount and arrangement. The American Naturalist 159: 40-56.

Franzreb, K.E., and R.D. Ohmert. 1978. The effects of timber harvesting on breeding birds in a mixed-coniferous forest. Condor 80: 431-441.

Germaine, S.S., S.H. Vessey, and D.E. Capen. 1997. Effects of small forest openings on the breeding bird community in a Vermont hardwood forest. Condor 99: 708-718.

Gill, S.A. 2003. Timing and duration of egg laying in duetting buff-breasted wrens. Journal of 
Field Ornithology 74:31-36.

Gottlander, M. 1987. Variation in song rate of the male pied flycatcher ficedula-hypoleuca: causes and consequences. Animal Behaviour 35:1037-1043.

Gram, W.K., P.A. Porneluzi, R.L. Clawson, J. Faaborg, and S.C. Richter. 2003. Effects of experimental forest management on density and nesting success of bird species in Missouri Ozark forests. Conservation Biology 17: 1324-1337.

Greenberg, C.H., and J.D. Lanham. 2001. Breeding bird assemblages of hurricane-created gaps and adjacent closed canopy forest in the southern Appalachians. Forest Ecology and Management, 154:251-260.

Grumbine, R.E. 1994. What is ecosystem management? Conservation Biology 8:27-38.

Guenette J.S., and M.A.Villard. 2005. Thresholds in forest bird response to habitat alteration as quantitative targets for conservation. Conservation Biology 10: 188-202.

Hagan, J.M. 1993. Decline of the rufous-sided towhee in the eastern United States. Auk 110: 863-874.

Hanski, I.K., T.J. Fenske, and G.J. Niemi. 1996. Lack of edge effect in nesting success of breeding birds in managed forest landscapes. The Auk 113:578-585.

Harrison, C.A., and J.C. Kilgo. 2004. Short-term breeding bird response to two harvest practices in a bottomland hardwood forest. Wilson Bulletin 116: 314-323.

Hanowski, J., N. Danz, and J. Lind. 2006. Response of breeding bird communities to forest harvest around seasonal ponds in northern forests, USA. Forest Ecology and Management 229:63-72.

Haulton, S. 2008. Effects of silvicultural practices on bird communities in deciduous forests of eastern and central North America. http://www.indiana.gov/dnr/forestry/files/foManagedForestBirdReview.pdf

Holland, S.M. 2008. Non-metric multidimensional scaling. http://www.uga.edu/strata/software/pdf/mdsTutorial.pdf

Hoover, J.P., M.C. Brittingham, and L.J. Goodrich. 1995. Effects of forest patch size on nesting success of wood thrushes. The Auk 112: 146-155.

Holmes, R.T., and T.W. Sherry. 2001. Thirty-year bird population trends in an unfragmented temperate deciduous forest: importance of habitat change. Auk 118: 589-609.

Holmes, S.B., and D.G. Pitt. 2007. Response of bird communities to selection harvesting in a northern tolerant hardwood forest. Forest Ecology and Management 238:280-292. 
Homan, R.N., B.S. Windmiller, and J.M. Reed. 2004. Critical thresholds associated with habitat loss for two vernal pool-breeding amphibians. Ecological Applications 14: 1547-1553.

Haggett, A.J. 2005. The concept and utility of ecological thresholds in biodiversity conservation. Biological Conservation 124: 301-310.

Hunt, P.D. 1996. Habitat selection by the American redstart along a successional gradient in northern hardwood forests: evaluation of habitat quality. Auk 113:875-888.

Hunter, W.C., D.A. Buehler, R.A. Canterbury, J.L. Confer, and P.B. Hamel. 2001. Conservation of disturbance-dependent birds in eastern North America. Wildlife Society Bulletin 29: 440-455.

Imbeau, L., and A. Desrochers. 2002. Area sensitivity and edge avoidance: the case of the three-toed woodpecker (Picoides tridactylus) in a managed forest. Forest Ecology and Management 164: 249-256.

Johnson, D.H. 2008. In defense of indices: the case of bird surveys. Journal of Wildlife Management 72: 857-868.

Karr, J.R., and R.R. Roth. 1971. Vegetation structure and avian diversity in several New World areas. The American Naturalist 105: 423-435.

Karr, J.R. 1981. Surveying birds with mist nets. Studies in Avian Biology 6:62-67.

Kilgo, J.C. 2005. Harvest-related edge effects on prey availability and foraging of hooded warblers in a bottomland hardwood forest. Condor 107: 627-636.

King, D.I., R.M. DeGraaf, and C.R. Griffin. 2001. Productivity of early-successional shrubland birds in clear-cuts and group-cuts in an eastern deciduous forest. Journal of Wildlife Management 65: 345-350.

King, D.I., and R.M. DeGraaf. 2004. Effects of group-selection opening size on the distribution and reproductive success of an early-successional shrubland bird. Forest Ecology and Management 190:179-185.

King, D.I., C. Chandler, R. Chandler, R.M. DeGraaf. 2005. Effects of silviculture on mature forest and early-successional shrubland passerine birds in northern and central New England. Page 21 in Kenefic, L.S., M.J. Twery, eds. Changing forests - challenging times: proceedings of the New England Society of American Foresters 85th Winter Meeting. General Technical Report NE-325. Newtown Square, PA: USDA Forest Service, Northeastern Research Station.

Keller, J. K., M. E. Richmond, and C. R. Smith. 2003. An explanation of patterns of breeding 
bird species richness and density following clearcutting in northeastern USA forests. Forest Ecology and Management 174:541-564.

Klaus, N.A., D.A. Buehler, and A.M. Saxton. 2005. Forest management alternatives and songbird breeding habitat on the Cherokee National Forest, Tennessee. Journal of Wildlife Management 69: 222-234.

Krementz, D.G., and J.S. Christie. 2000. Clearcut stand size and scrub-successional bird assemblages. Auk 117:913-924.

Kroodsma, D.E., B.E. Byers, S.L. Halkin, C. Hill, D. Minis, J.R. Bolsinger, J. Dawson, E. Donelan, J. Farrington, F.B. Gill, P. Houlihan, D. Innes, G. Keller, L. Macaulay, C.A. Marantz, J. Ortiz, P.K. Stoddard, and K. Wilda. 1999. Geographic variation in blackcapped chickadee songs and singing behavior. Auk 116:387-402.

Kruskal, J.B. 1964. Non-metric multidimensional scaling: a numerical method. Psychometrika 29:115-129.

Lent, R. A., and D. E. Capen. 1995. Effects of small-scale habitat disturbance on the ecology of breeding birds in a Vermont hardwood forest. Ecography 18:97-108.

Lindenmayer, D.B., J. Fischer, and R.B. Cunningham. 2005. Native vegetation cover thresholds associated with species responses. Biological Conservation 124: 311-316.

Loehle, C., T.B. Wigley, S. Rutzmoser, J.A. Gerwin, P.D. Keyser, R.A. Lancia, C.J. Reynolds, R.E. Thill, R. Weih, D. White, and P.B. Wood. 2005. Managed forest landscape structure and avian species richness in the southeastern US. Forest Ecology and Management 214: 279-293.

Manolis, J.C., D.E. Andersen, and F.J. Cuthbert. 2002. Edge effect on nesting success of ground nesting birds near regenerating clearcuts in a forest-dominated landscape. Auk 119:955-970.

Marquis, D. A. 1989. Alternative silvicultural systems-East. Pp 29-35 In Proceedings of the national silviculture workshop. USDA Forest Service Timber Management, Washington, DC.

Marshall, M.R., J.A. DeCecco, A.B. Williams, G.A. Gale, and R.J. Cooper. 2003. Use of regenerating clearcuts by late-successional bird species and their young during the post fledging period. Forest Ecology and Management 183: 127-135.

McCune, B., and J.B. Grace. 2002. Analysis of ecological communities. MjM Software Design, Gleneden, OR.

McDermott, M.E. 2007. Breeding and post-breeding forest bird community dynamics in 
regenerating clearcuts and two-age harvests in the central Appalachians. M.S. Thesis, West Virginia University, Morgantown, West Virginia

McDermott, M.E., and P.B. Wood. 2009. Short- and long-term applications of clearcut and two-age silviculture for conservation of breeding forest birds in the central Appalachians, USA. Biological Conservation 142: 212-220.

McDermott, M.E., and P.B. Wood. 2010. Influence of cover and food resource variation on post-breeding bird use of timber harvests with residual canopy trees. Wilson Journal of Ornithology 122: 545-555.

Miller, G.W. 1993. Financial aspects of partial cutting practices in central Appalachian hardwoods. U.S. Forest Service Research Paper NE-673.

Minchin, P.R. 1987. An evaluation of relative robustness of techniques for ecological ordinations. Vegetatio 71: 145-146.

Mitchell, M.S., S.H. Rutzmoser, T.B. Wigley, C. Loehle, J.A. Gerwin, P.D. Keyser, R.A. Lancia, R.W. Perry, C.J. Reynolds, R.E. Thrill, R. Weih, D. White, and P.B. Wood. 2006. Relationships between avian richness and landscape structure at multiple scales using multiple landscapes. Forest Ecology and Management 221: 155-169.

Moller, A.P. 1991. Parasite load reduces song output in a passerine bird. Animal Behaviour 41:723-730.

Mönkkönen, M., and P. Reunanen. 1999. On critical thresholds in landscape connectivity: a management perspective. Oikos 84: 302-306.

Moorman, C.E., D.C. Guynn, Jr., and J.C. Kilgo. 2002. Hooded warbler nesting success adjacent to group-selection and clearcut edges in a southeastern bottomland forest. The Condor 104:366-377.

Morrison, M.L. 1992. Bird abundance in forests managed for timber and wildlife resources. Biological Conservation 60: 127-134.

Nichols, J. D., J. E. Hines, J. R. Sauer, F. W. Fallon, J. E. Fallon, and P. J. Heglund. 2000. A double-observer approach for estimating detection probability and abundance from point counts. Auk 117:293-408.

Nyland, R.D. 1996. Silviculture: concepts and applications. McGraw Hill, St. Louis, MO.

Oksanen, J. 2010. Envfit\{vegan\}: fits an environmental vector or factor onto an ordination. Vegan version 1.16-32. http://cc.oulu.fi/ jarioksa/softhelp/vegan/html/envfit.html.

Otter, K., B. Chruszcz, and L. Ratcliffe. 1997. Honest advertisement and song output during the dawn chorus of black-capped chickadees. Behavioral Ecology 8:167-173. 
Pagen, R.W., F.R. Thompson, and D.E. Burhans. 2000. Breeding and post-breeding habitat use by forest migrant songbirds in the Missouri Ozarks. Condor 102: 738-747.

Pennsylvania Forest Products Association. 2004. The timber and forest products industry: vital to Pennsylvania's economy. http://paforestproducts.org/files/INDUSTRY1.pdf

Peterjohn, B., J. R. Sauer, and C. S. Robbing. 1995. Population trends from the North American Breeding Bird Survey. Pages 3-19 in T.E. Martin and D. M. Finch, eds., Ecology and management of neotropical migratory birds. Oxford University Press, New York and Oxford.

Radford, J.Q., and A.F. Bennett. 2004. Thresholds in landscape parameters: occurrence of the white-browed treecreeper (Climacteris affinis) in Victoria, Australia. Biological Conservation 117: 375-391.

Radford, J.Q., A.F. Bennett, and G.J. Cheers. 2005. Landscape-level thresholds of habitat cover for woodland-dependent birds. Biological Conservation 124: 317-337.

Rashotte, M.E., E.V. Sedunova, F. Johnson, and I.F. Patukhov. 2001. Influence of food and water availability on undirected singing and energetic status in adult male zebra finches (Taeniopygia guttata). Physiology and Behavior 74:533-541.

Rich, T.D., C.J. Beardmore, H. Berlanga, P.J. Blancher, M.S.W. Bradstreet, G.S. Butcher, D.W. Demarest, E.H. Dunn, W.C. Hunter, E.E. Iñigo-Elias, J.A. Kennedy, A. M. Martell, A.O. Panjabi, D.N. Pashley, K.V. Rosenberg, C.M. Rustay, J.S. Wendt, and T.C. Will. 2005. Partners in Flight North American Landbird Conservation Plan. Cornell Lab of Ornithology. Ithaca, NY.

Richards, D.G. 1981. Environmental acoustics and censuses of singing birds. Studies in Avian Biology 6:297-300.

Roberts, D., and J. Oksanen. 2010. Ordisurf \{vegan\}: fit and plot smooth surfaces of variables on ordination. Vegan version 1.16-32. http://cc.oulu.fi/ jarioksa/softhelp/vegan/html/ordisurf.html

Robbins, C.S., J.R. Sauer, R.S. Greenberg, and S. Droege. 1989. Population declines in North American birds that migrate to the neotropics. Proceedings of the National Academy of Science 1: 7658-7662.

Robinson, S. K. 1992. Population dynamics of breeding Neotropical migrants in a fragmented Illinois landscape, in Ecology and Conservation of Neotropical Migrant Landbirds (J. M. Hagan, III, and D. W. Johnson, eds.), pp. 408-418. Smithsonian Institute Press, Washington, D.C.

Robinson, S.K., F.R. Thompson III, T.M. Donovan, D.R. Whitehead, and J. Faaborg. 1995. 
Regional forest fragmentation and the nesting success of migratory birds. Science 267:1987-1990

Robinson, W.D., and S.K. Robinson. 1999. The effects of selective logging on forest bird populations in a fragmented landscape. Conservation Biology 13: 58-66.

Robinson, W.D., and S.K. Robinson. 2001. Avian nesting success in a selectively harvested north temperate deciduous forest. Conservation Biology 15: 1763-1771.

Rodewald, A.D., and R. H. Yahner. 2000. Bird communities associated with harvested hardwood stands containing residual trees. Journal of Wildlife Management 64:924-932.

Rodewald, A.D., and A.C. Vitz. 2005. Edge- and area-sensitivity of shrubland birds. Journal of Wildlife Management 69:681-588.

Rosenberg, K.V., J.D. Lowe, and A.A. Dhondt. 1999. Effects of forest fragmentation on breeding tanagers: A continental perspective. Conservation Biology 13:568-583.

Rudnicky, T.C., and M.L. Hunter. 1993. Avian nest predation in clearcuts, forests, and edges in a forest-dominated landscape. Journal of Wildlife Management 57:358-364.

Sallabanks, R., E.B. Arnett and J.M. Marzluff. 2000. An evaluation of research on the effects of timber harvest on bird populations. Wildlife Society Bulletin 28(4): 1144-1155.

Sauer, J.R., B.G. Peterjohn, and W.A. Link. 1994. Observer differences in the North American Breeding Bird Survey. Auk 111:50-62.

Schrott, G.R., K.A. With, and A.W. King. 2005. On the importance of landscape history for assessing extinction risk. Ecological Applications 15: 493-506.

Seoane, J., J. Bustamante, and R. Diaz-Delgado. 2004. Competing roles for landscape, vegetation, topography, and climate in predictive models of bird distribution. Ecological Modeling 171: 209-222.

Shifley, S.R., F.R. Thompson III, D.R. Larsen, and W.D. Dijak. 2000. Modeling forest landscape change in the Missouri Ozarks under alternative management practices. Comp. Elect. Agric. 27:7-24.

Skirvin, A. A. 1981. Effect of time of day and time of season on the number of observations and density estimates of breeding birds. Studies in Avian Biology 6:271-274.

Smith, D.M. 1962. The practice of silviculture. John Wiley and Sons, Inc., New York, NY.

Swift, T.L., and S.J. Hannon. 2010. Critical thresholds associated with habitat loss: a review of the concepts, evidence, and applications. Biological Reviews 85: 35-53. 
Thomas, J.W. 1996. Forest Service perspective on ecosystem management. Ecological Applications 6:703-705.

Thomas, W.R., J.W. Stringer, T.E. Connors, D.B. Hill, and T.G. Barnes. 2007. Kentucky Forest Fact Sheet. University of Kentucky Cooperative Extension Report For-53, Lexington, KY. http://www.ukwoodcenter.net/misc/for53.pdf

Thompson, F.R. III, J.R. Probst, and M.G. Raphael. 1995. Impacts of silviculture: overview and management recommendations. Pp. 201-219 in: Martin, T.E. and D.M. Finch eds. Ecology and management of neotropical migratory birds. Oxford University Press, New York, NY.

Thompson, F.R. III, S.K. Robinson, D.R. Whitehead, and J.D. Brawn. 1996. Management of central hardwood landscapes for the conservation of migratory birds. Pp 117-142 in: Thompson, F.R. III, ed. Management of Midwestern landscapes for the conservation of neotropical migratory birds. USDA Forest Service General Technical Report NC-187. North Central Forest Experimental Station, St. Paul, MN.

Titus, R.C., E.D. Ketterson, and V. Nolan Jr. 1997. High testosterone prior to song crystallization inhibits singing behavior in captive yearling dark-eyed juncos (Junco hyemalis). Hormones and Behavior 32:133-140.

USDA Forest Service. 2000. Northeast Forest Inventory and Analysis. http: //www.fs.fed.us/ne/fia/states/wv/index.html

Vega Rivera, J.H., J.H. Rappole, W.J. McShea, and C.A. Haas. 1998. Wood thrush postfledgling movements and habitat use in northern Virginia. Condor 100: 69-78.

Vitz, A.C., and A.D. Rodewald. 2006. Can regenerating clearcuts benefit mature forest songbirds? An examination of post-breeding ecology. Biological Conservation 127:477486.

Waide, R. B., and P. M. Narins. 1988. Tropical forest bird counts and the effect of sound attenuation. Auk 105:296-302.

Wallendorf, M.J., P.A. Porneluzi, W.K. Gram, R.L. Clawson, and J. Faaborg. 2007. Bird response to clear cutting in Missouri Ozark forests. Journal of Wildlife Management 71:1899-1905.

Weakland, C.A. 2000. Effects of diameter-limit and two-age timber harvesting on songbird populations on an industrial forest in central West Virginia. PhD dissertation. West Virginia University, Morgantown, West Virginia. 150 p.

Weakland, C.A., P.B. Wood and W.M. Ford. 2002. Responses of songbirds to diameter-limit cutting in the central Appalachians of West Virginia, U.S.A. Forest Ecology and Management 155:115-129. 
West Virginia Department of Commerce. 2010. Wood products.

http://www.wvcommerce.org/business/industries/woodproducts/default.aspx

Widmann, R.H., Butler, B.J., and Cook, G.W. 2010. West Virginia's forest resources, 2008. Research Note NRS-61. Newtown Square, PA: U.S. Department of Agriculture, Forest Service, Northern Research Station.

Wiens, J.A. 1994. Habitat fragmentation: island vs. landscape perspectives on bird conservation. Ibis 137: 97-104.

Will, T. C, J. M. Ruth, K. V. Rosenberg, D. Krueper, D. Hahn, J. Fitzgerald, R. Dettmers, C. J. Beardmore. 2005. The five elements process: designing optimal landscapes to meet bird conservation objectives. Partners in Flight Technical Series No. 1. Partners in Flight website: http://www.partnersinflight.org/pubs/ts/01-FiveElements.pdf.

Wilcove, D.S. and S.K. Robinson. 1990. The impact of forest fragmentation on bird communities in eastern North America. In: Biogeography and Ecology of Forest Bird Communities. A. Keast, ed. SPB Academic Publishing, The Hague, Netherlands.

Wilson, D. M., and J. Bart. 1985. Reliability of singing bird surveys: Effects of song phenology during the breeding season. Condor 87:69-73.

With, K.A., and T.O. Christ. 1995. Critical thresholds in species' responses to landscape structure. Ecology 76: 2446-2459.

Wood, P.B., J.P. Duguay, and J.V. Nichols. 2005. Cerulean Warbler use of regenerated clearcut and two-age harvests. Wilson Society Bulletin 33: 851-858.

Yahner, R.H., and D.P. Scott. 1988. Effects of forest fragmentation on depredation of artificial nests. Journal of Wildlife Management 52:158-161

Young, T.M., D.G. Hodges, and T.G. Rials. 2007. The forest products economy of Tennessee. Forest Products Journal 57: 12-19. 


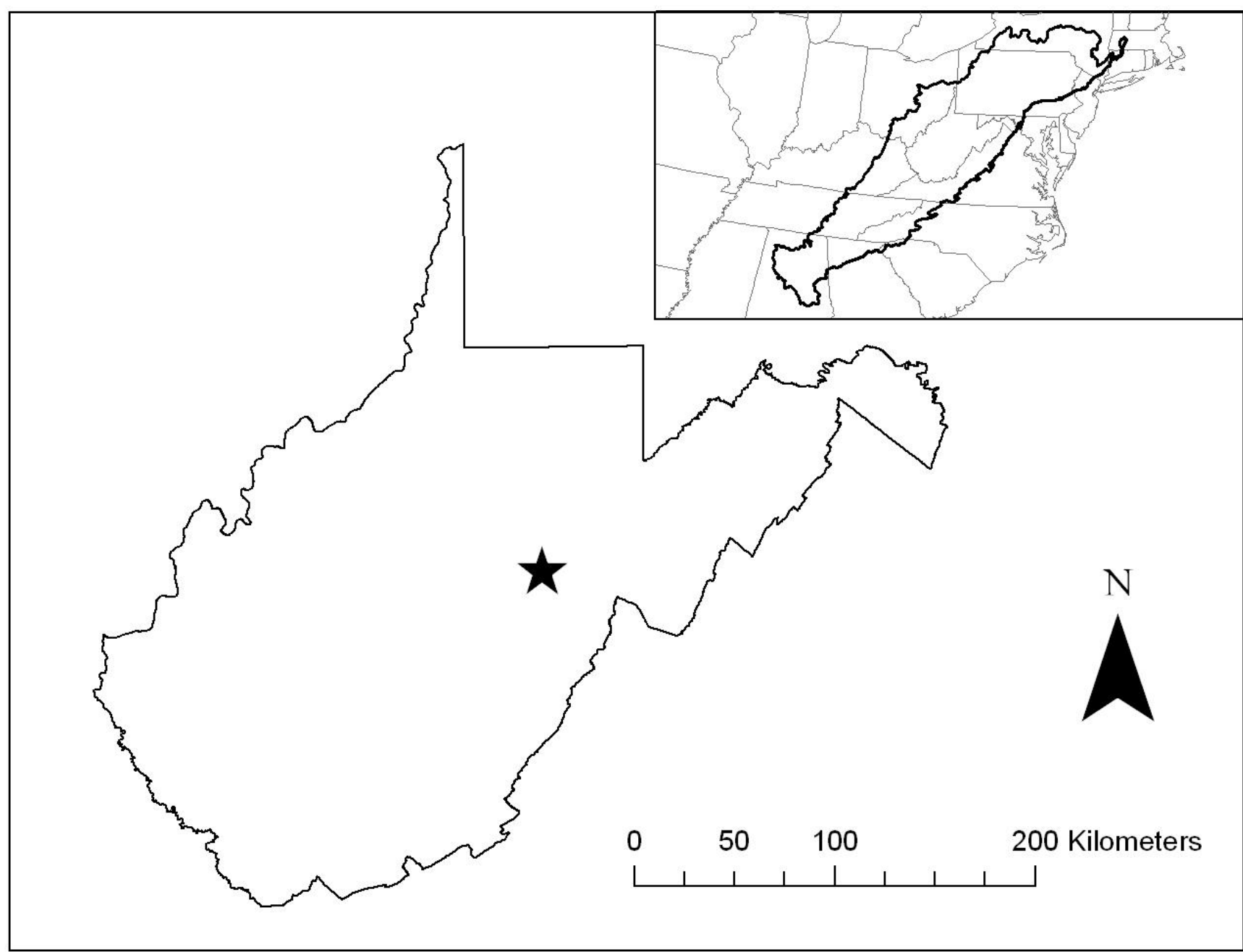

Figure 1. The upper inset map shows the location of West Virginia within the black boundary of the Appalachian Bird Conservation Region. The black star locates the study area within West Virginia. 


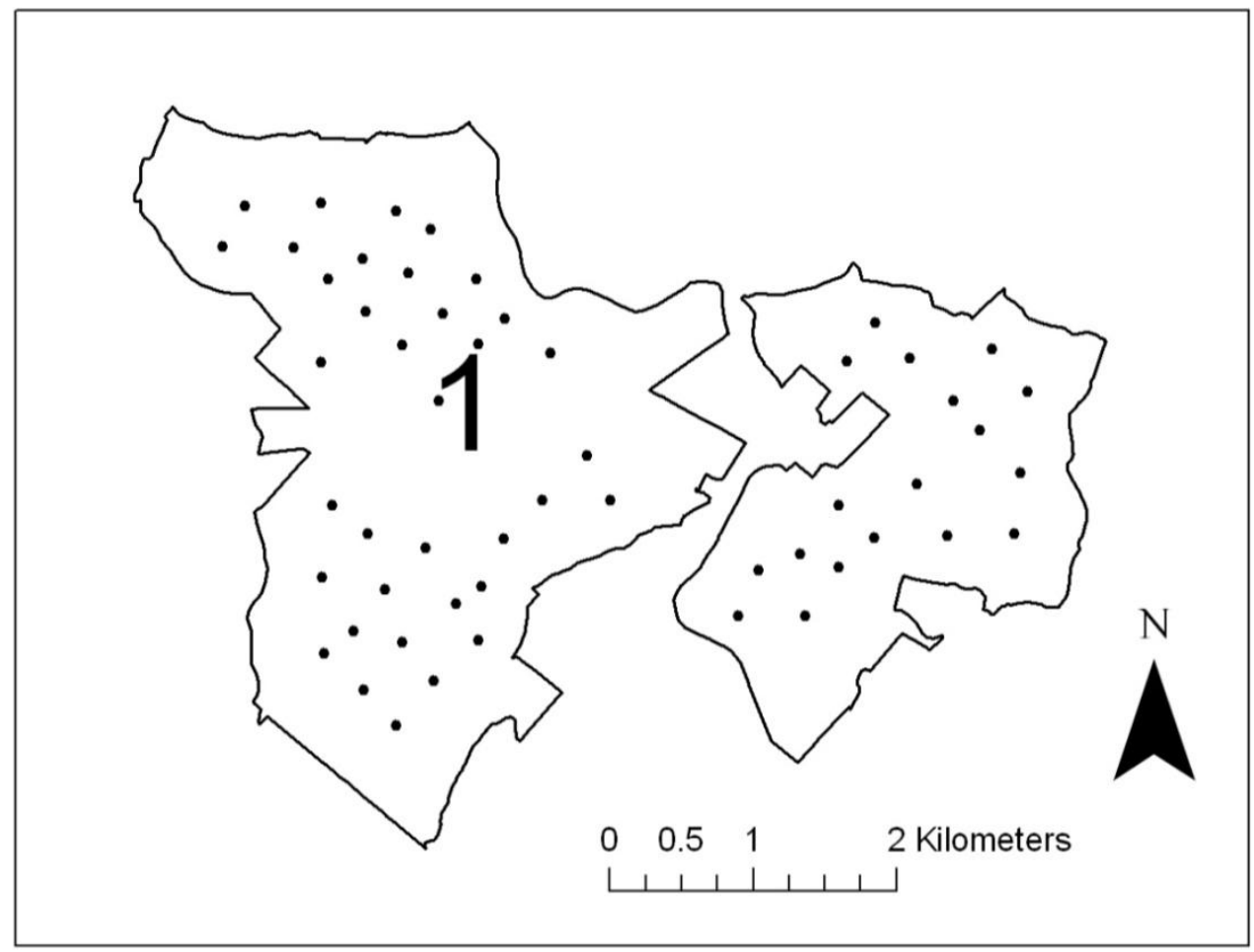

Figure 2. Point count locations at the Panther Run Tract, 2002-2003 and 2007-2009. The number indicates the elevational block.

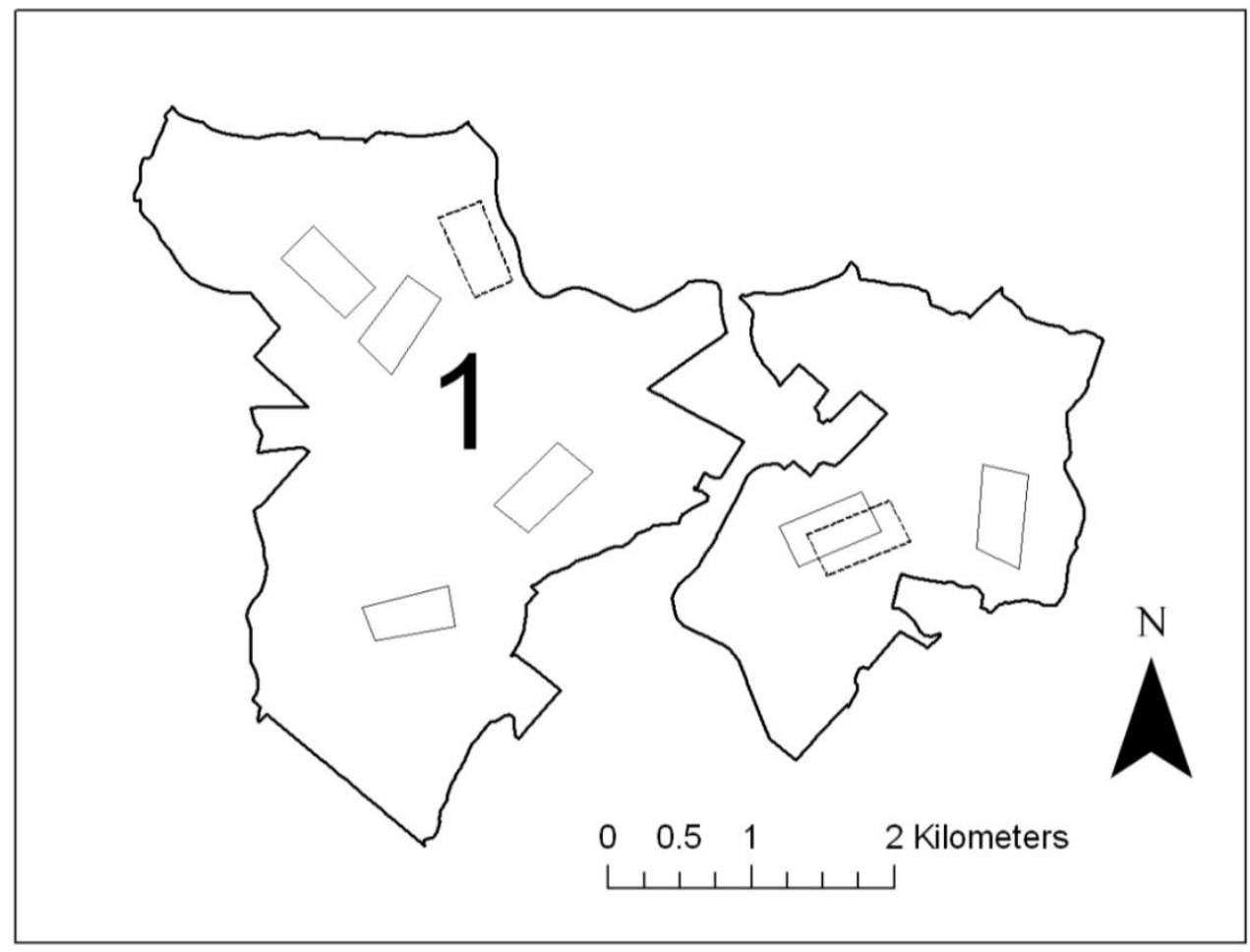

Figure 3. Nest plot locations at the Panther Run Tract. Solid lined plots are the original plots and plots with dashed lines were shifted to that location due to changing landcover. The number indicates the elevational block. 

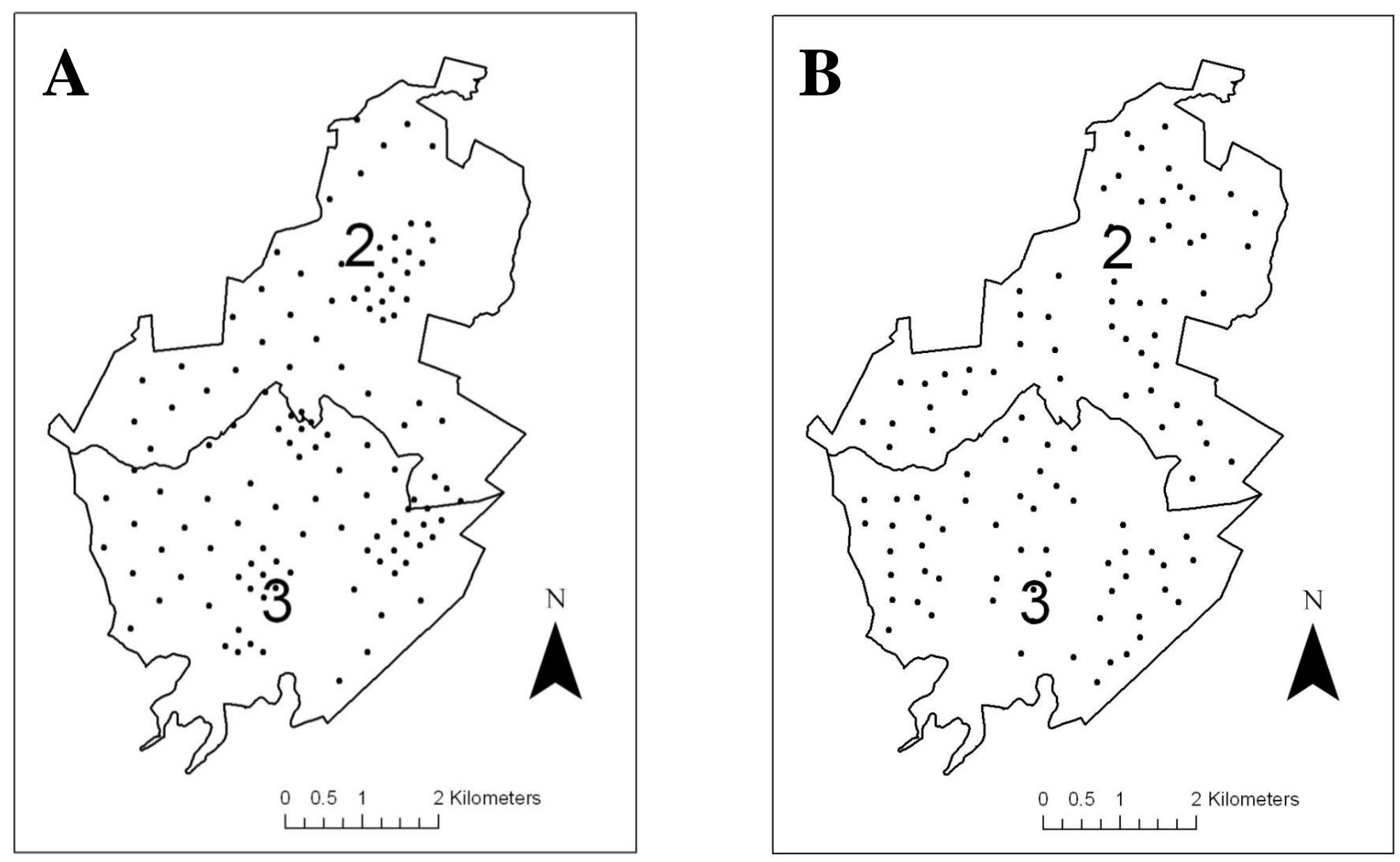

Figure 4. Point count locations at the Wildlife and Ecosystem Research Forest in A) 1996-1998 and B) 2001-2003 and $2007-2009$. The numbers represent the elevational blocks. 


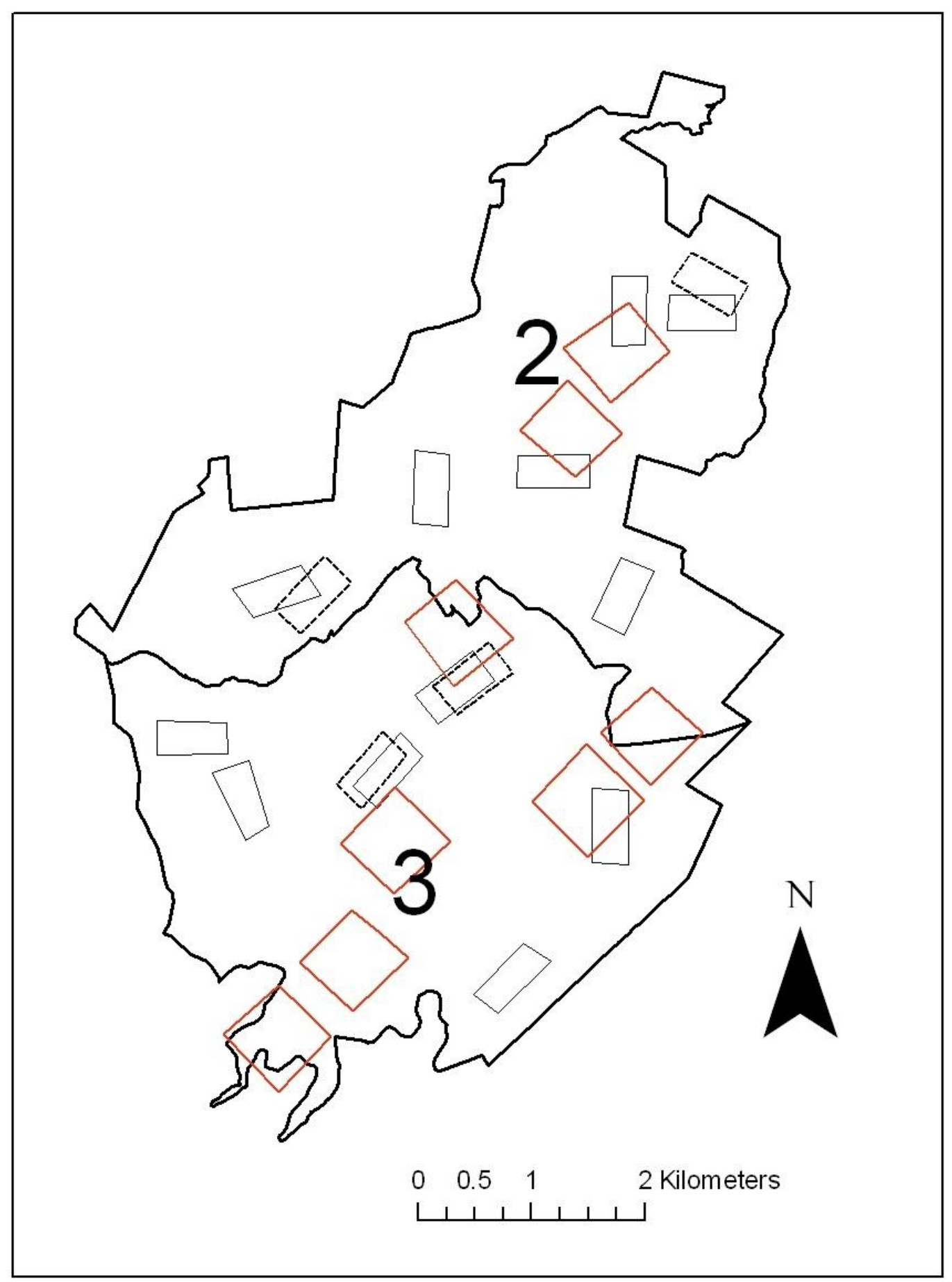

Figure 5. Nest plot locations at the Wildlife and Ecosystem Research Forest. Red lines are the nests plots in 1996-1998 and black lines are plots in 2001-2003 and 2007-2009. Plots with dashed lines represent plots that were shifted to that location due to changing landcover. The numbers represent the elevational blocks. 


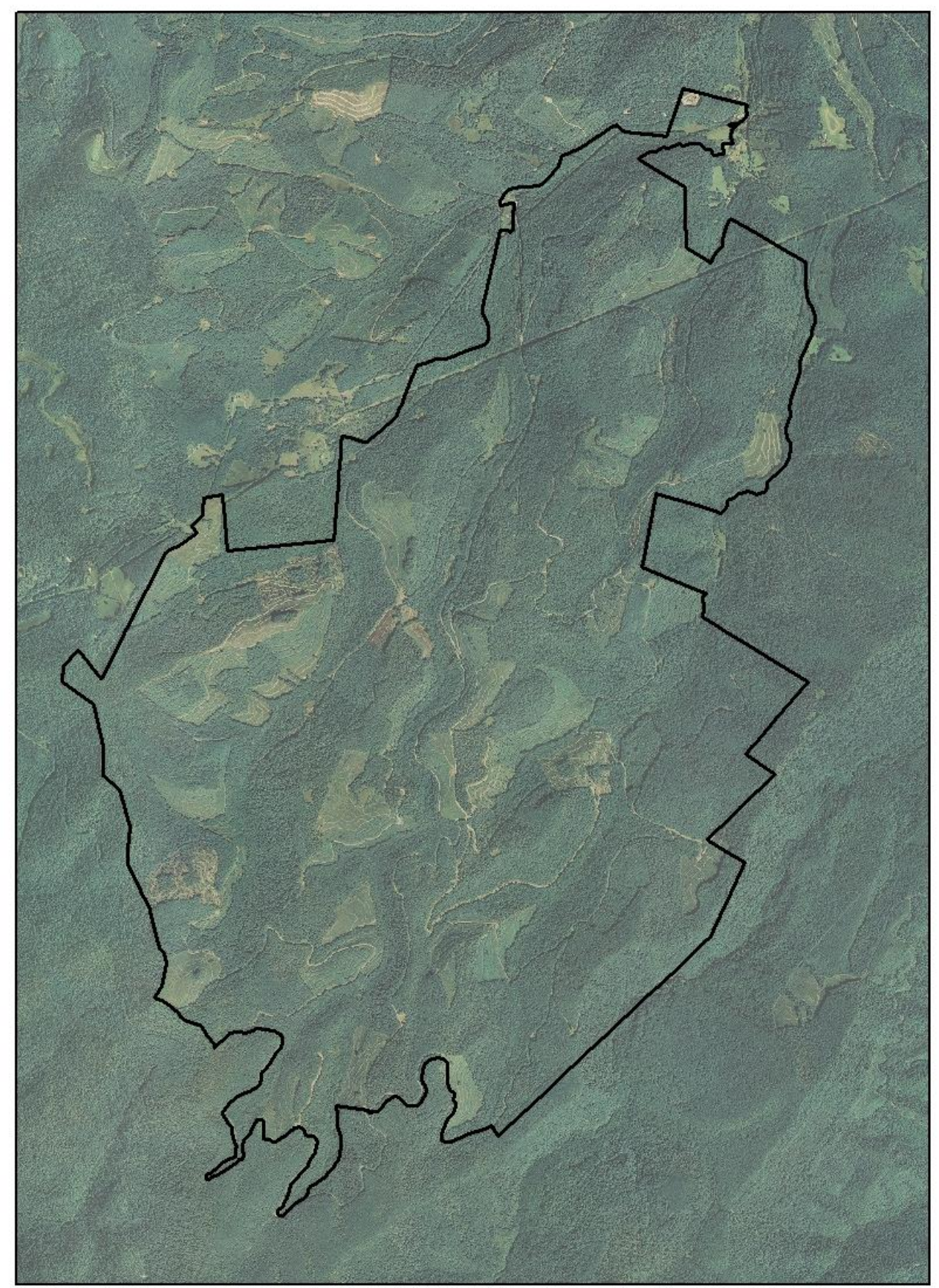

Figure 6. Aerial photo of the Wildlife and Ecosystem Research Forest and surrounding landscape in 2007. 


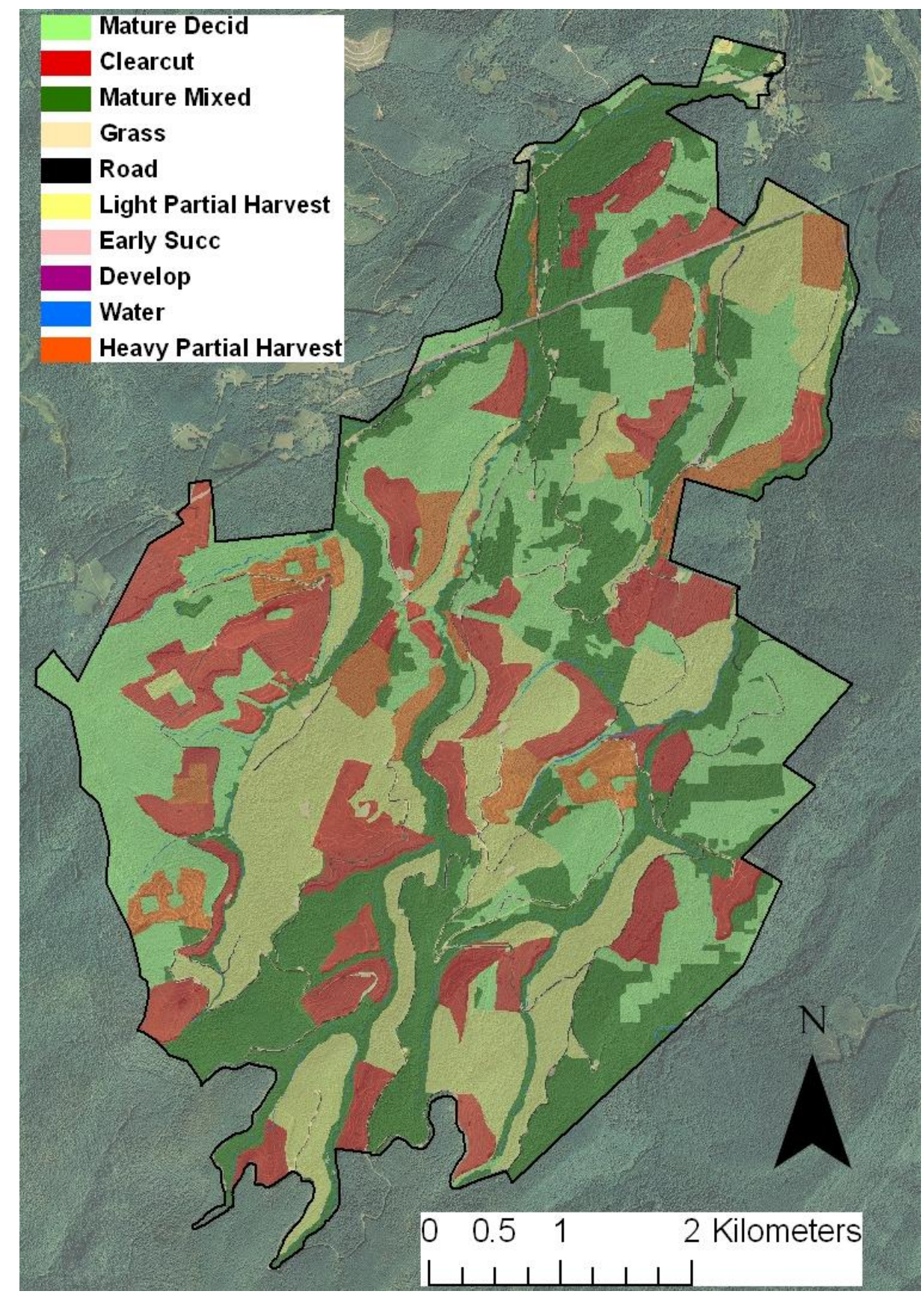

Figure 7. Aerial photo of the Wildlife and Ecosystem Research Forest and surrounding landscape in 2007 with the annual landcover layer overlayed. 


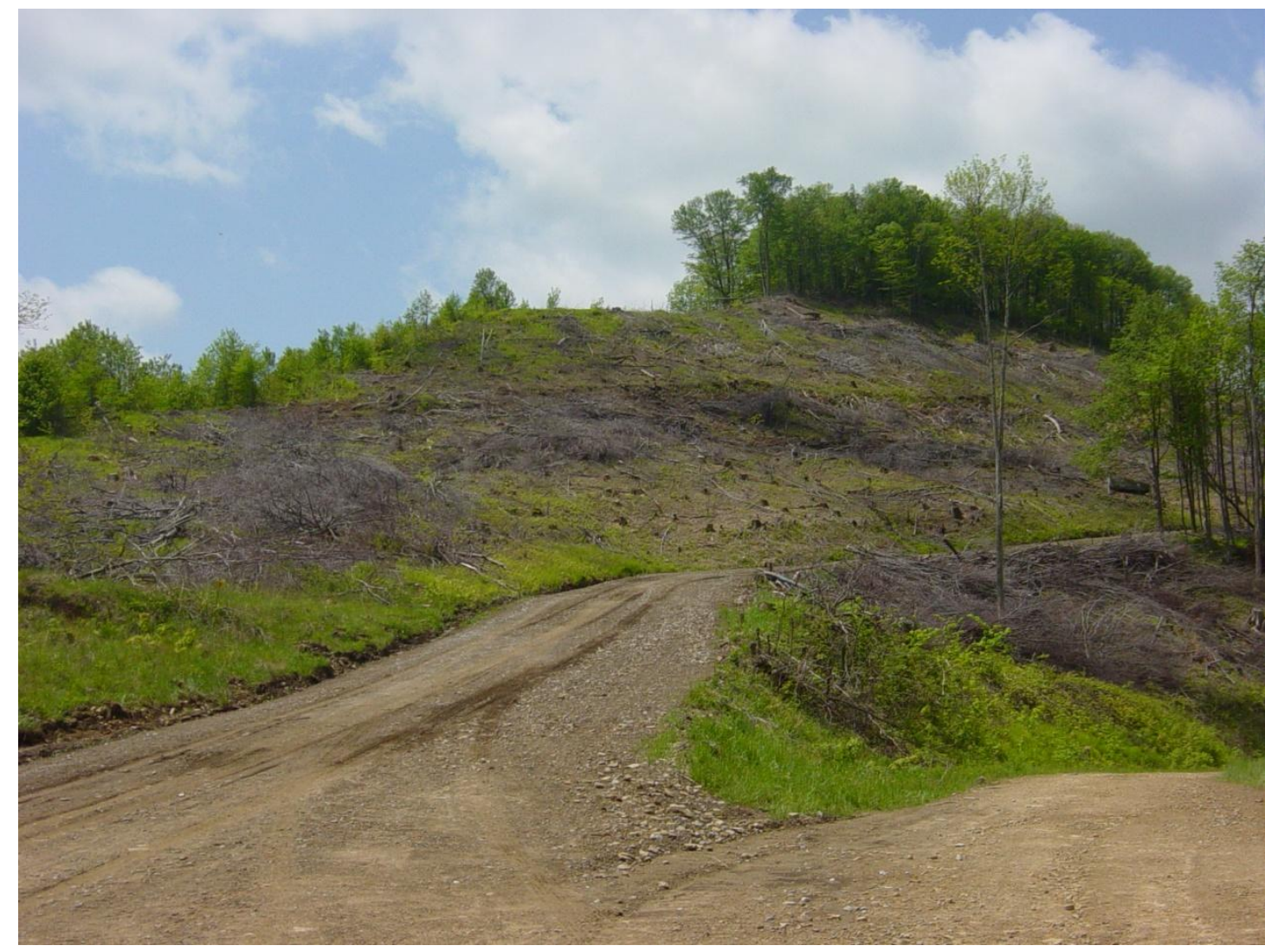

Figure 8. New clear-cut harvest at the Wildlife and Ecosystem Research Forest.

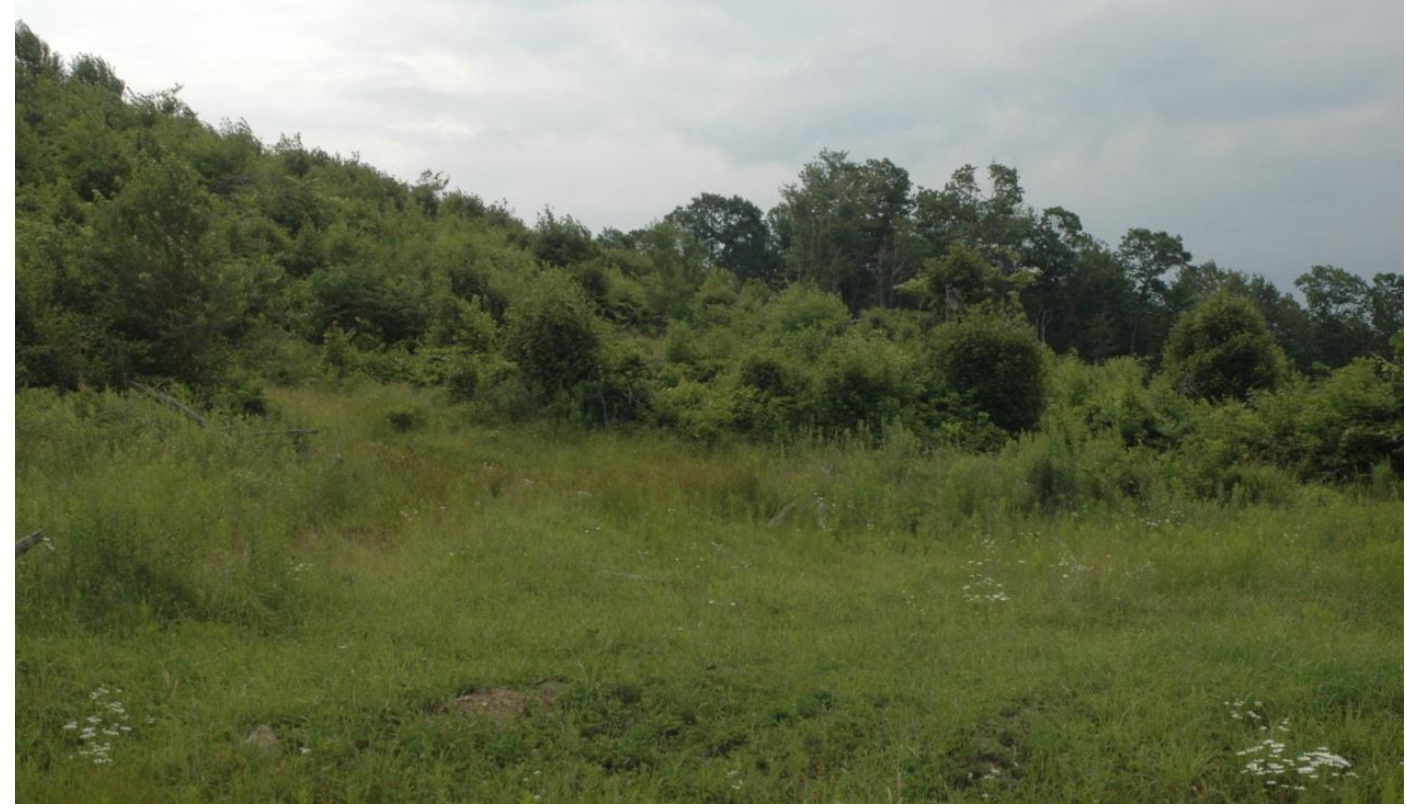

Figure 9. Approximately 2-year old clear-cut harvest with early vegetative regeneration at the Wildlife and Ecosystem Research Forest. 


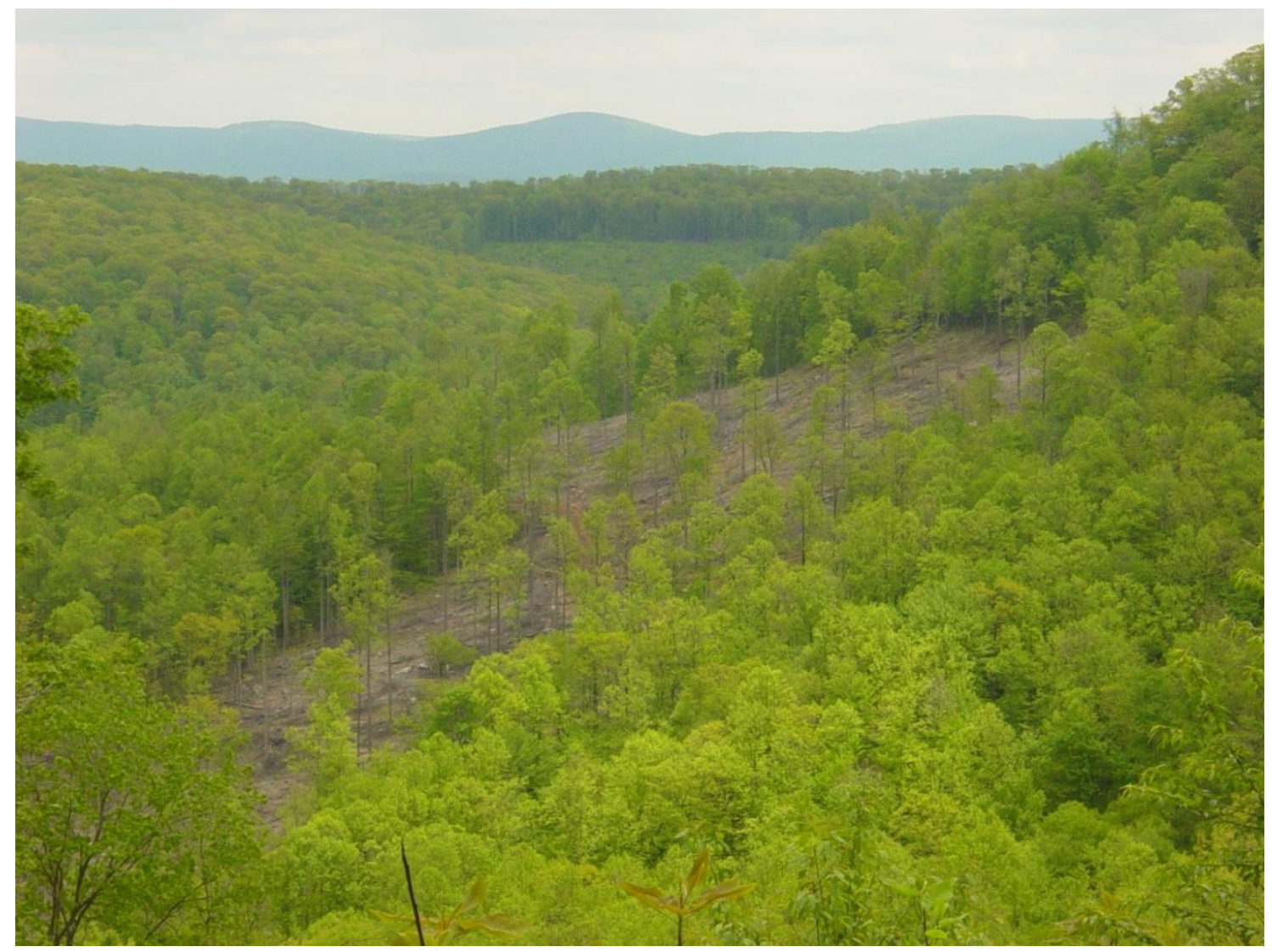

Figure 10. New heavy partial harvest at the Wildlife and Ecosystem Research Forest.

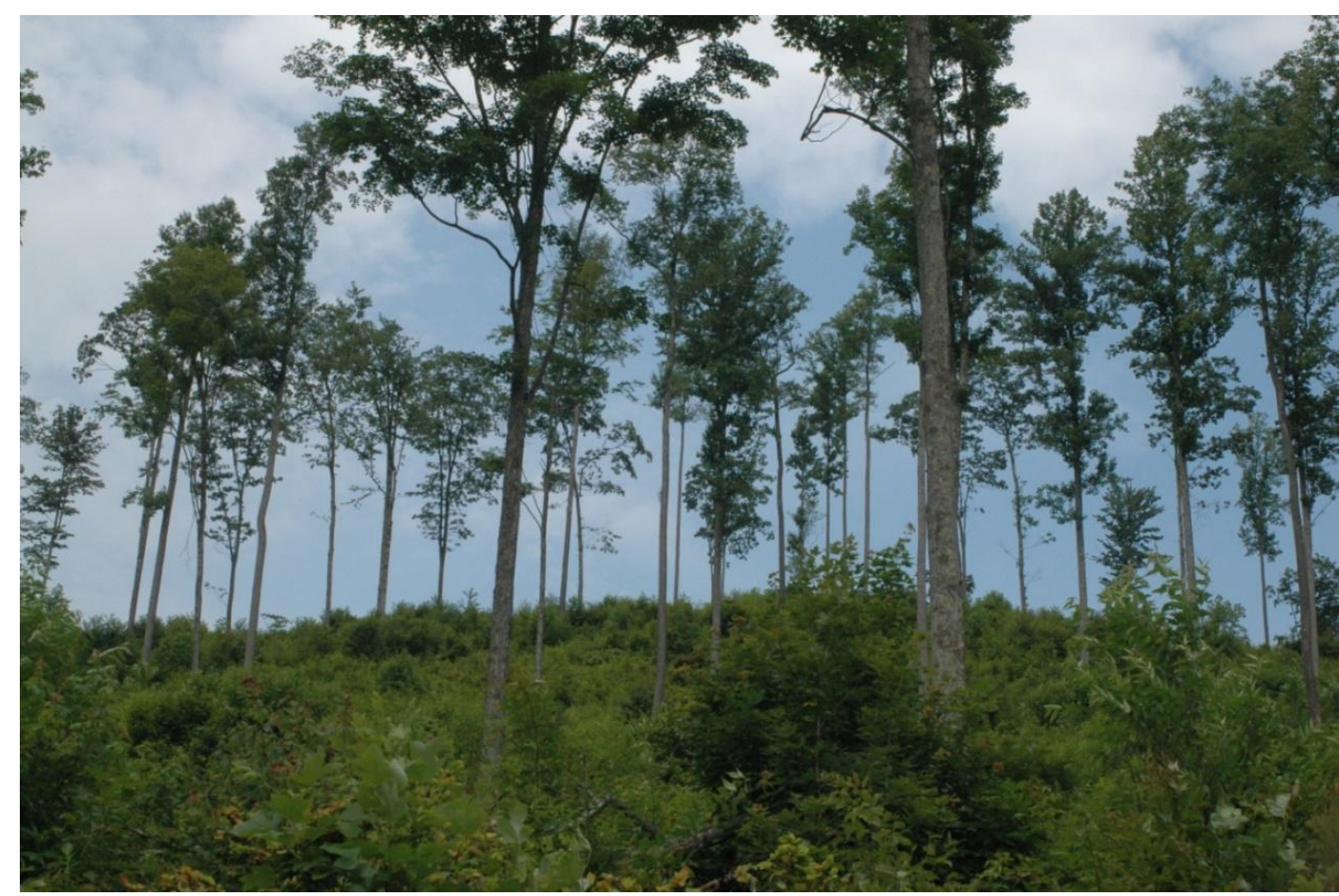

Figure 11. Approximately 2-year heavy partial harvest with early vegetation regeneration harvest at the Wildlife and Ecosystem Research Forest. 


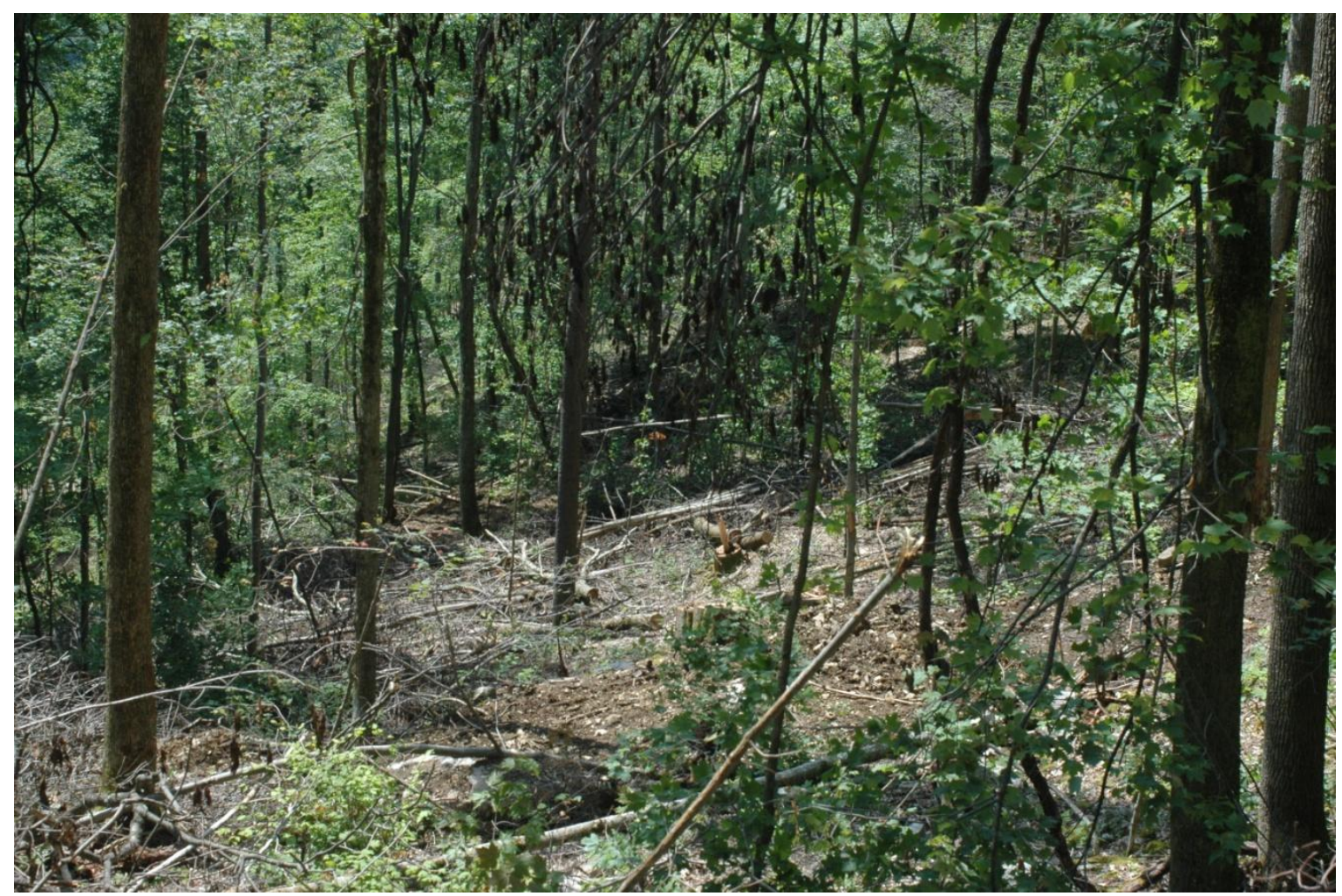

Figure 12. Light partial harvest in a mature deciduous stand at the Wildlife and Ecosystem Research Forest.

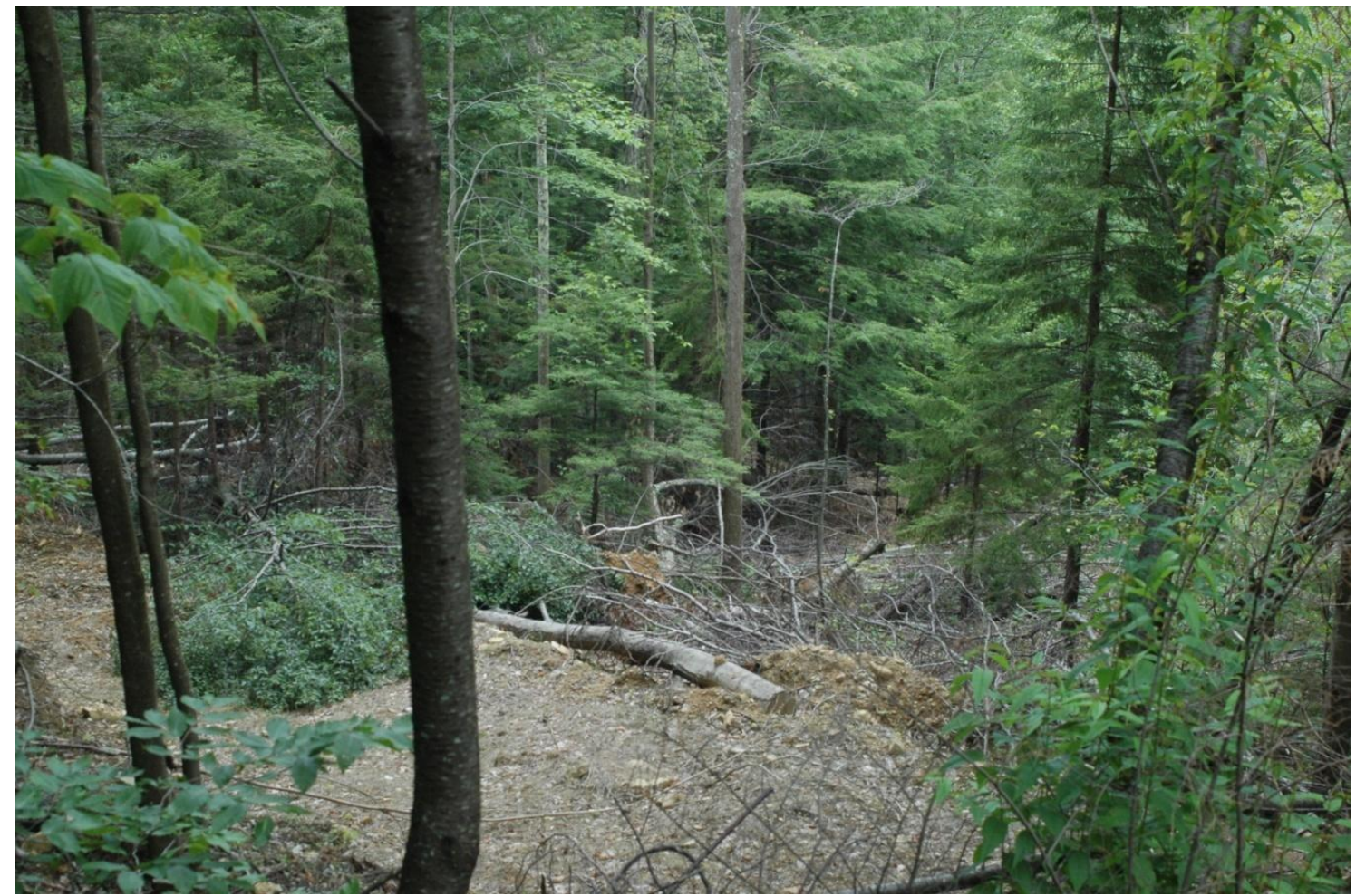

Figure 13. Light partial harvest in a mature mixed forest stand at the Wildlife and Ecosystem Research Forest. 


\section{CHAPTER 2}

THRESHOLD RESPONSES OF SONGBIRDS TO LONG-TERM TIMBER MANAGEMENT ON AN ACTIVE INDUSTRIAL FOREST 
Abstract- Forest managers often seek to balance economic benefits from timber harvesting with maintaining habitat for wildlife and ecosystem function and other human uses. Most research on the response of bird abundance to active timber management has been short-term, lasting 1-2 years, creating the need to investigate long-term avian responses that include non-linear thresholds during which a small change in habitat results in a disproportionate response in abundance and nest success. Our objectives were to identify temporal relative abundance and nest success trends and identify landscape-scale disturbance thresholds for species and habitat guilds over a 14 year period and using a variety of harvests (clear-cuts and heavy and light partial harvests). We conducted point counts and monitored nests at the Wildlife and Ecosystem Research Forest in Randolph County, WV from 1996-1998, 2001-2003, and 2007-2009. Early successional species increased in relative abundance across all three time periods, while interioredge and forest-interior guilds peaked in relative abundance mid-study after which the forestinterior guild declined. Of 44 analyzed species, four (9\%) declined significantly, 16 (36\%) increased significantly (only three species among all periods), and 14 (32\%) peaked in abundance mid-study, of which over the entire study period, nine species had no significant change in abundance, four declined, and one increased. Based on piecewise linear models, forest-interior and interior-edge guilds exhibited thresholds at $28 \%$ of the landscape, $10 \%$ harvesting by clear-cuts, and $18 \%$ harvesting by light partial harvests, after which abundances declined. Thresholds for the early successional guild were greater for total harvests (42\%), similar for harvesting by clear-cuts (11\%), and smaller for light partial harvests (10\%), and relative abundances increased after surpassing thresholds albeit at a reduced rate of increase after the clear-cut threshold. Some species differed from their guilds in their threshold values and responses to exceeding the thresholds. Even though relative abundance of most species (82\%) did not decline as the area affected by timber management increased, implementing management at or below our approximate harvest thresholds would reduce the number of declining species by half, maintaining higher relative abundances for four species with a net decline in abundance but who peaked in abundance mid-study, and maintain higher relative abundances of ten additional species. Implementing management at our thresholds would also prevent the increase in relative abundance for seven species and limit the increase in abundance for three species that increased throughout the study.

Keywords: timber management, thresholds, songbirds, relative abundance trends 


\section{Introduction}

Due to multiple-use demands on forests, forest managers often seek compromises when making management decisions. For example, economic benefits from timber harvesting and wood products are usually balanced with maintaining habitat for wildlife and ecosystem function and other human uses such as recreation, aesthetic beauty, and improved air and water quality. Already defined as a mandate for national forests through the Multiple Use-Sustained Yield Act of 1960, the management of these competing interests is important to consider across all public forestlands. Sustainable forestry certification programs ask private landowners (as well as other participants) to balance economic and ecological objectives such as conservation of biological diversity, maintenance of long-term site productivity, and protection of soil and water resources. Because private forestlands are common in the Eastern United States, management options should be provided for landowners to make informed management decisions.

West Virginia is the third most heavily forested state (78\%) in the United States with over 4.8 million ha of forests. Of these forested areas, $98 \%$ are available for timber harvesting (USDA Forest Service 2000) and all counties have a significant component of timberland (Childs 2005). Timber harvesting and related wood products are important economically for West Virginia, as they ranked ninth in wood industry share of total state employment and fourth in wood industry share of total gross state product (West Virginia Department of Commerce 2010). In 2008 approximately 9.5 million $\mathrm{m}^{3}$ of timber were harvested in West Virginia (Widmann et al. 2010) and when combined with other wood products, resulted in about 45,000 jobs (West Virginia Department of Commerce 2010) and contributed \$4 billion annually to the state (Childs 2005). The economic value of timber and wood products extends beyond West Virginia within the central Appalachian region. In Kentucky, forest industries provide 37,500 jobs and ships products worth $\$ 6.4$ billion annually (Thomas et al. 2007). In Tennessee, forests and forest products accounted for $6.6 \%$ of the state's economy, $\$ 21.7$ billion in economic output, and approximately 180,000 jobs (Young et al. 2007). Pennsylvania is the leading U.S. producer of hardwoods, over 1 billion board feet annually, and produces over $\$ 5.5$ billion of forest products yearly (Pennsylvania Forest Products Association 2004). Therefore, timber harvests are economically valuable throughout the region.

At the same time, many species of Neotropical migrant birds have been declining in West Virginia, the Allegheny Plateau, and other parts of the eastern United States (Askins et al. 1990, 
Peterjohn et al. 1995). Of the 50 mature-forest breeding passerines identified in the Allegheny Plateau by the Breeding Bird Survey, 28\% are significantly declining, (Sauer et al. 2008). Timber harvesting changes the composition and structure of mature forest habitats for bird species potentially resulting in edges with higher nest predation rates (Yahner and Scott 1988, Hoover et al. 1995), increased competition for resources from edge species (Wilcove and Robinson 1990), and reduced nest success within the stands (Bollinger and Linder 1994). However, studies in more heavily forested habitats have found no or limited edge effects (Rudnicky and Hunter 1993). Although Brown-headed Cowbird (Molothrus ater) parasitism can be a problem in some landscapes (Brittingham and Temple 1983, Robinson 1992), it generally is not in heavily forested areas where cowbird populations are relatively low (Annand and Thompson 1997, Rodewald and Yahner 2001, Moorman et al. 2002). In some cases, smaller residual forest patches can support less prey biomass for ground foraging bird species (Burke and Nol 1998) and gap formation and harvesting can depress arthropod availability (Duguay et al. 2000, Kilgo 2005). However, harvests increase the availability of early successional habitats, increasing the abundance of early successional specialist and generalist species (Drapeau et al. 2000, Duguay et al. 2001, McDermott and Wood 2009). Currently, 18 of 24 early successional species are declining across the Allegheny Plateau (Sauer et al. 2008), as their habitats are naturally returning to later successional states following human-induced forest changes earlier in the century (Hagan 1993, Hunt 1996). Also, forest-interior bird species and their young do not rely strictly on mature forests, but use early successional habitats post-breeding (Vega Rivera 1998, Pagen et al. 2000, Marshall et al. 2003, Dellinger 2007, McDermott 2007). Therefore, in a forest-dominated landscape harvesting might be an important management tool to support a broad array of bird species.

Long-term research is needed to investigate the response of bird communities to active timber management. Most research has been short-term in nature lasting only 1-2 years (Sallabanks et al. 2000). Short-term studies increase the likelihood that observed changes in bird abundance are due to yearly variability and not the management practices under consideration by the study or that they reflect only the immediate response to habitat changes (Sallabanks et al. 2000, Collins 2001). Long-term research encompasses not only the initial change in habitat but the continued successional vegetative response. Further, avian temporal response to landscape habitat change often is not linear in nature (Betts et al. 2007, Betts and Villard 2009), but can 
incorporate thresholds during which a small change in habitat results in a disproportionate response in bird abundance and/or nest success. Theory has predicted the occurrence of landscape thresholds (With and Christ 1995, Fahrig 2003), but until recently few statistical techniques were available to identify them (Guenette and Villard 2005, Haggett 2005). Empirical tests for landscape thresholds remain uncommon (Homan et al. 2004, Radford and Bennett 2004) but are becoming more frequent in empirical bird research (Imbeau and Desrochers 2002, Cushman and McGarigal 2003, Radford and Bennett 2004, Lindenmayer et al. 2005, Radford et al. 2005). Thresholds have been more commonly identified in agricultural landscapes than forest ones (Mönkkönen and Reunanen 1999), but this may be due to greater difficulty in identifying the distribution of habitat across a forest gradient (Wiens 1994). Thus, identifying timber harvesting thresholds would be of great value in management decisions.

Research also needs to consider changes in abundance at larger landscape scales to incorporate bird response to the heterogeneous mosaic of habitats created across the landscape. Managing bird diversity only at local scales overlooks broader patterns resulting from the reduction or change in habitat across the larger landscape (Faaborrg 1980, Gavin 1991). The number of species does not need to be maximized locally, but viable populations need to be maintained across the larger scale (Welsh and Healy 1993).

Finally, landscapes typically consist of multiple owners, which often have different objectives and use different management practices. Thus, research needs to consider a diversity of timber management practices including both even-aged and uneven-aged methods. Varied harvest types influence forest characteristics uniquely, resulting in different bird responses. Clear-cuts, the complete removal of mature trees, result in habitat for early successional species while temporarily displacing mature forest species (Annand and Thompson 1997, Duguay et al. 2001, Gram et al. 2003, Keller et al. 2003). Heavy partial harvests, including shelterwood and deferment harvests, create habitat for early successional species, while retained overstory trees provides some benefit for mature forest species (Annand and Thompson 1997, Rodewald and Yahner 2000, Augenfeld et al. 2008, McDermott and Wood 2009). Light partial harvests, including single-tree selection, diameter-limit cuts, and high-grading harvests, create forest openings similar to natural disturbances (Greenberg and Lanham 2001, Faccio 2003) while maintaining trees in a variety of age classes including older mature trees. By retaining many characteristics of mature forests, light partial harvests support mature forest bird species 
(Weakland et al. 2002, Gram et al. 2003, Campbell et al. 2007, Holmes and Pitt 2007) while increasing abundance of interior-edge species relying on canopy gaps (Lent and Capen 1995, Robinson and Robinson 1999, Greenberg and Lanham 2001, Weakland et al. 2002).

Our objective was to determine the long-term response of the avian community in a heavily forested landscape managed with a diversity of timber management practices. We identified 1) species and habitat guilds with significantly increasing or decreasing relative abundance and nest success trends, 2) threshold levels of disturbance from different harvest types after which relative abundance increased or decreased, and 3) nest success differences over a 14year period.

\section{Methods}

\subsection{Study Area}

We conducted our research on the Wildlife and Ecosystem Research Forest (WERF), located in Randolph County, West Virginia in the unglaciated Allegheny Mountain and Plateau region, from 1996-1998 (Weakland 2000), 2001-2003 (Dellinger 2005) and 2007-2009. This 3,413 ha forested area was established in 1994 by Westvaco Corporation to study the relations between industrial forest management practices and ecosystem processes and wildlife. The property was sold to Penn Virginia in the winter of 2007. Elevations are 734-1180 m and regional topography consists of narrow valleys with small, high-gradient streams, and steep slopes topped by broad ridges that generally run in a south-southwest to north-northeast direction. The site receives high annual average precipitation, more than $160 \mathrm{~cm}$ per year, with snow being common throughout the winter. As a result, the environment is cool and humid. Soils at the study area are acidic and well-drained inceptisols and ultisols.

Vegetation communities on the WERF vary by elevation. Red spruce (Picea rubens) and eastern hemlock (Tsuga canadensis) characterize stands above 1,000 m. Northern hardwoods including red maple (Acer rubrum), American beech (Fagus grandifolia), and black cherry (Prunus serotina) dominate at 850-1,000 m. Below $850 \mathrm{~m}$, cove hardwood and mixed mesophytic plant communities occur with species such as northern red oak (Quercus rubra), black birch (Betula lenta), and tulip poplar (Liriodendron tulipifera). Xeric oak-hickory communities dominated by black oak (Quercus velutina), scarlet oak (Quercus coccinea), and hickory (Carya spp.) also occur at low elevations. Communities of eastern hemlock, red spruce 
and rhododendron (Rhododendron spp.) are found in the riparian areas surrounding streams. Non-forest cover on the study area is limited. Grassy cover (1.9\%) resulted from road edges, gas well openings, and log landings. Additionally, roads covered $1.5 \%$, streams covered $0.1 \%$, and human development covered $<0.01 \%$.

At the study's inception, the WERF was primarily a 70- to 90-year-old even-aged mature forest that originated following logging during 1916-1928 (Keyser and Ford 2005). Since that time, much of the WERF has been actively managed using even-aged timber harvesting in the form of clear-cutting, shelterwood cuts, and deferment cuts, and uneven-age or partial harvesting via single-tree selection and high-grade harvests of mature sawtimber (Dellinger et al. 2007). Initial management included a balanced mixture of even and uneven-aged methods, although in 2007, management shifted to primarily uneven-aged techniques.

\subsection{Point Counts}

We conducted 50-m fixed-radius point counts (Hutto et al. 1986) at locations selected systematically from available points on a $241 \mathrm{~m}$ by $241 \mathrm{~m}$ grid established by Westvaco during a 1995 forest inventory. We surveyed 118 points from 1996-1997, 116 points in 1998, and 108 points from 2001-2003 and 2007-2009. The location of 40 points changed from 1998 to 2001 and two points were not sampled in 1998 due to limited access because of active timber harvests. Sample points were $241 \mathrm{~m}$ or $482 \mathrm{~m}$ apart and each point was marked with a $1 \mathrm{~m}$ by $1 \mathrm{~cm}$ aluminum stake and uniquely numbered.

Each year from 29 May to 4 July, birds were sampled at every point twice, once by each of two observers proficient in bird identification and distance estimation, with about three-week intervals between surveys. We conducted counts beginning at 0600 and ending no later than 1000 on mornings with suitable weather conditions (i.e., no rain, wind $\leq 4$ on the Beaufort scale). We recorded all individuals heard or observed within a 10-minute time span and noted whether each individual was within $50 \mathrm{~m}$, the type of detection (song, call, visual, or fly-over), and the sex if possible. Recently fledged young and flyovers were excluded from analyses. If a bird could not be identified by species, the observer attempted to locate and identify the individual after completing the count. Relative abundance at each survey station was the maximum count from the two samples each year. 


\subsection{Nest Searching and Monitoring}

We searched for and monitored nests for 11 focal species that were relatively common within the study area and represented a diversity of nesting habitats and heights. We selected two forest-interior species, Blue-headed Vireo (Vireo solitarius) as a subcanopy nester and Hermit Thrush (Catharus guttatus) as a ground nester. We selected five interior-edge species, American Robin (Turdus migratorius) and Wood Thrush (Hylocichla mustelina) as subcanopy/shrub nesters, Red-eyed Vireo (Vireo olivaceus) as a subcanopy nester, and Dark-eyed Junco (Junco hyemalis) and Veery (Catharus fuscescens) as ground nesters. Finally, we selected four edge/early successional species, Chestnut-sided Warbler (Dendroica pensylvanica) as a ground nester; and Eastern Towhee (Pipilo erythrophthalmus), Gray Catbird (Dumetella carolinensis), and Indigo Bunting (Passerina cyanea) as shrub nesters.

In 1996-1998, Weakland (2000) monitored nests on eight 40 ha nest-searching plots distributed across the study area. Plots sampled primarily mature forest, as few harvests were present on the study area, but included approximately 40 ha of light partial harvests and 25 ha of 2-aged harvests. In 2001-2003 (Dellinger 2005) and 2007-2009, we placed twelve nest plots, each approximately 20 ha in area, throughout the study area. We placed half the plots in areas of $>50 \%$ predominantly mature, closed-canopy hardwood forest, while the other half were placed in areas of $>50 \%$ early successional vegetation. All plots were orientated parallel to the slope to reflect the steep nature of the landscape and ensure they were not primarily in either ridges or valleys.

We searched each plot every three days, spending equal time in plots representing each habitat type to minimize potential sampling bias in the location of nests found. Additionally, we supplemented this nest searching with nests found at point count locations or while traveling to and from the counts. We used multiple techniques to locate nests including both systematic searches and behavioral observations. Once located, we checked each nest a minimum of every three days until the nest attempt was complete and identified as either successful or failed.

\subsection{Landcover}

We created a digital landcover layer for each year of the study in which bird data was collected, subdividing cover into ten types: clear-cuts (harvests with no residual trees), heavy partial harvests (clear-cuts with residual trees plus deferment and shelterwood cuts), light partial 
harvests [single-tree selection, diameter limit, and high-grade cuts with approximately 14-16 $\mathrm{m}^{2} /$ ha basal area (Dellinger 2007)], mature deciduous forest, mature mixed forest, herbaceous, shrub/scrub (mostly roadside), water, road, and development. We delineated cover types and stand boundaries annually at the beginning of each field season using $1 \mathrm{~m}$ resolution National Agriculture Imagery Program (NAIP) 1:10,000 scale aerial orthophotos, harvest shapefiles provided by the timber companies, and Universal Transverse Mercator (UTM) coordinates of habitat types measured in the field. From yearly landcover layers, we used Fragstats (McGarigal et al. 2002) to calculate the total area (ha) for five landcover classes: clear-cut, heavy partial harvest, light partial harvest, mature deciduous forest, and mature mixed forest. We also used Fragstats calculated core area (areas $>50 \mathrm{~m}$ from an edge) for mature forest (mature deciduous and mature mixed forest patches combined) and early successional cover (combined patches of clear-cuts, heavy partial harvests, and shrub/scrub cover).

\subsection{Data Analysis}

\subsubsection{Change in Relative Abundance}

To analyze changes in abundance, we determined the average relative abundance within each 3-year period (1996-98, 2001-03, and 2007-09) for all individual bird species with >10 detections, the natural break in the data, and for three habitat guilds (forest-interior, interioredge, and early succession) as described by Whitcomb et al. (1981), Ehrlich et al. (1988), and based on observations from other avian research in West Virginia (Appendix A). To account for detectability across habitats we only included birds within a 50-m radius and conducted removal model analysis (Farnsworth et al. 2002) comparing year and observer effects, for which we found no differences. For the relative abundance data we analyzed means across the three different 3-year periods rather than the nine individual years to highlight long-term trends and minimize yearly variability, assuming differences among 3-year periods were greater than differences within a 3-year period. We used the maximum value for each species or guild from the two counts at each survey location. Within the same 3-year periods, we analyzed species richness, measured as the maximum number of species/point over the two surveys each year, and the Shannon diversity index (Shannon 1948). We tested for differences in relative abundance and diversity among the three 3-year periods using the Kruskal-Wallis test (Kruskal and Wallis 1952) due to non-normal data with $\alpha=0.05$. For significant results, we conducted Dunnett- 
Tukey-Kramer multiple comparison tests using package DTK in Program R (R Core Development Team 2009), identifying pairwise comparisons as statistically different if the confidence limit for the difference in mean relative abundance did not include zero. To depict the range of total harvests for which the species was most abundant, the total harvests corresponding to the 3-year period or periods with the highest relative abundance were plotted versus the total range of harvests.

\subsubsection{Harvest Thresholds}

We identified harvest thresholds, a point at which a small increase in the percent of area in a particular harvest type causes a disproportionate change in relative abundance, across the nine years of data using piecewise linear models (Toms and Lesperance 2003) from the SiZer package in program R. Given that the percent harvests did not vary by a set amount annually, we were limited in the choice of other threshold techniques such as Bayesian analysis of change point (Barry and Hartigan 1993), which assume an equal interval on the x-axis, and by default chose piecewise linear models. Using annual relative abundance as the response variable, we developed three threshold models (total, clear-cut, and light partial) for each of the three habitat guilds and 11 focal species for which we conducted nest searches. The predictor variable for the models for each guild and species was percent of the landscape harvested (clear-cuts, heavy and light partial harvests combined), percent of landscape harvested using clear-cuts, or percent of landscape harvested using light partial harvests in each year. Models for each harvest type were developed separately from the other harvest types, using only the percent harvest for one type, and therefore the threshold for each harvest type should be interpreted individually. We did not construct a model for heavy partial harvests because they were not evenly applied throughout the study and had the smallest total area harvested of the three types (6\% of the landscape by 2007). For each model, we defined the threshold as the percent harvest at which the slope (relative abundance of each guild species/percent harvest) of the linear model changed and calculated 95\% confidence intervals for the threshold estimate by resampling the data using 1000 bootstrap samples. We measured the relative abundance slope, which represents the change in relative abundance associated with a changed from $0-100 \%$ of the landscape harvested, before and after the threshold. For example, a slope equal to two would indicate an increased abundance of two birds/point when the percent harvest increased from 0-100\% of the landscape. The first slope 
represents the rate of change in abundance before reaching the threshold and the second slope represents the response of the rate of change after exceeding the threshold. The second slope can change in direction of response (positive to negative or vice-versa) and magnitude (reduced or increased rate of change).

\subsubsection{Nest Success}

We calculated nest success for each focal species within each 3-year time period of the study (1996-1998, 2001-2003, and 2007-2009) using the modified Mayfield method (Mayfield 1961, 1975, Johnson 1979). Nests within each 3-year period were combined to increase sample size and because we reasoned that nest success within each 3-year period was more similar than nest success among the three time periods. We classified a nest as successful if at least one young fledged. If a nest failed between checks, the median day was used in calculating exposure (Mayfield 1961) and for nests of unknown fate, we calculated exposure to the last successful nest check and considered the nest successful (Manolis et al. 2000). We used program CONTRAST (Hines and Sauer 1989) to test for difference among these 3-year nest success groups with Chisquare tests.

\section{Results}

\subsection{Landcover}

During 1996-2007, forests at the WERF shifted from primarily mature forest (93\% in 1996) to a mix of mature forest ( $34 \%$ in 2009) and early successional (i.e., harvested) habitats (Table 1). Since 1996, mature deciduous forest area decreased 64\%, mature mixed forests $62 \%$, and core mature forest $83 \%$. In contrast, area in clear-cut and heavy partial harvests increased until 2007, when harvesting techniques shifted to primarily light partial harvests; the latter increased throughout the study. In 2008, the cover of early successional habitats surpassed the cover of mature forest. Core early successional habitat was minimal in 1996 but increased to 73 ha in 2009.

\subsection{Relative Abundance and Diversity}

We detected 76 species during the study; $44 \mathrm{had} \geq 10$ detections and were used in analysis (See appendix B for annual relative abundance for all species). Of these 44 species, $9 \%$ (4 
species) declined significantly from 1996-1998 to 2001-2003 (Table 2). In contrast, 16 species (36\%) increased in relative abundance during some portion of the study, six from 1996-1998 to 2001-2003, seven from 2001-2003 to 2007-2009, and three among all periods. The relative abundance of 14 species (32\%) peaked mid-study, 2001-2003, nine of which had no significant change in abundance between 1996-1998 and 2007-2009, four species declined, and one species increased. Ten species had no significant differences in relative abundance among the 3-year periods. From the first to the third 3-year periods (net change in relative abundance excluding 2001-2003), relative abundance for 17 species (39\%) increased, eight (18\%) decreased, and 19 (43\%) remained the same. The annual change in relative abundance for declining species ranged from 1.5-6.3\% (BLBW: -6.3\%, DOWO: -5.4\%, CAWA: -4.8\%, BHVI: -3.3\%, MAWA: -2.7\%, SCTA: -2.4\%, REVI: -1.5\%; no counts of GCKI after 2003).

Of the three habitat guilds, only early successional species increased in relative abundance across all three time periods (Table 2). The remaining guilds peaked in relative abundance during the middle period from 2001-2003. Only the forest-interior guild had the lowest relative abundance in 2007-2009. Based on these results (Table 2), Figs 2-4 depict the ranges of total harvests for which we observed the highest relative abundance for species by habitat guild. These harvest value ranges are determined based on the maximum and minimum harvest values from the 3-year period or periods with the highest relative abundance.

Species richness $(\mathrm{H}=95.7, p<0.001)$ and diversity $(\mathrm{H}=80.2, p<0.001)$ changed significantly across the three time periods. Both metrics significantly increased from the first to second period, reaching the highest diversity in 2001-2003 (Fig 1). These metrics then declined in 2007-2009 but remained significantly higher than the first three years, 1996-1998. We first detected five of our analyzed species (BWWA, COYE, FISP, SOSP, YBCU) in 2001-2003 species and detected nine additional new species for the first time during this period (BAOR, BBCU, BGGN, CAWR, CHSP, GCFL, GWWA, MODO, RBWO). We also detected three new species in 2007-2009 (ALFL, BRTH, YBCH). All new species were interior-edge or early successional species.

\subsection{Timber Harvest Thresholds}

Forest-interior and interior-edge guilds exhibited similar threshold patterns with thresholds occurring at $28 \%$ of the landscape harvested, $10 \%$ harvested by clear-cuts, and $18 \%$ 
harvested by light partial harvests (Table 3). Appendix C provides a visual depiction of sample piecewise linear regression output representing the major threshold patterns including difference in the direction and magnitude of the response. The relative abundance slopes for both guilds changed from positive to negative once the thresholds were surpassed (Appendix C.1), except for the light partial harvest threshold for the interior-edge guild, which remained positive after the threshold but was reduced (Table 3, Appendix C.2).

Early successional guild thresholds were greater than other guilds for total harvest (42\%), about the same as other guilds for harvesting by clear-cuts (11\%), and smaller for harvesting by light partial harvests (10\%). Slopes before and after thresholds were positive, but became steeper after surpassing overall harvest (Appendix C.3) and light partial harvest thresholds, indicating a more rapid increase in relative abundance. However, slope was reduced in steepness for this guild above the clear-cut threshold. Early succession threshold confidence intervals were broader than forest-interior or interior-edge confidence intervals (Table 3).

Thresholds of some species agreed with their guild results, but other species differed in their threshold value and response to exceeding the threshold (Table 3). Blue-headed Vireo threshold levels were greater for total harvest and clear-cut but lower for light partial harvest than the forest-interior guild and the direction of the response was reversed (Appendix C.4). While the direction of the response for Red-eyed Vireo and Veery was the same as the interioredge guild, threshold values were lower for Red-eyed Vireo and higher for Veery. In contrast, American Robin and Wood Thrush differed in both their threshold value and response.

Chestnut-sided Warbler had lower threshold values and an opposite response to the clear-cut threshold than did the early succession guild. Gray Catbird slopes indicated a minimal negative shift as a result of surpassing any of the thresholds.

The clear-cuts threshold for Wood Thrush and Indigo Bunting (Table 3) occurred at the highest harvest percentages measured near the end of the study (Appendix C.5). Without further data we cannot extrapolate this pattern and therefore consider neither to have a threshold within the range of values we measured.

\subsection{Nest Success}

We located and monitored 402 nests of 11 focal species; 129 in 1996-1999, 175 in 19961999, and 98 in 2007-2009. We found not cowbird parasitism of any nests. Nest success 
differed among the 3-year periods for four focal species (Table 4). Dark-eyed Junco success declined from the first to the second time period. Indigo Bunting and Veery success declined from the second to the third time period. Wood Thrush success declined from the first to the third time period.

\section{Discussion}

As a result of continuous timber management, the habitat within our study area changed from primarily mature forest (92\%) in 1996, to $61 \%$ harvested habitats and $34 \%$ mature stands in 2009. This change occurred as the result of multiple harvest types with light partial harvests most prevalent, especially after 2007, but with clear-cuts and to a lesser degree heavy partial harvests. In response to this broad range of habitat conditions, we identified a variety of temporal responses by guilds and species that often differed in direction, magnitude, and timing.

\subsection{Declining Trends}

For species with overall declining relative abundance ( 8 species), we observed two different patterns. Half the species declined from 1996-1998 to 2001-2003, indicating an immediate decline, but displayed no response to further harvesting. The other half had an initial short-term positive response to harvesting but subsequently declined in abundance, resulting in abundances lower than those of 1996-1998. The majority of the species in the declining group were forest-interior $(n=6)$ with a few interior-edge species $(n=2)$.

The initial decline associated with the first type of response reflects findings of declining relative abundance of late-successional bird species due to even-aged harvests (Annand and Thompson 1997, Duguay et al. 2001, Gram et al. 2003, Keller et al. 2003). The four species within this group (BHVI, BLBW, CAWA, and GCKI) all tended to be higher elevation species that preferred mixed mature forests. CAWA, the only forest-interior species in this group, has been found to be a higher elevation disturbance specialist and may have declined during the study in response to a larger, region-wide decline (Becker unpublished). The lack of continued declines in the other three species from 2001-2003 through 2007-2009 might be related to the change in harvesting techniques to primarily light partial harvests that have been shown to support mature forest species (Gram et al. 2003, Campbell et al. 2007, Holmes and Pitt 2007). 
We observed the second declining pattern for two forest-interior species (DOWO, MAWA) and two interior-edge species (REVI, and SCTA) that peaked in relative abundance mid-study but ultimately declined below 1996-1998 levels. All were found at lower elevations in predominantly mature deciduous forests. This temporary increase may have been a response to the creation of canopy gaps by light partial harvests that provided more habitat for interioredge species (Lent and Capen 1995, Robinson and Robinson 1999, Greenberg and Lanham 2001) and the creation of early successional habitats used by mature forest species during the post-breeding period (Pagen et al. 2000, Keller et al. 2003, Marshall et al. 2003, McDermott 2007). The eventual declines indicate a threshold above which these benefits were outweighed by lost habitat.

These two different declining patterns also may explain threshold differences among species and guilds. Blue-headed Vireo relative abundance followed the first response type, immediate decline, while its forest-interior guild followed the second, short-term increase. The guild was strongly influenced toward the second pattern by the inclusion of other guild members with this pattern. Interestingly, the light partial harvest threshold (14\%) for BHVI occurred earlier, between 1998 and 2001, than total harvest (40\%) and clear-cuts thresholds (18\%), 2007, when timber management shifted primarily to light partial harvests. This suggests that light partial harvests might have mitigated the decline in BHVI abundance.

The forest-interior and interior-edge guilds and many members of these guilds had thresholds that reflected a mid-study peak in relative abundance. Those guilds included the four species with the second declining trend mentioned above (DOWO, MAWA, REVI, and SCTA), but also nine species that returned to relative abundance levels similar to 1996-1998 and one species that remained significantly higher than at the start of the study. For these guilds and species, relative abundance increased until reaching their thresholds (27-29\% for total harvest, 8-10\% for clear-cuts, and 17-18\% for light partial harvests) and subsequently declined (Table 3). These thresholds occurred with conditions that were present five to seven years into the study, 2001-2003; however, because bird relative abundance data were not collected in either 1999 or 2000, we cannot be sure the actual threshold did not occur in these years. Therefore, by including values greater than the percent harvests measured in 1998, the threshold could range from 15-29\% total harvest, 3-10\% clear-cuts, and 11-18\% light partial harvests. Species from both guilds had similar thresholds and included Dark-eyed Junco, Hermit Thrush, Red-eyed 
Vireo, and Veery. We observed variation in these thresholds for a number of species. For instance, the threshold conditions for Red-eyed Vireo (17\% total harvest, $6 \%$ clear-cut, 11\% light partial harvest) occurred approximately a year earlier than that for the guilds, while the Veery threshold (32\% total harvest, 13\% clear-cut, 20\% light partial harvest) occurred approximately a year later.

\subsection{Increasing Trends}

More bird species increased in relative abundance (39\%, 17 species) than decreased, with early successional species $(n=9)$ being the primary beneficiaries. The relative abundance of all early successional species increased or remained the same. Early successional species have been found to benefit from even-aged harvests, both clear-cuts and heavy partial harvests, (Annand and Thompson 1997, Duguay et al. 2001, Gram et al. 2003, Keller et al. 2003 Rodewald and Yahner 2000, Augenfeld et al. 2007) and uneven-aged harvests if the gap size is large enough. Besides early successional species, we also identified seven interior-edge species (AMRE, AMRO, CEDW, DEJU, HOWA, NOFL, WOTH) and one forest-interior species (BAWW) that increased in relative abundance.

While many species increased in relative abundance, we found that the timing of the increase varied. From 1996-1998 to 2001-2003, six species (AMGO, AMRO, CEDW, GRCA, HOWA, NOFL) increased in relative abundance and then subsequently their relative abundance stabilized. This group, which included a greater percentage of forest-interior species, had a more immediate response to timber management but exhibited no response to continued management. In contrast, the relative abundance of seven species (AMRE, BAWW, BHCO, EATO, FISP, SOSP, WOTH) was initially stable, but then increased from 2001-2003 to 2007-2009. The delayed increase could be the result of a lag in the development of suitable early successional habitat or the need for larger proportions of the landscape in early successional habitat. Three early successional species (COYE, CSWA, INBU) increased in relative abundance in each 3year time period, exhibiting a continued benefit to further timber harvests. Finally, DEJU peaked in relative abundance mid-study but remained more abundant than at the beginning of the study, indicating a stronger intermediate response to timber management but that continued management while not the most beneficial, was an improvement over no harvesting. An additional 12 new species (2001-2003: BAOR, BBCU, BGGN, CAWR, CHSP, GCFL, GWWA, 
MODO, RBWO; 2007-2009: ALFL, BRTH, YBCH), that were not included in the analysis, were not detected until later in the study indicating a delayed response to timber management of at least 5-10 years. These species, interior-edge or early successional species, were either initially scarce and not detected until abundance began to increase as a result of timber management or colonized the study area once harvesting began. WEWA, a forest-interior species,

Although, increased relative abundance of Brown-headed Cowbirds may raise concerns about future increases in nest parasitism, past studies have found parasitism to be relatively low in highly forested habitats such as our study area (Annand and Thompson 1997, Rodewald and Yahner 2001, Duguay et al. 2001, Moorman et al. 2002). In our study we found no effects of parasitism, as cowbirds did not parasitize any of the 402 nests we monitored. Additionally, we observed no change in the relative abundance of avian nest predators (AMCR, BLJA) and a decline in forest-breeding raptors (BWHA, COHA, SSHA; Becker unpublished) as a result of timber management.

Increasing trends in relative abundance were evident for the early successional guild and its members, as well as for American Robin and Wood Thrush that contradicted their guild response. Both these species benefitted from continued increases in light partial harvests, although the Wood Thrush thresholds (49\% total harvest, 14\% light partial harvest) were lower than those for American Robin (56\% total harvest, 31\% light partial harvest). The inclusion of interior-edge species benefitting from increased light partial harvests for the interior-edge thresholds explains why the light partial harvest slope is reduced but remains positive after passing the threshold for the guild, while the slope is negative for total harvest and clear-cuts.

For the early successional guild, slope increased in steepness after the threshold, indicating a more rapid increase in relative abundance. The total harvest threshold ranged from $42-51 \%$ of the landscape, values that were not observed until 2007-2008. During this period, we identified three new species (Alder Flycatcher, Brown Thrasher, and Yellow-breasted Chat) within the study area. Timing within this guild varied by species, as Chestnut-sided Warbler followed a similar pattern, but the threshold occurred earlier (1998) and at a lower percent total harvest (15\%).

The relative abundance threshold of early successional species was influenced by harvest type. We found little response to small amounts of light partial harvests. All species had a 
minimal or slightly negative slope until surpassing the threshold of 7-11\% light partial harvest. However, the clear-cut threshold differed among the species. For the guild and Eastern Towhee, the most rapid increase in relative abundance occurred from 0 to $11 \%$ clear-cuts, after which the slope remained positive but decreased in steepness. As a result, even though the guild continued to increase in relative abundance, the greatest benefit occurred when the first $10 \%$ of the landscape was harvested by clear-cuts. In contrast, Chestnut-sided Warbler and Indigo Bunting increased throughout the study as percent clear-cuts increased. Therefore, the early successional guild includes at least two types of species, those which benefitted most from the initial harvests and those which continued to benefit from long-term harvesting.

\subsection{Species Diversity}

Past research has shown that species diversity across the larger landscape increases in response to both uneven-aged (Annand and Thompson 1997, Robinson and Robinson 1999, Campbell et al. 2007) and even-aged harvests (Annand and Thompson 1997, Baker and Lacki 1997) and overall disturbance (Mitchell et al. 2006, 2008). Increased diversity is attributed to the increase in species using forest gaps and early successional habitats (Lent and Capen 1995, Robinson and Robinson 1999, Greenberg and Lanham 2001) and greater overall variation in forest age (Mitchell et al. 2006). We found similar results with species richness (species/point) and Shannon diversity, greatest from 2001-2003. Despite declining from 2001-2003 to 20072009, diversity remained greater than at the beginning of the study. Therefore, while timber harvests resulted in greater species diversity across the landscape, the decline in diversity in the last 3-year period indicates there are limits to this increase after which the returns are diminished. Our results are consistent with the intermediate disturbance hypothesis (Connell 1978), which states that diversity is maximized when disturbance is neither too rare nor too frequent.

\subsection{Regional Trends}

We also considered our temporal trends in respect to the larger region-wide trends within the Allegheny Plateau using BBS trends from 1980-2007 (Sauer et al. 2008) to isolate the effects of timber management from other confounding regional factors. A majority of our trends (80\%) contradicted region-wide patterns. Twelve of 13 significantly declining species (AMRO, BAWW, BHCO, BLJA, CEDW, EAWP, FISP, INBU, RBGR, SOSP, VEER, and WOTH), 
seven of 10 non-significantly declining species (ACFL, AMCR, AMGO, AMRE, COYE, EATO, and GRCA), 13 of 16 significantly increasing species (BHVI, BLBW, BTBW, HETH, MAWA, OVEN, PIWO, REVI, RBNU, TUTI, WBNU, WIWR, and YBCU), and three of five nonsignificantly increasing species (BCCH, HOWA, and MOWA) contradicted regional abundance patterns. The differences strongly support different temporal trends within our study area due to timber management than across the rest of the region. The nine exceptions were AMGO, CAWA, CSWA, DEJU, DOWO, GCKI, HOWA, NOFL, and SCTA for which our observed trends coincided with regional patterns. Since a large proportion of the species' trends run counter to regional patterns, the trends are probably stronger than our data suggests.

\subsection{Priority Conservation Species}

We documented trends for 11 priority bird species for conservation as defined by Partner's in Flight within the Mid-Atlantic Ridge and Valley physiogeographic region, which includes the West Virginia portion of the Allegheny Plateau (Rosenberg 2003). This designation accounts for global threats to the species, high concern for regional or local populations, or responsibility for conserving large or important populations of the species. Timber management had minimal negative effects on the relative abundance of most priority species. We found declining relative abundance trends for only three species (BLBW, CAWA, and SCTA) of which two (CAWA, SCTA) had corresponding regional declines based on BBS results from 1980-2007 (Sauer et al. 2008). Only the decline of BLBW contradicted the region-wide increase. Of the remaining eight species, five increased in relative abundance (WOTH, HOWA, and all three shrub species: EATO, FISP, INBU). The relative abundance of the final three species did not change (ACFL, BTBW, EAWP), although BTBW relative abundance did temporarily increase. Additionally, we detected three new priority species (BRTH, GWWA, YBCH) that colonized the study area as a result of timber management.

Beyond individual species, timber management improved the total conservation index value of the study area (Nuttle et al. 2003). The conservation value was calculated by multiplying the relative abundance of each analyzed bird species within a given 3-year period by the species' PIF priority score and then summing the conservation value for all species within the 3-year period. Similar to patterns of community richness, the total conservation index value was 
greatest from 2001-2003 (118.8), and while it was reduced from 2007-2009 (99.1) remained greater than the initial conservation value from 1996-1998 (81.1).

\subsection{Nest Success}

While relative abundance is important in identifying habitat use, nest success must also be considered as an indicator of habitat quality. The effects of timber management on nest success have not been studied as much as the effects on relative abundance, and most researchers have reported few differences in success. Robinson and Robinson (2001), Moorman et al. (2002), and Gram et al. (2003) found uneven-aged harvests had little overall effect on productivity, while Duguay et al. (2001), Moorman et al. (2002), and Gram et al. (2003) found the same for even-aged harvests. We also found few differences in nest success. Of the 11 focal species, only Wood Thrush nest success was significantly different (declined) from the beginning of the study (1996-1998) to the end (2007-2009), which contrasted with an increase in relative abundance. We also identified significant short-term nest success declines in Darkeyed Junco and longer-term declines in Veery and Indigo Bunting. However, our results were hampered by the small sample sizes within each 3-yr period for many of the species. The small sample sizes limited our ability to detect significant differences and increased the influence of a small set of nests for a given species. We recommend in future research to select a smaller group of species to ensure greater sample for each species.

\subsection{Management Implications and Conclusions}

In managing for avian diversity, no single approach can provide the required habitat for all species at all times. Instead, a diversity of management techniques and tools, including both even-aged and uneven-aged timber management, is the most effective approach for enhancing species richness and diversity (Haulton 2008). By increasing habitat heterogeneity using a variety of silvicultural practices, managers can increase avian diversity on the landscape (Loehle et al. 2005, Mitchell et al. 2006), but also must avoid excess heterogeneity that may negatively affect diversity (Mitchell et al. 2006).

Overall, we found that of the 44 species analyzed, 39\% increased in relative abundance, $18 \%$ decreased in abundance, and $43 \%$ had no change. Thirty-two percent of the species had their greatest abundance in 2001-2003, apparently a short-term response to timber harvest. In 
general, the relative abundance of $82 \%$ of the species did not decline as the area harvested increased to over $60 \%$ of the landscape, indicating a net loss of habitat but minimal reduction in habitat quality.

Implementing management at or below our approximate harvest thresholds (30\% total harvests, $10 \%$ clear-cuts, and $20 \%$ light partial harvests), the number of declining species would be reduced by half, maintaining higher relative abundance for four species who peaked in abundance mid-study but had a net decline in abundance, as well as maintaining higher relative abundances of ten additional species, which peaked in relative abundance mid-study but ultimately had no change or increased but less than peak abundance. Implementing management at our thresholds would also prevent the increase in relative abundance for seven species and limit the increase in abundance for three species that increased throughout the study. Overall, management at our thresholds would maintain higher abundance for three species of conservation concern (BTBW, EAWP, SCTA), prevent an increase in relative abundance for three species (EATO, FISP, WOTH), and limit the increase for INBU. We note that these thresholds are only applicable to similar landscapes over an equivalent time period, as we cannot predict the future bird response to continued harvesting and stand maturation. Because bird data was not collected every year from 1996-2009, greater uncertainty exists for threshold harvest values occurring the year before or after such a gap.

Some species will still decline but the inclusion of more light partial harvests could minimize the decline for some species such as Blue-headed Vireo and increase the relative abundance of species such as American Robin and Wood Thrush. Increasing the percentage of light partial harvest could also increase total harvest threshold values as this type of harvest has been found to support more mature forest bird species than even-aged harvests (Gram et al. 2003, Campbell et al. 2007, Holmes and Pitt 2007).

A threshold of $10 \%$ clear-cuts includes the most beneficial period for the early successional guild and many of its species; however, many species will continue to increase in relative abundance with greater percentages of clear-cuts. Therefore, if the primary management goal is early successional species this value could be increased. The guild and $75 \%$ of all species increased more rapidly with $>10 \%$ light partial harvests, so implementing a greater proportion of light partial harvests in conjunction with clear-cuts could be beneficial for this guild. Another option to increase the even-aged threshold would be to incorporate a greater percent of heavy 
partial harvests. We did not analyze heavy partial harvests as no heavy partial harvests occurred in five of the nine years (1997-1998 and 2007-2009) and heavy partial harvests covered only $6 \%$ of the landscape, but other studies have found heavy partial harvests to be a viable alternative to clear-cuts for early successional birds and that mature forest birds will use the residual trees in the cuts (Duguay et al, 2001, McDermott and Wood 2009).

Landowners must also consider economic objectives when setting harvesting objectives. Given the minimal negative bird response to $>60 \%$ harvesting of the landscape, landowners and managers should be able to maintain economically viable timber operations while using harvests to successfully manage habitat for many bird species, especially early successional. Surpassing our defined thresholds should not be defined as a bad choice, as the threshold values inherently include uncertainty and most of the bird community would not be negatively affected. If the thresholds are set too low to retain an economically viable timber flow, the alternatives are to sell the property or a conversion to other land uses that may be more detrimental to birds.

We identified three priorities for future research. First, there is a need to determine whether nest success and productivity follow trends similar to those exhibited by abundance relative to timber management. Also, research is needed to evaluate the effects of different proportions of harvest types on the landscape. We had a single proportion for each year of our study; however, we expect that increasing or decreasing the percentage of each harvest type could change the results for individual species and overall threshold values. Finally, thresholds are dynamic and will continue to change as the landscape continues to change. Therefore, continued monitoring is needed to determine the future bird response to additional harvests but also to stand maturation following the cessation of harvesting.

\section{Acknowledgments}

We thank the National Council for Air and Stream Improvement and the MeadWestvaco Corporation for funding our research and MeadWestvaco and Penn Virginia for providing housing for researchers and access to their property. We also thank the many field technicians who helped collect and enter data. J. T. Anderson, M. P. Strager, R. Dellinger, and M. Ford provided helpful comments on this manuscript. Use of trade names does not imply endorsement by the Federal government. 


\section{Literature Cited}

Annand, E.M., Thompson III, F.R., 1997. Forest bird response to regeneration practices in central hardwood forests. Journal of Wildlife Management 61, 159-171.

Askins, R.A., Lynch, J.F., Greenberg, R., 1990. Population declines in migratory birds in Eastern North America. Current Ornithology 7, 1-57.

Augenfeld, K.H., Franklin, S.B., Snyder, D.H., 2008. Breeding bird communities of upland hardwood forest 12 years after shelterwood logging. Forest Ecology and Management 255, 1271-1282.

Baker, M.D., Lacki, M.J., 1997. Short-term changes in bird communities in response to silvicultural prescriptions. Forest Ecology and Management 96, 27-36.

Barry, D., Hartigan, J.A., 1993. A Bayesian analysis for change point problems. Journal of the American Statistical Association 35, 309-319.

Betts, M.G., Forbes, G.J., Diamond, A.W., 2007. Thresholds in songbird occurrence in relation to landscape structure. Conservation Biology 21, 1046-1058.

Betts, M.G., Villard, M., 2009. Landscape thresholds in species occurrence as quantitative targets in forest management: generality in space and time?, in: Villard, M., Johnson, B.G., (Eds.), Setting Conservation Targets for Managed Forest Landscapes. Cambridge University Press, New York, pp. 185-206.

Bollinger, E.K. Linder, E.T., 1994. Reproductive success of neotropical migrants in a fragmented Illinois forest. Wilson Bulletin 106, 46-54.

Brittingham, M., Temple, S., 1983. Have cowbirds caused forest songbirds to decline? Bioscience 33, 31-35.

Burke, D.M., Nol, E., 1998. Influence of food abundance, nest site habitat, and forest fragmentation on breeding ovenbirds. Auk 115, 96-104.

Campbell, S.P., Witham, J.W., Hunter, Jr., M.L., 2007. Long-term effects of group-selection timber harvesting on abundance of forest birds. Conservation Biology 21, 1218-1229.

Childs, R.A., 2005. West Virginia's forests: growing West Virginia's future. West Virginia Division of Forestry Report. http://www.wvforestry.com/Economic\%20Impact\%20Study.pdf (accessed 29 October 2010).

Collins, S.L., 2001. Long-term research and the dynamics of bird populations and communities. Auk 118, 583-588.

Connell, J.H., 1978. Diversity in tropical rainforests and coral reefs. Science 199, 1302-1310. 
Cushman, S.A., McGarigal, K., 2003. Landscape level patterns of avian diversity in the Oregon Coast Range. Ecological Monographs 73, 259-281.

Dellinger, R., 2005. Nesting success and nest site characteristics of four thrush species on a managed forest. PhD dissertation. West Virginia University, Morgantown, West Virginia. 98 p.

Dellinger, T.A., 2007. Post-fledging ecology and survival of neotropical migratory songbirds on a managed Appalachian forest. M.S. Thesis. West Virginia University, Morgantown, West Virginia. $122 \mathrm{p}$.

Dellinger, R., Wood, P., Keyser, P., 2007. Occurrence and nest survival of four thrush species on a managed central Appalachian forest. Forest Ecology and Management 243, 248-258.

Drapeau, P., Leduc, A., Giroux, J.F., Savard, J.P.L., Bergeron, Y., Vickery, W.L., 2000. Landscape-scale disturbances and changes in bird communities of boreal mixed-wood forests. Ecological Monographs 70, 423-444.

Duguay, J.P., Wood, P.B., Miller, G.W., 2000. The effects of timber harvests on invertebrate biomass and avian nest success. Wildlife Society Bulletin 28, 1123-1131.

Duguay, J.P., Wood, P.B., Nichols, J.V., 2001. Songbird abundance and avian nest survival rates in forests fragmented by different silvicultural treatments. Conservation Biology 15, 1405-1415.

Ehrlich, P.R., Dobkin, D.S., Wheye, D., 1988. The Birder's Handbook, Simon and Schuster, New York.

Faaborg, J., 1980. Potential uses and abuses of diversity concepts. Transactions of the Missouri Academy of Science 14, 41-49.

Faccio, S.D., 2003. Effects of ice storm-created gaps on forest breeding bird communities in central Vermont. Forest Ecology and Management 186, 133-145.

Fahrig, L., 2003. Effects of habitat fragmentation on biodiversity. Annual Reviews of Ecology and Systematics 34, 487-515.

Farnsworth, G.L., Pollock, K.H., Nichols, J.D., Simons, T.R., Hines, J.E., Sauer, J.R., 2002. A removal model for estimating detection probabilities from point-count surveys. Auk 119, 414425.

Gavin, T.A., 1991. New approaches in managing biodiversity: a matter of scale, in: Decker, D.J., Krasny, M.E., Goff, G.R., Smith, C.R., Gross, D.W., (Eds.), Challenges in the Conservation of Biological Resources: a Practitioner's Guide. Westview Press, Boulder, pp. 97-103. 
Gram, W.K., Porneluzi, P.A., Clawson, R.L., Faaborg, J., Richter, S.C., 2003. Effects of experimental forest management on density and nesting success of bird species in Missouri Ozark forests. Conservation Biology 17, 1324-1337.

Greenberg, C.H., Lanham, J.D., 2001. Breeding bird assemblages of hurricane-created gaps and adjacent closed canopy forest in the southern Appalachians. Forest Ecology and Management $154,251-260$.

Guenette J.S., Villard, M.A., 2005. Thresholds in forest bird response to habitat alteration as quantitative targets for conservation. Conservation Biology 10, 188-202.

Haulton, S., 2008. Effects of silvicultural practices on bird communities in deciduous forests of eastern and central North America. http://www.indiana.gov/dnr/forestry/files/foManagedForestBirdReview.pdf (accessed 29 October 2010)

Hagan, J.M., 1993. Decline of the rufous-sided towhee in the eastern United States. Auk 110, 863-874.

Haggett, A.J., 2005. The concept and utility of ecological thresholds in biodiversity conservation. Biological Conservation 124, 301-310.

Hines, J.E., Sauer, J.R., 1989. Program CONTRAST - A General Program for the Analysis of Several Survival or Recovery Rate Estimates. US Fish and Wildlife Service, Fish and Wildlife Technical Report 24, Washington, DC.

Holmes, S.B., Pitt, D.G., 2007. Response of bird communities to selection harvesting in a northern tolerant hardwood forest. Forest Ecology and Management 238, 280-292.

Homan, R.N., Windmiller, B.S., Reed, J.M., 2004. Critical thresholds associated with habitat loss for two vernal pool-breeding amphibians. Ecological Applications 14, 1547-1553.

Hoover, J.P., Brittingham, M.C., Goodrich, L.J., 1995. Effects of forest patch size on nesting success of wood thrushes. Auk 112, 146-155.

Hunt, P.D., 1996. Habitat selection by the American redstart along a successional gradient in northern hardwood forests: evaluation of habitat quality. Auk 113, 875-888.

Hutto, R. L., Pletschet, S.M., Hendricks, P., 1986. A fixed-radius point count method for nonbreeding and breeding season use. Auk 103, 593-602.

Imbeau, L., Desrochers, A., 2002. Area sensitivity and edge avoidance: the case of the three-toed woodpecker (Picoides tridactylus) in a managed forest. Forest Ecology and Management 164, 249-256.

Johnson, D.H., 1979. Estimating nest success: the Mayfield method and an alternative. Auk 96, 651-661. 
Keller, J.K., Richmond, M.E., Smith, C.R., 2003. An explanation of patterns of breeding bird species richness and density following clearcutting in northeastern USA forests. Forest Ecology and Management 174, 541-564.

Keyser, P.D., Ford, W.M., 2005. Ten years of research on the MeadWestvaco Wildlife and Ecosystem Research Forest. U.S. Department of Agriculture Forest Service General Technical Report NE-330, Northeastern Research Station, Newtown Square, PA.

Kilgo, J.C., 2005. Harvest-related edge effects on prey availability and foraging of hooded warblers in a bottomland hardwood forest. Condor 107, 627-636.

Kruskal, W.H., Wallis, W.A., 1952. Use of ranks in one-criterion variance analysis. Journal of the American Statistical Association 47, 583-621.

Lent, R.A., Capen, D.E., 1995. Effects of small-scale habitat disturbance on the ecology of breeding birds in a Vermont hardwood forest. Ecography 18, 97-108.

Lindenmayer, D.B., Fischer, J., Cunningham, R.B., 2005. Native vegetation cover thresholds associated with species responses. Biological Conservation 124, 311-316.

Loehle, C., Wigley, T.B., Rutzrnoser, S., Gerwin, J.A., Keyser, P.D., Lancia, R.A., Reynolds, C.J., Thill, R.E., Weih, R., White, D., Wood, P.B., 2005. Managed forest landscape structure and avian species richness in the southeastern US. Forest Ecology and Management 214, 279-293.

Manolis, J.C., Andersen, D.E., Cuthbert, F.J., 2000. Uncertain nest fates in songbird studies and variation in Mayfield estimation. Auk 117, 615-626.

Marshall, M.R., DeCecco, J.A., Williams, A.B., Gale, G.A., Cooper, R.J., 2003. Use of regenerating clearcuts by late-successional bird species and their young during the post fledging period. Forest Ecology and Management 183, 127-135.

Mayfield, H., 1961. Nesting success calculated from exposure. Wilson Bulletin 73, 255-261.

Mayfield, H., 1975. Suggestions for calculating nest success. Wilson Bulletin 87, 456-466.

McDermott, M.E., 2007. Breeding and post-breeding forest bird community dynamics in regenerating clearcuts and two-age harvests in the central Appalachians. MS Thesis. West Virginia University, Morgantown, WV.

McDermott, M.E., Wood, P.B., 2009. Short- and long-term applications of clearcut and two-age silviculture for conservation of breeding forest birds in the central Appalachians, USA. Biological Conservation 142, 212-220.

McGarigal, K., Cushman, S.A., Neel, M.C., Ene, E., 2002. FRAGSTATS: Spatial Pattern Analysis Program for Categorical Maps. Computer software program produced by the authors at 
the University of Massachusetts, Amherst.

http://www.umass.edu/landeco/research/fragstats/fragstats.html

Mitchell, M.S., Rutzmoser, S.H., Wigley, T.B., Loehle, C., Gerwin, J.A., Keyser, P.D., Lancia, R.A., Perry, R.W., Reynolds, C.J., Thill, R.E., Weih, R., White, D., Wood, P.B., 2006.

Relationships between avian richness and landscape structure at multiple scales using multiple landscapes. Forest Ecology and Management 221, 155-169.

Mitchell, M.S., Reynolds-Hoglund, M.J., Smith, M.L., Wood, P.B., Beebe, J.A., Keyser, P.D., Loehle, C., Reynolds, C.J., Van Deusen, P., White, Jr., D., 2008. Projected long-term response of Southeastern birds to forest management. Forest Ecology and Management 256, 1884-1896.

Mönkkönen, M., Reunanen, P., 1999. On critical thresholds in landscape connectivity: a management perspective. Oikos 84, 302-306.

Moorman, C.E., Guynn, Jr., D.C. Kilgo, J. C., 2002. Hooded warbler nesting success adjacent to group-selection and clearcut edges in a southeastern bottomland forest. Condor 104, 366-377.

Nuttle, T., Leidof, A., Burger, Jr., L.W., 2003. Assessing conservation value of bird communities with partners in flight-based ranks. Auk 120, 541-549.

Pagen, R.W., Thompson, F.R., Burhans, D.E., 2000. Breeding and post-breeding habitat use by forest migrant songbirds in the Missouri Ozarks. Condor 102, 738-747.

Pennsylvania Forest Products Association, 2004. The timber and forest products industry: vital to Pennsylvania's economy. http://paforestproducts.org/files/INDUSTRY1.pdf (accessed 29 October 2010)

Peterjohn, B., Sauer, J.R., Robbing, C.S., 1995. Population trends from the North American Breeding Bird Survey, in: Martin, T.E., Finch, D.M. (Eds.), Ecology and Management of Neotropical Migratory Birds. Oxford University Press, New York and Oxford, pp. 3-19.

R Development Core Team, 2009. R: A language and environment for statistical computing, reference index version 2.9.2. R Foundation for Statistical Computing, Vienna, Austria. ISBN 3900051-07-0, http://www.R-project.org.

Radford, J.Q., Bennett, A.F., 2004. Thresholds in landscape parameters: occurrence of the whitebrowed treecreeper (Climacteris affinis) in Victoria, Australia. Biological Conservation 117, 375-391.

Radford, J.Q., Bennett, A.F., Cheers, G.J., 2005. Landscape-level thresholds of habitat cover for woodland-dependent birds. Biological Conservation 124, 317-337.

Robinson, S.K., 1992. Population dynamics of breeding Neotropical migrants in a fragmented Illinois landscape, in: Hagan, III, J.M., Johnson, D.W. (Eds.), Ecology and Conservation of Neotropical Migrant Landbirds. Smithsonian Institute Press, Washington, D.C., pp. 408-418. 
Robinson, W.D., Robinson, S.K., 1999. Effects of selective logging on forest bird populations in a fragmented landscape. Conservation Biology 13, 58-66.

Robinson, S.K., Robinson, W.D., 2001. Avian nesting success in a selectively harvested north temperate deciduous forest. Conservation Biology 15, 1763-1771.

Rodewald, A.D., Yahner, R.H., 2000. Bird communities associated with harvested hardwood stands containing residual trees. Journal of Wildlife Management 64, 924-932.

Rodewald, A.D., Yahner, R.H., 2001. Avian nesting success in forested landscapes: influence of landscape composition, stand, nest-patch microhabitat, and biotic interactions. Auk 118, 10181028.

Rosenberg, K.V., 2003. Partner's in Flight bird conservation plan: the Mid-Atlantic Ridge and Valley (physiographic area 12). Cornell Lab of Ornithology. Ithaca, NY.

http://www.partnersinflight.org/bcps/plan/pl_12_10.pdf

Rudnicky, T.C., Hunter, M.L., 1993. Avian nest predation in clearcuts, forests, and edges in a forest-dominated landscape. Journal of Wildlife Management 57, 358-364.

Sallabanks, R., Arnett, E.B., Marzluff, J.M., 2000. An evaluation of research on the effects of timber harvest on bird populations. Wildlife Society Bulletin 28, 1144-1155.

Sauer, J.R., Hines, J.E., Fallon, J., 2008. The North American Breeding Bird Survey, Results and Analysis 1966 - 2007. Version 5.15.2008. USGS Patuxent Wildlife Research Center, Laurel, MD.

Shannon, C.E., 1948. A mathematical theory of communication. Bell Systems Technical Journal 27, 379-423 and 623-656.

Thomas, W.R., Stringer, J.W., Connors, T.E., Hill, D.B., Barnes, T.G., 2007. Kentucky Forest Fact Sheet. University of Kentucky Cooperative Extension Report For-53, Lexington, KY. http://www.ukwoodcenter.net/misc/for53.pdf

Toms, J.D., Lesperance, M.L., 2003. Piecewise regression: a tool for identifying ecological thresholds. Ecology 84, 2034-2041.

USDA Forest Service, 2000. Northeast Forest Inventory and Analysis.

http: //www.fs.fed.us/ne/fia/states/wv/index.html (accessed 29 October 2010)

Vega Rivera, J.H., Rappole, J.H., McShea, W.J., Haas, C.A., 1998. Wood thrush post-fledgling movements and habitat use in northern Virginia. Condor 100, 69-78.

Weakland, C.A., 2000. Effects of diameter-limit and two-age timber harvesting on songbird populations on an industrial forest in central West Virginia. PhD dissertation. West Virginia University, Morgantown, West Virginia. 150 p. 
Weakland, C.A., Wood, P.B., Ford, W.M., 2002. Responses of songbirds to diameter-limit cutting in the central Appalachians of West Virginia, USA. Forest Ecology and Management $155,115-129$.

Welsh, C.J.E., Healy, W.M., 1993. Effect of even-age timber management on bird species diversity and composition in northern hardwoods of New Hampshire. Wildlife Society Bulletin $21,143-154$.

West Virginia Department of Commerce, 2010. Wood products. http://www.wvcommerce.org/business/industries/woodproducts/default.aspx (accessed 29 October 2010).

Whitcomb, R.F., Robbins, C.S., Lynch, J.F., Klimkiewicz, B.L., Bystrak, D., 1981. Effects of forest fragmentation on avifauna of the eastern deciduous forest, in: Burgess, R.L., Sharpe, D.M. (Eds.), Forest Island Dynamics in Man-dominated Landscapes. Springer-Verlag, New York, pp. 125-205.

Widmann, R.H., Butler, B.J., Cook, G.W., 2010. West Virginia’s forest resources, 2008.

Research Note NRS-61. Newtown Square, PA: U.S. Department of Agriculture, Forest Service, Northern Research Station.

Wiens, J.A., 1994. Habitat fragmentation: island vs. landscape perspectives on bird conservation. Ibis $137,97-104$.

Wilcove, D.S., Robinson, S.K., 1990. The impact of forest fragmentation on bird communities in eastern North America. In: Keast, A. (Ed.), Biogeography and Ecology of Forest Bird Communities. SPB Academic Publishing, The Hague, Netherlands.

With, K.A., Christ, T.O., 1995. Critical thresholds in species' responses to landscape structure. Ecology 76, 2446-2459.

Yahner, R.H., Scott, D.P., 1988. Effects of forest fragmentation on depredation of artificial nests. Journal of Wildlife Management 52, 158-161.

Young, T.M., Hodges, D.G., Rials, T.G., 2007. The forest products economy of Tennessee. Forest Products Journal 57, 12-19. 


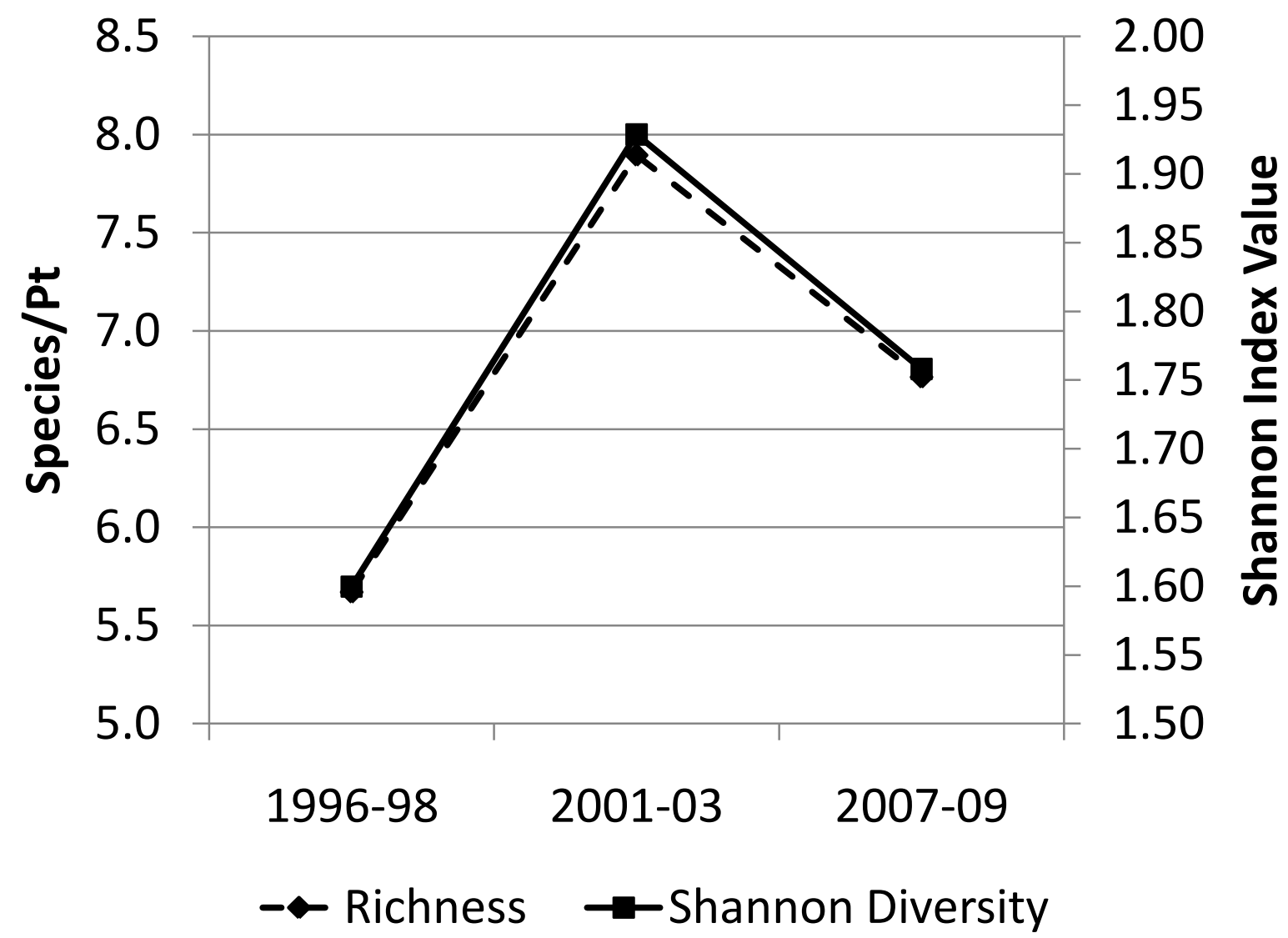

Figure 1. Bird diversity among 3-year periods using species richness (species/pt) and Shannon diversity at the Wildlife and Ecosystem Research Forest from 1996-2009. All 3-year periods for both diversity metrics are significantly different $(\alpha=0.05)$ according to the Dunnett-TukeyKramer multiple comparison test. 


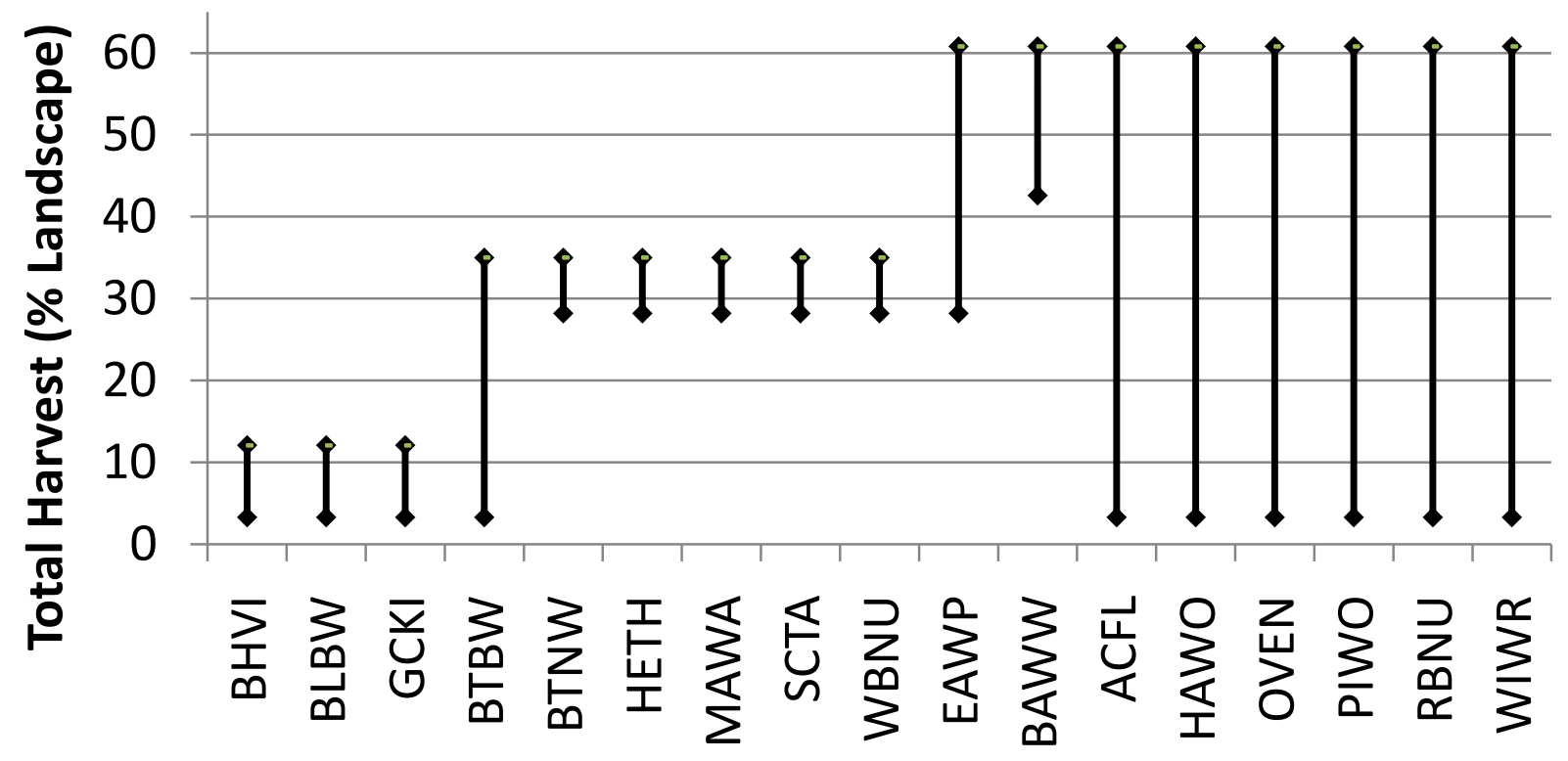

Figure 2. Percent total harvests of the landscape (range) for the 3-year period or periods with the largest relative abundance for each forest-interior species at the Wildlife and Ecosystem Research Forest from 1996-2009.

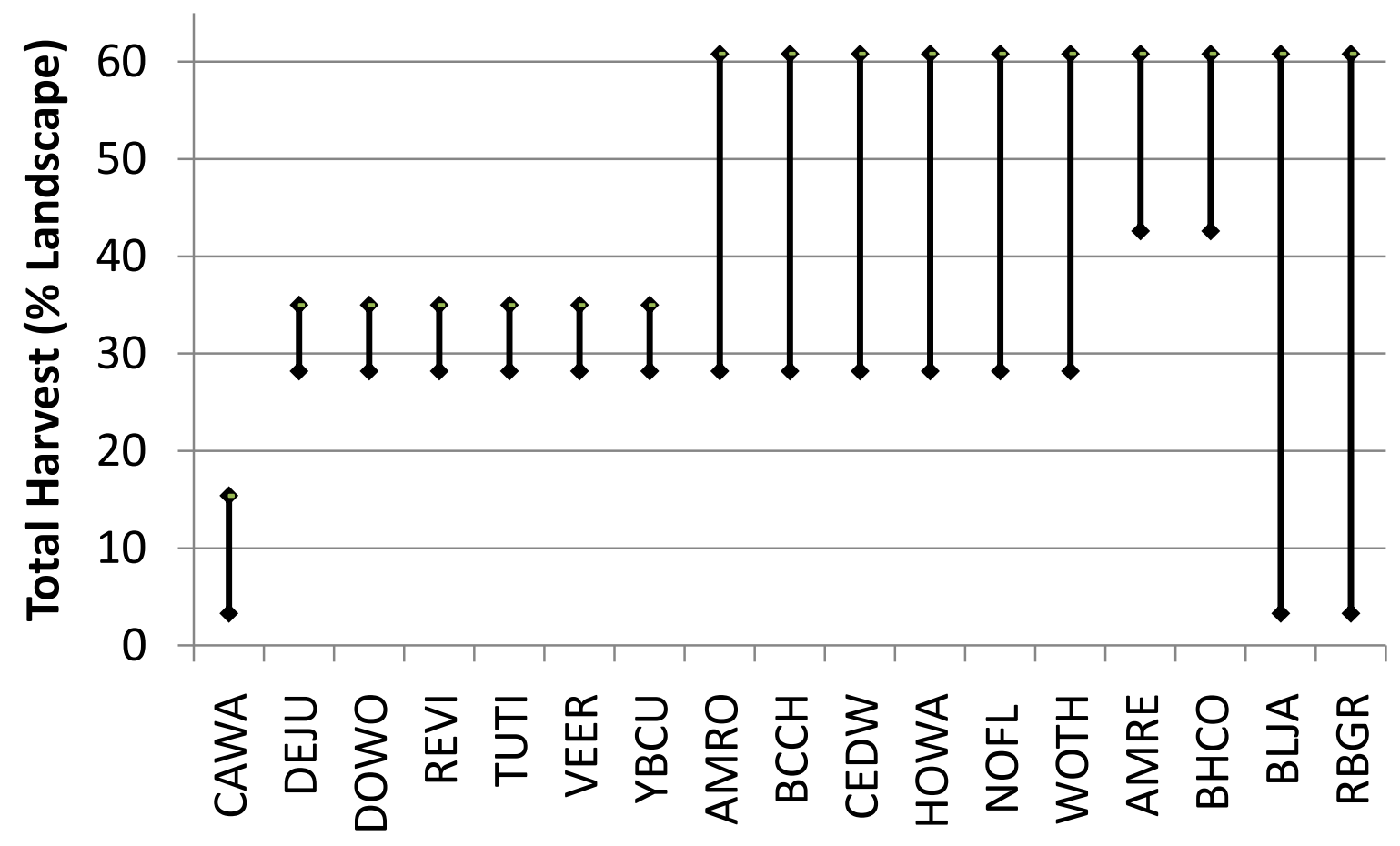

Figure 3. Percent total harvests of the landscape (range) for the 3-year period or periods with the largest relative abundance for each interior-edge species at the Wildlife and Ecosystem Research Forest from 1996-2009. 


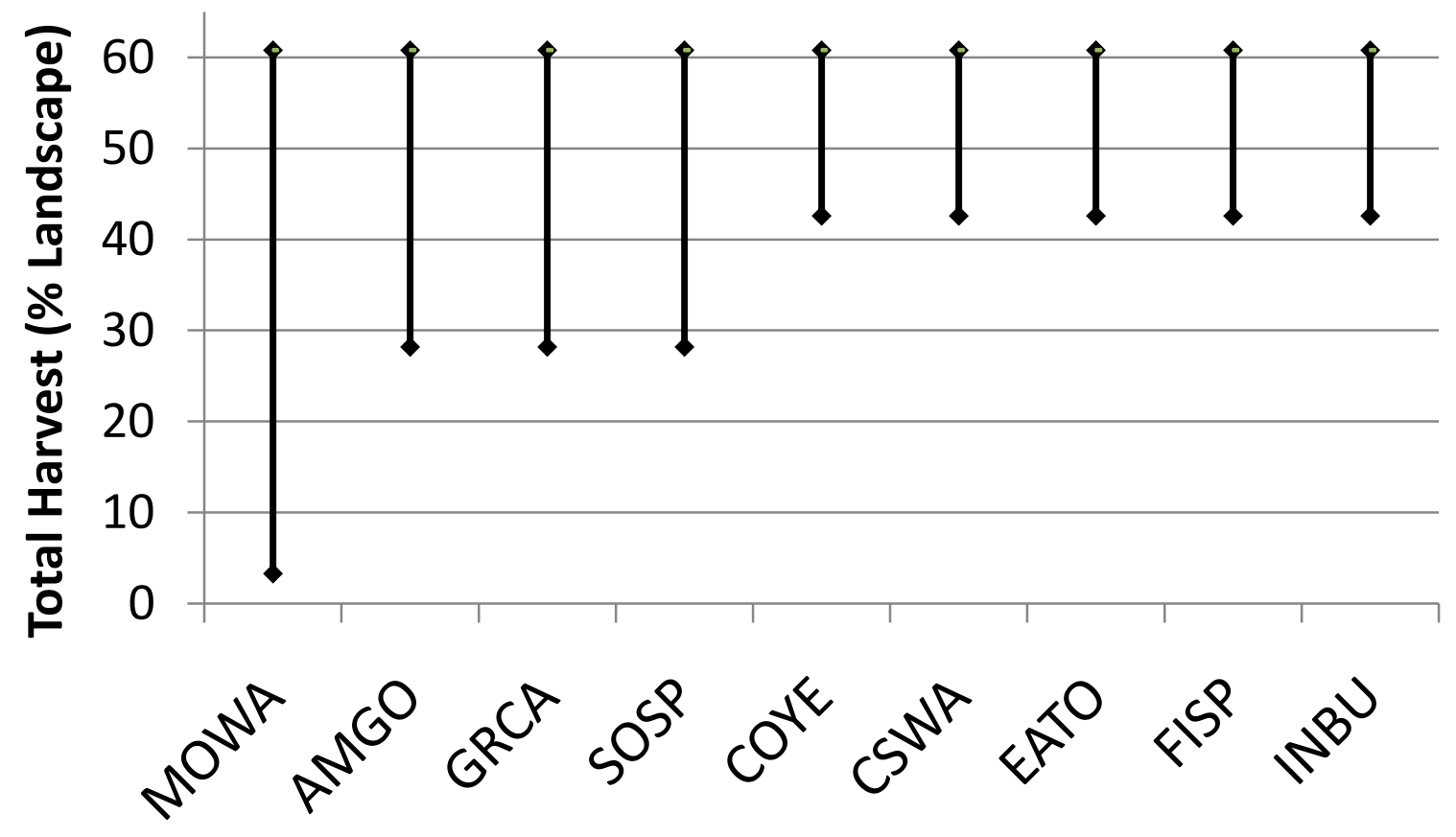

Figure 4. Percent total harvests of the landscape (range) for the 3-year period or periods with the largest relative abundance for each early successional species at the Wildlife and Ecosystem Research Forest from 1996-2009. 
Table 1. Annual amounts of landcover (ha) at the Wildlife and Ecosystem Research Forest, 1996-2009.

\begin{tabular}{|c|c|c|c|c|c|c|c|c|c|c|}
\hline & & \multicolumn{9}{|c|}{ Year } \\
\hline & & 1996 & 1997 & 1998 & 2001 & 2002 & 2003 & 2007 & 2008 & 2009 \\
\hline \multicolumn{11}{|l|}{$\underline{\text { Landcover }}$} \\
\hline \multirow{2}{*}{ Mature Deciduous } & ha & 1379.8 & 1287.1 & 1268.9 & 1068.2 & 1009.7 & 933.4 & 780.4 & 624.1 & 492.7 \\
\hline & $\%$ & 44.7 & 41.7 & 41.1 & 34.6 & 32.7 & 30.2 & 25.3 & 20.2 & 16.0 \\
\hline \multirow[t]{2}{*}{ Mature Mixed } & ha & 1470.2 & 1291.1 & 1209.8 & 1011.6 & 964.4 & 927.2 & 836.2 & 668.8 & 565.6 \\
\hline & $\%$ & 47.6 & 41.8 & 39.2 & 32.8 & 31.2 & 30.0 & 27.1 & 21.7 & 18.3 \\
\hline \multirow[t]{2}{*}{ Clear-cut } & ha & 50.7 & 81.3 & 98.2 & 241.0 & 259.2 & 326.7 & 537.5 & 551.9 & 551.9 \\
\hline & $\%$ & 1.6 & 2.6 & 3.2 & 7.8 & 8.4 & 10.6 & 17.4 & 17.9 & 17.9 \\
\hline \multirow[t]{2}{*}{ Hvy Partial Harvest } & ha & 0.0 & 42.6 & 42.6 & 78.7 & 85.4 & 90.4 & 187.5 & 187.5 & 187.5 \\
\hline & $\%$ & 0.0 & 1.4 & 1.4 & 2.5 & 2.8 & 2.9 & 6.1 & 6.1 & 6.1 \\
\hline \multirow[t]{2}{*}{ Lt Partial Harvest ${ }^{\mathrm{a}}$} & ha & 52.2 & 250.8 & 333.5 & 553.3 & 632.9 & 662.6 & 590.8 & 900.1 & 1134.7 \\
\hline & $\%$ & 1.7 & 8.1 & 10.8 & 17.9 & 20.5 & 21.5 & 19.1 & 29.2 & 36.8 \\
\hline \multicolumn{11}{|l|}{ Core Habitat } \\
\hline \multirow[t]{2}{*}{ Forest } & ha & 1165.8 & 983.6 & 928.7 & 725.1 & 666.8 & 558.9 & 425.9 & 252.6 & 201.9 \\
\hline & $\%$ & 37.8 & 31.9 & 30. & 23.5 & 21.6 & 18.1 & 13.8 & 8.2 & 6.5 \\
\hline \multirow[t]{2}{*}{ Early Succession } & ha & 1.2 & 8.4 & 8.4 & 26.1 & 31.5 & 32.3 & 73.3 & 72.6 & 72.6 \\
\hline & $\%$ & 0.0 & 0.3 & 0.3 & 0.8 & 1.0 & 1.0 & 2.4 & 2.4 & 2.4 \\
\hline
\end{tabular}

${ }^{\mathrm{a}}$ Declined from 2003 to 2007 due to clear-cut harvesting of previous light partial harvests 
Table 2. Average relative abundance of bird species and guilds among 3-year periods at the Wildlife and Ecosystem Research Forest, WV, 1996-2009.

\begin{tabular}{|c|c|c|c|c|c|c|c|c|}
\hline \multirow{3}{*}{$\begin{array}{l}\text { Species }^{\mathrm{a}} \\
\text { Forest-interior }\end{array}$} & \multicolumn{6}{|c|}{ Average Abundance $(\text { Birds/pt })^{\mathrm{b}}$} & \multirow{3}{*}{$\begin{array}{r}\text { Kruskal } \\
\text {-Wallis } \\
88.41\end{array}$} & \multirow{3}{*}{$\frac{\mathrm{P}}{<0.001}$} \\
\hline & \multicolumn{2}{|c|}{$1996-98$} & \multicolumn{2}{|c|}{ 2001-03 } & \multicolumn{2}{|c|}{ 2007-09 } & & \\
\hline & 2.83 & $\mathrm{~B}$ & 3.75 & $\mathrm{C}$ & 2.30 & A & & \\
\hline ACFL & 0.08 & & 0.07 & & 0.04 & & 1.79 & 0.409 \\
\hline BAWW & 0.14 & A & 0.15 & A & 0.28 & $\mathrm{~B}$ & 23.88 & $<0.001$ \\
\hline BHVI & 0.68 & $\mathrm{~B}$ & 0.38 & A & 0.37 & A & 49.82 & $<0.001$ \\
\hline BLBW & 0.08 & $\mathrm{~B}$ & 0.00 & A & 0.01 & A & 38.86 & $<0.001$ \\
\hline BTBW & 0.31 & $\mathrm{AB}$ & 0.41 & $\mathrm{~B}$ & 0.27 & $\mathrm{~A}$ & 6.51 & 0.039 \\
\hline BTNW & 0.49 & A & 0.89 & $\mathrm{~B}$ & 0.44 & A & 81.33 & $<0.001$ \\
\hline EAWP & 0.01 & A & 0.05 & B & 0.02 & $\mathrm{AB}$ & 9.83 & 0.007 \\
\hline GCKI & 0.04 & $\mathrm{~B}$ & 0.00 & $\mathrm{~A}$ & 0.00 & $\mathrm{~A}$ & 18.95 & $<0.001$ \\
\hline HAWO & 0.11 & & 0.17 & & 0.11 & & 8.37 & 0.015 \\
\hline HETH & 0.06 & A & 0.14 & B & 0.06 & A & 11.65 & 0.003 \\
\hline MAWA & 0.24 & B & 0.46 & $\mathrm{C}$ & 0.15 & A & 43.09 & $<0.001$ \\
\hline OVEN & 0.15 & & 0.15 & & 0.18 & & 1.79 & 0.409 \\
\hline PIWO & 0.05 & & 0.07 & & 0.04 & & 2.87 & 0.238 \\
\hline RBNU & 0.01 & & 0.02 & & 0.01 & & 0.45 & 0.800 \\
\hline SCTA & 0.27 & B & 0.54 & $\mathrm{C}$ & 0.18 & A & 80.87 & $<0.001$ \\
\hline WBNU & 0.04 & A & 0.23 & B & 0.08 & A & 52.23 & $<0.001$ \\
\hline WIWR & 0.15 & & 0.13 & & 0.10 & & 2.87 & 0.238 \\
\hline Interior-edge & 3.21 & A & 5.27 & $\mathrm{C}$ & 3.72 & B & 111.96 & $<0.001$ \\
\hline AMRE & 0.04 & A & 0.03 & A & 0.15 & B & 30.34 & $<0.001$ \\
\hline AMRO & 0.07 & A & 0.19 & B & 0.23 & B & 27.88 & $<0.001$ \\
\hline $\mathrm{BCCH}$ & 0.20 & A & 0.32 & B & 0.22 & $\mathrm{AB}$ & 7.60 & 0.022 \\
\hline $\mathrm{BHCO}$ & 0.05 & $\mathrm{AB}$ & 0.02 & A & 0.08 & $\mathrm{~B}$ & 8.73 & 0.013 \\
\hline BLJA & 0.15 & & 0.23 & & 0.24 & & 4.57 & 0.102 \\
\hline CAWA & 0.60 & B & 0.22 & A & 0.20 & A & 78.77 & $<0.001$ \\
\hline CEDW & 0.01 & A & 0.19 & B & 0.17 & B & 47.69 & $<0.001$ \\
\hline DEJU & 0.34 & A & 1.11 & $\mathrm{C}$ & 0.54 & B & 118.53 & $<0.001$ \\
\hline DOWO & 0.04 & B & 0.11 & $\mathrm{C}$ & 0.01 & A & 35.12 & $<0.001$ \\
\hline HOWA & 0.12 & A & 0.23 & B & 0.30 & B & 28.70 & $<0.001$ \\
\hline NOFL & 0.03 & A & 0.08 & B & 0.07 & B & 6.84 & 0.033 \\
\hline RBGR & 0.13 & & 0.12 & & 0.15 & & 2.18 & 0.336 \\
\hline REVI & 0.88 & B & 1.10 & $\mathrm{C}$ & 0.69 & A & 44.04 & $<0.001$ \\
\hline TUTI & 0.00 & A & 0.37 & B & 0.01 & A & 170.56 & $<0.001$ \\
\hline VEER & 0.43 & A & 0.73 & B & 0.43 & A & 30.05 & $<0.001$ \\
\hline WOTH & 0.09 & $\mathrm{~A}$ & 0.10 & $\mathrm{AB}$ & 0.16 & B & 13.40 & 0.001 \\
\hline YBCU & 0.00 & A & 0.06 & B & 0.00 & A & 30.15 & $<0.001$ \\
\hline Early Succession & 0.61 & A & 1.07 & B & 1.92 & $\mathrm{C}$ & 74.52 & $<0.001$ \\
\hline AMCR & 0.05 & & 0.03 & & 0.02 & & 5.40 & 0.067 \\
\hline
\end{tabular}


Table2. Continued

\begin{tabular}{|c|c|c|c|c|c|c|c|c|}
\hline \multirow{3}{*}{$\frac{\text { Species }}{\text { AMGO }}$} & \multicolumn{6}{|c|}{ Average Abundance (Birds/pt) ${ }^{\mathrm{a}}$} & \multirow{3}{*}{$\begin{array}{r}\begin{array}{r}\text { Kruskal } \\
\text {-Wallis }\end{array} \\
6.65\end{array}$} & \multirow{3}{*}{$\begin{array}{l}\mathrm{P} \\
0.036\end{array}$} \\
\hline & \multicolumn{2}{|c|}{ 1996-98 } & \multicolumn{2}{|c|}{$2001-03$} & \multicolumn{2}{|c|}{ 2007-09 } & & \\
\hline & 0.01 & A & 0.05 & $\mathrm{~B}$ & 0.05 & $\mathrm{~B}$ & & \\
\hline COYE & 0.00 & A & 0.03 & B & 0.08 & $\mathrm{C}$ & 29.39 & $<0.001$ \\
\hline CSWA & 0.18 & A & 0.34 & $\mathrm{~B}$ & 0.48 & $\mathrm{C}$ & 41.86 & $<0.001$ \\
\hline EATO & 0.20 & A & 0.13 & A & 0.53 & $\mathrm{~B}$ & 76.67 & $<0.001$ \\
\hline FISP & 0.00 & A & 0.01 & A & 0.08 & B & 43.96 & $<0.001$ \\
\hline GRCA & 0.03 & A & 0.11 & $\mathrm{~B}$ & 0.10 & B & 20.53 & $<0.001$ \\
\hline INBU & 0.13 & A & 0.29 & B & 0.44 & $\mathrm{C}$ & 60.14 & $<0.001$ \\
\hline MOWA & 0.01 & & 0.02 & & 0.02 & & 4.13 & 0.127 \\
\hline SOSP & 0.00 & A & 0.03 & $\mathrm{AB}$ & 0.07 & $\mathrm{~B}$ & 26.29 & $<0.001$ \\
\hline
\end{tabular}

${ }^{\mathrm{a}} \mathrm{See}$ appendix B for AOU species codes.

${ }^{\mathrm{b}}$ Abundance in 3-year periods with different letters are significantly different $(\alpha=0.05)$ using the Dunnett-Tukey-Kramer multiple comparison test. 
Table 3. Thresholds (\%) in relative abundance for total harvests, clear-cut harvest, and light partial harvests at the Wildlife and Ecosystem Research Forest, WV, 1996-2009.

\begin{tabular}{|c|c|c|c|c|c|c|c|c|c|c|c|c|}
\hline \multirow[b]{2}{*}{ Species } & \multicolumn{4}{|c|}{ Total Percent Harvested } & \multicolumn{4}{|c|}{ Percent Clear-cuts } & \multicolumn{4}{|c|}{ Percent Light Partial Harvests } \\
\hline & $\begin{array}{l}\text { Thres } \\
\text { hold }\end{array}$ & $95 \% \mathrm{CI}^{\mathrm{a}}$ & $\begin{array}{l}\text { First } \\
\text { Slope }\end{array}$ & $\begin{array}{c}\text { Second }^{\mathrm{b}} \\
\text { Slope }\end{array}$ & $\begin{array}{l}\text { Thres } \\
\text { hold }\end{array}$ & $95 \% \mathrm{CI}^{\mathrm{a}}$ & $\begin{array}{l}\text { First } \\
\text { Slope }\end{array}$ & $\begin{array}{l}\text { Second }^{\mathrm{b}} \\
\text { Slope }\end{array}$ & $\begin{array}{l}\text { Thres } \\
\text { hold }\end{array}$ & $95 \% \mathrm{CI}^{\mathrm{a}}$ & $\begin{array}{l}\text { First }^{b} \\
\text { Slope }\end{array}$ & $\begin{array}{l}\text { Second } \\
\text { Slope }\end{array}$ \\
\hline Forest-interior & 28.4 & $(28-30)$ & 3.42 & -3.79 & 10.4 & $(9-11)$ & 12.90 & -11.03 & 18.0 & $(17-18)$ & 3.31 & -3.91 \\
\hline BHVI & 40.3 & $(16-45)$ & -1.62 & 1.25 & 18.3 & $(15-20)$ & -4.05 & 6.02 & 14.3 & $(12-24)$ & -4.78 & 0.50 \\
\hline HETH & 26.5 & $(10-30)$ & 0.49 & -0.25 & 8.2 & $(3-10)$ & 2.11 & -0.65 & 17.0 & $(4-18)$ & 0.63 & -0.30 \\
\hline Interior-edge & 28.4 & $(25-28)$ & 6.62 & -1.40 & 10.4 & $(8-11)$ & 22.87 & -7.97 & 18.0 & $(5-32)$ & 8.10 & 1.58 \\
\hline AMRO & 55.8 & $(28-56)$ & 0.19 & 3.65 & 10.4 & $(10-24)$ & 1.46 & 0.34 & 31.1 & $(7-33)$ & 0.38 & 3.23 \\
\hline DEJU & 28.4 & $(28-31)$ & 3.20 & -1.46 & 10.4 & $(10-11)$ & 9.74 & -3.95 & 18.0 & $(18-19)$ & 4.36 & -1.75 \\
\hline REVI & 17.4 & $(14-22)$ & 4.33 & -1.18 & 5.8 & $(5-7)$ & 17.18 & -3.35 & 10.8 & $(7-13)$ & 5.54 & -1.36 \\
\hline VEER & 31.8 & $(28-35)$ & 1.06 & -1.00 & 13.2 & $(10-15)$ & 3.22 & -3.24 & 20.2 & $(18-22)$ & 1.31 & -1.30 \\
\hline WOTH & 48.9 & $(10-55)$ & -0.07 & 1.70 & 24.1 & $(6-24)$ & -0.15 & 2388.20 & 13.9 & $(5-31)$ & -0.94 & 1.01 \\
\hline \multicolumn{13}{|l|}{ Early } \\
\hline Succession & 42.4 & $(9-56)$ & 2.67 & 4.81 & 11.2 & $(8-24)$ & 8.69 & 5.76 & 10.4 & $(5-32)$ & 0.39 & 7.07 \\
\hline CSWA & 15.3 & $(9-57)$ & 0.10 & 0.81 & 3.4 & $(3-21)$ & -0.15 & 1.66 & 9.8 & $(5-33)$ & 0.13 & 1.45 \\
\hline EATO & 51.1 & $(15-56)$ & 0.63 & 2.91 & 11.2 & $(10-24)$ & 2.73 & 1.20 & 10.8 & $(9-31)$ & -0.04 & 2.18 \\
\hline INBU & 42.4 & $(9-56)$ & 0.61 & 1.20 & 24.1 & $(5-24)$ & 1.13 & 2218.90 & 6.8 & $(5-32)$ & -0.64 & 1.57 \\
\hline GRCA & 35.1 & $(9-55)$ & 0.31 & -0.03 & 15.0 & $(7-21)$ & 0.89 & -0.38 & 21.5 & $(5-32)$ & 0.47 & 0.02 \\
\hline
\end{tabular}

${ }^{a}$ Threshold confidence interval as a result of 1000 bootstrap samples.

${ }^{\mathrm{b}}$ The slope is the change in relative abundance when the variable changes from $0-100 \%$ of the landscape harvested. The first slope is rate of change in abundance prior to threshold and second slope is rate of change after surpassing the threshold; a + slope indicates increasing abundance while a - slope indicates decreasing abundance. 
Table 4. Nest success (surv) for focal species during each three-year period at the Wildlife and Ecosystem Research Forest, WV, 1996-2009.

\begin{tabular}{|c|c|c|c|c|c|c|c|c|c|c|c|c|}
\hline \multirow[b]{2}{*}{ Species } & \multicolumn{4}{|c|}{ 1996-1998 } & \multicolumn{4}{|c|}{$2001-2003$} & \multicolumn{4}{|c|}{ 2007-2009 } \\
\hline & $\mathrm{n}$ & Surv $^{a}$ & & SE & $\mathrm{n}$ & Surv $^{a}$ & & SE & $\mathrm{n}$ & Surv $^{\mathrm{a}}$ & & SE \\
\hline AMRO & 7 & 0.229 & & 0.159 & 10 & 0.507 & & 0.199 & 9 & 0.437 & & 0.231 \\
\hline BHVI & 10 & 0.441 & & 0.183 & 9 & 0.072 & & 0.088 & 6 & 0.205 & & 0.188 \\
\hline CSWA & 1 & 0.183 & & 0.311 & 11 & 0.319 & & 0.168 & 6 & 0.565 & & 0.228 \\
\hline DEJU & 37 & 0.425 & B & 0.100 & 30 & 0.164 & A & 0.066 & 25 & 0.342 & $\mathrm{AB}$ & 0.112 \\
\hline EATO & 10 & 0.111 & & 0.093 & 22 & 0.192 & & 0.099 & 12 & 0.083 & & 0.076 \\
\hline GRCA & 1 & & & & 3 & 0.290 & & 0.254 & 6 & 0.293 & & 0.223 \\
\hline HETH & 5 & 0.162 & & 0.165 & 18 & 0.214 & & 0.099 & 5 & 0.619 & & 0.297 \\
\hline INBU & 4 & 0.180 & $\mathrm{AB}$ & 0.258 & 15 & 0.720 & B & 0.178 & 14 & 0.216 & A & 0.142 \\
\hline REVI & 10 & 0.186 & & 0.124 & 9 & 0.197 & & 0.153 & 3 & 0.167 & & 0.299 \\
\hline VEER & 23 & 0.189 & $\mathrm{AB}$ & 0.080 & 36 & 0.346 & B & 0.087 & 7 & 0.054 & A & 0.071 \\
\hline WOTH & 21 & 0.317 & B & 0.107 & 12 & 0.207 & $\mathrm{AB}$ & 0.120 & 5 & 0.031 & A & 0.077 \\
\hline
\end{tabular}

\footnotetext{
${ }^{\mathrm{a}}$ Success values with different letters are significantly different at alpha $=0.05$
} 
Appendix A. All bird species detected at the Wildlife and Ecosystem Research Forest, WV 1996-2009

\begin{tabular}{|c|c|c|c|}
\hline $\mathrm{Name}^{\mathrm{a}}$ & Scientific Name & AOU Code & Habitat Guild ${ }^{\mathrm{b}}$ \\
\hline Acadian Flycatcher ${ }^{\mathrm{a}}$ & Empidonax virescens & ACFL & FI \\
\hline Alder Flycatcher & Empidonax alnorum & ALFL & IE \\
\hline American Crow $^{\mathrm{a}}$ & Corvus brachyrhynchos & AMCR & ES \\
\hline American Goldfinch ${ }^{\mathrm{a}}$ & Spinus tristis & AMGO & ES \\
\hline American Redstart $^{\mathrm{a}}$ & Setophaga ruticilla & AMRE & IE \\
\hline American Robin ${ }^{\mathrm{a}}$ & Turdus migratorius & AMRO & $\mathrm{IE}$ \\
\hline Baltimore Oriole & Icterus galbula & BAOR & IE \\
\hline Barred Owl & Strix varia & BDOW & FI \\
\hline Belted Kingfisher & Ceryle alcyon & BEKI & ES \\
\hline Black-and-white Warbler ${ }^{\mathrm{a}}$ & Mniotilta varia & BAWW & FI \\
\hline Black-billed Cuckoo & Coccyzus erythropthalmus & $\mathrm{BBCU}$ & IE \\
\hline Blackburnian Warbler $^{\mathrm{a}}$ & Dendroica fusca & BLBW & FI \\
\hline Black-capped Chickadee ${ }^{\mathrm{a}}$ & Poecile atricapillus & $\mathrm{BCCH}$ & IE \\
\hline Black-throated Blue Warbler ${ }^{\mathrm{a}}$ & Dendroica caerulescens & ВTBW & FI \\
\hline Black-throated Green Warbler ${ }^{\mathrm{a}}$ & Dendroica virens & BTNW & FI \\
\hline Blue Jay $^{\mathrm{a}}$ & Cyanocitta cristata & BLJA & IE \\
\hline Blue-gray Gnatcatcher & Polioptila caerulea & BGGN & IE \\
\hline Blue-headed Vireo $^{a}$ & Vireo solitarius & BHVI & FI \\
\hline Blue-winged Warbler & Vermivora pinus & BWWA & ES \\
\hline Brewster's Warbler & $\begin{array}{l}\text { Helminthophila } \\
\text { leucobronchialis }\end{array}$ & BRWA & ES \\
\hline Broad-winged Hawk & Buteo platypterus & BWHA & FI \\
\hline Brown Creeper & Certhia familiaris & BRCR & FI \\
\hline Brown Thrasher & Toxostoma rufum & BRTH & ES \\
\hline Brown-headed Cowbird $^{\mathrm{a}}$ & Molothrus ater & $\mathrm{BHCO}$ & IE \\
\hline Canada Warbler ${ }^{\mathrm{a}}$ & Wilsonia canadensis & CAWA & IE \\
\hline Carolina Wren & Thryothorus ludovicianus & CAWR & ES \\
\hline Cedar Waxwing $^{\mathrm{a}}$ & Bombycilla cedrorum & CEDW & IE \\
\hline Cerulean Warbler & Dendroica cerulea & CERW & FI \\
\hline Chestnut-sided Warbler ${ }^{\mathrm{a}}$ & Dendroica pensylvanica & CSWA & ES \\
\hline Chipping Sparrow & Spizella passerina & CHSP & ES \\
\hline Common Raven & Corvus corax & CORA & FI \\
\hline Common Yellowthroat ${ }^{\mathrm{a}}$ & Geothlypis trichas & COYE & ES \\
\hline Cooper's Hawk & Accipiter cooperii & COHA & IE \\
\hline Dark-eyed Junco $^{\mathrm{a}}$ & Junco hyemalis & DEJU & $\mathrm{IE}$ \\
\hline Downy Woodpecker ${ }^{\mathrm{a}}$ & Picoides pubescens & DOWO & $\mathrm{IE}$ \\
\hline Eastern Phoebe & Sayornis phoebe & EAPH & ES \\
\hline Eastern Towhee $^{\mathrm{a}}$ & Pipilo erythrophthalmus & EATO & ES \\
\hline
\end{tabular}


Appendix A. Continued

\begin{tabular}{|c|c|c|c|}
\hline Name & Scientific Name & AOU Code & Habitat Guild \\
\hline Eastern Wood-pewee ${ }^{\mathrm{a}}$ & Contopus virens & EAWP & FI \\
\hline Field Sparrow ${ }^{\mathrm{a}}$ & Spizella pusilla & FISP & ES \\
\hline Golden-crowned Kinglet ${ }^{\mathrm{a}}$ & Regulus satrapa & GCKI & FI \\
\hline Golden-winged Warbler & Vermivora chrysoptera & GWWA & ES \\
\hline Gray Catbird ${ }^{\mathrm{a}}$ & Dumetella carolinensis & GRCA & ES \\
\hline Great-crested Flycatcher & Myiarchus crinitus & GCFL & IE \\
\hline Hairy Woodpecker $^{\mathrm{a}}$ & Picoides villosus & HAWO & FI \\
\hline Hermit Thrush ${ }^{\mathrm{a}}$ & Catharus guttatus & HETH & FI \\
\hline Hooded Warbler ${ }^{\mathrm{a}}$ & Wilsonia citrina & HOWA & IE \\
\hline Indigo Bunting ${ }^{\mathrm{a}}$ & Passerina cyanea & INBU & ES \\
\hline Kentucky Warbler & Oporornis formosus & KEWA & FI \\
\hline Least Flycatcher & Empidonax minimus & LEFL & FI \\
\hline Louisiana Waterthrush & Seiurus motacilla & LOWA & FI \\
\hline Magnolia Warbler $^{\mathrm{a}}$ & Dendroica magnolia & MAWA & FI \\
\hline Mourning Dove & Zenaida macroura & MODO & ES \\
\hline Mourning Warbler ${ }^{\mathrm{a}}$ & Oporornis philadelphia & MOWA & ES \\
\hline Nashville Warbler & Vermivora ruficapilla & NAWA & ES \\
\hline Northern Cardinal & Cardinalis cardinalis & NOCA & ES \\
\hline Northern Flicker ${ }^{\mathrm{a}}$ & Colaptes auratus & NOFL & IE \\
\hline Northern Parula & Parula americana & NOPA & IE \\
\hline Northern Waterthrush & Seiurus noveboracensis & NOWA & FI \\
\hline Ovenbird $^{\mathrm{a}}$ & Seiurus aurocapillus & OVEN & FI \\
\hline Pileated Woodpecker ${ }^{\mathrm{a}}$ & Dryocopus pileatus & PIWO & FI \\
\hline Prairie Warbler & Dendroica discolor & PRAW & ES \\
\hline Red-bellied Woodpecker & Melanerpes carolinus & RBWO & IE \\
\hline Red-breasted Nuthatch ${ }^{\mathrm{a}}$ & Sitta canadensis & RBNU & FI \\
\hline Red-eyed Vireo ${ }^{a}$ & Vireo olivaceus & REVI & IE \\
\hline Red-shouldered Hawk & Buteo lineatus & RSHA & IE \\
\hline Red-tailed Hawk & Buteo jamaicensis & RTHA & IE \\
\hline Rose-breasted Grosbeak ${ }^{\mathrm{a}}$ & Pheucticus ludovicianus & RBGR & IE \\
\hline Ruby-throated Hummingbird & Archilochus colubris & RTHU & IE \\
\hline Ruffed Grouse & Bonasa umbellus & RUGR & IE \\
\hline Scarlet Tanager ${ }^{\mathrm{a}}$ & Piranga olivacea & SCTA & FI \\
\hline Song Sparrow ${ }^{\mathrm{a}}$ & Melospiza melodia & SOSP & ES \\
\hline Tufted Titmouse ${ }^{a}$ & Baeolophus bicolor & TUTI & IE \\
\hline Turkey Vulture & Cathartes aura & TUVU & ES \\
\hline Veery $^{\mathrm{a}}$ & Catharus fuscescens & VEER & IE \\
\hline White-breasted Nuthatch ${ }^{a}$ & Sitta carolinensis & WBNU & FI \\
\hline
\end{tabular}


Appendix A. Continued

\begin{tabular}{lllc}
\hline Name & Scientific Name & AOU Code & Habitat Guild \\
\hline White-eyed Vireo & Vireo griseus & WEVI & ES \\
Wild Turkey & Meleagris gallopavo & WITU & IE \\
Willow Flycatcher & Empidonax traillii & WIFL & ES \\
Winter Wren $^{\text {a }}$ & Troglodytes troglodytes & WIWR & FI \\
Wood Thrush $^{\text {a }}$ & Hylocichla mustelina & WOTH & IE \\
Worm-eating Warbler $^{\text {Yellow-bellied Sapsucker }}$ & Helmitheros vermivorus & WEWA & FI \\
Yellow-billed Cuckoo $^{\text {a }}$ & Sphyrapicus varius & YBSA & FI \\
Yellow-breasted Chat & Coccyzus americanus & YBCU & IE \\
Yellow-throated Vireo & Icteria virens & YBCH & ES \\
\hline
\end{tabular}

${ }^{\mathrm{a}} \mathrm{Sp}$ ecies analyzed for temporal trends

${ }^{\mathrm{b}}$ Forest-interior $=$ FI; Interior-edge $=$ IE; Early Succession=ES 
Appendix B. Annual relative abundance for birds detected at the Wildlife and Ecosystem Research Forest, WV, 1996-2009.

\begin{tabular}{|c|c|c|c|c|c|c|c|c|c|}
\hline \multirow[b]{2}{*}{ Species } & \multicolumn{9}{|c|}{ Relative Abundance (Birds/pt) } \\
\hline & 1996 & 1997 & 1998 & 2001 & 2002 & 2003 & 2007 & 2008 & 2009 \\
\hline ACFL & 0.08 & 0.08 & 0.08 & 0.07 & 0.08 & 0.09 & 0.09 & 0.04 & 0.05 \\
\hline ALFL & 0.00 & 0.00 & 0.00 & 0.00 & 0.00 & 0.00 & 0.00 & 0.01 & 0.01 \\
\hline AMCR & 0.02 & 0.03 & 0.06 & 0.06 & 0.02 & 0.01 & 0.01 & 0.03 & 0.01 \\
\hline AMGO & 0.00 & 0.01 & 0.02 & 0.06 & 0.07 & 0.01 & 0.01 & 0.04 & 0.03 \\
\hline AMRE & 0.03 & 0.04 & 0.05 & 0.02 & 0.21 & 0.15 & 0.11 & 0.20 & 0.31 \\
\hline AMRO & 0.12 & 0.07 & 0.03 & 0.28 & 0.24 & 0.06 & 0.14 & 0.13 & 0.37 \\
\hline BAOR & 0.00 & 0.00 & 0.00 & 0.00 & 0.02 & 0.00 & 0.01 & 0.00 & 0.00 \\
\hline BAWW & 0.14 & 0.18 & 0.12 & 0.09 & 0.30 & 0.36 & 0.27 & 0.33 & 0.38 \\
\hline BBCU & 0.00 & 0.00 & 0.00 & 0.00 & 0.01 & 0.00 & 0.00 & 0.00 & 0.00 \\
\hline $\mathrm{BCCH}$ & 0.10 & 0.25 & 0.24 & 0.44 & 0.29 & 0.17 & 0.14 & 0.12 & 0.22 \\
\hline BEKI & 0.00 & 0.00 & 0.00 & 0.00 & 0.01 & 0.00 & 0.00 & 0.00 & 0.00 \\
\hline BGGN & 0.00 & 0.00 & 0.00 & 0.00 & 0.02 & 0.01 & 0.01 & 0.02 & 0.00 \\
\hline $\mathrm{BHCO}$ & 0.01 & 0.10 & 0.03 & 0.01 & 0.04 & 0.02 & 0.04 & 0.09 & 0.06 \\
\hline BHVI & 0.84 & 0.92 & 0.28 & 0.42 & 0.44 & 0.27 & 0.19 & 0.30 & 0.36 \\
\hline BLBW & 0.08 & 0.04 & 0.11 & 0.01 & 0.00 & 0.00 & 0.02 & 0.01 & 0.01 \\
\hline BLJA & 0.15 & 0.14 & 0.08 & 0.23 & 0.23 & 0.10 & 0.10 & 0.16 & 0.29 \\
\hline BRCR & 0.01 & 0.01 & 0.04 & 0.00 & 0.00 & 0.00 & 0.02 & 0.00 & 0.01 \\
\hline BRTH & 0.00 & 0.00 & 0.00 & 0.00 & 0.00 & 0.00 & 0.00 & 0.01 & 0.01 \\
\hline BRWA & 0.00 & 0.00 & 0.00 & 0.00 & 0.01 & 0.01 & 0.01 & 0.00 & 0.00 \\
\hline BTBW & 0.33 & 0.31 & 0.31 & 0.40 & 0.35 & 0.26 & 0.15 & 0.24 & 0.21 \\
\hline BTNW & 0.37 & 0.62 & 0.47 & 0.82 & 0.88 & 0.80 & 0.21 & 0.37 & 0.56 \\
\hline BWWA & 0.00 & 0.00 & 0.00 & 0.00 & 0.00 & 0.01 & 0.01 & 0.01 & 0.02 \\
\hline CAWA & 0.58 & 0.75 & 0.47 & 0.22 & 0.15 & 0.15 & 0.09 & 0.12 & 0.19 \\
\hline CAWR & 0.00 & 0.00 & 0.00 & 0.00 & 0.02 & 0.00 & 0.00 & 0.00 & 0.00 \\
\hline CEDW & 0.02 & 0.00 & 0.01 & 0.05 & 0.22 & 0.20 & 0.07 & 0.19 & 0.14 \\
\hline CERW & 0.02 & 0.01 & 0.01 & 0.00 & 0.07 & 0.06 & 0.01 & 0.00 & 0.00 \\
\hline CHSP & 0.00 & 0.00 & 0.00 & 0.00 & 0.04 & 0.02 & 0.00 & 0.00 & 0.01 \\
\hline CORA & 0.00 & 0.00 & 0.01 & 0.01 & 0.00 & 0.01 & 0.00 & 0.00 & 0.02 \\
\hline COYE & 0.00 & 0.00 & 0.00 & 0.01 & 0.05 & 0.06 & 0.04 & 0.07 & 0.15 \\
\hline CSWA & 0.18 & 0.19 & 0.19 & 0.17 & 0.48 & 0.48 & 0.29 & 0.53 & 0.44 \\
\hline DEJU & 0.25 & 0.40 & 0.38 & 1.11 & 0.76 & 0.62 & 0.29 & 0.38 & 0.49 \\
\hline DOWO & 0.03 & 0.05 & 0.04 & 0.15 & 0.10 & 0.10 & 0.00 & 0.01 & 0.04 \\
\hline EATO & 0.19 & 0.26 & 0.13 & 0.26 & 0.67 & 0.50 & 0.28 & 0.48 & 0.72 \\
\hline EAPH & 0.01 & 0.00 & 0.00 & 0.02 & 0.00 & 0.01 & 0.00 & 0.01 & 0.01 \\
\hline EAWP & 0.02 & 0.02 & 0.00 & 0.02 & 0.06 & 0.06 & 0.01 & 0.02 & 0.04 \\
\hline FISP & 0.00 & 0.00 & 0.00 & 0.00 & 0.07 & 0.04 & 0.06 & 0.07 & 0.09 \\
\hline GCFL & 0.00 & 0.00 & 0.00 & 0.00 & 0.01 & 0.00 & 0.01 & 0.00 & 0.01 \\
\hline
\end{tabular}


Appendix B. Continued

\begin{tabular}{|c|c|c|c|c|c|c|c|c|c|}
\hline \multirow[b]{2}{*}{ Species } & \multicolumn{9}{|c|}{ Relative Abundance (Birds/pt) } \\
\hline & 1996 & 1997 & 1998 & 2001 & 2002 & 2003 & 2007 & 2008 & 2009 \\
\hline GCKI & 0.02 & 0.09 & 0.02 & 0.00 & 0.00 & 0.00 & 0.00 & 0.01 & 0.00 \\
\hline GRCA & 0.04 & 0.01 & 0.03 & 0.11 & 0.11 & 0.11 & 0.09 & 0.06 & 0.09 \\
\hline GWWA & 0.00 & 0.00 & 0.00 & 0.00 & 0.03 & 0.01 & 0.03 & 0.01 & 0.02 \\
\hline HAWO & 0.08 & 0.11 & 0.13 & 0.28 & 0.14 & 0.07 & 0.04 & 0.11 & 0.12 \\
\hline HETH & 0.02 & 0.10 & 0.06 & 0.19 & 0.09 & 0.06 & 0.02 & 0.04 & 0.06 \\
\hline HOWA & 0.11 & 0.14 & 0.11 & 0.16 & 0.54 & 0.54 & 0.29 & 0.31 & 0.58 \\
\hline INBU & 0.12 & 0.11 & 0.16 & 0.23 & 0.46 & 0.46 & 0.32 & 0.47 & 0.48 \\
\hline LEFL & 0.00 & 0.01 & 0.00 & 0.00 & 0.00 & 0.00 & 0.00 & 0.01 & 0.00 \\
\hline LOWA & 0.00 & 0.01 & 0.02 & 0.00 & 0.00 & 0.00 & 0.01 & 0.01 & 0.00 \\
\hline MAWA & 0.25 & 0.17 & 0.31 & 0.47 & 0.35 & 0.24 & 0.14 & 0.11 & 0.09 \\
\hline MODO & 0.00 & 0.00 & 0.00 & 0.00 & 0.02 & 0.00 & 0.01 & 0.02 & 0.02 \\
\hline MOWA & 0.00 & 0.01 & 0.01 & 0.04 & 0.01 & 0.01 & 0.01 & 0.01 & 0.02 \\
\hline NAWA & 0.02 & 0.00 & 0.00 & 0.00 & 0.00 & 0.00 & 0.00 & 0.00 & 0.00 \\
\hline NOCA & 0.00 & 0.00 & 0.01 & 0.00 & 0.03 & 0.00 & 0.00 & 0.01 & 0.02 \\
\hline NOFL & 0.03 & 0.02 & 0.04 & 0.07 & 0.15 & 0.07 & 0.04 & 0.04 & 0.10 \\
\hline NOPA & 0.01 & 0.01 & 0.01 & 0.00 & 0.01 & 0.04 & 0.00 & 0.00 & 0.00 \\
\hline NOWA & 0.01 & 0.00 & 0.00 & 0.00 & 0.00 & 0.00 & 0.00 & 0.00 & 0.00 \\
\hline OVEN & 0.13 & 0.18 & 0.15 & 0.11 & 0.28 & 0.35 & 0.21 & 0.33 & 0.35 \\
\hline PIWO & 0.04 & 0.07 & 0.03 & 0.05 & 0.06 & 0.06 & 0.01 & 0.02 & 0.05 \\
\hline PRWA & 0.00 & 0.00 & 0.00 & 0.00 & 0.00 & 0.01 & 0.00 & 0.00 & 0.00 \\
\hline RBGR & 0.16 & 0.14 & 0.07 & 0.11 & 0.19 & 0.18 & 0.06 & 0.11 & 0.20 \\
\hline RBNU & 0.03 & 0.01 & 0.01 & 0.04 & 0.01 & 0.01 & 0.00 & 0.01 & 0.01 \\
\hline RBWO & 0.00 & 0.00 & 0.00 & 0.00 & 0.02 & 0.00 & 0.00 & 0.02 & 0.02 \\
\hline REVI & 0.58 & 0.93 & 1.12 & 1.12 & 1.32 & 1.05 & 0.59 & 0.66 & 0.98 \\
\hline RTHU & 0.00 & 0.00 & 0.00 & 0.02 & 0.00 & 0.01 & 0.00 & 0.01 & 0.01 \\
\hline SCTA & 0.22 & 0.31 & 0.28 & 0.57 & 0.56 & 0.40 & 0.19 & 0.19 & 0.16 \\
\hline SOSP & 0.00 & 0.00 & 0.00 & 0.03 & 0.04 & 0.02 & 0.04 & 0.07 & 0.06 \\
\hline TUTI & 0.00 & 0.01 & 0.00 & 0.03 & 0.20 & 0.05 & 0.02 & 0.02 & 0.06 \\
\hline VEER & 0.42 & 0.53 & 0.34 & 0.68 & 0.57 & 0.58 & 0.30 & 0.24 & 0.33 \\
\hline WBNU & 0.02 & 0.05 & 0.04 & 0.36 & 0.19 & 0.07 & 0.05 & 0.04 & 0.15 \\
\hline WEVI & 0.01 & 0.00 & 0.00 & 0.00 & 0.00 & 0.01 & 0.01 & 0.01 & 0.01 \\
\hline WEWA & 0.02 & 0.01 & 0.00 & 0.00 & 0.04 & 0.01 & 0.02 & 0.02 & 0.01 \\
\hline WIFL & 0.00 & 0.00 & 0.00 & 0.00 & 0.00 & 0.00 & 0.00 & 0.00 & 0.01 \\
\hline WIWR & 0.11 & 0.20 & 0.15 & 0.16 & 0.06 & 0.09 & 0.03 & 0.08 & 0.11 \\
\hline WOTH & 0.14 & 0.05 & 0.07 & 0.08 & 0.25 & 0.21 & 0.16 & 0.19 & 0.32 \\
\hline YBCH & 0.00 & 0.00 & 0.00 & 0.00 & 0.00 & 0.00 & 0.00 & 0.01 & 0.01 \\
\hline YBCU & 0.00 & 0.00 & 0.00 & 0.17 & 0.00 & 0.01 & 0.01 & 0.00 & 0.01 \\
\hline YBSA & 0.00 & 0.00 & 0.00 & 0.00 & 0.00 & 0.00 & 0.00 & 0.01 & 0.01 \\
\hline YTVI & 0.03 & 0.00 & 0.03 & 0.00 & 0.01 & 0.01 & 0.01 & 0.00 & 0.00 \\
\hline
\end{tabular}


Appendix C. Examples of piece-wise linear regression output. Stacked dots represent the relative abundance values measured at each annual percent harvest. There are nine stacks representing each year except for clear-cut harvests in which there are eight stacks because percent harvest did not differ from 2008-2009. The red line represents the slope before and after the thresholds, which is the point at which the line changes.

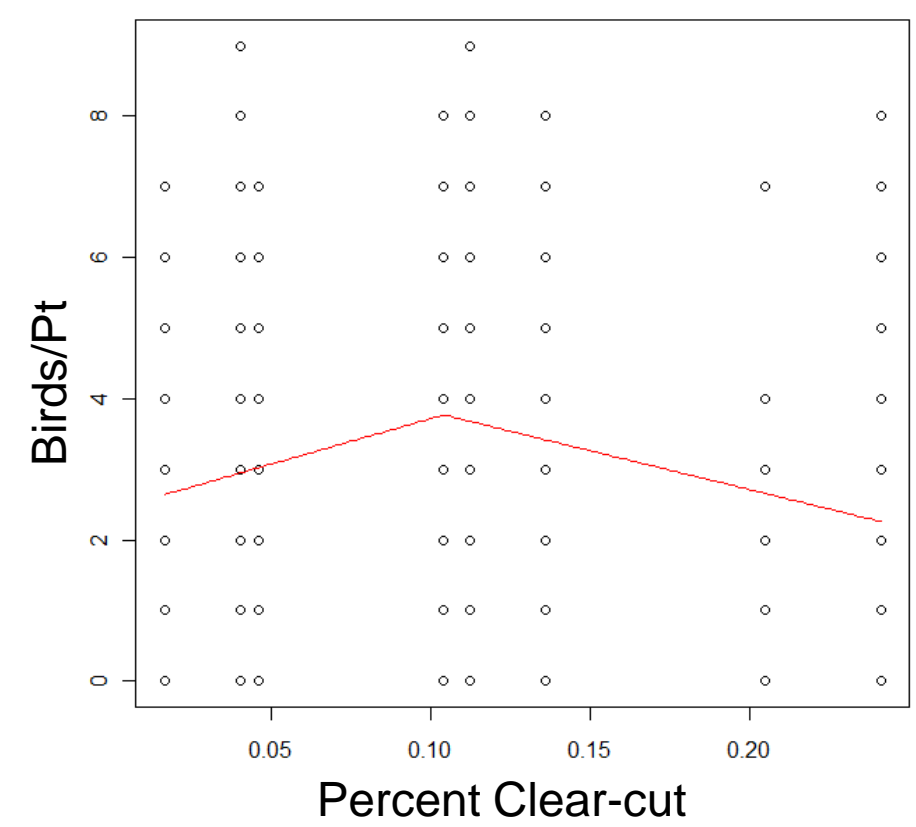

1. Forest-interior guild clear-cut threshold: mid-study abundance peak

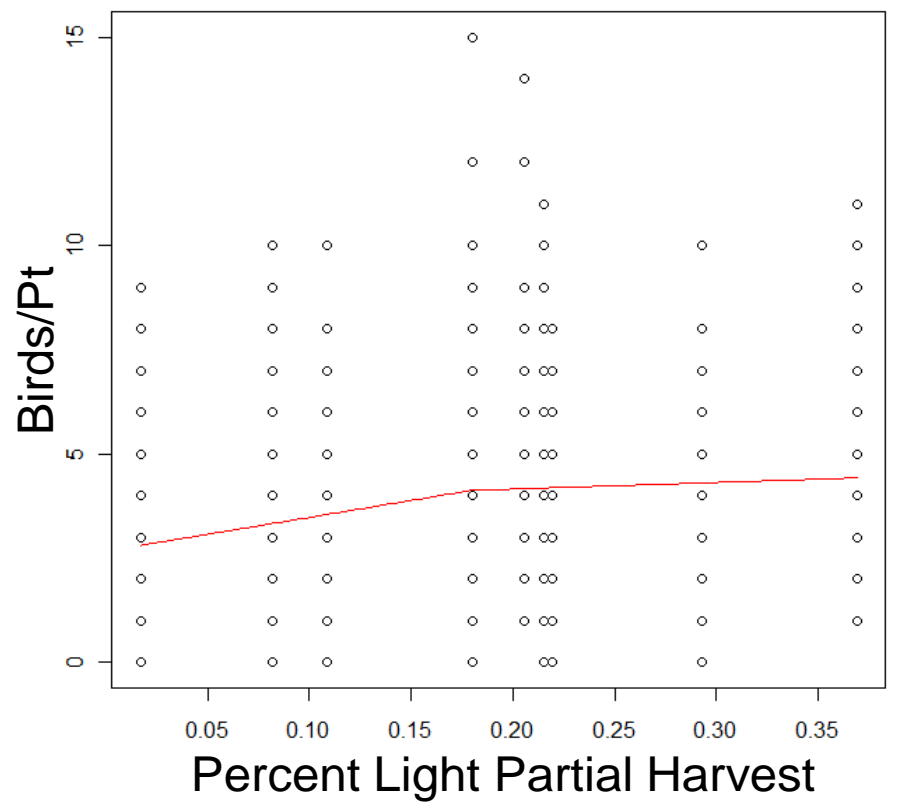

2. Interior-edge guild light partial harvest threshold: reduced slope steepness 
Appendix C. Continued

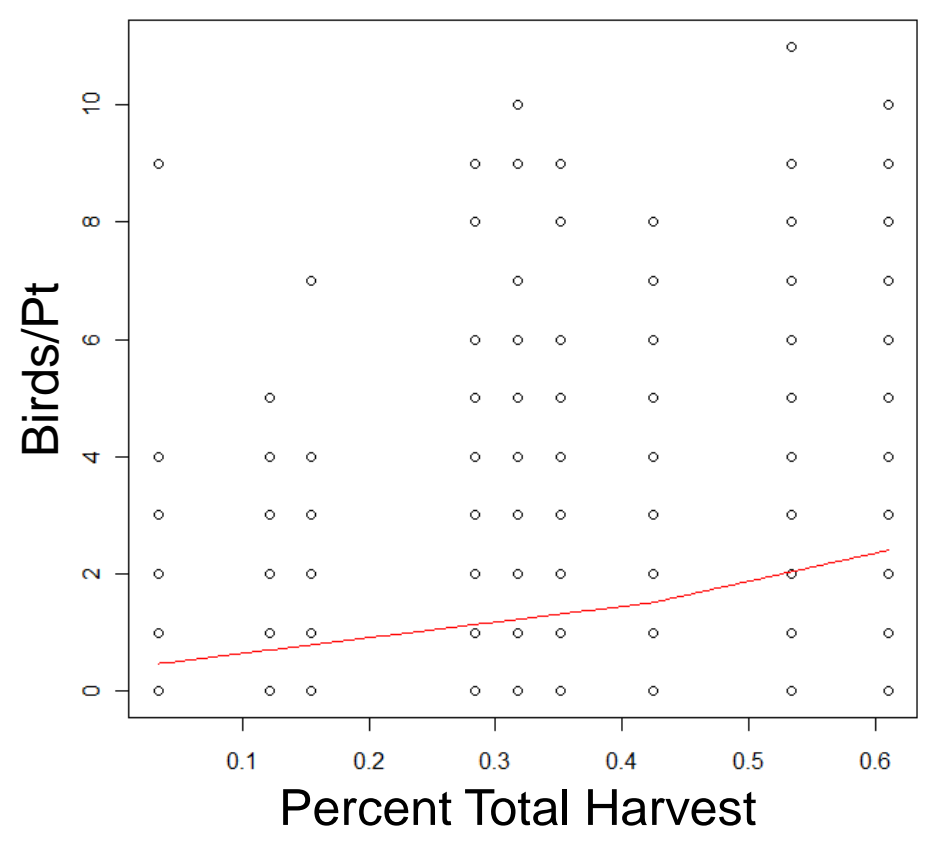

3. Early successional guild total harvest threshold: increased slope steepness

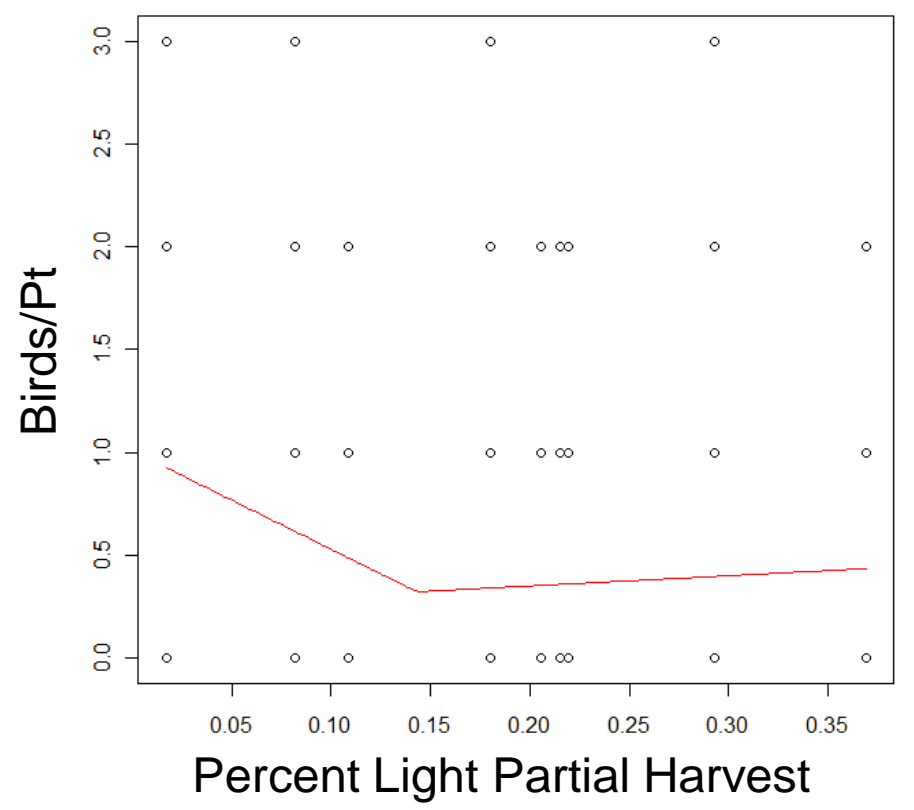

4. Blue-headed Vireo light partial harvest threshold: initial decline then leveling-off 
Appendix C. Continued

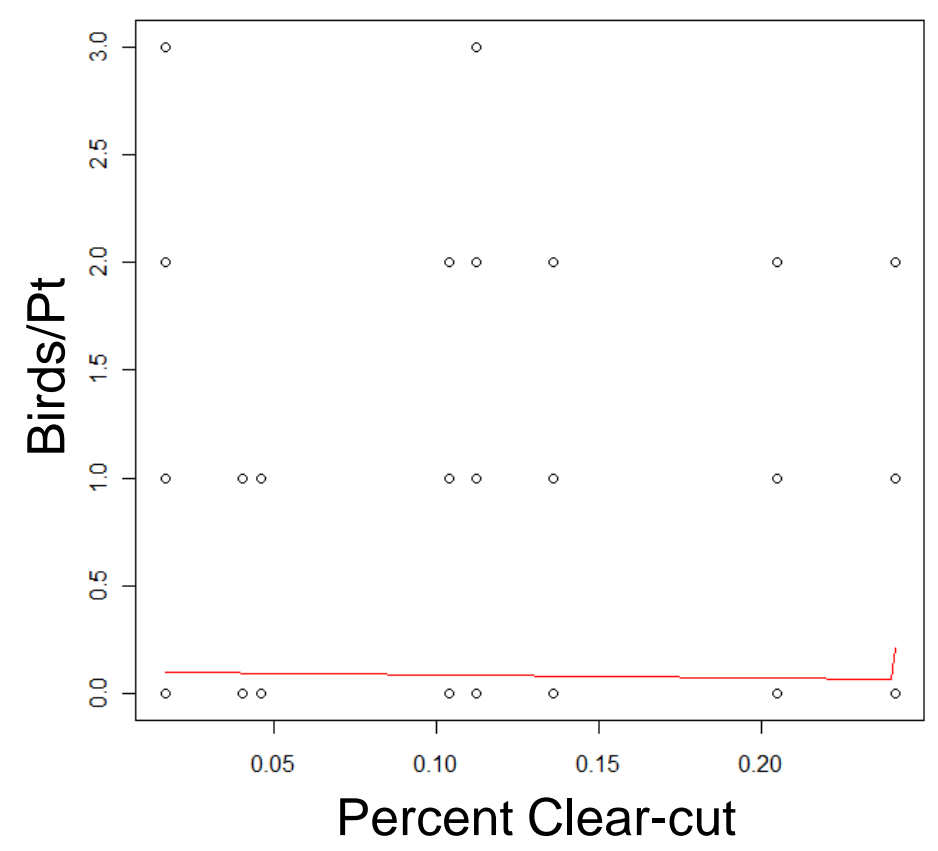

5. Wood Thrush clear-cut threshold: Sharp 
CHAPTER 3

REASSESSING FOREST SONGBIRD HABITAT ASSOCIATIONS: INFLUENCE OF DISTURBANCE ON RELATIVE ABUNDANCE AND NEST SUCCESS ON A MANAGED LANDSCAPE IN THE CENTRAL APPALACHIANS 


\begin{abstract}
Timber management affects both mature forest and early successional bird species, many of which have been declining in relative abundance. Most research has focused on the short-term effects of different types of timber harvests on birds, overlooking the broader spectrum of habitat conditions resulting from long-term management. Our objective was to use these broader habitat conditions to categorize bird species into habitat groups, identify habitat commonalities between group members, and determine habitat conditions associated with successful nests. We conducted point counts and monitored nests at the Wildlife Ecosystem Research Forest in Randolph County, WV from 1996-1998, 2001-2003, and 2007-2009. Using non-metric multidimensional scaling (NMDS), we identified four habitat groups: mature forest, disturbedcanopy low elevation, disturbed-canopy high elevation, and early succession. NMDS group regression tree abundance models had reduced error rates compared to traditional habitat guilds (forest-interior, interior-edge, early successional). Early successional species increased in relative abundance with greater amount of clear-cuts, heavy partial harvests, and edge density. The disturbed-canopy species were divided into two groups based on elevation. We found no consistent metrics among these species, but models contained variables representing aspects of disturbed mature forests including increased intermixing of habitats, a greater diversity of habitats, increased edge habitat, reduced patch shape complexity, and greater amounts of light partial harvests. Mature (undisturbed) forest species declined in relative abundance with increased clear-cuts, core early succession habitat, and habitat intermixing and reduced patch shape complexity. Early successional species were more influenced by local-scale variables and disturbed-canopy species were more influence by landscape-scale variables; most species were influenced to some degree by variables at both scales. Nest success models had high error due to small sample sizes. Few nest variables were also retained in relative abundance models suggesting different conditions are required for successful breeding than for high relative abundance. Our results highlight the need to reconsider the classification of bird species with respect to habitat created by timber management. Group members shared many habitat commonalities and model error was improved over traditional habitat guilds. Variation among species remains with models for most species containing additional variables compared to group models.
\end{abstract}

Key Words: timber management, bird-habitat relations, NMDS ordination, bird habitat guilds 
Over half of all passerines nesting in West Virginia are forest species (Hall 1983). Of the 50 mature-forest breeding passerines identified in the Allegheny Plateau by the Breeding Bird Survey, 28\% are significantly declining (Sauer et al. 2008). Area-sensitive forest songbirds may be negatively impacted by forest disturbance in the short-term and at smaller spatial scales (Temple 1986), although other studies have indicated limited tolerance to forest management (Thompson et al. 1992), a reduced effect of silvicultural versus agricultural disturbance (Rodewald 2002), and use of early successional habitats post-breeding (Vega Rivera et al. 1998, Marshall et al. 2003, Dellinger 2007, McDermott 2007) by forest-breeding songbirds. Furthermore, forest management can create habitat needed by early successional species, $75 \%$ (18 of 24) of which are declining across the Allegheny Plateau (Sauer et al. 2008).

The Allegheny Plateau provides important summer breeding habitat for many bird species and is considered a "major area of high importance" (Rosenberg and Wells 1995), ranking in the top five physiographic regions for 28 of 34 avian species of conservation interest. Timber is also economically important within this region, especially in West Virginia where the wood industry ranks $9^{\text {th }}$ in share of total state employment and $4^{\text {th }}$ in wood industry share of total gross state product (West Virginia Department of Commerce 2010). In the state approximately 9.5 million $\mathrm{m}^{3}$ of timber is harvested annually (Widmann et al. 2010) and when combined with wood products results in 45,000 jobs (West Virginia Department of Commerce 2010) and over 4 billion dollars annually to the state (Childs 2005). This heavily forested region, therefore, provides a valuable context to study forest management and its implications for avian species of high conservation importance.

Much research has focused on avian response to different types and methods of timber harvests including those that compared the effects of even-aged and uneven-aged management to unmanaged forests (Weakland et al. 2002, Duguay et al. 2001, Augenfeld et al. 2008), the differences between harvest types (Annand and Thompson 1997, Baker and Lacki 1997, Duguay et al. 2001, Dellinger et al. 2007, McDermott and Wood 2009), and the effects of modifying existing harvesting techniques, for example retaining residual trees in clear-cuts (Brawn et al. 2001, Harrison and Kilgo 2004). However, most such studies have been short-term or have only focused on bird community response following initial harvest (Keller et al. 2003, Campbell et al. 2007). Sallabanks et al. (2000) also noted these limitations in extant research investigating bird response to forest management and recommended that "future research should:1 ) be more long- 
term; 2) incorporate rigorous experimental designs in which treatments are assigned randomly and better replicated; and 3) although difficult, measure parameters related to avian fitness and population viability."

Research has indentified a positive linear relation between bird diversity and vertical structural diversity (Karr and Roth 1971) and found temporal change in vegetative structure as an important local factor in determining changes in bird abundance (Holmes and Sherry 2001). Due to past clear-cutting of a majority of eastern forests, most forests are 70-100 year old even-aged forests characterized by a dense overstory and open subcanopy, reducing vertical diversity. These forests have not yet achieved the greater structural complexity of old-growth forests and disturbances such as fire, that create structural diversity, are often limited apart from timber management.

Landowners in the Allegheny Plateau use several timber harvest types (Smith 1995), each of which has varying effects on the treated forest (Smith 1962). Clear-cuts usually remove all mature trees resulting in early successional, shrub habitat. Heavy partial harvest via deferment or shelterwood cuts result in early successional habitat similar to clear-cuts, although they retain some residual trees providing limited vertical structure and canopy cover. Light partial harvests via single-tree, group-selection, or high-grading harvests of mature sawtimber result in a continuous but broken canopy that retains many mature forest characteristics, but with understory development within the created gaps. Because of intermixed ownership patterns in the Allegheny Plateau, it is not uncommon for forested landscapes to consist of forests managed with a mix of these harvesting practices. Thus, a study at the landscape scale that encompasses forests managed using different harvesting techniques would provide a more complete understanding of the effects timber management may have on forest breeding birds. Such improved knowledge can better inform improved conservation planning.

The goal of our study was to evaluate breeding bird-habitat relations among a wide gradient of disturbance levels in a managed landscape. Therefore, we examined relative abundance and nest success of forest songbirds on a landscape structured by active forest management, by considering a variety of harvesting techniques, over a 14-year period. Our objectives were to 1) develop empirically-derived habitat groups for forest-breeding birds, 2) compare habitat relations between these groups and traditional habitat guild groupings, 3 ) 
compare habitat relations among bird species within our empirically-derived habitat groups, and 4) determine the influence of habitat characteristics on nest success.

\section{METHODS}

Study area. - We conducted our research at the Wildlife and Ecosystem Research Forest (WERF), located in Randolph County, West Virginia in the unglaciated Allegheny Mountain and Plateau region from 1996-1998 (Weakland 2000), 2001-2003 (Dellinger 2005), and 2007-2009. This 3,413 ha forested area was established in 1994 by Westvaco Corporation to study relations between commercial forest management practices and ecosystem processes and wildlife. In 2002 we added the 1,705 ha Panther Run Tract (PRT), also owned by MeadWestvaco Corporation, located $16 \mathrm{~km}$ north of the WERF. Both properties were sold to Penn Virginia in the winter of 2007. Elevations at the WERF are 734-1,180 m, whereas at Panther Run elevations are 634-914 m. Regional topography consists of narrow valleys with small, highgradient streams, and steep slopes topped by broad ridges that generally run in a south-southwest to north-northeast direction. The sites receive high annual average precipitation, more than 160 $\mathrm{cm}$, with snow common throughout the winter resulting in a cool and humid environment. Soils are acidic and well-drained inceptisols and ultisols.

Vegetation communities on the study areas vary by elevation. Red spruce (Picea rubens) and eastern hemlock (Tsuga canadensis) characterize stands above 1,000 m. Northern hardwoods including red maple (Acer rubrum), American beech (Fagus grandifolia), and black cherry (Prunus serotina) dominate at 850-1,000 m. Below $850 \mathrm{~m}$, cove hardwood and mixed mesophytic plant communities occur with species such as northern red oak (Quercus rubra), black birch (Betula lenta), and tulip poplar (Liriodendron tulipifera) dominating the canopy. Xeric oak-hickory communities dominated by black oak (Quercus velutina), scarlet oak (Quercus coccinea), and hickory (Carya spp.) also occur at low elevations. Communities of eastern hemlock, red spruce and rhododendron (Rhododendron spp.) are found in the riparian areas.

Although primarily mature forest at the study's inception, the WERF is currently a mixture of harvested and mature forest stands as a result of timber management. In 2002, PRT had comparable proportions of clear-cuts to the WERF, but slightly higher proportions of light partial harvests and total harvests. Forest management included even-aged timber harvesting in 
the form of clear-cuts, shelterwood cuts, and deferment cuts, and partial harvesting via group selection and high-grade harvests of mature sawtimber (Dellinger et al. 2007). Initially, management included a balance of even and uneven-aged methods; in 2007, management shifted to primarily uneven-aged techniques.

Non-forest habitat on the study area was limited. At the end of the study, grassy habitat covered $1.9 \%$ and included road edges, gas well openings, and log landings. Roads covered $1.5 \%$, streams $0.1 \%$, and human development $<0.01 \%$.

Point counts. - We counted breeding birds using 50-m fixed-radius plots (Hutto et al. 1986) at points selected systematically from existing points on a 241 x $241 \mathrm{~m}$ grid established by Westvaco during a 1995 forest inventory. We surveyed 118 points in 1996-1997, 116 in 1998, 108 in 2001, and 162 in 2002-2003 and 2007-2009. Sample points were either $241 \mathrm{~m}$ or $482 \mathrm{~m}$ apart at the WERF and $480 \mathrm{~m}$ apart at PRT; each point was marked with a uniquely numbered 1 $\mathrm{x} 1 \mathrm{~cm}$ aluminum stake.

Each year from 29 May to 4 July, every point count was sampled twice, once by each of two observers proficient in bird identification and distance estimation, with at least a three-week interval between surveys. We conducted counts beginning at 0600 EST and ending no later than 1000 on mornings with suitable weather conditions (i.e., no rain, little wind). We recorded species of all individuals heard or observed within a 10-minute time span and within $50 \mathrm{~m}$, the type of detection (song, call, visual, or fly-over), and sex if possible. Recently fledged young and flyovers were noted but excluded from analyses. If a bird could not be identified to species, the observer attempted to locate and identify the individual after completing the count. For the final relative abundance at point, we used the maximum count from the two samples each year.

Nest searching. - In 2001-2003 and 2007-2009, we monitored nests from mid-May until mid-July for eleven focal species that were relatively common within the study area and represented a variety of nesting habitats. We selected two forest-interior species, Blue-headed Vireo (Vireo solitarius) as a subcanopy nester and Hermit Thrush (Catharus guttatus) as a ground nester. We selected five interior-edge species, American Robin (Turdus migratorius) and Wood Thrush (Hylocichla mustelina) as subcanopy-shrub nesters, Red-eyed Vireo (Vireo olivaceus) as a subcanopy nester, and Dark-eyed Junco (Junco hyemalis) and Veery (Catharus fuscescens) as ground nesters. Finally, we selected four early successional species, including Chestnut-sided Warbler (Dendroica pensylvanica) as a ground nester; and Eastern Towhee 


\section{(Pipilo erythrophthalmus), Gray Catbird (Dumetella carolinensis), and Indigo Bunting}

(Passerina cyanea) as shrub nesters.

We divided the study area into three elevational blocks and randomly located six nest plots, each approximately 20 ha, distributed throughout each block (Fig. 1). The lowest elevation Panther Run Tract was defined as one elevational block, and the WERF was divided into two approximately equal area blocks along the elevational gradient. Within each block, we placed half the plots in areas with $>50 \%$ intact, predominantly mature, hardwood forest, while the other half were placed in areas with $>50 \%$ closed-canopy early successional vegetation. Due to harvesting within mature forest plots, we shifted five plots once during the study to maintain mature forest conditions (Fig. 1). All plots were orientated perpendicular to the slope to reflect the steep nature of the landscape and to ensure they were not primarily in either ridges or valleys.

Throughout the breeding season, we searched each plot every three days from 0600 until 1300, spending equal time in plots, at least 18 days or 126 person hours, representing each habitat type to minimize potential sampling bias. Additionally, we monitored nests found opportunistically at point-count locations or while traveling to and from the counts. We located nests using both systematic searches and behavioral observations (Martin and Geupel 1993). Once located, we checked each nest a minimum of every 3 days until the nest attempt was complete and identified as either successful or failed.

Landcover and Landscape Pattern Metrics. - We created a digital landcover layer for each year of the study in which bird data was collected, subdividing cover into ten types: clearcuts (Clear; harvests with no residual trees), heavy partial harvests (HvyPH; clear-cuts with residual trees plus deferment and shelterwood cuts), light partial harvests (LtPH; single-tree selection and high-grade cuts), mature deciduous forest (Decid), mature mixed forest (Mixed), herbaceous cover, shrub/scrub cover (mostly roadside), water, road, and development. Data were not available to define the age of each harvest, because landcover was not available from 1999-2000 and 2004-2006, so harvest classification remained constant throughout (a clear-cut in the first year was still a clear-cut in the last year). We defined cover types and stand boundaries annually using $1 \mathrm{~m}$ resolution National Agriculture Imagery Program (NAIP) 1:10,000 scale aerial orthophotos, harvest shapefiles provided by the timber companies, and ground-truthing.

We calculated landcover and landscape pattern metrics at two scales: landscape, within each of the three elevational blocks (Fig.1), and local, covering areas within $100 \mathrm{~m}$ of each point 
count or nest. Variables at the landscape-scale influence selection of the landscape by birds, while local-scale variables influence selection of territories within this larger area. For each year of the study, we calculated total area of five harvest-based landcover classes: clear-cut, heavy partial harvest, light partial harvest, mature deciduous forest, and mature mixed forest. We calculated annual landscape pattern metrics with Fragstats (McGarigal et al. 2002) selecting metrics indentified as important to avian species in past research in the area (Demeo 1999, Weakland 2000, Williams 2002, Bosworth 2003, and Dellinger 2005). Area-weighted mean shape index (AWMSI) measures the shape complexity of patches of all cover types by measuring the perimeter-to-area ratio weighted by the size of its patches. Timber management should decrease AWMSI as harvests are often more regularly shaped than natural stands. We calculated interspersion and juxtaposition (IJI), a measure of the intermixing of cover types relative to the maximum intermixing possible, Shannon diversity index (SHDI), a measure of the diversity of different cover types, and contrast-weighted edge density (CWED), a measure of the amount of edge per ha that gives different weights to the intersection of different cover types (Appendix 1). We calculated core area, area $>50 \mathrm{~m}$ from an edge, for mature forest (mature deciduous and mature mixed forest patches combined) and for early successional cover (combined patches of clear-cuts, heavy partial harvests, and shrub/scrub cover). We measured shrub cover annually so that it could be included in the calculation of core early successional habitat but this variable was not included as separate landcover variable. Finally, at each point or nest, we measured elevation using the 30-m National Elevation Dataset (NED), slope, and aspect.

Data analysis. - We treated each point in each year as individual samples $(\mathrm{n}=1270)$ with associated unique habitat conditions and bird counts. All point locations were sampled in multiple years and each year was treated as a separate sample because habitat could change annually.

Relative abundance for each avian species at each point was the maximum count from the two surveys within each year. We analyzed the 15 species detected at $\geq 20 \%$ of survey points including Black-and-white Warbler (Mniotilta varia; BAWW), Black-throated Blue Warbler (Dendroica caerulescens; BTBW), Black-throated Green Warbler (Dendroica virens; BTNW), Blue-headed Vireo (BHVI), Canada Warbler (CAWA), Chestnut-sided Warbler (CSWA), Darkeyed Junco (DEJU), Eastern Towhee (EATO), Hooded Warbler (Wilsonia citrina; HOWA), Indigo Bunting(INBU), Magnolia Warbler (Dendroica magnolia; MAWA), Ovenbird (Seiurus 
aurocapillus; OVEN), Red-eyed Vireo (REVI), Scarlet Tanager (Piranga olivacea; SCTA), and Veery (VEER). We included four additional species for which we had nest searched [American Robin (AMRO), Gray Catbird (GRCA), Hermit Thrush (HETH), and Wood Thrush (WOTH)] and three early successional species which occurred at $<20 \%$ of the points but were species of conservation concern [Golden-winged Warbler (Vermivora chrysoptera; GWWA) and Bluewinged Warbler (Vermivora pinus; BWWA)] or had recently become abundant but were detected at $<20 \%$ of points due to initial absence within the study area [Common Yellowthroat (Geothlypis trichas; COYE)].

To describe the range of habitat conditions available for avian species throughout the study, we created boxplots for each landcover variable and landscape pattern metric at both the local and landscape scales (Figs. 2, 3). The central line of the boxplot measures the median for each variable, while the ends of the box are the first and third quartiles. The whiskers on each boxplot extend to 1.5 times the interquartile range with dots representing values further than this cutoff.

We used non-metric multidimensional scaling (NMDS; Kruskal 1964) to identify which bird species were identified in similar habitat conditions. McCune and Grace (2002) identified NMDS as the ordination method of choice for characterizing most ecological community structure. We created models using the metaMDS function in the vegan package in program $\mathrm{R}$ (R Development Core Team 2009) using 2-6 dimensions. Since stress decreases as the number of dimensions increase, we selected the model with the fewest dimensions for which adding an additional dimension did not greatly reduce overall stress. The metaMDS function included multiple random starts to avoid the model becoming stuck on local minima. The distance between points was measured using the Bray-Curtis distance metric (Bray and Curtis 1957). To handle zero dissimilarities in species among some of the points, we used the "add" command which adds a small positive value instead of zero for the dissimilarity value. We then grouped species with similar habitat relations based on their location within the NMDS ordination.

To interpret the NMDS ordination, we correlated the habitat metrics to the ordination using vector fitting and the envfit function in the vegan package in program $\mathrm{R}$. Variables were area of five cover types (clear-cut, mature deciduous forest, mature mixed forest, light partial harvest, and heavy partial harvest), four landscape pattern metrics (AWMSI, SHDI, IJI, and CWED) at the landscape and local scales, and three additional local variables (elevation, degree 
slope, and aspect). We only included variables on the resulting plot with $p \leq 0.05$. Additionally, to identify non-linear patterns, we fitted a smooth curve to the ordination for the previously mentioned variables using the ordisurf function in program $\mathrm{R}$.

To compare models between traditional habitat guilds and NMDS-defined habitat groups and to determine commonalities in habitat relations among bird species within each NMDS habitat group, we created regression tree models (De'ath and Fabricius 2000) for each guild, NMDS group, and species. We assigned birds to traditional habitat guilds based on Whitcomb et al. (1981), Ehrlich et al. (1988), and observations from previous research in West Virginia (Appendix 1). We created models using the mvpart package in program $\mathrm{R}$ using 10-fold crossvalidation and the "pick" functions to interactively select the best tree size, balancing the number of branches versus the decline in relative error. We created three models: landscape, local, and combined using relative abundance as the response variable and the landcover and landscape pattern metrics in Fig. 2 and Fig. 3 as the predictor variables. To assess fit for each model, we calculated relative error (the inverse of the variance explained by the model) and cross-validation error such that values close to 0 were perfect predictors while values close to 1 were poor predictors (De'ath 2002). Cross-validation error better represents the predictive abilities of models using new data.

To examine landscape differences between successful and unsuccessful nests, we used classification trees (De'ath and Fabricius 2000). We initially modeled individual species; however, due to the limited number of nests, model fits were poor. Thus, we instead modeled the combined nests of species within each NMDS habitat group. We created models using the mvpart package in program R using 10-fold cross-validation and the "pick" functions to select tree size. The response variable was nest outcome (success or failure), and we used the same landcover and landscape pattern metric variables and the same three models (landscape, local, and combined) as for the relative abundance models. To assess model fit, we calculated the misclassification rates to determine how often successful and unsuccessful nests and nests within the two time periods were classified incorrectly within the model and also as a result of crossvalidation. We measured cross-validation error using the same approach as described above for the abundance models. 


\section{RESULTS}

Habitat Condition. - Our point count survey locations included a broad array of habitat conditions (Fig. 2 and 3; see Appendix 2 for mean and SE). Elevation ranged from 629-1073 m (middle 50\%: 829-972 m), while slope ranged from flat $\left(0^{\circ}\right)-32^{\circ}$ (middle 50\%: 8.8-18.9 ${ }^{\circ}$ ). AWMSI ranged from 1.1-2.1 at the local scale but was skewed toward larger value, while the landscape scale distribution was narrower (3.0-3.6) but more even. At the local scale CWED ranged from 0-368 m/ha, including > 25\% values without any edge, while landscape scale CWED was narrower (66-104 m/ha). Outliers expanded local scale IJI, which ranged from 9-100, but most of the data ranged from 42-81. Landscape IJI had a narrower range (62-79) and a more even distribution. The distribution of SHDI at the local scale ranged from no diversity (0)-0.8 but was skewed towards larger values, while landscape scale SHDI ranged from 1.1-1.7. Of the core metrics, mature forest had a broader range (52-921 ha) than early succession (2.7-150 ha).

Cover types at the local scale ranged from complete absence ( 0 ha) to complete cover (3.13 ha) for all types except heavy partial harvest, which peaked at $2.8 \mathrm{ha}$, but harvest landcover types included many zero values (Fig. 2). At least $50 \%$ of the values for clear-cut and light partial harvest were zeroes as were at least $75 \%$ of the heavy partial harvest values. At the landscape scale (Fig. 3), mature deciduous (141-828 ha), mature mixed (114-925 ha), and light partial harvests (17-759 ha) had the largest ranges, while the ranges of clear-cut (25-325 ha) and heavy partial harvest (0-119 ha) were narrower and had smaller maximums.

Non-metric multidimensional scaling. - The strongest NMDS ordination model included three dimensions and resulted in a stress of 22.8. As a result of the ordination, we placed the 15 species into four groups (Fig. 4). Correlations of habitat metrics to each species location in the ordination resulted in linear (Fig. 5) and non-linear (Fig. 6) relations.

The first NMDS group, early succession, included seven shrubland species (BWWA, COYE, CSWA, EATO, GRCA, GWWA, and INBU) located farthest left on the ordination (Fig. 4). The location of this group within the NMDS ordination was correlated with increasing area in clear-cuts, heavy partial harvests, and SHDI at both scales (Fig. 5; Fig. 6).

The second and third groups, both associated with disturbed mature forests, were separated from each other based on elevation, which became higher moving down the second axis of the ordination (Fig 5). A low-elevation disturbance group included BAWW, HOWA, OVEN, and WOTH, and a high-elevation disturbance group included AMRO, CAWA, DEJU, 
and VEER (Fig. 4). Local light partial harvests increased moving from the center of the ordination towards both groups (Fig. 6), while landscape light partial harvest increased only towards the lower elevation disturbance group (Fig. 5). Similarly, local CWED was greatest in a band running through both groups (Fig. 6) while landscape CWED increased toward the lower elevation group (Fig. 5).

The last group, undisturbed mature forest, included BHVI, BTBW, BTNW, HETH, MAWA, REVI, and SCTA. At both scales, the upper portion of this group was associated with more mature deciduous forest (Fig. 6), whereas mature mixed, elevation, and core mature forest increased moving downward to the right on the ordination toward the lower portion of this group (Fig. 5). SHDI and IJI increased moving left on the NMDS ordination from the mature forest group towards the other three groups (Fig. 5; Fig. 6).

Abundance regression trees. - NMDS group models had lower errors than traditional habitat guild models, except for early successional species that were the same for the guild and NMDS group, indicating an improved classification of guilds due to greater similarity in required habitat conditions (Table 1). Error and cross-validation error for models at all scales were improved for both NMDS disturbance groups versus the interior-edge guild and for the mature forest NMDS group versus the forest-interior guild.

The two disturbed-canopy mature forest NMDS groups differed from each other in their response to elevation and mature mixed forests. The low-elevation group responded negatively to area in mature mixed forests and elevations $>845 \mathrm{~m}$, while the high-elevation group responded positively to area in mature mixed forest and elevations $>837 \mathrm{~m}$. Both increased in response to area in light partial harvests but at different scales. The undisturbed mature forest NMDS group declined in relative abundance with greater disturbances at both scales, more core early successional habitat at the landscape scale, and more area in clear-cuts at the local scale, but increased in response to greater habitat diversity and elevation $>862 \mathrm{~m}$.

The early succession NMDS group contained the same members as the early succession habitat guild. Relative abundance of the early successional NMDS group increased with greater area in clear-cuts and heavy partial harvests at the local scale and declined with more area in mature mixed forest at the landscape scale.

We found common habitat variables among individual species within each NMDS group (Table 2). The relative abundance of all early successional species increased as the area of clear- 
cuts increased at the local scale, although the actual branching point varied from 0.74-1.81 ha (24-58\% of the local area). Three species (COYE, CSWA, GRCA), all at the local scale and GRCA at the landscape scale, increased in relative abundance with increasing area in heavy partial harvests. At the landscape scale, relative abundances of four species (CSWA, EATO, GWWA, INBU) increased when CWED exceeded $88-103 \mathrm{~m} / \mathrm{ha}$, while three species (BWWA, COYE, EATO) declined with greater area in mature mixed forests.

The traditional interior-edge and forest-interior guilds were subdivided into three different NMDS groups (Fig. 4). These NMDS group included species from both traditional guilds except for the high-elevation disturbance group that included only interior-edge species (Table 2). Within the low-elevation disturbance group, all four species decreased in relative abundance when elevation surpassed $798-859 \mathrm{~m}$ and three species declined with greater area in mature mixed forests (Table 2). All four species also increased in relative abundance with increasing area in partial harvests, two at the landscape scale and two at the local scale. Half the species increased in relative abundance when CWED was $>103 \mathrm{~m} / \mathrm{ha}$, near the maximum measured value. Within the high-elevation disturbance group, all species increased in relative abundance when elevation surpassed $824-947 \mathrm{~m}$. At the local scale, relative abundance of all species increased in response to metrics indicating a more disturbed forest, but the actual metrics varied among the individual species (two species for IJI, two species for SHDI, and one species for CWED). At the landscape scale, the relative abundance of two species decreased with more mature deciduous forest and three species decreased when AWMSI declined below an index value from $3.14-3.28$.

Within the mature forest NMDS group, relative abundance of all species decreased when metrics associated with forest disturbance increased. Variables at the local scale differed by species, though some species declined when clear-cut area increased to more than $0.004-0.56$ ha $(0.1-18 \%$ of the local area). At the landscape scale, two species declined with increasing amounts of clear-cuts, two species declined with increasing amounts of core early successional habitat, and three species declined, each with increasing AWMSI and IJI.

Individual species relative abundance models had at least one variable in common with their respective NMDS group models, except for BTBW, but also included additional variables, except for BWWA and OVEN (Tables 1 and 2). All members of the early-successional group shared a positive response to area in clear-cuts, while three out of seven species shared the 
negative response to mature mixed forest and only GRCA shared the positive response to heavy partial harvests. The variable branching values differed for most species. Models for all species in both disturbed-canopy mature forest groups included the elevation variables of the group model. For species in the high-elevation group, a negative response to AWMSI was most commonly shared. All species in the low-elevation group shared a positive response to light partial harvests (two were at a different scale) and three species shared a negative response to mature mixed forests. Within these groups, branching values were similar for most shared variables except for CAWA. Finally, of the seven undisturbed mature forest species, three shared no variables or only elevational variables with the group. The remaining four species shared a negative response to either core early successional habitats or clear-cuts. The cut-offs for about half of the shared variables within this group differed.

The scale of the variables retained in the combined models varied among individual species, but patterns differentiated the NMDS groups (Table 1). Combined models included variables from both scales for 14 species, and models for four species each included only local or landscape variables. Among individual species' models with each NMDS group, combined models including variables from both scales were tied or most common. However, in reviewing species' models with only single-scale variables, early-successional group species models had only local variables, high- and low-elevation disturbance groups species had only landscape variables, and mature-forest group species had a mixture of both scales. This pattern within the individual species is consistent with the combined models variables for each NMDS group.

Nest success classification trees. - Classification trees for nest outcome (success or failure) had relative errors ranging from $0.37-0.95$, but predictive results were poor, i.e., $\mathrm{CV} \geq 1$ for all models except the undisturbed mature forest group at the landscape scale (Table 3). Abundance and nest success models for each NMDS group had some similar variables. For the low elevation disturbed-canopy forest group, nest success was greater with increasing edge density at the local scale (Table 3), while relative abundance increased with increasing edge density at the landscape scale (Table 1). For the high elevation disturbed-canopy forest group, nest success increased with decreasing area in mature mixed forest locally, but relative abundance increased with increasing area in matured mixed forest at the landscape scale. 


\section{DISCUSSION}

Our results suggest that we should consider reclassification of species within their current habitat guilds (Whitcomb et al. 1981, Ehrlich et al. 1988) with respect to disturbance of mature forests by timber harvests. Compared with traditional guilds, species in the NMDS ordination groups had more habitat relations in common and lower model errors, creating more cohesive ecological units. Traditional guilds seemed too broadly defined and personal observations of some species indicated broader use of habitats than would be expected. The more narrowly defined NMDS groups better reflected the biological relations between the species and habitat. As an additional benefit, the NMDS groups were aligned with types of disturbance created by timber harvests, making management objectives easier to define than possible with traditional guilds. We want to clarify that we are not supporting the use of these exact species assemblages within each NMDS groups as a classification, but rather the data-driven refinement of traditional guilds relative to habitat conditions. The actual assemblages in any given areas depend on a variety of factors such as habitat, elevation, etc.

The early successional guild best classified species and no species differed between the traditional guild and NMDS groups; however, based on our NMDS results, we suggest reorganizing both the traditional interior-edge and forest-interior guilds. Within NMDS groups, Black-and-white Warbler and Ovenbird, traditionally considered to be forest-interior species, were shifted to the disturbed-canopy forest group, and Red-eyed Vireo, an interior-edge guild member, was moved to the undisturbed mature forest group. This reclassification may indicate some elasticity in use of disturbed and undisturbed mature forests by members of both guilds. The commonalities within the NMDS groupings indicate the need for three types of habitats to support the full diversity of species: early successional regenerating forests, disturbed mature forests with increased opening of the canopy and small gap creation, and undisturbed mature forests.

Members of these newly defined groups have many habitat relations in common and these groups improve upon the traditional habitat guilds, but we still found variation among individual species within groups. Of species considered, all except two included additional variables beyond those included in their NMDS group models. Further, we realize that the NMDS groups were defined and then compared to traditional habitat guilds using the same avian data, which might favor the NMDS groups over traditional guilds. Locally, this does not present 
a problem as the data drove the creation of the groups; however, future research is needed to confirm if our groupings are consistent over a larger spatial scale.

Early successional NMDS group. - Similar to findings in previous research, we found that the early successional NMDS group was positively associated with regenerating forests created through even-aged timber management, including clear-cuts and heavy partial harvests (Annand and Thompson 1997, Duguay et al. 2001, Gram et al. 2003, Keller et al. 2003, Rodewald and Yahner 2000, Augenfeld et al. 2008). Area in clear-cuts had the greatest effect on relative abundance of these species with heavy partial harvests and CWED also being influential but to a lesser degree.

Although Krementz and Christie (2000) found no effects of even-aged harvest patch size on early successional bird relative abundance, most other studies suggest some degree of areasensitivity (Lent and Capen 1995, Costello et al. 2000, Gram et al. 2003, Brito-Aguilar 2005, Rodewald and Vitz 2005, Askins et al. 2007). In our study, we did not detect increases in relative abundance of early successional species until there was at least $24-58 \%$ of the area in clear-cuts at the local scale and detected no relationship at the landscape scale. Further, area of core early successional habitat was not retained in any of the models for early successional species. Greater edge density increased relative abundance for some species indicating that early successional forests mixed with other habitat types would support greater relative abundances compared to early successional forests alone. Rodewald and Vitz (2005), however, found seven of eight early successional species avoided clear-cut edges and preferred larger openings.

Of all the NMDS ordination groups, early successional species were least influenced by elevation, with neither elevation nor elevational block included in models for any species. The early succession group and three species within it (BWWA, COYE, EATO) were less abundant as mixed mature forests increased, revealing an indirect preference for lower elevations where mixed mature forests were less common. Still, some early successional species, such as Mourning Warbler (Oporornis philadelphia), were more common at higher elevations. This greater flexibility in regard to elevation and inclusion of a greater area of habitat might benefit such species by increasing the probability of finding inherently more ephemeral early successional habitats in heavily forested environments.

Early successional nest success models had no variables in common with the group abundance models, suggesting that conditions required for successful breeding might be different 
than for high relative abundance. However, the positive relationship between IJI and nest success could, along with the similar relationship between CWED and relative abundance, reflect an adaptation among these species for niches associated with the mixing of mature and regenerating forests. Most studies of the influence of edge on mature-forest bird nest success found no effect (Duguay et al. 2001, Moorman et al. 2002, Gram 2003) or detrimental effects (Flaspohler et al. 2001, Manolis et al. 2002), but our result suggests a positive effect for early successional species. Future research is necessary to determine specific habitat conditions within early successional habitats that support high relative abundance and nest success. Our study underscores the importance of large sample sizes in evaluating habitat relationships for nest success; we had to combine species by NMDS group to conduct our analysis. We suggest that future studies focus on a smaller, more select group of species.

Disturbed-canopy mature forest NMDS groups. - We identified two NMDS groups using disturbed mature forests. Within these forests, bird species composition shifted within a relatively narrow elevation $(800-850 \mathrm{~m})$, necessitating the creation of two habitat groups. Beyond that distinction, though, we found no consistent relationship with any single habitat metrics among the species within either group. Group members responded to increased interspersion, habitat diversity, availability of edge, and a reduction in patch shape complexity, a function of the inclusion of regularly-shaped timber harvests, all different aspects of disturbed forests. Thus, a mix of forest management practices on a landscape likely enhances habitat quality for disturbed mature forest birds.

Our results were similar to previous studies of the interior-edge guild (Lent and Capen 1995, Robinson and Robinson 1999, Greenberg and Lanham 2001) with light partial harvests positively related to relative abundance for species in disturbed mature forests. However, the influence of light partial harvests was less pronounced with species associated with higher elevations. As was the case with the early successional forest NMDS group, forests with increased IJI, SHDI, and CWED, supported higher relative abundances, perhaps due to a greater variety of habitats compared to stands with just light partial harvests. At the local scale, disturbed-canopy mature forest species relative abundance increased with $>71 \%$ of the area in light partial harvests compared to a cut-off of $>24-58 \%$ clear-cuts for early successional species, suggesting a need for larger patches of disturbed mature forest than for early successional forest. 
Nest success models for both disturbed-canopy mature forest groups had few variables in common with their related group relative abundance models. At the local scale, nest success decreased with increasing areas in mature deciduous forests for the low elevation group and increasing areas in mature mixed forests for the high elevation group; both forest types are the dominant mature forest landcover within their respective elevation ranges. Area in another common cover type, light partial harvests, was not retained in any of the nest success models, but this could be due to low sample sizes. Regardless, we cannot reach conclusions about nest success in this cover type. However, previous research has found minimal response of nest success to light partial harvests (Robinson and Robinson 2001, Moorman et al. 2002, Gram et al. 2003).

Undisturbed mature forest NMDS group._-Undisturbed mature forest species declined in relative abundance as clear-cut and core early successional habitats increased, even when clearcuts were uncommon at the local scale (0.1-18\%). Areas in heavy and light partial harvests were not included in any models for these species, indicating a minimal or reduced effect in comparison to area of clear-cuts. Relative abundance of the undisturbed mature forest group also decreased with a greater mixing of habitats, a reduction in shape complexity, and increase in edge density, all characteristics of more disturbed forests. Mature forest birds exhibited some resilience to disturbance as models for the guild, the NMDS ordination, and models for some individual species included a positive response to increased habitat diversity.

Similar to abundance models, nest success models for undisturbed mature forest species indicated flexibility and benefits from some forest disturbance. Nest success increased with greater CWED and area in light partial harvests, both indicative of a more open forest canopy and supporting use of light partial harvests in managing this group of species.

Although mature forest birds can be area-sensitive (Temple 1986), we did not retain core forest in any model for this group suggesting against area-sensitivity or that the influence of area-sensitivity is less pronounced than other changes in landscape and cover. This is consistent with results from Bayard and Elphick (2010), who found that that only about a quarter of the 1065 studies of area-sensitivity among forest songbirds discovered a positive response to greater patch size.

We observed an elevation gradient within the mature forest NMDS group, but not as strong as for the disturbed mature forest groups. Moving down the second NMDS axis, we 
observed a shift from lower elevation, deciduous species such as Red-eyed Vireo, Scarlet Tanager, and Black-throated Green Warbler to higher elevation, mixed forest species such as Hermit Thrush and Magnolia Warbler. Across this elevational gradient, we observed a partitioning of habitats among similar species such as the shift from Wood Thrush at low elevations to Hermit Thrush at high elevation similar to that reported by Dellinger et al. (2007) or from Red-eyed Vireo at low elevations to Blue-head Vireo at high elevations.

Scale. - Most species (64\%) in all guilds and groups responded to a mixture of local and landscape scale variables. The larger-scale variables likely influence the selection of the landscape in which the bird settles, while local variables probably influence selection of territories within this larger area. Landcover types had greater effects at the local scale, while the landscape pattern metrics, such as AWMSI, IJI, and SHDI, had a greater effect at the landscape scale.

The remaining guilds and groups (36\%) included variables for only a single spatial scale. For example, the early successional NMDS group was only influenced by local variables, which would be expected for species that must take advantage of the patchy, small-scale, and ephemeral disturbances common in this heavily forested region. In contrast, disturbed mature forest species were influenced by broader landscape variables. They generally did not respond to small localized disturbance but selected mature forest landscapes with greater overall disturbance relative to available mature forests. Undisturbed mature forest species were influenced by variables at both spatial scales. Thus, mature forest species also selected more intact mature forest landscapes; however, they also responded locally within the larger landscape by avoiding sources of major canopy disturbance such as clear-cuts.

Relation among NMDS group and harvest type. - We found that the NMDS groups tended to align with different harvest types. Metrics associated with clear-cuts and heavy partial harvests were associated with early successional species. Light partial harvests were associated with disturbed-canopy forest species. No harvesting was associated with mature forest species. Clear-cuts had the greatest overall influence both positive (early succession species) and negative (mature forest species). Because of the negative response to clear-cuts by mature forest birds, partial harvests provide an alternative timbering option for managers interested in reducing the effects of harvesting on this group of birds. Light partial harvests provide habitat for disturbedcanopy mature forest species while retaining many characteristics of undisturbed mature forests. 
Although Heavy partial harvests have more open canopies than light partial harvests and undisturbed forests, research has shown that mature forest species will use residual trees in these harvests (Duguay et al, 2001, McDermott and Wood 2009). Heavy partial harvests also provide habitat for early successional species similar to that provided in clear-cuts.

Our results found a positive response by early successional birds and no negative response in the models for the other NMDS groups to heavy partial harvests. No negative associations within the models does not guarantee the absence of a negative responses to heavy partial harvests only that the response was less pronounced than the observed response to clearcuts. Of harvesting treatments examined, clear-cuts appeared to promote the greatest positive response for early successional species. Potential negative effects of clear-cut harvests for other species groups could be minimized by using heavy partial harvests. Overall, a variety of harvesting techniques led to high avian diversity in this landscape.

\section{ACKNOWLEDGMENTS}

We thank the National Council for Air and Stream Improvement and the MeadWestvaco Corporation for funding our research and MeadWestvaco and Penn Virginia for providing housing for researchers and access to their property. We also thank the many field technicians who helped collect and enter data. J. T. Anderson and M. P. Strager provided helpful comments on this manuscript. Use of trade names does not imply endorsement by the Federal government. 


\section{LITERATURE CITED}

Annand, E. M., and F. R. Thompson III. 1997. Forest bird response to regeneration practices in central hardwood forests. Journal of Wildlife Management 61:159-171.

Askins, R.A., B. Zuckerberg, and L. Novak. 2007. Do the size and landscape context of forest openings influence the abundance and breeding success of shrubland songbirds in southern New England? Forest Ecology and Management 250:137-147.

Augenfeld, K.H., S.B. Franklin, and D.H. Snyder. 2008. Breeding bird communities of upland hardwood forest 12 years after shelterwood logging. Forest Ecology and Management 255:1271-1282.

Baker, M.D., and M.J. Lacki. 1997. Short-term changes in bird communities in response to silvicultural prescriptions. Forest Ecology and Management 96:27-36.

Bayard, T.S., and C.S. Elphick. 2010. How area sensitivity in birds in studied. Conservation Biology 24:938-947.

Bosworth, S.B. 2003. Cerulean warbler relative abundance and frequency of occurrence relative to large-scale edge. M.S. Thesis. West Virginia University, Morgantown.

Brawn, J.D., S.K. Robinson, and F.R. Thompson III. 2001. The role of disturbance in the ecology and conservation of birds. Annual Review of Ecological Systems 32:251-276.

Bray, J.R., and J.S. Curtis. 1957. An ordination of the upland forest communities of southern Wisconsin. Ecological Monographs 27:326-349.

Brito-Aguilar, R. 2005. Effects of even-aged forest management on early successional bird species in Missouri Ozark Forest. MS Thesis, University of Missouri-Columbia, Columbia.

Campbell, S.P., J.W. Witham, and M.L. Hunter Jr. 2007. Long-term effects of group selection timber harvesting on abundance of forest birds. Conservation Biology 21:1218-1229.

Childs, R.A. 2005. West Virginia's forests: growing West Virginia's future. West Virginia Division of Forestry Report. [Online.] Available at www.wvforestry.com/Economic\%20Impact\%20Study.pdf.

Costello, C.A., M. Yamasaki, P.J. Pekins, W.B. Leak, and C.D. Neefus. 2000. Songbird response to group selection harvests and clearcuts in a New Hampshire northern hardwood forest. Forest Ecology and Management 127:41-54.

De'ath, G., and K.E. Fabricius. 2000. Classification and regression trees: a powerful yet simple technique for ecological data analysis. Ecology 81:3178-3192.

De'ath, G. 2002. Multivariate regression trees: a new technique for modeling speciesenvironment relationships. Ecology 83:1105-1117. 
Dellinger, R. 2005. Nesting success and nest site characteristics of four thrush species on a managed forest. PhD dissertation. West Virginia University, Morgantown.

Dellinger, R., P. Wood, and P. Keyser. 2007. Occurrence and nest survival of four thrush species on a managed central Appalachian forest. Forest Ecology and Management 243:248258.

Dellinger, T.A. 2007. Post-fledging ecology and survival of neotropical migratory songbirds on a managed Appalachian forest. M.S. Thesis. West Virginia University, Morgantown.

Demeo, T.E. 1999. Forest songbird abundance and viability at multiple spatial scales on the Monongahela National Forest, West Virginia. PhD dissertation. West Virginia University, Morgantown.

Duguay, J.P., P.B. Wood, and J.V. Nichols. 2001. Songbird abundance and avian nest survival rates in forests fragmented by different silvicultural treatments. Conservation Biology 5:14051415.

Ehrlich, P.R., D.S. Dobkin, and D. Wheye. 1988. The Birder's Handbook. Simon and Schuster, New York.

Flaspohler, D.J., S.A Temple, and R.N. Rosenfield. 2001. Species-specific edge effects on nest success and breeding bird density in a forested landscape. Ecological Applications 11:32-46.

Gram, W.K., P.A. Porneluzi, R.L. Clawson, J. Faaborg, and S.C. Richter. 2003. Effects of experimental forest management on density and nesting success of bird species in Missouri Ozark forests. Conservation Biology 17:1324-1337.

Greenberg, C.H., and J.D. Lanham. 2001. Breeding bird assemblages of hurricane-created gaps and adjacent closed canopy forest in the southern Appalachians. Forest Ecology and Management 154:251-260.

Hall, G.A. 1983. West Virginia Birds. Carnegie Museum of Natural History, Pittsburgh.

Harrison, C.A., and J.C. Kilgo. 2004. Short-term breeding bird response to two harvest practices in a bottomland hardwood forest. Wilson Bulletin 116:314-323.

Holmes, R.T., and T.W. Sherry. 2001. Thirty-year bird population trends in an unfragmented temperate deciduous forest: importance of habitat change. Auk 118:589-609.

Hutto, R.L., S.M. Pletschet, and P. Hendricks. 1986. A fixed-radius point count method for nonbreeding and breeding season use. Auk 103:593-602.

Karr, J.R., and R.R. Roth. 1971. Vegetation structure and avian diversity in several New World areas. The American Naturalist 105:423-435. 
Keller, J.K., M.E. Richmond, and C.R. Smith. 2003. An explanation of patterns of breeding bird species richness and density following clearcutting in northeastern USA forests. Forest Ecology and Management 174:541-564.

Krementz, D.G., and J.S. Christie. 2000. Clearcut stand size and scrub-successional bird assemblages. Auk 117:913-924.

Kruskal, J.B. 1964. Nonmetric multidimensional scaling: a numerical method. Psychometrika 29:115-129.

Lent, R.A., and D.E. Capen. 1995. Effects of small-scale habitat disturbance on the ecology of breeding birds in a Vermont hardwood forest. Ecography 18:97-108.

Manolis, J.C., D.E. Andersen, and F.J. Cuthbert. 2002. Edge effect on nesting success of ground nesting birds near regenerating clearcuts in a forest-dominated landscape. Auk 119:955970.

Marshall, M.R., J.A. DeCecco, A.B. Williams, G.A. Gale, and R.J. Cooper. 2003. Use of regenerating clearcuts by late-successional bird species and their young during the post fledging period. Forest Ecology and Management 183:127-135.

Martin, T.E., and G.R. Geupel. 1993. Nest-monitoring plots: methods for locating nests and monitoring success. Journal of Field Ornithology 64:507-519.

McCune, B., and J.B. Grace. 2002. Analysis of Ecological Communities. MjM Software Design, Gleneden, OR.

McDermott, M.E. 2007. Breeding and post-breeding forest bird community dynamics in regenerating clearcuts and two-age harvests in the central Appalachians. MS Thesis. West Virginia University, Morgantown.

McDermott, M.E., and P.B. Wood. 2009. Short- and long-term applications of clearcut and two-age silviculture for conservation of breeding forest birds in the central Appalachians, USA. Biological Conservation 142:212-220.

McGarigal, K., S.A. Cushman, M.C. Neel, and E. Ene. 2002. FRAGSTATS: Spatial Pattern Analysis Program for Categorical Maps. Computer software program produced by the authors at the University of Massachusetts, Amherst. [Online.] Available at www.umass.edu/landeco/research/fragstats/fragstats.html

Moorman, C.E., D.C. Guynn Jr., and J.C. Kilgo. 2002. Hooded warbler nesting success adjacent to group-selection and clearcut edges in a southeastern bottomland forest. Condor 104:366-377. 
R Development Core Team. 2009. R: A language and environment for statistical computing, reference index version 2.9.2. R Foundation for Statistical Computing, Vienna, Austria. ISBN 3900051-07-0. [Online.] Available at http://www.R-project.org.

Robinson, W.D., and S.K. Robinson. 1999. Effects of selective logging on forest bird populations in a fragmented landscape. Conservation Biology 13:58-66.

Robinson, S.K., and W.D. Robinson. 2001. Avian nesting success in a selectively harvested north temperate deciduous forest. Conservation Biology 15:1763-1771.

Rodewald, A.D. 2002. Nest predation in forested regions: landscape and edge effects. Journal of Wildlife Management 66:634-640.

Rodewald, A.D., and R.H. Yahner. 2000. Bird communities associated with harvested hardwood stands containing residual trees. Journal of Wildlife Management 64:924-932.

Rodewald, A.D., and A.C. Vitz. 2005. Edge- and area-sensitivity of shrubland birds. Journal of Wildlife Management 69:681-588.

Rosenberg, K.V., and J.V. Wells. 1995. Importance of geographic areas to neotropical migrant birds in the Northeast. Hadley, MA: USDI Fish and Wildlife Service Report.

Sallabanks, R., E.B. Arnett, and J.M. Marzluff. 2000. An evaluation of research on the effects of timber harvest on bird populations. Wildlife Society Bulletin 28:1144-1155.

Sauer, J.R., J.E. Hines, and J. Fallon. 2008. The North American Breeding Bird Survey, Results and Analysis 1966 - 2007. Version 5.15.2008. USGS Patuxent Wildlife Research Center, Laurel, MD.

Smith, D.M. 1962. The Practice of Silviculture. John Wiley and Sons, Inc., New York.

Smith, D.W. 1995. The southern Appalachian hardwood region. Pages 173-226 in Regional Silviculture of the United States, Third edition, (J.W. Barrett, Ed.). John Wiley and Sons, Inc., New York.

Temple, S.A. 1986. Predicting impacts of habitat fragmentation of forest birds: a comparison of two models. Pages 340-347 in Wildlife 2000: Modeling Habitat Relationships of Terrestrial Vertebrates (J. Verner, M.L. Morrison, and C.J. Ralph, Eds.). University of Wisconsin Press. Madison.

Thompson, F.R., III, W.D. Dijak, T.G. Kulowiec, and D.A. Hamilton. 1992. Effects of evenaged forest management on breeding bird densities. Journal of Wildlife Management 56:23-29.

Vega Rivera, J.H., J.H. Rappole, W.J. McShea, and C.A. Haas. 1998. Wood thrush postfledgling movements and habitat use in northern Virginia. Condor 100:69-78. 
Weakland, C.A. 2000. Effects of diameter-limit and two-age timber harvesting on songbird populations on an industrial forest in central West Virginia. PhD dissertation. West Virginia University, Morgantown.

Weakland, C.A., P.B. Wood, and W.M. Ford. 2002. Responses of songbirds to diameter-limit cutting in the central Appalachians of West Virginia, USA. Forest Ecology and Management 155:115-129.

West Virginia Department of Commerce. 2010. Wood products. [Online.] Available at www.wvcommerce.org/business/industries/woodproducts/default.aspx.

Whitcomb, R.F., C.S. Robbins, J.F. Lynch, B.L. Klimkiewicz, and D. Bystrak. 1981. Effects of forest fragmentation on avifauna of the eastern deciduous forest. Pages 125-205 in Forest Island Dynamics in Man-dominated Landscapes (R.L. Burgess and D.M. Sharpe (Eds.). SpringerVerlag, New York.

Widmann, R.H., B.J. Butler, and G.W. Cook. 2010. West Virginia's forest resources, 2008. Research Note NRS-61. Newtown Square, PA: U.S. Department of Agriculture, Forest Service, Northern Research Station.

Williams Jr., G.E. 2002. Relations of nesting behavior, nest predators, and nesting success of wood thrush (Hylocichla mustelina) to habitat characteristics at multiple scales. PhD dissertation. West Virginia University, Morgantown. 


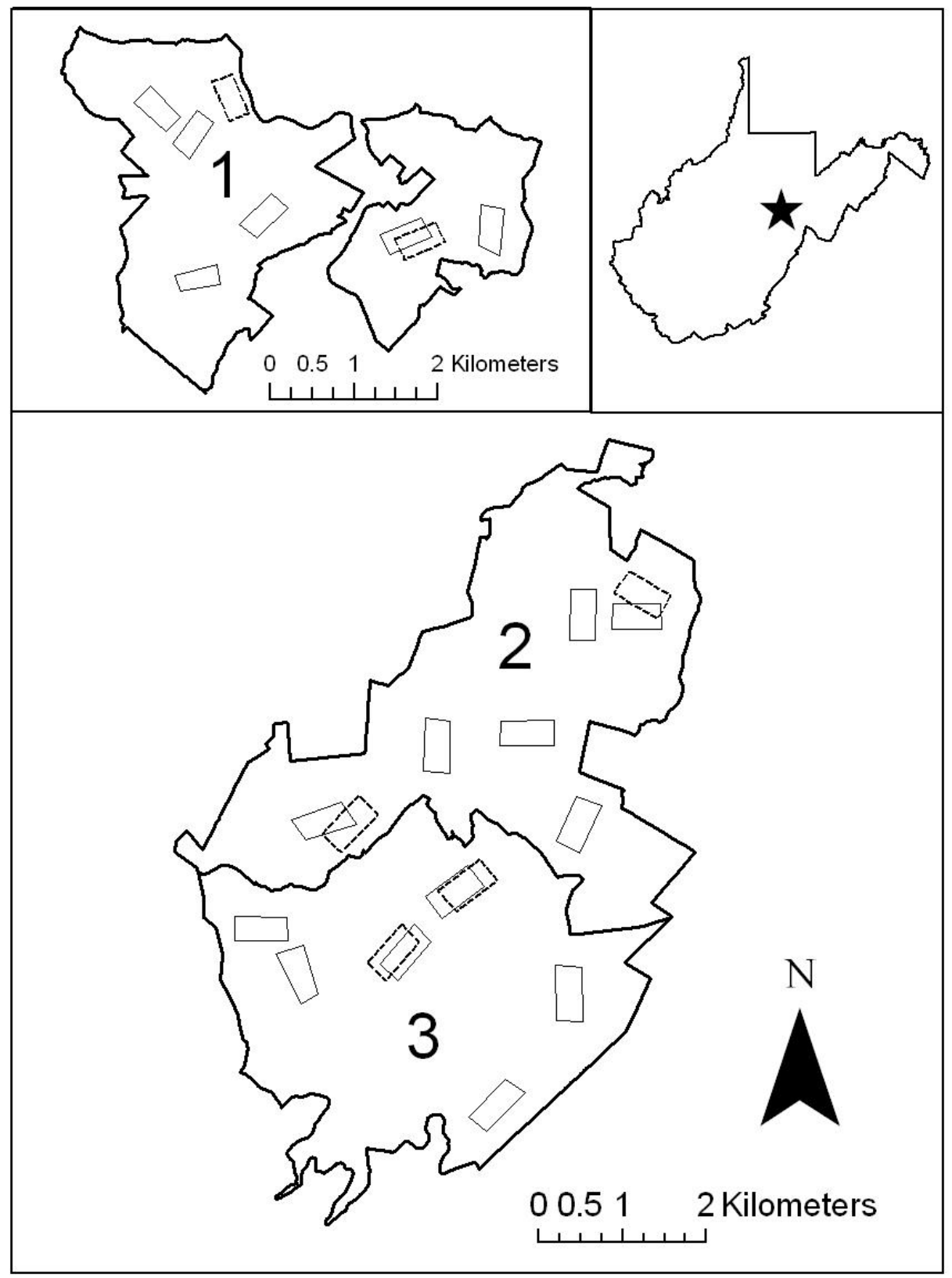

Figure 1. Landscape blocks and nest searching plots (dashed plots were shifted due to timber harvests) within the Wildlife and Ecosystem Research Forest (lower) and Panther Run Tract (upper left), WV. 

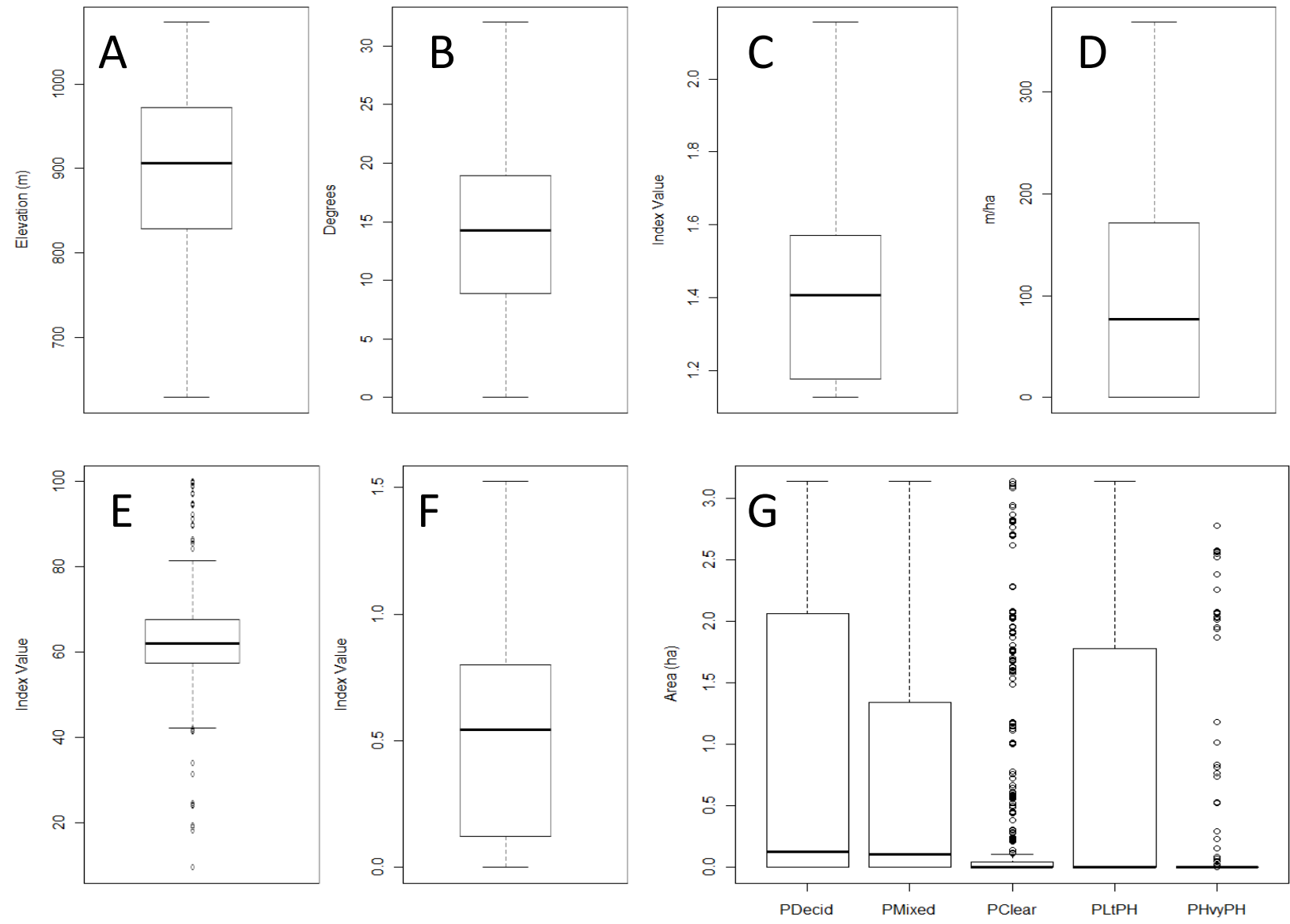

Figure 2. Local-scale boxplot results at point count locations $(\mathrm{n}=1270)$ for A) elevation and B) degree slope and within $100 \mathrm{~m}$ of plot center for C) area-weighted mean shape index, D) contrast-weighted edge density, E) interspersion-juxtaposition, F) Shannon diversity index, and G) the area of five landcover types (mature deciduous, mature mixed, clear-cut, light partial harvest, and heavy partial harvest) at the Wildlife and Ecosystem Research Forest and Panther Run Tract (combined) for entire study period, 1996 - 2009. The central line of the boxplot measures the median for each variable, while the ends of the box are the first and third quartiles. The whiskers on each boxplot extend to 1.5 times the interquartile range with dots representing values further than this cutoff. 

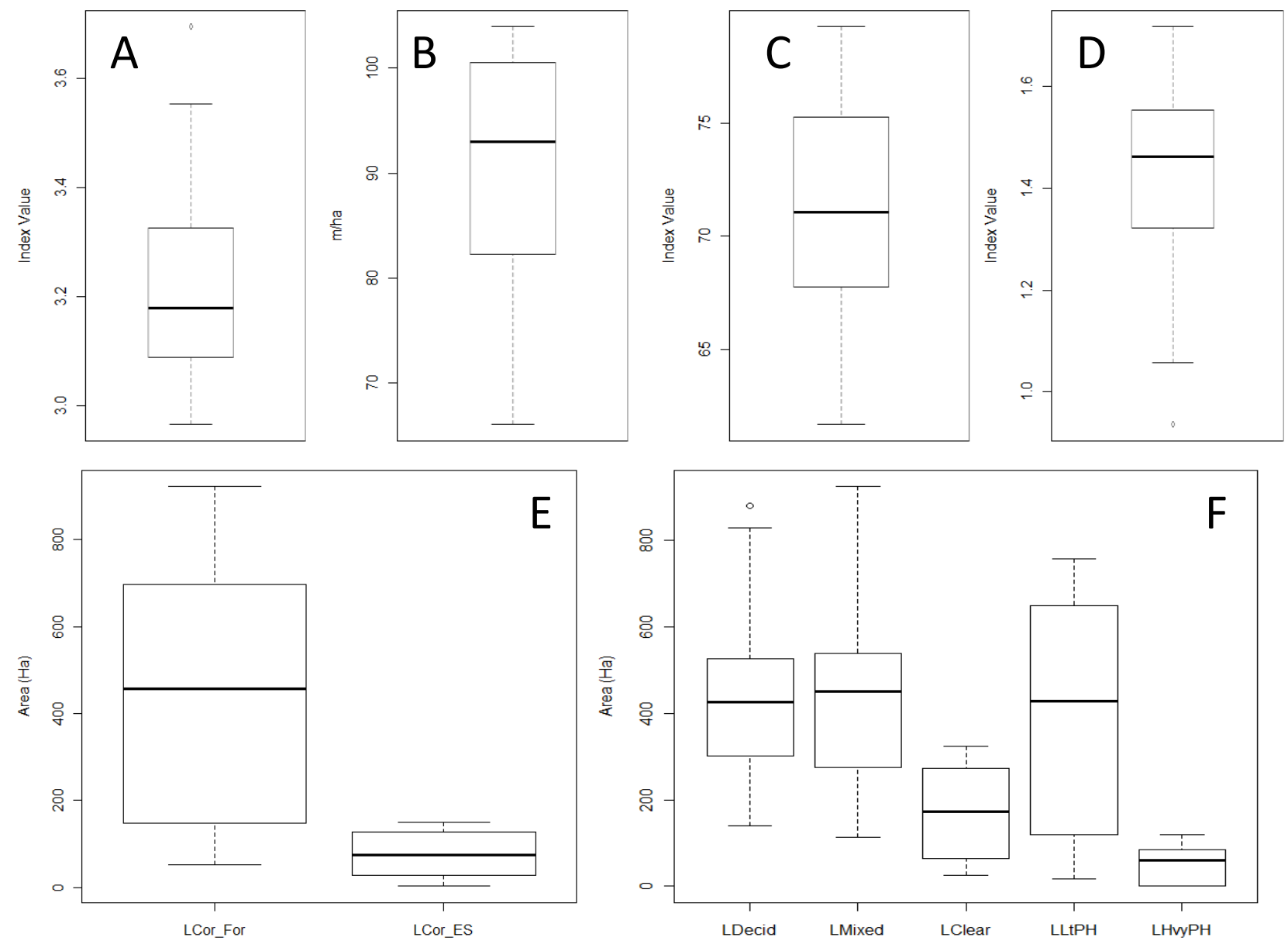

Figure 3. Landscape-scale boxplot results for A) area-weighted mean shape index, B) contrast-weighted edge density, C)

interspersion-juxtaposition, D) Shannon diversity index, E) the area of core mature forest and core early succession, and F) the area of five landcover types (mature deciduous, mature mixed, clear-cut, light partial harvest, and heavy partial harvest) at the Wildlife and Ecosystem Research Forest and Panther Run Tract (combined) for entire study period, 1996 - 2009. The central line of the boxplot measures the median for each variable, while the ends of the box are the first and third quartiles. The whiskers on each boxplot extend to 1.5 times the interquartile range with dots representing values further than this cutoff. 


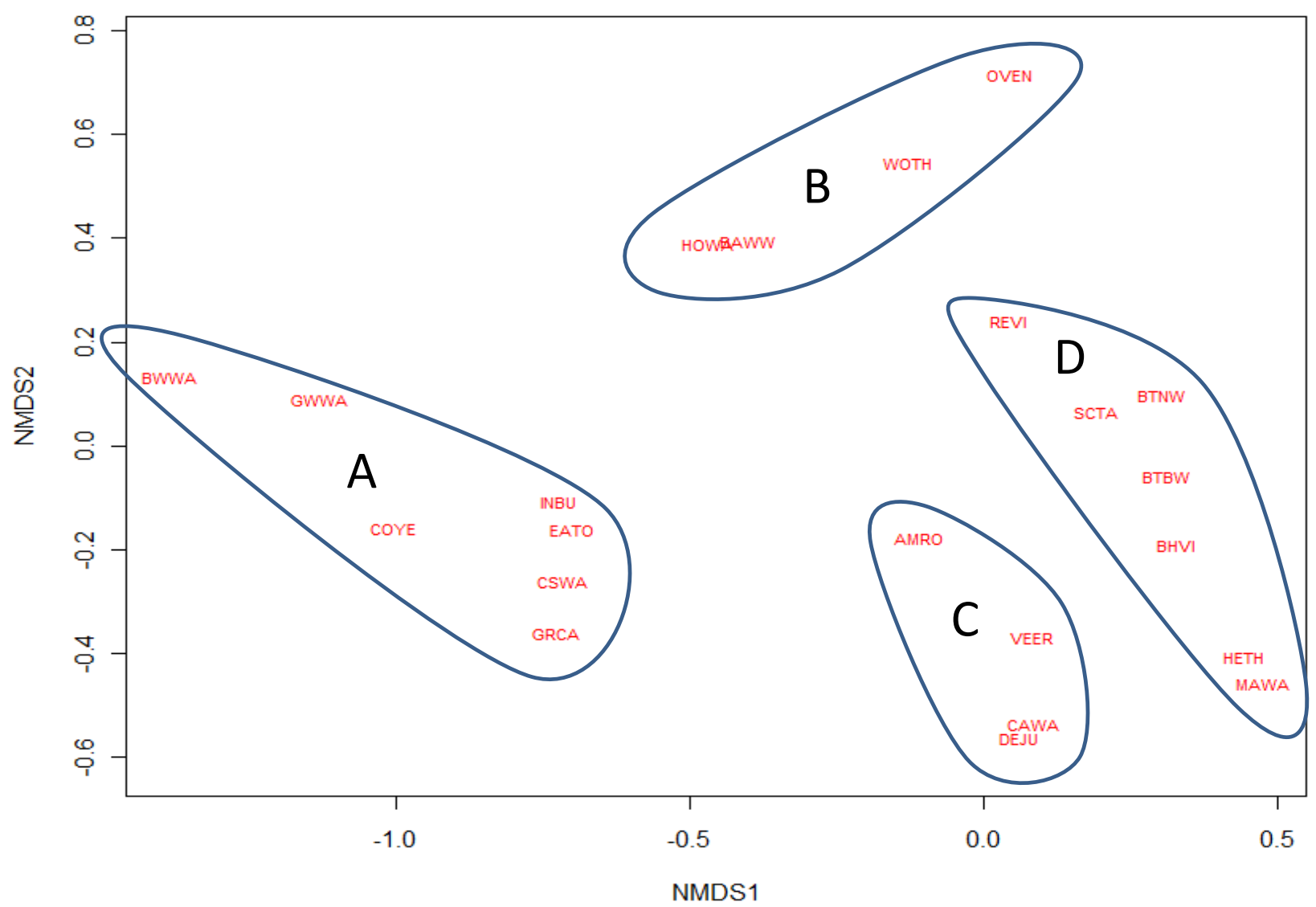

Figure 4. Groupings of selected bird species A) early succession, B) low elevation disturbance, C), high elevation disturbance D), mature forest as a result of NMDS $(\mathrm{k}=3)$ at the Wildlife and Ecosystem Research Forest and Panther Run Tract. 

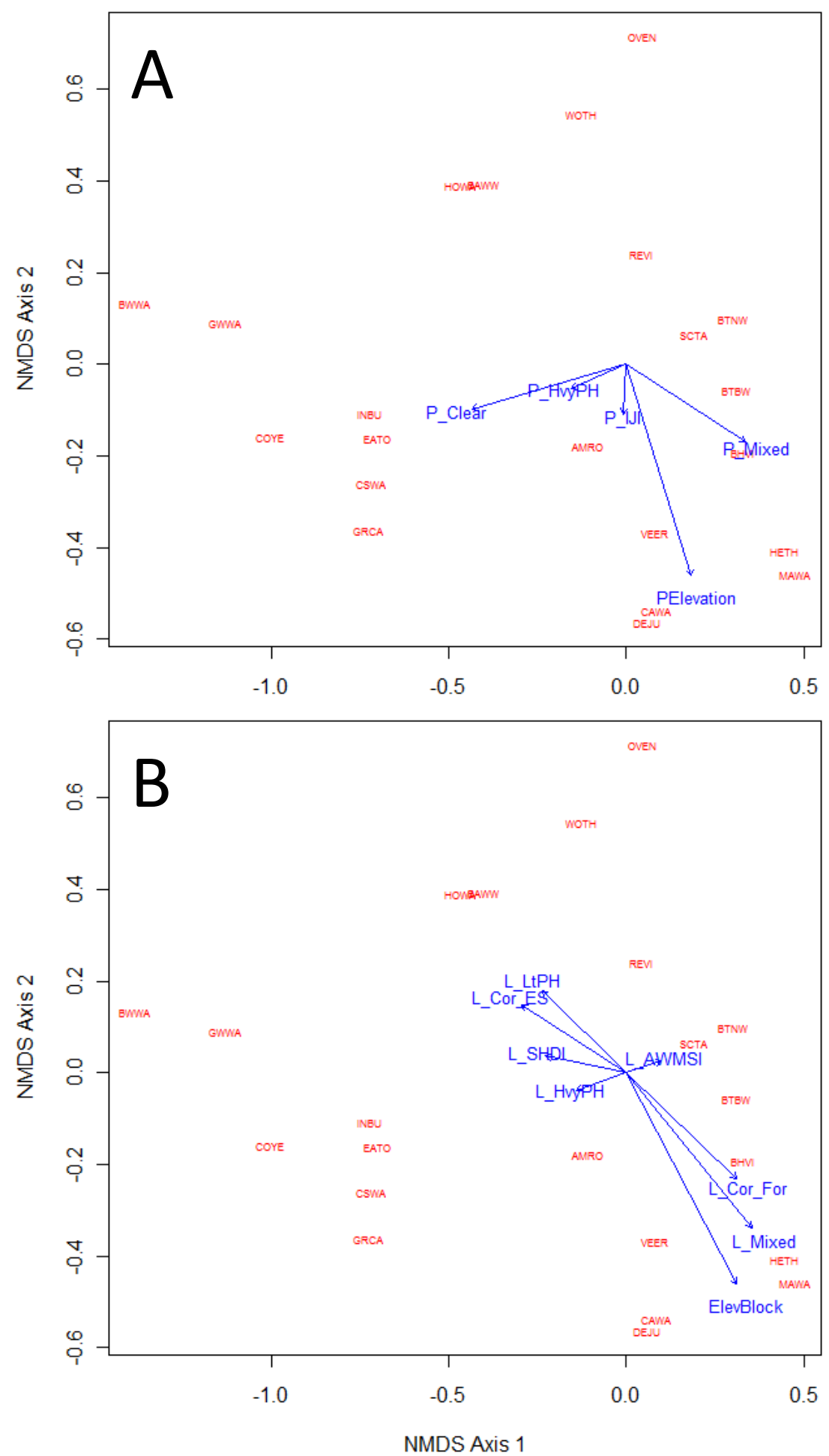

Figure 5. Linear vector fitting for landscape pattern metrics and landcover on the first two axes of NMDS ordination ( $\mathrm{k}=3)$ at the A) local and $\mathrm{B}$ ) landscape scales. Variables with $\mathrm{p} \leq 0.05$ are plotted. 


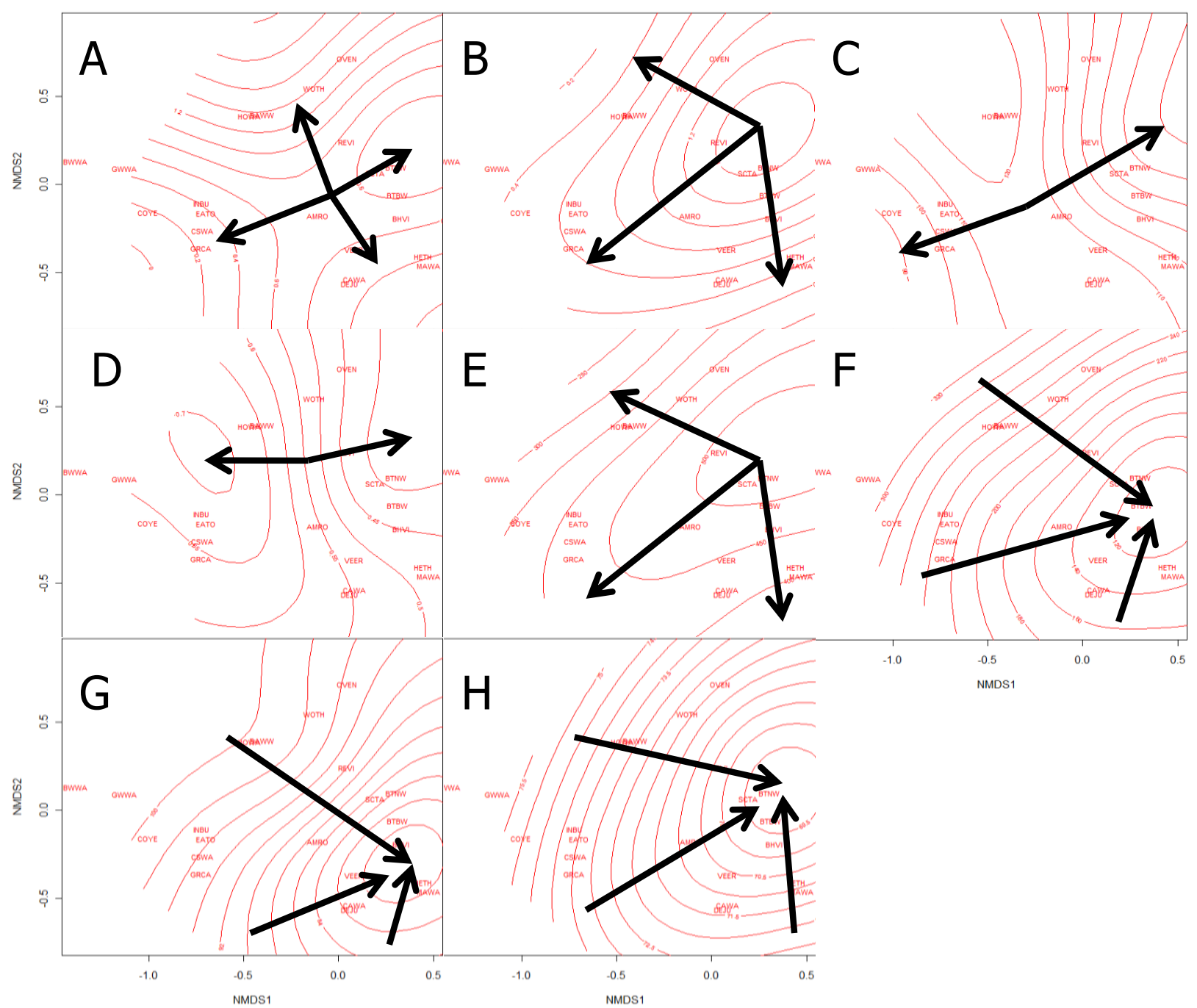

Figure 6. Smoothed curves on the NMDS ordination $(\mathrm{k}=3)$ for non-linear metrics and landcover at the local scale [A) light partial harvest, B) mature deciduous, C) contrast weighted edge density, and D) Shannon diversity] and at the landscape scale [E) mature deciduous, F) clear-cut, $\mathrm{G})$ contrast-weighted edge density, and $\mathrm{H}$ ) interspersion-juxtaposition. Arrows point from higher values to lower values. 
Table 1. Regression tree results identifying landscape pattern metrics and landcover types influencing a change in relative abundance of traditional habitat guilds and NMDS ordination habitat groups at the Wildlife and Ecosystem Research Forest from 1996-2009.

\begin{tabular}{|c|c|c|c|c|}
\hline Species & Model & Landcover and landscape pattern metrics ${ }^{\mathrm{a}, \mathrm{b}}$ & Error & $\begin{array}{l}\mathrm{CV} \\
\text { Error }\end{array}$ \\
\hline \multicolumn{5}{|l|}{ Habitat Guild } \\
\hline \multirow[t]{3}{*}{ Early Succession } & Landscape & Mixed (-418.1 ha; 2.5) & 0.91 & 0.92 \\
\hline & Local & Clear (+0.77 ha; 4.6), HvyPH (+0.52 ha; 3.8$)$ & 0.64 & 0.67 \\
\hline & Combined & P_Clear (+0.77 ha; 4.6), P_HvyPH (+0.52 ha; 3.8) & 0.64 & 0.68 \\
\hline \multirow[t]{3}{*}{ Interior-edge } & Landscape & $\begin{array}{l}\text { SHDI (+1.41; 1.4), IJI (-72.4; 1.3), Clear (-137.2 ha; 1.3), CWED (-92 m/ha; } 1.6) \text {, } \\
\text { SHDI }(+1.72 ; 1.7)\end{array}$ & 0.82 & 0.85 \\
\hline & Local & LtPH (+2.44 ha; 1.3), CWED (+155.3 m/ha; 1.2) & 0.97 & 0.99 \\
\hline & Combined & L_SHDI (+1.41; 1.4), L_IJI (-72.4; 1.3), L_Clear $(-137.2 ; 1.3)$ & 0.87 & 0.91 \\
\hline \multirow[t]{3}{*}{ Forest-interior } & Landscape & IJI $(-72.4 ; 1.5)$, SHDI $(+1.45 ; 1.3,-1.49 ; 1.3)$ & 0.89 & 0.91 \\
\hline & Local & Clear (-0.77 ha; 2.3), Elev (+917.5 m; 1.3) & 0.86 & 0.88 \\
\hline & Combined & P_Clear (-0.77 ha; 2.3), Elev (+917.5; 1.3), L_AWMSI $(-3.16 ; 1.4)$ & 0.83 & 0.87 \\
\hline \multicolumn{5}{|l|}{ NMDS Group } \\
\hline \multirow[t]{3}{*}{ Early Succession } & Landscape & Mixed (-418.1 ha; 2.5$)$ & 0.91 & 0.92 \\
\hline & Local & Clear (+0.77 ha; 4.6), HvyPH (+0.52 ha; 3.8$)$ & 0.64 & 0.67 \\
\hline & Combined & P_Clear (+0.77 ha; 4.6), P_HvyPH (+0.52 ha; 3.8) & 0.64 & 0.68 \\
\hline \multirow{3}{*}{$\begin{array}{l}\text { Low Elev. Mat. Dist. } \\
\text { Forest }\end{array}$} & Landscape & Mixed (-299.3 ha; 3.4), CWED (+102.2 m/ha; 1.7), Block $(-2.5 ; 2.6)$ & 0.66 & 0.69 \\
\hline & Local & Elevation (-844.5 m; 2.6), Mixed (-0.003 ha; 1.9), LtPH (+2.38 ha; 1.6) & 0.78 & 0.84 \\
\hline & Combined & L_Mixed (-299.3 ha; 3.4), LCWED (+102.2 m/ha; 1.7), Block $(-2.5 ; 2.6)$ & 0.66 & 0.69 \\
\hline \multirow{3}{*}{$\begin{array}{l}\text { High Elev. Mat. Dist. } \\
\text { Forest }\end{array}$} & Landscape & Mixed (+208.5 ha; 4.0), LtPH(+482.3 ha; 1.6$),$ AWMSI $(-3.15 ; 1.6)$ & 0.78 & 0.78 \\
\hline & Local & Elevation $(+948.5 \mathrm{~m} ; 1.9,+837 \mathrm{~m} ; 2.2)$ & 0.85 & 0.87 \\
\hline & Combined & L_Mixed (+208.5 ha; 4.0), L_LtPH(+482.3 ha; 1.6), L_AWMSI $(-3.15 ; 1.6)$ & 0.78 & 0.79 \\
\hline \multirow{3}{*}{$\begin{array}{l}\text { Undisturbed Mature } \\
\text { Forest }\end{array}$} & Landscape & Cor_ES $(-88.1$ ha; 1.7$)$, SHDI $(+1.45 ; 1.5)$ & 0.78 & 0.82 \\
\hline & Local & Clear (-0.45 ha; 2.0), Elevation (+862 m; 1.4) & 0.84 & 0.88 \\
\hline & Combined & L_Cor_ES (-88.1 ha; 1.7), L_SHDI (+1.45; 1.5), P_Clear (-0.88 ha; $2.2,-0.51$ ha; 2.1$)$ & 0.71 & 0.74 \\
\hline
\end{tabular}

\footnotetext{
${ }^{a}$ Variables are listed in order with the first variable explaining the most variation, + and - indicate the direction of the relation in relative to higher relative abundance, the first value in parentheses is the cutoff value for the branch while the second is factor by which abundance is increased (ex. 2.5 means the higher abundance is 2.5 times greater than the lower abundance)

${ }^{\mathrm{b}}$ Variables with the prefix $\mathrm{L}$ are landscape variables and the prefix $\mathrm{P}$ are local variables
} 
Table 2. Regression tree results identifying landscape pattern metrics and landcover types influencing a change in relative abundance of focal bird species at the Wildlife and Ecosystem Research Forest from 1996-2009.

\begin{tabular}{|c|c|c|c|c|}
\hline Species $^{\mathrm{a}}$ & Model & Landcover and landscape pattern metrics ${ }^{\mathrm{b}}$ & $\begin{array}{c}\text { Erro } \\
\mathrm{r} \\
\end{array}$ & $\begin{array}{c}\mathrm{CV} \\
\text { Error } \\
\end{array}$ \\
\hline \multicolumn{5}{|c|}{ Undisturbed Mature Forest } \\
\hline \multirow[t]{3}{*}{$\mathrm{BHVI}^{\mathrm{FI}}$} & Landscape & 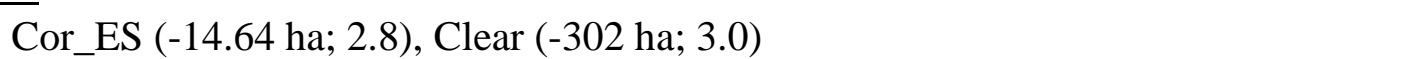 & 0.97 & 0.89 \\
\hline & Local & Elevation (+875 m; 2.2), Clear (-0.004 ha; 1.6$)$ & - & - \\
\hline & Combined $^{c}$ & L_Cor_ES (-14.64 ha; 2.8), Elevation (+875 m; 2.1) & 0.86 & 0.89 \\
\hline \multirow[t]{3}{*}{$\mathrm{BTBW}^{\mathrm{FI}}$} & Landscape & Mixed (+208.5 ha; 4.4) & 0.96 & 0.97 \\
\hline & Local & CWED (-15.85 m/ha; 2.4) & 0.95 & 1.00 \\
\hline & Combined & P_CWED $(-15.85 \mathrm{~m} / \mathrm{ha} ; 2.4)$, DegSlope $\left(+22.29^{\circ} ; 2.4\right)$ & 0.91 & 1.00 \\
\hline \multirow[t]{3}{*}{$\mathrm{BTNW}^{\mathrm{FI}}$} & Landscape & SHDI $(+1.45 ; 1.8)$, IJI $(-72.4 ; 1.8)$, Clear $(-324.6$ ha; 3.0$)$ & 0.90 & 0.92 \\
\hline & Local & Clear (-0.45 ha; 3.2), Elevation (+997 m; 1.8) & 0.89 & 0.91 \\
\hline & Combined & $\begin{array}{l}\text { P_Clear }(-0.45 \text { ha; } 3.2) \text {, Elevation }(+997 \mathrm{~m} ; 1.8), \text { L_SHDI }(+1.447 ; 1.8) \text {, } \\
\text { L_Cor_ES }(-122.7 \mathrm{ha} ; 1.8)\end{array}$ & 0.83 & 0.87 \\
\hline \multirow[t]{3}{*}{$\mathrm{HETH}^{\mathrm{FI}}$} & Landscape & CWED (-93.61 m/ha; 4.6), AWMSI $(-3.12 ; 2.4)$ & 0.96 & 1.00 \\
\hline & Local & IJI (+90.45; 8.6), DegSlope $\left(-11.31^{\circ} ; 3.8\right)$, Elevation (+1017 m; 8.2) & 0.84 & 1.15 \\
\hline & Combined & P_IJI (+90.45; 8.6), DegSlope $\left(-11.31^{\circ} ; 3.8\right)$, Elevation (+1017 m; 8.2) & 0.84 & 1.15 \\
\hline \multirow[t]{3}{*}{$\operatorname{MAWA}^{\mathrm{F}}$} & Landscape & Block $(+2.5 ; 4.7)$, AWMSI $(-3.15 ; 2.2)$ & 0.85 & 0.86 \\
\hline & Local & Mixed $(+1.06 ; 3.7)$ & 0.91 & 1.02 \\
\hline & Combined & Block (+2.5; 4.6), P_Decid (-0.32 ha; 4.0), L_AWMSI $(-3.15 ; 2.2)$ & 0.78 & 0.84 \\
\hline \multirow[t]{3}{*}{$\mathrm{REVI}^{\mathrm{IE}}$} & Landscape & Cor_ES $(-122.7 \mathrm{ha} ; 1.5,+14.64 ; 1.7), \mathrm{IJI}(-78.6 ; 1.8)$ & 0.90 & 0.93 \\
\hline & Local & IJI (+45.5; 4.0), Decid (+2.05 ha; 1.3$)$ & 0.80 & 1.02 \\
\hline & Combined & P_IJI (-9.60; 2.7), L_Cor_ES $(-122.7$ ha; $1.5,+14.64 ; 1.8)$, P_Decid $(+1.26$ ha; 1.2$)$ & 0.79 & 1.54 \\
\hline \multirow[t]{3}{*}{$\operatorname{SCTA}^{\mathrm{FI}}$} & Landscape & IJI $(-72.4 ; 2.2)$, AWMSI $(-3.14 ; 1.8)$ & 0.93 & 0.95 \\
\hline & Local & Clear $(-0.56$ ha; 2.3$)$ & 0.98 & 1.02 \\
\hline & Combined & L_IJI $(-72.4 ; 2.2)$, L_AWMSI $(-3.14 ; 1.8)$ & 0.93 & 0.96 \\
\hline
\end{tabular}


Table 2. Continued

\begin{tabular}{|c|c|c|c|c|}
\hline Species & Model & Landcover and landscape pattern metrics & Error & $\begin{array}{l}\mathrm{CV} \\
\text { Error }\end{array}$ \\
\hline \multicolumn{5}{|c|}{ Low Elevation Disturbed Forest } \\
\hline \multirow[t]{3}{*}{$\mathrm{BAWW}^{\mathrm{FI}}$} & Landscape & Block (-2.5; 4.8), LtPH (+222.5 ha; 1.9), CWED (+103.4 m/ha; 1.5) & 0.86 & 0.90 \\
\hline & Local & Elevation $(-798 \mathrm{~m} ; 4.8)$ & 0.95 & 1.54 \\
\hline & Combined & $\begin{array}{l}\text { Block (-2.5; 4.8), L_LtPH (+222.5 ha; 1.9), L_CWED (+103.4 m/ha; } 2.2) \text {, } \\
\text { Elevation }(-723 \mathrm{~m} ; 1.8,+676.6 \mathrm{~m} ; 3.2)\end{array}$ & 0.84 & 0.90 \\
\hline \multirow[t]{3}{*}{ HOWA $^{\mathrm{IE}}$} & Landscape & $\begin{array}{l}\text { LtPH (+707.6 ha; 4.0), Mixed (-299.3 ha; 2.9), CWED (+103.8 m/ha; 1.6), AWMSI (-3.08; } \\
\text { 2.5) }\end{array}$ & 0.76 & 0.79 \\
\hline & Local & Elevation (-858.5 m; 2.9), Mixed (-0.003 ha; 2.4) & 0.91 & 1.04 \\
\hline & Combined & L_LtPH (+707.6 ha; 4.0), L_Mixed (-299.3 ha; 2.9) & 0.79 & 0.83 \\
\hline \multirow[t]{3}{*}{$\mathrm{OVEN}^{\mathrm{FI}}$} & Landscape & Mixed $(-208.5 \mathrm{ha} ; 3.5)$ & 0.90 & 0.91 \\
\hline & Local & LtPH (+2.42 ha; 3.0), Elevation $(-840.5 \mathrm{~m} ; 2.5)$ & 0.89 & 0.97 \\
\hline & Combined & L_Mixed (-208.5 ha; 3.5), P_LtPH (+2.42 ha; 2.2), P_Decid (+0.24 ha; 2.3$)$ & 0.87 & 0.93 \\
\hline \multirow[t]{3}{*}{$\mathrm{WOTH}^{\mathrm{IE}}$} & Landscape & Mixed (-299.3 ha; 3.8) & 0.93 & 0.93 \\
\hline & Local & Elevation (-835 m; 3.4), IJI (-61.79; 2.2), LtPH (+2.23 ha; 4.2), Decid (+0.51 ha; 2.1) & 0.94 & 0.96 \\
\hline & Combined & P_IJI (+98.04; 9.1), L_Mixed (-299.3 ha; 3.5), P_Decid (+3.14 ha; 3.4) & 0.93 & 0.99 \\
\hline \multicolumn{5}{|c|}{ High Elevation Disturbed Forest } \\
\hline \multirow[t]{3}{*}{$\mathrm{AMRO}^{\mathrm{IE}}$} & Landscape & Decid (-367.2 ha; 2.7), AWMSI $(-3.17 ; 2.4)$ & 0.94 & 0.96 \\
\hline & Local & IJI (+75.6; 4.0), Elevation (+991.5 m; 3.8), SHDI (+0.91; 1.9) & 0.79 & 1.83 \\
\hline & Combined & P_IJI (+89.34; 8.0), Elevation (+991.5 m; 3.6), L_AWMSI $(-3.14 ; 2.0)$ & 0.83 & 1.60 \\
\hline \multirow[t]{3}{*}{$\mathrm{CAWA}^{\mathrm{IE}}$} & Landscape & Mixed (+529 ha; 4.0), AWMSI $(-3.28 ; 28.5)$ & 0.87 & 0.89 \\
\hline & Local & Elevation $(+824 ; 8.1)$ & 0.95 & 0.97 \\
\hline & Combined & $\begin{array}{l}\text { L_Mixed (+529 ha; 4.0), DegSlope }\left(+23.68^{\circ} ; 3.2\right), \text { L_AWMSI }(-3.28 ; 40.8), \text { P_CWED } \\
(+112.7 \mathrm{~m} / \mathrm{ha} ; 2.0), \text { P_LtPH }(+2.65 \text { ha; } 3.3)\end{array}$ & 0.75 & 0.83 \\
\hline \multirow[t]{3}{*}{ DEJU ${ }^{\mathrm{IE}}$} & Landscape & AWMSI $(-3.14 ; 2.6,+3.10 ; 2.2)$, Block $(+2.5 ; 4.4)$, CWED $(-98.69 \mathrm{~m} / \mathrm{ha} ; 1.9)$ & 0.77 & 0.79 \\
\hline & Local & Elevation (+947 m; 2.2), IJI (+75.08; 2.5), CWED (+43.61 m/ha; 1.5), SHDI (+0.53; 1.4) & 0.92 & 0.97 \\
\hline & Combined & L_AWMSI $(-3.14 ; 2.6)$, Elevation $(+945 \mathrm{~m} ; 2.2)$, Block $(+2.5 ; 4.4)$ & 0.82 & 0.86 \\
\hline \multirow[t]{3}{*}{$\mathrm{VEER}^{\mathrm{IE}}$} & Landscape & Clear (-279.4 ha; 9.3), Decid (-345 ha; 1.6), LtPH (-253.2 ha; 1.8) & 0.89 & 0.92 \\
\hline & Local & Elevation $(+837 \mathrm{~m} ; 3.2)$ & 0.94 & 0.95 \\
\hline & Combined & L_Clear (-279.4 ha; 9.3), L_Decid (-345 ha; 1.6) & 0.90 & 0.92 \\
\hline
\end{tabular}


Table 2. Continued

\begin{tabular}{|c|c|c|c|c|}
\hline Species & Model & Landcover and landscape pattern metrics & Error & $\begin{array}{l}\mathrm{CV} \\
\text { Error }\end{array}$ \\
\hline \multicolumn{5}{|c|}{ Early Succession } \\
\hline \multirow[t]{3}{*}{$\underset{\mathrm{S}}{\mathrm{BWWA}^{\mathrm{E}}}$} & Landscape & Mixed (-114.3 ha; 13.5$)$ & 0.99 & 1.01 \\
\hline & Local & Clear (+1.81 ha; 71.6) & 0.85 & 1.48 \\
\hline & Combined & P_Clear (+1.81 ha; 71.6) & 0.85 & 1.48 \\
\hline \multirow[t]{3}{*}{$\mathrm{COYE}^{\mathrm{ES}}$} & Landscape & SHDI (+1.72; 6.2), Mixed (-418.1 ha; 5.6) & 0.95 & 0.99 \\
\hline & Local & Clear (+1.81 ha; 12.5$)$, Elevation $(-813 \mathrm{~m} ; 2.6)$ & 0.89 & 1.07 \\
\hline & Combined & P_Clear $(+1.81$ ha; 1.8$)$, P_HvyPH (+2.14 ha; 18.0$),$ L_SHDI $(+1.72 ; 11.8)$ & 0.89 & 1.09 \\
\hline \multirow[t]{3}{*}{$\operatorname{CSWA}^{\mathrm{ES}}$} & Landscape & Clear (+127.5 ha; 2.5), CWED (+102.9 m/ha; 1.6) & 0.95 & 0.97 \\
\hline & Local & Clear (+0.74 ha; 4.5) & 0.80 & 0.81 \\
\hline & Combined & P_Clear (+0.74 ha; 4.5), P_HvyPH (+0.83 ha; 4.4) & 0.76 & 0.80 \\
\hline \multirow[t]{3}{*}{ EATO $^{\mathrm{ES}}$} & Landscape & Mixed (-388.6 ha; 3.7), Clear (-324.5 ha; 2.1) & 0.88 & 0.89 \\
\hline & Local & Clear $(+0.45$ ha; 3.7$)$ & 0.88 & 0.93 \\
\hline & Combined & P_Clear (+0.45 ha; 3.7), L_CWED (+102.9 m/ha; 2.3$)$ & 0.84 & 0.89 \\
\hline \multirow[t]{3}{*}{$\mathrm{GRCA}^{\mathrm{ES}}$} & Landscape & HvyPH (+62.11 ha; 2.8$)$ & 0.99 & 1.00 \\
\hline & Local & Clear (+0.77 ha; 8.2), AWMSI (+1.78; 5.2), HvyPH (+2.02 ha; 12.5$)$ & 0.86 & 0.97 \\
\hline & Combined & P_Clear (+0.77 ha; 8.0), P_AWMSI (+1.78; 5.2), L_IJI $(-66.53 ; 3.3)$ & 0.86 & 0.98 \\
\hline \multirow[t]{3}{*}{$\mathrm{GWWA}_{\mathrm{S}}^{\mathrm{E}}$} & Landscape & CWED (+99.3 m/ha; 14.6) & 0.98 & 1.00 \\
\hline & Local & Clear (+1.81 ha; 20.4), LtPH (+0.46 ha, 4.6) & - & - \\
\hline & Combined & L_IJI (-71.42; 4.7), L_CWED (+99.3 m/ha; 16.1), P_Clear (+1.81 ha; 20.5) & 0.79 & 1.15 \\
\hline \multirow[t]{3}{*}{$\mathrm{INBU}^{\mathrm{ES}}$} & Landscape & CWED (+87.86 m/ha; $3.0,+102.9 \mathrm{~m} / \mathrm{ha} ; 1.7)$ & 0.92 & 0.94 \\
\hline & Local & Clear (+1.18 ha; 4.9) & 0.78 & 0.79 \\
\hline & Combined & P_Clear (+1.18 ha; 4.9), L_CWED (+103.4 m/ha; $2.1,+102.9$ m/ha; 2.9) & 0.72 & 0.75 \\
\hline
\end{tabular}

${ }^{\mathrm{a}}$ Superscript identifies traditional habitat guild (FI=forest-interior, $\mathrm{IE}=$ interior-edge, $\mathrm{ES}=$ early succession)

${ }^{\mathrm{b}}$ Variables are listed in order with the first variable explaining the most variation, + and - indicate the direction of the relation relative to higher relative abundance, the first value in parentheses is the cutoff value for the branch while the second is the factor by which abundance is increased (ex. 2.8 means the higher abundance is 2.8 times greater than the lower abundance)

${ }^{\mathrm{c}}$ Variables with the prefix $\mathrm{L}$ are landscape variables and the prefix $\mathrm{P}$ are local variables 
Table 3. Classification tree results identifying landscape pattern metrics and landcover types distinguishing successful and unsuccessful nests of NMDS ordination habitat groups at the Wildlife and Ecosystem Research Forest from 2001-2009.

\begin{tabular}{|c|c|c|c|c|c|c|c|c|}
\hline \multirow[b]{2}{*}{ Group $^{c}$} & \multirow[b]{2}{*}{$\mathrm{N}$} & \multirow[b]{2}{*}{ Model } & \multirow[b]{2}{*}{ Landcover and landscape pattern metrics ${ }^{\mathrm{a}}$} & \multicolumn{3}{|c|}{ Missclass Rates } & \multirow[b]{2}{*}{ Error } & \multirow{2}{*}{$\begin{array}{l}\mathrm{CV} \\
\text { Error }\end{array}$} \\
\hline & & & & Null & Model & $\mathrm{CV}$ & & \\
\hline \multirow[t]{3}{*}{ Undisturbed Mature Forest } & 58 & Landscape & CWED (+94.1 m/ha), LtPH (+222.5 ha) & 0.38 & 0.24 & 0.35 & 0.64 & 0.91 \\
\hline & & Local & SHDI $(-3.1)$ & 0.38 & 0.28 & 0.40 & 0.73 & 1.05 \\
\hline & & Combined $^{\mathrm{b}}$ & L_CWED (+94.1m/ha) & 0.38 & 0.26 & 0.42 & 0.68 & 1.10 \\
\hline \multirow[t]{3}{*}{ High Elev. Disturbed For. } & 140 & Landscape & Decid (-156.1 ha) & 0.42 & 0.40 & 0.49 & 0.95 & 1.15 \\
\hline & & Local & Mixed (-0.06 ha) & 0.42 & 0.16 & 0.55 & 0.37 & 1.30 \\
\hline & & Combined & P_Mixed (-0.06 ha) & 0.42 & 0.15 & 0.54 & 0.36 & 1.27 \\
\hline \multirow[t]{3}{*}{ Low Elev. Disturbed For. } & 69 & Landscape & IJI (-70.7), Decid (-404 ha) & 0.28 & 0.25 & 0.34 & 0.90 & 1.23 \\
\hline & & Local & Decid (-1.51 ha), CWED (+133.2 m/ha) & 0.28 & 0.15 & 0.46 & 0.53 & 1.67 \\
\hline & & Combined & L_AWMSI (-3.24), P_CWED $(-162,+133 \mathrm{~m} / \mathrm{ha})$ & 0.28 & 0.15 & 0.39 & 0.53 & 1.40 \\
\hline \multirow[t]{3}{*}{ Early Succession } & 148 & Landscape & Decid (-322 ha), AWMSI (+3.33) & 0.47 & 0.43 & 0.58 & 0.91 & 1.25 \\
\hline & & Local & $\mathrm{IJI}(+58.2)$ & 0.47 & 0.29 & 0.47 & 0.62 & 1.00 \\
\hline & & Combined & P_IJI (+58.2) & 0.47 & 0.29 & 0.47 & 0.62 & 1.00 \\
\hline
\end{tabular}

${ }^{\mathrm{a}}$ Variables are listed in order with the first variable explaining the most variation, + and - indicate the direction of the relationship in relation to successful nests, the value in parentheses is the cutoff value for the branch

${ }^{\mathrm{b}}$ Variables with the prefix $\mathrm{L}$ are landscape variables and the prefix $\mathrm{P}$ are local variables

'Group members: Early Succession (BWWA, COYE, CSWA, EATO, GRCA, GWWA, INBU), Low Elevation Disturbed (BAWW, HOWA, OVEN, WOTH), High Elevation Disturbed (AMRO, CAWA, DEJU, VEER), Mature Forest (BHVI, BTBW, BTNW, HETH, MAWA, REVI, SCTA). 
Appendix 1. Bird species detected at the Wildlife and Ecosystem Research Forest, 1996-2009

\begin{tabular}{|c|c|c|c|}
\hline $\mathrm{Name}^{\mathrm{a}}$ & Scientific Name & AOU Code & Habitat Guild ${ }^{\mathrm{b}}$ \\
\hline Acadian Flycatcher ${ }^{\mathrm{a}}$ & Empidonax virescens & ACFL & FI \\
\hline Alder Flycatcher & Empidonax alnorum & ALFL & IE \\
\hline American Crow ${ }^{\mathrm{a}}$ & Corvus brachyrhynchos & AMCR & ES \\
\hline American Goldfinch ${ }^{\mathrm{a}}$ & Spinus tristis & AMGO & ES \\
\hline American Redstart ${ }^{\mathrm{a}}$ & Setophaga ruticilla & AMRE & IE \\
\hline American Robin ${ }^{\mathrm{a}}$ & Turdus migratorius & AMRO & IE \\
\hline Baltimore Oriole & Icterus galbula & BAOR & IE \\
\hline Barred Owl & Strix varia & BDOW & FI \\
\hline Belted Kingfisher & Ceryle alcyon & BEKI & ES \\
\hline Black-and-white Warbler ${ }^{\mathrm{a}}$ & Mniotilta varia & BAWW & FI \\
\hline Black-billed Cuckoo & Coccyzus erythropthalmus & BBCU & IE \\
\hline Blackburnian Warbler $^{\mathrm{a}}$ & Dendroica fusca & BLBW & FI \\
\hline Black-capped Chickadee $^{a}$ & Poecile atricapillus & $\mathrm{BCCH}$ & IE \\
\hline Black-throated Blue Warbler ${ }^{\mathrm{a}}$ & Dendroica caerulescens & BTBW & FI \\
\hline Black-throated Green Warbler & Dendroica virens & BTNW & FI \\
\hline Blue Jay $^{\mathrm{a}}$ & Cyanocitta cristata & BLJA & IE \\
\hline Blue-gray Gnatcatcher & Polioptila caerulea & BGGN & IE \\
\hline Blue-headed Vireo $^{a}$ & Vireo solitarius & BHVI & FI \\
\hline Blue-winged Warbler & Vermivora pinus & BWWA & ES \\
\hline Brewster's Warbler & $\begin{array}{l}\text { Helminthophila } \\
\text { leucobronchialis }\end{array}$ & BRWA & ES \\
\hline Broad-winged Hawk & Buteo platypterus & BWHA & FI \\
\hline Brown Creeper & Certhia familiaris & BRCR & FI \\
\hline Brown Thrasher & Toxostoma rufum & BRTH & ES \\
\hline Brown-headed Cowbird $^{a}$ & Molothrus ater & $\mathrm{BHCO}$ & IE \\
\hline Canada Warbler ${ }^{\mathrm{a}}$ & Wilsonia canadensis & CAWA & IE \\
\hline Carolina Wren & Thryothorus ludovicianus & CAWR & ES \\
\hline Cedar Waxwing $^{\mathrm{a}}$ & Bombycilla cedrorum & CEDW & IE \\
\hline Cerulean Warbler & Dendroica cerulea & CERW & FI \\
\hline Chestnut-sided Warbler ${ }^{a}$ & Dendroica pensylvanica & CSWA & ES \\
\hline Chipping Sparrow & Spizella passerina & CHSP & ES \\
\hline Common Raven & Corvus corax & CORA & FI \\
\hline Common Yellowthroat ${ }^{\mathrm{a}}$ & Geothlypis trichas & COYE & ES \\
\hline Cooper's Hawk & Accipiter cooperii & COHA & IE \\
\hline Dark-eyed Junco $^{\mathrm{a}}$ & Junco hyemalis & DEJU & IE \\
\hline Downy Woodpecker ${ }^{\mathrm{a}}$ & Picoides pubescens & DOWO & IE \\
\hline Eastern Phoebe & Sayornis phoebe & EAPH & ES \\
\hline Eastern Towhee $^{\mathrm{a}}$ & Pipilo erythrophthalmus & EATO & ES \\
\hline
\end{tabular}


Appendix 1. Continued

\begin{tabular}{|c|c|c|c|}
\hline Name & Scientific Name & AOU Code & Habitat Guild \\
\hline Eastern Wood-pewee ${ }^{a}$ & Contopus virens & EAWP & FI \\
\hline Field Sparrow $^{\mathrm{a}}$ & Spizella pusilla & FISP & ES \\
\hline Golden-crowned Kinglet ${ }^{a}$ & Regulus satrapa & GCKI & FI \\
\hline Golden-winged Warbler & Vermivora chrysoptera & GWWA & ES \\
\hline Gray Catbird $^{\mathrm{a}}$ & Dumetella carolinensis & GRCA & ES \\
\hline Great-crested Flycatcher & Myiarchus crinitus & GCFL & $\mathrm{IE}$ \\
\hline Hairy Woodpecker ${ }^{\mathrm{a}}$ & Picoides villosus & HAWO & FI \\
\hline Hermit Thrush ${ }^{\mathrm{a}}$ & Catharus guttatus & HETH & FI \\
\hline Hooded Warbler ${ }^{\mathrm{a}}$ & Wilsonia citrina & HOWA & IE \\
\hline Indigo Bunting $^{\mathrm{a}}$ & Passerina cyanea & INBU & ES \\
\hline Kentucky Warbler & Oporornis formosus & KEWA & FI \\
\hline Least Flycatcher & Empidonax minimus & LEFL & FI \\
\hline Louisiana Waterthrush & Seiurus motacilla & LOWA & FI \\
\hline Magnolia Warbler ${ }^{\mathrm{a}}$ & Dendroica magnolia & MAWA & FI \\
\hline Mourning Dove & Zenaida macroura & MODO & ES \\
\hline Mourning Warbler ${ }^{\mathrm{a}}$ & Oporornis philadelphia & MOWA & ES \\
\hline Nashville Warbler & Vermivora ruficapilla & NAWA & ES \\
\hline Northern Cardinal & Cardinalis cardinalis & NOCA & ES \\
\hline Northern Flicker ${ }^{\mathrm{a}}$ & Colaptes auratus & NOFL & IE \\
\hline Northern Parula & Parula americana & NOPA & IE \\
\hline Northern Waterthrush & Seiurus noveboracensis & NOWA & FI \\
\hline Ovenbird $^{\text {a }}$ & Seiurus aurocapillus & OVEN & FI \\
\hline Pileated Woodpecker ${ }^{\mathrm{a}}$ & Dryocopus pileatus & PIWO & FI \\
\hline Prairie Warbler & Dendroica discolor & PRAW & ES \\
\hline Red-bellied Woodpecker & Melanerpes carolinus & RBWO & IE \\
\hline Red-breasted Nuthatch ${ }^{\mathrm{a}}$ & Sitta canadensis & RBNU & FI \\
\hline Red-eyed Vireo $^{\mathrm{a}}$ & Vireo olivaceus & REVI & IE \\
\hline Red-shouldered Hawk & Buteo lineatus & RSHA & IE \\
\hline Red-tailed Hawk & Buteo jamaicensis & RTHA & $\mathrm{IE}$ \\
\hline Rose-breasted Grosbeak ${ }^{\mathrm{a}}$ & Pheucticus ludovicianus & RBGR & IE \\
\hline Ruby-throated Hummingbird & Archilochus colubris & RTHU & IE \\
\hline Ruffed Grouse & Bonasa umbellus & RUGR & IE \\
\hline Scarlet Tanager ${ }^{\mathrm{a}}$ & Piranga olivacea & SCTA & FI \\
\hline Song Sparrow ${ }^{\mathrm{a}}$ & Melospiza melodia & SOSP & ES \\
\hline Tufted Titmouse $^{a}$ & Baeolophus bicolor & TUTI & IE \\
\hline Turkey Vulture & Cathartes aura & TUVU & ES \\
\hline Veery $^{\mathrm{a}}$ & Catharus fuscescens & VEER & IE \\
\hline White-breasted Nuthatch ${ }^{\mathrm{a}}$ & Sitta carolinensis & WBNU & FI \\
\hline White-eyed Vireo & Vireo griseus & WEVI & ES \\
\hline
\end{tabular}


Appendix 1. Continued

\begin{tabular}{lllc}
\hline Name & Scientific Name & AOU Code & Habitat Guild \\
\hline Wild Turkey & Meleagris gallopavo & WITU & IE \\
Willow Flycatcher $^{\text {Winter Wren }}{ }^{\text {a }}$ & Empidonax traillii & WIFL & ES \\
Wood Thrush $^{\text {a }}$ & Troglodytes troglodytes & WIWR & FI \\
Worm-eating Warbler $^{\text {Hylocichla mustelina }}$ & WOTH & IE \\
Yellow-bellied Sapsucker $^{\text {Yellow-billed Cuckoo }}{ }^{\mathrm{a}}$ & Helmitheros vermivorus & WEWA & FI \\
Yellow-breasted Chat & Coccyzus americanus & YBSA & FI \\
Yellow-throated Vireo & Ycteria virens & YBCH & IE \\
\hline
\end{tabular}

${ }^{a}$ Species analyzed for temporal trends

${ }^{\mathrm{b}}$ Forest-interior $=$ FI; Interior-edge $=$ IE; Early Succession=ES 
Appendix 2. Mean landscape metrics at the local and landscape at the Wildlife and Ecosystem Research Forest and Panther Run Tract (combined) for entire study period, 1996 - 2009

\begin{tabular}{llrr}
\hline Metric & Mean & SE \\
\hline & & \\
& Elevation (m) & 892.3 & 2.6 \\
Slope (deg) & 14.4 & 0.2 \\
AWMSI & 1.42 & 0.01 \\
CWED (m/ha) & 97.3 & 2.6 \\
IJI & 62.4 & 0.5 \\
SHDI & 0.51 & 0.01 \\
Decid (ha) & 0.94 & 0.03 \\
Mixed (ha) & 0.82 & 0.03 \\
Clear (ha) & 0.36 & 0.02 \\
LtPH (ha) & 0.78 & 0.03 \\
HvyPH (ha) & 0.09 & 0.01 \\
& & \\
AWMSI & 4.22 & 0.99 \\
CWED (m/ha) & 89.7 & 0.99 \\
IJI & 72.1 & 0.95 \\
SHDI & 2.43 & 0.99 \\
Decid (ha) & 454.0 & 5.8 \\
Mixed (ha) & 425.2 & 6.0 \\
Clear (ha) & 174.2 & 3.1 \\
LtPH (ha) & 374.8 & 7.4 \\
HvyPH (ha) & 51.0 & 1.5 \\
CorFor (ha) & 450.6 & 7.9 \\
CorES (ha) & 79.1 & 1.7 \\
\hline
\end{tabular}


CHAPTER 4

RESPONSE OF CANADA WARBLERS (WILSONIA CANADENSIS) TO CHANGING FOREST CHARACTERISTICS IN THE SOUTHERN PORTION OF THEIR RANGE 
ABSTRACT.---Although Canada Warblers (Wilsonia canadensis) have been declining in the eastern United States, their population in the Appalachian Bird Conservation Region (BCR), the southern edge of their range, remains stable. Given this stable population, this BCR may make important contributions to the species' conservation. Our study objectives were to evaluate the response of Canada Warbler abundance and nest success to habitat characteristics at multiple spatial scales in response to active forest management. We conducted point counts (1996-1998, 2001-2003, and 2007-2009) and monitored nests (first and thirds sampling periods) at the Wildlife and Ecosystem Research Forest (WERF), Randolph County, WV in and evaluated relative abundance and nest success as a function of landscape metrics, landcover, and microhabitat features. During the study, relative abundance of Canada Warblers decreased on the WERF and the Appalachian BCR, but at lower yearly rates on the former. Early in the study, relative abundance was greater closer to roads, but as timber harvest became more common, it was positively related to area of light partial harvests at the local scale. Nest success was $45.6 \%$ ( \pm 18.3) during 1996-1998 ( $\mathrm{n}=10)$ and 24.9\% ( \pm 14.6$)$ during 2007-2009 ( $\mathrm{n}=17)$, but did not differ $(P=0.38)$ between these periods. Nests in 2007-2009 had less intermediate canopy cover and residual trees but more green cover, woody debris, and pole trees than nests in 1996-1998. Successful nests had more low cover, less vertical diversity, more woody debris, more saplings, and greater edge density than unsuccessful nests. Compared to available habitat, nest sites had less mature deciduous and mixed cover but more clear-cuts and light partial harvests suggesting Canada Warblers are disturbance-dependent. We found a positive response in relative abundance to all three timber harvest types (clear-cut, heavy partial, and light partial) and improved in habitat through understory development and greater retention of residual trees; however, warblers responded most positively to light partial harvests possibly because of the availability of both residual trees and understory shrubs. Our research finds preliminary support for use of timber harvests as a management tool for Canada Warblers in the southern portion of their range. Long-term monitoring of abundance and nest success will be required to confirm successful management. 
Like many other neotropical migrant songbirds in the eastern United States, the Canada Warbler (Wilsonia canadensis), a woodland species, has been declining throughout its range (Robbins et al. 1989; Terborgh 1989, 1992; Finch 1991; Hagan and Johnston 1992; Askins 1993) at a high annual rate (3.8\% since 1980; Sauer et al. 2008, Appendix I). Ranked by Smith et al. (1993) as the seventh highest conservation priority of 132 species of neotropical migrants, concern for this species recently has increased resulting in its' inclusion on the 2007 Audubon Watchlist for U.S. birds (Butcher et al. 2008), the U.S Fish and Wildlife Service's Birds of Conservation Concern 2008 (U.S Fish and Wildlife Service 2008), and threatened listing by the Committee on the Status of Endangered Wildlife in Canada (COSEWIC 2008). The species is also under consideration for uplisting from least concern to vulnerable on the International Union for Conservation of Nature (IUCN) Redlist by BirdLife International due to estimated population declines (BirdLife International 2009). The causes of Canada Warbler population declines remain unknown, but studies have suggested loss of forested wetland breeding habitat and latesuccessional forests (Conway 1999), increased urban development within forested landscapes (Miller 1999), reduced understory vegetation due to deer herbivory (DeGraaf et al. 1991), and loss of wintering habitat (Faccio et al. 1998) as possible factors.

Canada Warblers typically breed from the southern boreal forests of Canada south through the northeast and Great Lakes regions of the United States, and southward along the Appalachian Mountains. Breeding Bird Survey (BBS) data indicate declining population trends since 1980 across all Bird Conservation Regions (BCR) in their range except for the Appalachian Mountains (+1.2\%) and Prairie Hardwood Transition (+6.3\%; Sauer et al. 2008). This stable population within the Appalachian Mountain BCR may contribute to conservation of the species by providing a source population.

Canada Warblers inhabit a wide range of deciduous and coniferous forests, but are most common in mixed coniferous-deciduous forests that are moist and have well-developed understory shrub layers (Conway 1999). Canada Warblers also are positively associated with natural disturbances such as wind or tree-fall created forest gaps (Hall 1984, Hagan and Grove 1999, Mitchell 1999, Faccio 2003), outbreaks of invasive insects such as spruce budworm (Choristoneura fumiferana; Crawford and Jennings 1989), and regenerating forests 6 to 20 years post-harvest in the northern (Titterington et al. 1979, Hagan et al. 1997) and southern portions of their range (Mauer et al 1981, Weakland 2002). This species seems primarily disturbance- 
dependent at higher elevations, especially in the southern portion of its range, including the Appalachian Mountains. Lambert and Faccio (2005) suggested that elevation influences this shift to primarily disturbed habitats compared to the more diverse habitat use in their core range because wet conditions at lower elevations limit canopy closure and promote understory growth, whereas understory development at higher elevations is primarily disturbance-driven through gap creation. In managing for Canada Warblers, this shift in habitat use from core breeding range to its' southern edge needs to be considered; however, minimal research is available outside the core of the warbler's range, and almost none in the central and southern Appalachians.

Studies in the United States and Canada have found different responses of warbler abundances when comparing natural disturbances with timber harvests. Buford and Capen (1999) and Drapeau et al. (2000) found that abundance decreased in response to harvested areas while Mauer et al. (1981) found an increase on such sites. Lambert and Faccio (2005) and Hallworth et al. (2008a) reported that pairing and fledging rates were similar in regenerating harvests and forested wetlands, but overall productivity was higher in forested wetlands because territory densities were greater, indicating higher quality habitat. With respect to harvesting techniques, Canada Warbler abundance has been shown to increase in both clear-cut and partial harvests (Mauer et al. 1981, Hagan et al. 1997, King and DeGraaf 2000). Conversely, Hagan et al. (1997) and Lambert and Faccio (2005) found abundance declined in clear-cut harvests versus partial harvests. Within recently harvested stands, the most important features seem to be high understory shrub density (Christian et al. 1996, Hagan and Meehan 2002, Hallworth et al. 2008b) and the retention of some overstory trees (Hagan et al. 1997, Lambert and Faccio 2005, Hallworth et al. 2008b).

Given the limited research throughout the Canada Warbler's southern range and the conservation opportunity provided by stable populations compared to large declines throughout the core range, we studied this species in the central Appalachians. The objective of our study was to determine the response of Canada Warbler abundance and nest success to changing forest characteristics at multiple spatial scales as a result of forest management practices, including clear-cut and partial harvests, in the Allegheny Mountains.

\section{METHODS}

Study Area.---Research was conducted from 1996-1998 (Weakland 2000), 2001-2003 (Dellinger 2005), and 2007-2009 at the Wildlife and Ecosystem Research Forest (WERF) 
located in southwestern Randolph County, West Virginia in the unglaciated Allegheny Mountain and Plateau Region. The WERF is a 3,413 ha forested area, established in 1994 by Westvaco Corporation to study the ecological effects of industrial forest management practices on ecosystem processes and wildlife. Elevations range from 734-1,180 m and regional topography consists of narrow valleys with small, high-gradient streams, and steep slopes topped by broad ridges that generally run in a south-southwest to north-northeast direction. Annual average precipitation is generally $>160 \mathrm{~cm}$ per year, with snow common throughout the winter, resulting in a cool and humid environment. Soils are acidic and well-drained inceptisols and ultisols.

Vegetation communities on the WERF vary by elevation. Red spruce (Picea rubens) and Eastern hemlock (Tsuga canadensis) characterize stands above 1,000 m. Northern hardwoods including red maple (Acer rubrum), American beech (Fagus grandifolia), and black cherry (Prunus serotina) dominate at 850-1,000 m. Below $850 \mathrm{~m}$, cove hardwood and mixed mesophytic plant communities occur with species such as northern red oak (Quercus rubra), black birch (Betula lenta), and tulip poplar (Liriodendron tulipifera). Xeric oak-hickory communities dominated by black oak (Quercus velutina), scarlet oak (Quercus coccinea), and hickory (Carya spp.) also occur at low elevations. Communities of eastern hemlock, red spruce and rhododendron (Rhododendron spp.) are found in the riparian areas surrounding streams.

At the study's inception in 1996, the WERF was primarily a 70-90 year old even-aged mature forest due to logging from 1916-1928 (Keyser and Ford 2005). In 2009, it consisted of a mix of mature and successional forests due to recent timber harvests. Forest management during the study included even-aged timber harvesting in the form of clear-cutting, shelterwood cuts, and deferment cuts, and uneven-age or partial harvesting via single-tree and diameter limit harvests of mature sawtimber (Dellinger et al. 2007). Additional early successional habitat was created by other disturbance including haul roads and a few gas wells.

Point Count.---During 1996-1998, 2001-2003, and 2007-2009, we sampled breeding birds using 50-m fixed-radius plots (Hutto et al. 1986) located at points selected systematically in 1995 from a grid of points used by Westvaco for forest inventory. We surveyed 118 points from 1996-1998 and 108 points from 2001-2009. Sample points were $241 \mathrm{~m}$ or $482 \mathrm{~m}$ apart and each point was marked with a $1 \mathrm{~m} \mathrm{X} 1 \mathrm{~cm}$ aluminum stake and uniquely numbered.

Each year from 29 May to 4 July, every 50-m plot was sampled twice, once by each of two observers proficient in bird identification and distance estimation, with at least a three-week 
interval between surveys. We conducted counts beginning at $0600 \mathrm{EST}$ and ending no later than 1000 on mornings with suitable weather conditions (i.e., no rain, little wind). We recorded all individuals heard or observed within a 10-minute time span and noted whether each individual was within $50 \mathrm{~m}$, the type of detection (song, call, visual, or fly-over), and the sex if possible. Recently fledged young and flyovers were excluded from analyses. If a bird could not be identified to species, the observer attempted to locate and identify the individual after completing the count.

To determine the concurrent region-wide trend, we obtained Canada Warbler abundance data collected during 1998-2006, the years which data was available, at off-road point counts in multiple studies from all states within the Appalachian BCR except New York, Connecticut, and Massachusetts. Sources included the Alabama Department of Conservation and Natural Resources, the Kentucky Fish and Wildlife Service, the National Park Service, the North Carolina State Cooperative Fish and Wildlife Research Unit, the North Carolina Wildlife Resource Commission, the Pennsylvania Breeding Bird Atlas, the Tennessee Wildlife Resources Agency, the US Forest Service, the West Virginia Department of Natural Resources, and the West Virginia Cooperative Fish and Wildlife Research Unit. The number of counts completed annually was 2551-6499. They were conducted following typical count procedures (Hutto et al. 1986) and were at least $250 \mathrm{~m}$ apart. Only detections from within $50 \mathrm{~m}$ were included in the analysis to keep results comparable to our 50-m fixed radius counts.

Nest Searching and Monitoring.---We searched for and monitored Canada Warbler nests in 1996-1998 and in 2007-2009. We included a single nest discovered incidentally as part of another project in 2001-2003 (Dellinger 2005) for analyses of microhabitat and landscape metrics at successful and unsuccessful nests to increase sample size. During 1996-1998, Weakland (2000) monitored nests on eight 40 ha nest-searching plots distributed across the study area that included diameter-limit harvests, two-age harvests, and unharvested forest. In 20072009, we divided the study area into six sections of equal area and placed two nest plots of approximately 20 ha (12 total) in each. We placed one plot in an area of $>50 \%$ unharvested, laterotation forest (predominantly hardwood), while the other was placed in an area of $>50 \%$ harvested successional forests, primarily scrub habitat. All plots in both studies were oriented perpendicularly to the prevailing topography to ensure they were not primarily in either ridges or valleys. 
We searched each plot every three days, spending equal time in plots representing each habitat type to minimize potential sampling bias in the location of nests found. Additionally, we supplemented this nest searching with nests found at point count locations or while traveling to and from the counts. We used multiple techniques to locate nests including both systematic searches and behavioral observations. Once located, we checked each nest a minimum of every three days until the nest attempt was complete and then identified it as either successful or failed.

Landcover and Landscape Metrics.---We created a digital landcover layer using $1 \mathrm{~m} \mathrm{X} 1$ $m$ raster grids for each year of the study, subdividing cover into ten types: clear-cut harvests (even-age harvests with no residual trees), heavy partial harvests (clear-cuts with residual trees plus deferment and shelterwood cuts), light partial harvests (single-tree selection and diameter limit cuts), mature deciduous forest, mature mixed forest, herbaceous groundcover (mostly grass log-landings), shrub/scrub (mostly roadside), water, road, and development. Few harvests were present in 1996 at the initiation of the study, so harvested stands ranged in age from 1-12 years and were primarily shrub habitat with the oldest stands beginning the transition into pole-stage forests. We defined cover types and stand boundaries annually using 1-m resolution NAIP 1:10,000 scale aerial orthophotographs, harvest shapefiles provided by the timber companies, and ground-truthing.

We measured landcover and landscape metrics at two scales: landscape, encompassing the entire study area, and local, covering areas within $300 \mathrm{~m}$ of each point count and nest. From landcover layers, we calculated the total area (ha) for five landcover classes: clear-cut, heavy partial harvest, light partial harvest, mature deciduous forest, and mature mixed forest. We calculated landscape metrics with Fragstats (McGarigal et al. 2002) selecting metrics indentified as important to avian species in past research (Demeo 1999, Weakland 2000, Williams 2002, Bosworth 2003, Dellinger 2005). Area-weighted mean shape index (AWMSI) measures the shape complexity of patches of all cover types by measuring the perimeter-to-area ratio weighted by the size of its patches. Timber management should decrease AWMSI as harvests are more regularly shaped than natural stands (Mladenoff et al. 1993). We also calculated interspersion and juxtaposition (IJI), which is a measure of the intermixing of cover types relative to the maximum intermixing possible, Shannon diversity index (SHDI), which is a measure of the diversity of different cover types, and contrast-weighted edge density (CWED), which is a measure of the amount of edge per unit area and that gives the intersection of different cover 
types different weights (Appendix II). We calculated core area, area $>50 \mathrm{~m}$ from an edge, for mature forest (mature deciduous and mature mixed forest patches combined) and for early successional cover (combined patches of clear-cuts, heavy partial harvests, and shrub/scrub cover). Using the spatial analyst extension and a haul road shapefile in ArcGIS (ESRI, 2003), we also calculated the distance to the nearest logging road for each nest and point count.

Microhabitat.---We sampled vegetation using a 0.04-ha circular plot centered at each nest based on James and Shugart (1970) and BBIRD (Martin et al. 1997) protocols. Two 22.6-m long transects, one oriented parallel and one perpendicular to the slope, intersected at the plot center. Using a 3.8-cm diameter sighting tube, we recorded the presence or absence of ground cover at $2.26 \mathrm{~m}$ intervals along the two transects (10 points each transect omitting the center point; Noon 1981). At each interval, we pointed the sighting tube directly downward and recorded the ground cover observed at the crosshairs (green, leaf litter, woody debris, moss, water, or bare). At each interval, we also used the sighting tube to estimate canopy cover in six height classes $(<3 \mathrm{~m}, 3-6 \mathrm{~m},>6-12 \mathrm{~m},>12-18 \mathrm{~m},>18-24 \mathrm{~m}$, and $>24 \mathrm{~m})$ by aiming the tube directly overhead and recording all height classes in which the crosshairs intersected green cover. We calculated the overall vertical diversity as the sum of the tube hits across the canopy height classes.

Within a 5-m radius centered on each count location and nest site, we counted the number of saplings taller than $0.5 \mathrm{~m}$ with a diameter at breast height ( $\mathrm{dbh})<2.54 \mathrm{~cm}$ and the number of pole trees with dbh $2.54-7.6 \mathrm{~cm}$. Within a 22.6-m radius, we counted the number of small trees (>7.6-22.9 cm dbh), medium trees (>22.9-38.1 cm dbh), and large trees $(>38.1 \mathrm{~cm} \mathrm{dbh})$. These three classes were summed to determine the number of residual canopy trees.

Finally, at each nest, we visually estimated the percent concealment of the nests from overhead and $2 \mathrm{~m}$ away from the nest in each of the cardinal directions. We calculated average concealment as the mean of the concealment from the four sides.

Statistical Analysis

Relative Abundance.---To analyze yearly trends in abundance, we conducted a Poisson regression because the data were measured as a count. We used the generalized linear model function in program R (R Development Core Team 2009) with a significance of $\alpha=0.05$. We used the number of Canada Warblers counted at each point count as the dependent variable and 
the year during which the count occurred as the independent variable. We conducted separate analyses for the WERF from 1996-2009 and for the Appalachian BCR from 1998-2006.

We next created regression tree models (De'ath and Fabricius 2000) to assess relations between landscape metrics and Canada Warbler relative abundance. We created models using the "mvpart package" in program R using 10-fold cross-validation and the "pick" functions to interactively select the best regression tree size, balancing the number of branches versus the decline in relative error. We attempted an overall model for all nine years combined, but the regression tree branched based primarily on a single sharp decline in abundance prior to 2001 masking the effects of the more subtle changes in abundance and is, therefore, not reported. Instead, we created separate models for each 3-year time period of the study (1996-1998, 20012003, and 2007-2009) to account for possible temporal changes in the relation between abundance and landscape metrics. Within each time period, we created three models: landscape scale, local scale, and combined. In each model, we used relative abundance of Canada Warblers at each point as the response variable and included variables measuring the area of five landcover types (clear-cut, mature deciduous forest, mature mixed forest, light partial harvest, and heavy partial harvest) and five landscape metrics (AWMSI, SHDI, IJI, CWED, and distance to road). To assess fit for each model, we calculated the relative error (the inverse of the variance explained by the model) and the cross-validation error such that values close to zero are perfect predictors while values close to one are poor predictors (De'ath 2002). Cross-validation error better represents the predictive abilities of models using new data.

Nest Success.---We calculated nest success using the Mayfield method (Mayfield 1961, 1975, Johnson 1979) for two time periods: nests found during 1996-1998 and nests found during 2007-2009. Rather than comparing annual success, we combined nests into 3-year periods to increase sample size and because we assumed that habitat was more similar within each 3-year period than between the two periods. We classified a nest as successful if at least one young fledged. If a nest failed between checks, the median day was used in calculating exposure (Mayfield 1961). We used program CONTRAST (Hines and Sauer 1989) to test for difference between the two time periods using Chi-square tests.

To compare differences in microhabitat between nests found early and late during the study and between successful and unsuccessful nests, we used classification trees (De'ath and Fabricius 2000). Again, we created models using the "mvpart package" in program R using 10- 
fold cross-validation and the "pick" functions to select tree size. The response variable was either the time period (early, 1996-1998, or late, 2007-2009) or nest outcome (success or failure). For each comparison, we created three separate microhabitat models representative of different components of the habitat (canopy and vertical structure, ground cover, and spatial distribution of tree stems) and a combined global model. The first model incorporated the six canopy cover variables and vertical diversity. The second included only ground cover variables (percent cover of green vegetation, grass, shrub, herbaceous vegetation, fern, litter, woody debris, bare ground, moss), percent concealment directly over the nest, and average percent concealment from the sides of the nest. The third model included stem density variables (the number of saplings, pole trees, and residual trees). The global model included all microhabitat variables.

We also examined local and landscape scale differences between successful and unsuccessful nests by creating classification trees using the same landcover and landscape metric variables used for the relative abundance models. Because specific nest locations and hence, UTM coordinates, were not available for the early period nests, only nests from 2007-2009 and the single nest from 2001-2003, could be included in these models.

To assess model fit, we calculated the misclassification rates to determine how often successful and unsuccessful nests and nests within the two time periods were classified incorrectly within the model and also as a result of cross-validation. We measured crossvalidation error as we did with abundance models.

Habitat Use.---We examined differences in landcover and landscape metrics between areas used by Canada Warblers and available habitat. Available habitat was the landcover and landscape metrics within $300 \mathrm{~m}$ of all point count locations. Used habitat was metrics measured at point count locations with Canada Warblers present and at nest sites. To determine if these differences varied by year, we used an ANOVA, which is robust to non-normal data (Zar 2010), to test for a significant interaction between group (all point counts, presence point counts, and nest sites) and year using the "aov" function in R. If the interaction was significant, we tested differences within each 3-year time period (1996-1998, 2001-2003, and 2007-2009), combining years within each period. If the interaction was not significant, we tested differences across all nine years combined. In R, we tested each variable using the Shapiro-Wilk (Shapiro and Wilk 1965) test and determined that the distributions were not normal. Therefore, we tested 
differences among the mean values of each variable for each group using the Kruskal-Wallis test (Kruskal and Wallis 1952) when comparing all nine years. We also used the Kruskal-Wallis test for the period 2007-2009 to test for differences among the three groups. Since we had no landcover and landscape metrics for nests in 1996-1998 and only one nest in 2001-2003, we compared only two groups (all point counts and presence point counts) within these two time periods and used Mann-Whitney tests.

For variables that were significantly different using the Kruskal-Wallis tests, we determined which pairs were significantly different using the Tukey-Kramer multiple comparison test (Kramer 1956) in the DTK package in R. We tested all combinations of groups (available, used point counts, used nest sites) performing three tests for each variable.

\section{RESULTS}

Landcover and Landscape Metrics.---During 1996-2009, forests on the WERF shifted from primarily mature forest (93\% in 1996) to a mix of mature forest (34\% in 2009) and 1-12 year post-harvest early successional habitats (Table 1). Mature deciduous and mature mixed cover has declined steadily since 1996, 64\% and 62\%, respectively. In contrast, clear-cuts and heavy and light partial harvests have all increased, although clear-cuts and heavy partial harvests leveled off after 2007 due to a change in harvesting techniques to primarily light partial harvests. Overall, clear-cuts increased from 51 to 552 ha, while heavy partial harvests increased from 0 to 188 ha, and light partial harvest increased from 52 to 1135 ha. In 2008, the cover of early successional forest surpassed the cover of mature forest.

Landscape metrics were influenced by this shift from mature forest to a mix of cut and uncut stands (Table 1). After initially declining until 2001, AWMSI remained relatively the same, indicating an initial reduction in the complexity of stand configuration with the initiation of timber harvests but a limited effect afterward. From 1996 to 2007, CWED increased by 32\%, but then began declining, probably due to the addition of further harvests adjacent to each other essentially creating one larger cut and reducing edge contrast between the two. Similarly, by 2008 the study area reached the highest diversity of habitat types (SHDI) and the highest percent of intermixing of cover types (IJI).

Relative Abundance.---Relative abundance of Canada Warblers decreased over the study period (Fig. 1). At the WERF, we observed an initial increase from 1996 to 1997, followed by a sharp decline until 2001, after which abundance leveled-off until increasing again in 2009. 
While the magnitude is different, these patterns on the WERF are similar to relative abundance patterns found on point counts throughout the Appalachian BCR (Fig. 1). Within the BCR, a similar sharp decline occurred until 2000 followed by a leveling-off of abundance. The Poisson regression coefficients for Canada Warbler relative abundance were negative for both the WERF $($ Coeff. $=-0.108, \mathrm{SE}=0.013, P<0.001)$ and BCR (Coeff. $=-0.194, \mathrm{SE}=0.015, P<0.001)$, but significantly smaller for the WERF $(Z=-4.33, P<0.001)$ indicating a less severe decline at the WERF than the Appalachian BCR.

Different landscape metrics and landcover influenced Canada Warbler abundance for each 3-year period (Table 2; see Appendix III for graphical models). In 1996-1998, abundance increased with more heavy partial harvests at the landscape scale and reduced distance to road at the local scale and for the combined model. In 2001-2003, no landscape scale variables were retained. At the local and combined scale, although abundance again was greater as the distance to road was reduced, abundance also increased with more light partial harvests and clear-cuts within 300 m of the point count. In 2007-2009, abundance decreased with more mature mixed forest at the landscape scale and increased with more light partial harvests within $300 \mathrm{~m}$ of the count and for the combined model. The cross-validation errors for all models were close to one indicating that the models are generally poor predictors.

Nest Success.---We located and monitored 27 nests, 10 in 1996-1999 and 17 in 20072009. Of the 27 nests, 15 were successful, 11 failed, and one was abandoned before any eggs were laid. The abandoned nest was used only in analyses to compare microhabitat at nests found early and late during the study.

Mayfield nest success in 1996-1998 (45.6 \pm 18.3 SE) and 2007-2009 (24.9 \pm 14.6$)$ was not significantly different $\left(\chi^{2}=0.78, P=0.38\right)$. Crude nest success, the percent of nests fledging at least one young was 60\% in 1996-1998 and 63\% in 2007-2009.

Several microhabitat variables differentiated nests monitored early (1996-1998) and late (2007-2009) in the study (Table 3; see Appendix IV for graphical models, see Appendix V for microhabitat means and ranges). For canopy cover variables, 15 later nests $(88 \%)$ had $<32.5 \%$ intermediate canopy cover (12-18m high) compared to only two early nests (22\%). Among ground and concealment cover variables, green cover was the most important, with 14 late nests $(82 \%)$ having $>47.5 \%$ cover compared to one early nest $(11 \%)$. The remaining three late period nests had $>17.5 \%$ woody debris cover compared to only one of the remaining eight early nests. 
For stem density variables, residual trees best differentiated the two time periods, with 12 late (71\%) and zero early nests having $<7.5$ residual trees. Of the five remaining late nests, three had $>12$ pole trees while all early nests had $<12$ pole trees. The global model incorporated residual trees and green cover as did the previous models but had the poorest fit with the highest crossvalidation error and misclassification rates.

Of the three models (canopy cover, ground cover, and stem density), ground cover was the best having the smallest misclassification rates (7\%, 28\% for predicting new nests) and crossvalidation error indicating predictions would explain about $25 \%$ of the variability. The other two models, canopy cover and stem density, had the same cross-validation rates and misclassification rates errors indicating the models would predict about $17 \%$ and $11 \%$ of the variability, respectively.

We identified differences among microhabitat and landscape scale variables at successful and unsuccessful nests, although the cross-validation errors were greater than one for all models indicating poor predictors probably due to small sample sizes (Table 3; see Appendix IV for graphical models). The misclassification rates were $15-30 \%$ for existing nest data but were higher when predicting outcomes of new nests (45-68\%). Among canopy cover variables, seven successful nests $(47 \%)$ had $>57.5 \%$ low cover from 3-6 m compared to zero unsuccessful nests. Of the remaining eight successful nests, six had vertical diversity <24.5 compared to only two of the 11 unsuccessful nests. Woody debris was the only important ground cover variable with ten successful nests $(67 \%)$ having $>12.5 \%$ woody debris cover compared to three unsuccessful nests $(27 \%)$. For stem density variables, results depended on whether the nest had $>6.5$ residual trees. Of nests with $>6.5$ residual trees, seven successful nests had $<11.5$ pole trees compared to two unsuccessful nests with $>11.5$ pole trees. Of nests with $<6.5$ residual trees the two nests with $>342.5$ saplings and <1 sapling were successful while only $44 \%$ of the nests with $>1$ and $<342.5$ saplings were successful. The global microhabitat model results were the same as for canopy cover.

Finally, in evaluating landcover and metrics, no variables were retained at the landscape scale and CWED was most important at the local scale. Also at the local scale, all successful nests had an edge density $>61.6 \mathrm{~m} /$ ha compared to $57 \%$ of unsuccessful nests. This model had a high cross-validation error and similar misclassification rates to other nest outcome models. 
Habitat Use.---Two variables, SHDI and light partial harvest, had a significant interaction of group (all point counts, presence point counts, and nest sites) and year (Table 4) so we analyzed these variables separately for the three year classes. In 2007-2009, points with Canada Warblers present were surrounded by more light partial harvests than were all count stations. We observed differences for SHDI between all points and points with Canada Warblers only in 1996-1998; points with warbler detections had a greater diversity of habitats.

For variables without significant year-group interactions, we found significant differences for all remaining cover types (mature deciduous, mature mixed, clear-cut, light partial harvest, and heavy partial harvest), distance to road, and AWMSI. Although significant overall, multiple comparisons identified no group differences for AWMSI. Nest sites had less mature deciduous and mixed cover but more clear-cuts and light partial harvests than all count stations. Nest sites also had less mature mixed cover and more clear-cuts than presence counts. Stations with warblers present were closer to a road and had fewer heavy partial harvests.

\section{DISCUSSION}

Response to Temporal Habitat Disturbance.---Our results suggest that Canada Warblers were associated with disturbances in our study area and selectively used harvested areas, especially to breed, as indicated in previous research in the northern (Titterington et al. 1979, DeGraff 1985, Hagan et al. 1997) and southern portions of their range (Mauer et al 1981, Weakland 2002). In comparing yearly abundance to landcover changes for the three time periods, we observed a shift in habitat use. Initially, Canada Warblers seemed to be limited by the availability of patches of disturbance. They occurred in greater abundance closer to roads suggesting that they were using roadside habitat. Also, because abundance increased in the 1996-1998 period with greater heavy partial harvests at the landscape scale, this suggests use of the limited available cuts. Higher Shannon diversity index values at presence stations compared to all stations in 1996-1998 further support this species' use of areas with disturbances. Generally, habitat diversity was low for most of the study area due to mature forest cover, but increased in areas in which forest cover was disturbed such as harvests and roadsides.

Lambert and Faccio (2005) suggested a lag time until new harvests become suitable in structure and this idea is evidenced by the delayed appearance of light partial harvest and clearcuts in the relative abundance (CART) models beginning in 2001. Starting five years after harvest initiation, we observed warblers still using roadside successional habitats, as indicated by 
the negative relation of distance to road in the models, but they were beginning to use recently harvested stands as understory structure developed.

During the last period, 2007-2009, abundance was primarily influenced by light partial harvests and the distance to road was no longer included in the models. We identified similar selection of harvested habitat at nesting sites. On average, cover within $300 \mathrm{~m}$ of nest sites had greater than three times more clear-cut harvests and almost double the amount of light partial harvests than was available across all point count locations and less than half the amount of mature forest, both deciduous and mixed.

Canada Warbler abundance was more sensitive to local-scale variables than landscape scale variables. In 2001-2003, no landscape scale variables were retained in relative abundance models, and when we combined models, the local variables were retained over landscape variables in all models. Northern hardwood forests historically have been limited in naturally occurring large-scale disturbance (Lorimer 2001) and, therefore, birds must instead rely on small-scale wind and tree-fall gaps. Past research has found positive associations between such small-scale disturbances and avian abundance (Hall 1984, Hagan and Grove 1999, Mitchell 1999, Faccio 2003). Therefore, habitat selection based on local cover would be advantageous for species associated with patchy and small-scale disturbances.

Response to Timber Harvests.---Although Canada Warbler response to all three types of harvests on our study area (clear-cut, heavy partial, and light partial harvests) was positive, we found that light partial harvests received greater use by Canada Warblers than clear-cut harvests, a finding similar to that of Hagan et al. (1997) and Lambert and Faccio (2005). Light partial harvests were positively related to abundance in both the 2001-2003 and 2007-2009 regression trees and, while clear-cut harvests also were positive in the 2001-2003 model, area in partial harvests explained more variability. Further, point count stations with warblers present had more light partial harvests than all count stations. We also observed an increase in abundance beginning in 2008 when harvesting shifted to primarily light partial harvests, although future research is necessary to determine if this pattern continues. Canada Warblers appear to have responded most positively to light partial harvests possibly because they provided both residual trees and a developing understory. Territories were distributed throughout partial harvests. Although we observed Canada Warblers breeding within clear-cut harvests, territories were 
limited to the periphery of the cuts near forested edges or patches of remaining trees indicating minimal use of the interior areas of the cuts.

We are hesitant to compare use by Canada Warbler of heavy and light partial harvests because no heavy partial harvests occurred in five of the nine years (1997-1998 and 2007-2009). Also, the area of heavy partial harvests was smaller, around one sixth the area of light partial harvests. We suggest this is an important area for future research.

Timber harvests seem to have improved habitat quality for Canada Warblers on our study area. Many studies have identified high understory shrub density (Christian et al. 1996, Hagan and Meehan 2002, Hallworth et al. 2008b) and retention of some overstory trees (Hagan et al. 1997, Lambert and Faccio 2005, Hallworth et al. 2008b) as the most important microhabitat variables for Canada Warblers. These variables relate to the higher amounts of woody debris, sapling density, low cover, and edge density that we observed at successful nest locations. In comparing early (2007-2009) to late (1996-1998) nests, classification tree models indicated increased associations with many of these same microhabitat variables. Later nests were associated with reduced intermediate canopy cover and residual trees as a result of the removal of trees through timber harvests; however, this same disturbance opened the canopy, increased light availability and promoted understory development. For this reason, we believe, later nests also had more green vegetation, woody debris, and pole trees. The increase in understory shrub density not only provided greater concealment for nests but increased available foraging habitat within the 3-5 m vegetative strata where Canada Warblers focus their foraging (Sabo and Holmes 1983, Sodhi and Paszkowski 1995, Hallworth 2008b). We must note that the reduction in residual trees should not be interpreted as their complete removal, as all later nest sites included residual trees. Clearly, there is a trade-off between maintaining breeding perches (Hallworth 2008a) and providing canopy openings that promote understory development.

Even though we found that Canada Warblers were associated with harvests and that attributes of microhabitat were enhanced, we urge caution when interpreting our results. Indeed, we did not document increases in either relative abundance or nest success, two requirements for successful management, as a function of timber harvest. Alternatively, yearly relative abundance declined across the entire Appalachian BCR, as it did on our study area, making it impossible to isolate the effects of timber management on relative abundance. Regardless, we did identify two potentially positive responses to timber harvests. Based on the results of the Poisson regression, 
the yearly decline at our study site was smaller than that for the Appalachian BCR, possibly indicating a muting of the region-wide decline via timber harvests. Also, from 2008 to 2009, we measured an increase in relative abundance, possibly indicating the start of a positive trend in abundance. However, further research is necessary to confirm these trends as well as possible causes of the region-wide decline. Furthermore, our study does not consider factors on the CAWA wintering ground or during migration that may be related to survival or fitness.

Although we found no significant change in nest success from 1996-1998 compared to 2007-2009, the Mayfield nest success value in 2007-2009 was half that of the 1996-1998 value. Nest sample sizes were small and estimates of success may have been biased downward by our inability to find nests early in the annual nesting cycle in 2007-2009. Nine nests in 2007-2009 fledged within three days of finding the nest compared with only three nests in 1996-1998. Given the already limited sample size, the reduction in exposure-days in the later period could result in lower estimated nest success. Taking this into account, we compared crude nest success and found similar rates between the two time periods, also indicating no relation between nest success and the observed changes in habitat conditions. No change in fledging rates could increase overall productivity if the number of breeding pairs increased in recently harvested habitats. Still, we are hesitant in making strong statements about the response of Canada Warbler nest success to timber management given the limitations of our nest sample sizes.

\section{CONSERVATION IMPLICATIONS}

Given that we identified a positive association between Canada Warblers and highelevation disturbance, we hypothesize that timber harvests can be used to enhance habitat quality for Canada Warblers in the southern portion of their range as others have suggested for their core range (Titterington et al. 1979, DeGraff 1985, Hagan et al. 1997). Our results indicated a positive response to all three types of timber harvests (clear-cut, heavy partial, and light partial harvests); however, CAWA response was greatest to light partial harvests, probably because residual trees and understory shrubs were both present. Hagan et al. (1997) found stands most suitable 6-20 years post-harvest, thus a post-harvest lag time to allow for suitable stand development (approximately five years) appears beneficial to providing CAWA habitat. Forest management may be an especially useful tool for enhancing CAWA habitat in heavily forested states such as West Virginia (78\% forest) where early successional habitats are limited (10\% of timberlands; Trani et al. 2001), and where timber management is the primary source of new early 
successional habitats due to minimal large-scale natural disturbance in higher elevation habitats such as northern hardwood forests (Lorimer 2001). However, long-term monitoring of abundance and nest success in managed forest landscapes in the southern portion of the species' range is needed to confirm this hypothesis. If confirmed this region could provide an important source population for this species.

Beyond using timber harvests to manage Canada Warblers, the creation of early successional habitat provides auxiliary benefits for many other bird species. We detected a variety of priority species identified by the Appalachian Mountains Joint Venture (2010) using the timber harvests including Alder Flycatcher (Empidonax alnorum), Blue-winged Warbler (Vermivora pinus), Brown Thrasher (Toxostoma rufum), Cerulean Warbler (Dendroica cerulea), Eastern Towhee (Pipilo erythrophthalmus), Field Sparrow (Spizella pusilla), Golden-winged Warbler (Vermivora chrysoptera), Hooded Warbler (Wilsonia citrina), Indigo Bunting (Passerina cyanea), Kentucky Warbler (Oporornis formosus), Northern Flicker (Colaptes auratus), Prairie Warbler (Dendroica discolor), Wood Thrush (Hylocichla mustelina), and Yellow-breasted Chat (Icteria virens).

\section{ACKNOWLEDGMENTS}

We thank the National Council for Air and Stream Improvement and the MeadWestvaco Corporation for funding our research and MeadWestvaco and Penn Virginia for providing housing for researchers and access to their property. We also thank the many field technicians who helped collect and enter data. J. T. Anderson, T. B. Wigley, and M. P. Strager provided helpful comments on this manuscript. Use of trade names does not imply endorsement by the Federal government.

\section{LITERATURE CITED}

American Bird Conservancy. 2009. BCR 28: Appalachian Mountains.

www.abcbirds.org/abcprograms/domestic/landscape/BCR/appalachian.html. (accessed 2 September 2010).

Appalachian Joint Venture. 2010. Landbird priority species. www.amjv.org/conservation/landbirds.pdf (accessed 27 August 2010)

BirdLife International. 2009. Canada Warbler (Wilsonia canadensis): uplist to vulnerable? www.birdlifeforums.org/WebX/.2cba64f0 (accessed 27 August 2010)

Bosworth, S. B. 2003. Cerulean Warbler relative abundance and frequency of occurrence 
relative to large-scale edge. Thesis. West Virginia University, Morgantown, USA.

Buford, E. W. and D. E. Capen. 1999. Abundance and productivity of forest songbirds in a managed unfragmented landscape in Vermont. Journal of Wildlife Management 63:180 188.

Butcher, G. S., D. K. Niven, A. O. Panjabi, D. N. Pashley, and K. V. Rosenberg. 2008. The 2007 watchlist for United States birds. American Birds 61:18-25.

Christian, D. P., J. M. Hanowski, M. Reuvers-House, G. J. Niemi, J. G. Blake, and W. E. Berguson. 1996. Effects of mechanical strip thinning of aspen on small mammals and breeding birds in northern Minnesota, USA. Canadian Journal of Forest Resources 26:1284-1294.

Conway, C. J. 1999. Canada Warbler (Wilsonia canadensis). The birds of North America. Number 421.

COSEWIC. 2008. COSEWIC assessment and status report on the Canada Warbler Wilsonia canadensis in Canada. Committee on the Status of Endangered Wildlife in Canada. Ottawa, Canada. www.sararegistry.gc.ca/virtual_sara/files/cosewic/sr_canada_warbler_0808_e.pdf (accessed 27 August 2010)

Crawford, H. S. and D. T. Jennings. 1989. Predation by birds on spruce budworm Choristoneura fumiferana: functional, numerical, and total responses. Ecology 70: 152 163.

De'ath, G. and K. E. Fabricius. 2000. Classification and regression trees: a powerful yet simple technique for ecological data analysis. Ecology 81:3178-3192.

De'ath, G. 2002. Multivariate regression trees: a new technique for modeling speciesenvironment relationships. Ecology 83:1105-1117.

DeGraaf, R.M. 1985. Breeding bird assemblages in New England northern hardwoods. Pages 5-22 in Conference Proceedings Johnson State College on the Impact of Timber Management Practices on Nongame Birds in Vermont (R.J. Regan and D.E. Capen, Editors), Johnson, USA.

DeGraaf, R. M., W. M. Healy, and R. T. Brooks. 1991. Effects of thinning and deer browsing on breeding birds in New England oak woodlands. Journal of Forest Ecology and Management 41:179-191. 
Dellinger, R. 2005. Nesting success and nest site characteristics of four thrush species on a managed forest. Dissertation. West Virginia University, Morgantown, USA

Dellinger, R., P. Wood, and P. Keyser. 2007. Occurrence and nest survival of four thrush species on a managed central Appalachian forest. Forest Ecology and Management 243:248-258.

Demeo, T. E. 1999. Forest songbird abundance and viability at multiple spatial scales on the Monongahela National Forest, West Virginia. Dissertation. West Virginia University, Morgantown, USA.

Drapeau, P., A. Leduc, J. F. Giroux, J. P. L. Savard, Y. Bergeron, and W. L. Vickery. 2000. Landscape-scale disturbances and changes in bird communities of boreal mixed-wood forests. Ecological Monographs 70:423-444.

Environmental Systems Research Institute (ESRI). 2003. ArcGIS Version 9.2 with the Spatial Analyst Extension. Redlands California, USA.

Faccio, S. D. 2003. Effects of ice storm-created gaps on forest breeding bird communities in central Vermont. Forest Ecology and Management 186:133-145.

Faccio, S. D., C. C. Rimmer, and K. P. McFarland. 1998. Results of the Vermont forest bird monitoring program, 1989-1996. Northeastern Naturalist 5:293-312.

Finch, D. M. 1991. Population ecology, habitat requirements, and conservation of neotropical migratory birds. USDA, Forest Service, General Technical Report RM-205. Rocky Mountain Forest and Range Experiment Station, Fort Collins, Colorado, USA.

Hagan, J. M. and D. W. Johnston (Editors). 1992. Ecology and conservation of neotropical migrant landbirds. Smithsonian Institution Press, Washington, D.C., USA.

Hagan, J. M., P. S. McKinley, A. L. Meehan, and S. L. Grove. 1997. Diversity and abundance of landbirds in a northeastern industrial forest. Journal of Wildlife Management 61:718735.

Hagan, J. M. and S. L. Grove. 1999. Bird abundance and distribution in managed and oldgrowth forest in Maine. Report No. MM-9901. Manomet Center for Conservation Sciences, Brunswick, Maine, USA. www.manometmaine.org/pdf/BirdReport99.PDF. (accessed 27 August 2010)

Hagan, J. M. and A. L. Meehan. 2002. The effectiveness of stand-level and landscape-level 
variables for explaining bird occurrence in an industrial forest. Forest Science 48:231242.

Hall, G. A. 1984. Population decline of neotropical migrants in an Appalachian forest. American Birds 18:14-18.

Hallworth, M., P. M. Benham, J. D. Lambert, and L. Reitsma. 2008a. Canada Warbler (Wilsonia canadensis) breeding ecology in young forest stands compared to a red maple (Acer rubrum) swamp. Forest Ecology and Management 255:1353-1358.

Hallworth, M., A. Ueland, E. Anderson, J. D. Lambert, and L. Reitsma. 2008b. Habitat selection and site fidelity of Canada Warblers (Wilsonia canadensis) in central New Hampshire. Auk 125:880-888.

Hines, J. E. and J. R. Sauer. 1989. Program CONTRAST - A general program for the analysis of several survival or recovery rate estimates. USDI, Fish and Wildlife Service, Fish and Wildlife Technical Report 24, Washington, D.C., USA.

Hutto, R. L., S. M. Pletschet, and P. Hendricks. 1986. A fixed-radius point count method for nonbreeding and breeding season use. Auk 103:593-602.

James, F. C. and H. H. Shugart. 1970. A quantitative method of habitat description. Audubon Field Notes 24:727-736.

Johnson, D. H. 1979. Estimating nest success: the Mayfield method and an alternative. Auk 96:651-661.

Keyser, P. D. and W. M. Ford. 2005. Ten years of research on the MeadWestvaco Wildlife and Ecosystem Research Forest. USDA, Forest Service, General Technical Report NE-330, Northeastern Research Station, Newtown Square, Pennsylvania, USA.

King, D. I. and R. M. DeGraaf. 2000. Bird species diversity and nesting success in mature, clearcut, and shelterwood forest in northern New Hampshire, USA. Forest Ecology and Management 129:227-235.

Kramer, C. Y. 1956. Extension of multiple range tests to group means with unequal numbers of replications. Biometrics 12:307-310.

Kruskal, W. H. and W. A. Wallis. 1952. Use of ranks in one-criterion analysis of variance. Journal of the American Statistics Association 47:583-621.

Lambert, J. D. and S. D. Faccio. 2005. Canada Warbler population status, habitat use, and 
stewardship guidelines for northeastern forests. Vermont Institute of Natural Science, Technical Report 05-4, Woodstock, Vermont, USA.

Lorimer, C. G. 2001. Historical and ecological roles of disturbance in eastern North American forests: 9,000 years of change. Wildlife Society Bulletin 29:425-439.

Martin, T. E., C. Paine, C. H. Conway, W. M. Hochachka, P. Allen, and W. Jenkins. 1997. BBIRD field protocol. www.umt.edu/bbird/protocol/BBIRDPROT.pdf. (accessed 27 August 2010)

Maurer, B. A., L. B. McArthur, and R. C. Whitmore. 1981. Effects of logging on guild structure of a forest bird community in West Virginia. American Birds 35:11-13.

Mayfield, H. 1961. Nesting success calculated from exposure. Wilson Bulletin 73:255-261.

Mayfield, H. 1975. Suggestions for calculating nest success. Wilson Bulletin 87:456-466.

McGarigal, K., S. A. Cushman, M. C. Neel, and E. Ene. 2002. FRAGSTATS: Spatial Pattern Analysis Program for Categorical Maps. Computer software program produced by the authors at the University of Massachusetts, Amherst. www.umass.edu/landeco/research/fragstats/fragstats.html

Miller, N. A. 1999. Landscape and habitat predictors of Canada Warbler (Wilsonia canadensis) and Northern Waterthrush (Seiurus noveboracensis) occurrence in Rhode Island swamps. Thesis. University of Rhode Island, Kingston, USA.

Mitchell, J. M. 1999. Habitat relationships of five northern bird species breeding in hemlock ravines in Ohio, USA. Natural Areas Journal 19:3-11.

Mladenoff, D. J., M. A. White, and J. Pastor. 1993. Comparing spatial patterns in unaltered oldgrowth and disturbed forest landscapes. Ecological Applications 3:294-306.

Noon, B.R. 1981. Techniques for sampling avian habitats. Pages 42-50 in The use of multivariate statistics in studies of wildlife habitats (D.E. Capen, Editor). USDA Forest Service General Technical Report RM-57.

R Development Core Team. 2009. R: A language and environment for statistical computing, reference index version 2.9.2. R Foundation for Statistical Computing, Vienna, Austria. ISBN 3-900051-07-0, www.R-project.org.

Robbins, C. S., J. R. Sauer, R. S. Greenberg, and S. Droege. 1989. Population declines in North American birds that migrate to the neotropics. Proceedings of the National Academy of Sciences of the USA 86:7658-7662. 
Sabo, S. R. and R. T. Holmes. 1983. Foraging niches and the structure of forest bird communities in contrasting montane habitats. Condor 85:121-138.

Sauer, J. R. and S. Droege. 1992. Geographic patterns in population trends of neotropical migrant in North America. Pages 26-42 in Ecology and conservation of neotropical migrant landbirds. (J. K. Hagan III and D. W. Johnston, Editors.). Smithsonian Institution Press, Washington, D.C., USA.

Sauer, J. R., J. E. Hines, and J. Fallon. 2008. The North American Breeding Bird Survey, Results and Analysis 1966-2007. Version 5.15.2008. USGS, Patuxent Wildlife Research Center, Laurel, Maryland, USA. www.mbr-pwrc.usgs.gov/bbs/bbs.html. (accessed 27 August 2010)

Shapiro, S. S. and M. B. Wilk. 1965. An analysis of variance test for normality. Biometrika 52:591-611.

Smith, C. R., D. M. Pence, and R. J. O’Connor. 1993. Status of neotropical migratory birds in the Northeast: a preliminary assessment. Pages 172-188 in Status and management of neotropical migratory birds (D. M. Finch and P. W. Stangel, Editors). USDA, Forest Service, General Technical Report RM-229, Rocky Mountain Forest and Range Experiment Station, Fort Collins, Colorado, USA.

Sodhi, N. S. and C. A. Paszkowski. 1995. Habitat use and foraging behavior of four parulid warblers in a second-growth forest. Journal of Field Ornithology 66:277-288.

Titterington, R. W., H. S. Crawford, and B. N. Burgason. 1979. Songbird response to commercial clear-cutting in Maine spruce-fir forests. Journal of Wildlife Management 43:602-609.

Terborgh, J. 1989. Where have all the birds gone? Princeton University Press, Princeton, New Jersey, USA.

Terborgh, J. 1992. Why American songbirds are vanishing. Scientific American 266:56-62.

Trani, M. K., R. T. Brooks, T. L. Schmidt, V. A. Rudis, and C. M. Gabbard. 2001. Patterns and trends of early successional forests in the eastern United States. Wildlife Society Bulletin 29:413-424.

U.S. Fish and Wildlife Service. 2008. Birds of conservation concern 2008. United States

Department of Interior, Fish and Wildlife Service, Division of Migratory Bird Management, Arlington, Virginia, USA. 
Weakland, C. A. 2000. Effects of diameter-limit and two-age timber harvesting on songbird populations on an industrial forest in central West Virginia. Dissertation. West Virginia University, Morgantown, USA.

Weakland, C. A., P. B. Wood, and W. M. Ford. 2002. Responses of songbirds to diameter-limit cutting in the central Appalachians of West Virginia, USA. Forest Ecology and Management 155:115-129.

Williams Jr., G. E. 2002. Relations of nesting behavior, nest predators, and nesting success of Wood Thrush (Hylocichla mustelina) to habitat characteristics at multiple scales. Dissertation. West Virginia University, Morgantown, USA.

Zar, J. H. 2010. Biostatistical analysis. Fifth Edition. Prentice Hall, Upper Saddle River, New Jersey, USA. 


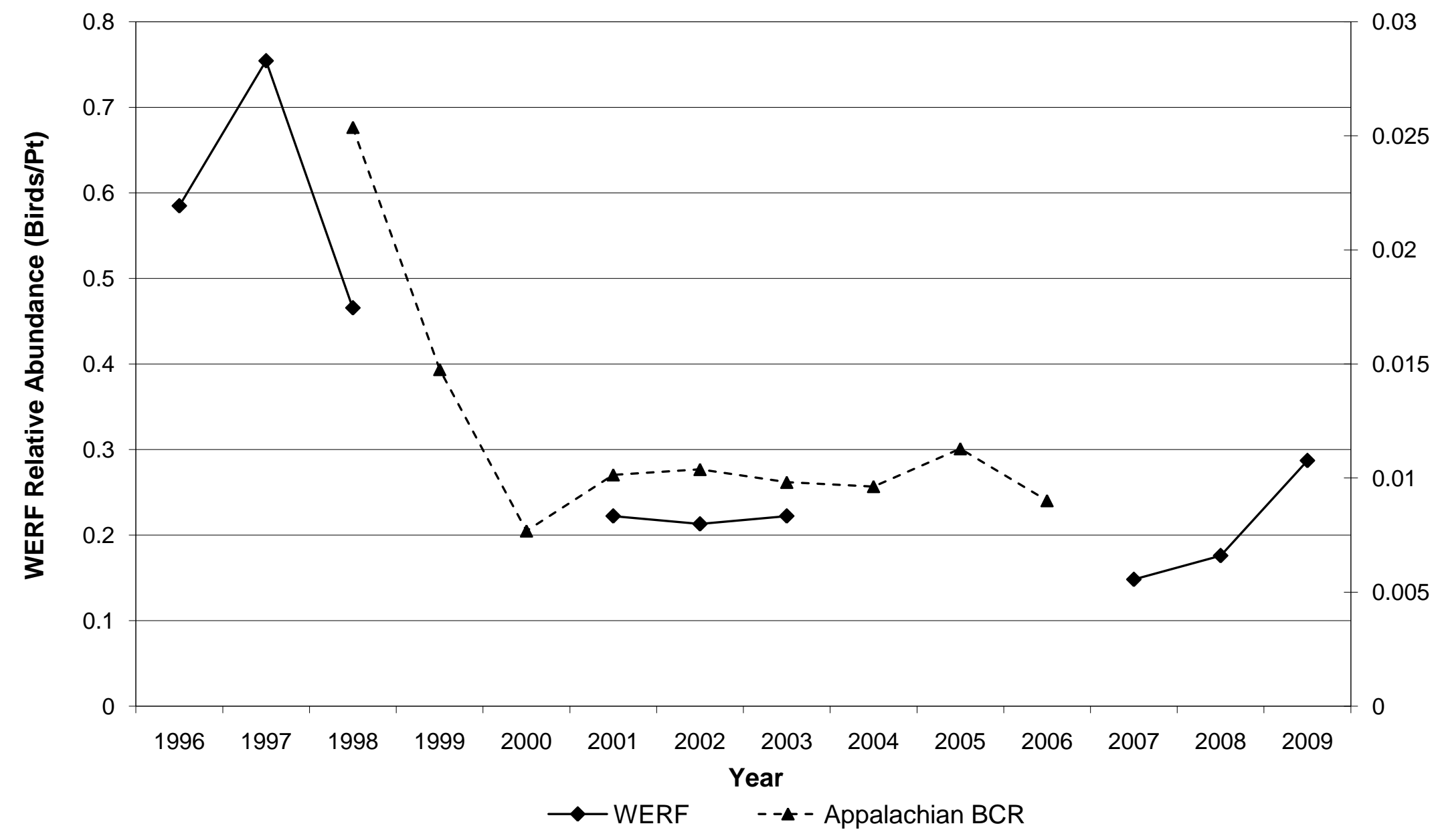

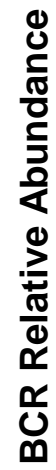

FIG. 1. Relative abundance (number of individuals/pt/year) of Canada Warblers by year at point counts on the Wildlife and Ecosystem Research Forest (WERF) and throughout the entire Appalachian Bird Conservation Region, 1996-2009. 


\begin{tabular}{|c|c|c|c|c|c|c|c|c|c|}
\hline & 1996 & 1997 & 1998 & 2001 & 2002 & 2003 & 2007 & 2008 & 2009 \\
\hline \multicolumn{10}{|l|}{ Landscape Metrics $^{\mathrm{a}}$} \\
\hline AWMSI & 3.67 & 3.57 & 3.45 & 3.29 & 3.29 & 3.35 & 3.33 & 3.26 & 3.30 \\
\hline CWED (m/ha) & 75.1 & 77.2 & 78.3 & 83.1 & 84.8 & 91.6 & 99.0 & 98.3 & 96.1 \\
\hline IJI & 65.3 & 65.2 & 66.2 & 71.0 & 72.1 & 73.0 & 76.9 & 77.7 & 77.7 \\
\hline SHDI & 1.04 & 1.27 & 1.33 & 1.52 & 1.55 & 1.59 & 1.70 & 1.70 & 1.65 \\
\hline \multicolumn{10}{|l|}{ Landcover $(\%)$} \\
\hline Clear-cut Harvest & 1.6 & 2.6 & 3.2 & 7.8 & 8.4 & 10.6 & 17.4 & 17.9 & 17.9 \\
\hline Heavy Partial Harvest & 0.0 & 1.4 & 1.4 & 2.5 & 2.8 & 2.9 & 6.1 & 6.1 & 6.1 \\
\hline Light Partial Harvest & 1.7 & 8.1 & 10.8 & 17.9 & 20.5 & 21.5 & 19.1 & 29.2 & 36.8 \\
\hline Mature Deciduous & 44.7 & 41.7 & 41.1 & 34.6 & 32.7 & 30.2 & 25.3 & 20.2 & 16.0 \\
\hline Mature Mixed & 47.6 & 41.8 & 39.2 & 32.8 & 31.2 & 30.0 & 27.1 & 21.7 & 18.3 \\
\hline
\end{tabular}

${ }^{a}$ AWMSI = Area-weighted mean shape index, CWED = Contrast-weighted edge density, IJI = Interspersion juxtaposition, SHDI $=$ Shannon diversity index . 
TABLE 2. Landcover and landscape metrics retained in regression trees of Canada Warbler relative abundance during each three year time period (1996-1998, 2001-2003, and 2007-2009) at the Wildlife and Ecosystem Research Forest.

\begin{tabular}{|c|c|c|c|}
\hline Time Period & Scale & Landcover and Landscape Metrics $^{a}$ & CV Error \\
\hline \multicolumn{4}{|c|}{ 1996-1998 } \\
\hline & Landscape & Heavy Partial Harvest (+42.6 ha; 1.4$)$ & 1.01 \\
\hline & Local and Combined $^{\mathrm{b}}$ & Distance to Road $(-63.5 \mathrm{~m} ; 1.8)$ & 1.05 \\
\hline \multicolumn{4}{|l|}{$2001-2003$} \\
\hline & Landscape & None & - \\
\hline & Local and Combined & $\begin{array}{l}\text { Light Partial Harvests }(+26.34 \text { ha; } 5.5) \text {, } \\
\text { Distance to Road (-358.6 m; } 9.3) \text {, } \\
\text { Mature Deciduous }(-5.05 \text { ha; } 9.3) \text {, } \\
\text { Clear-cuts }(+7.55 \text { ha; } 2.9)\end{array}$ & 0.93 \\
\hline \multicolumn{4}{|l|}{$2007-2009$} \\
\hline & Landscape & Mature Mixed (-617.2 ha; 1.8) & 1.02 \\
\hline & Local and Combined & Light Partial Harvests (+15.84 ha; 5.3$)$ & 0.93 \\
\hline
\end{tabular}

${ }^{\mathrm{a}}$ Variables are listed in order with the first variable explaining the most variation, + and indicate the direction of the relationship and number is the branching value; the second value is the multiplier describing the difference between the abundance on either side of the split.

${ }^{b}$ Results for local and combined models were identical for all 3-year periods. 
TABLE 3. Variables retained in classification trees comparing Canada Warbler nests found in 1996-1998 $(n=9)$ and in 2007-2009 $(n=17)$ and comparing successful $(n=15)$ and unsuccessful nests $(n=11)$ in 1996-1998 and 2007-2009 for microhabitat and successful $(n=11)$ and unsuccessful nests $(n=7)$ in 2007-2009 for landscape metrics at the Wildlife and Ecosystem Research Forest.

\begin{tabular}{|c|c|c|c|c|c|}
\hline \multirow[b]{2}{*}{ Comparison } & \multirow[b]{2}{*}{ Model } & \multirow[b]{2}{*}{ Variables $^{\text {a }}$} & \multicolumn{2}{|c|}{ Missclass Rates } & \multirow{2}{*}{$\begin{array}{l}\mathrm{CV} \\
\text { Error }\end{array}$} \\
\hline & & & Model & $\mathrm{CV}$ & \\
\hline \multicolumn{6}{|c|}{ 1996-1998 vs. 2007-2009 } \\
\hline \multicolumn{6}{|c|}{ Microhabitat } \\
\hline & Canopy Cover & Cover $12-18 m(-32.5 \%)$ & 0.17 & 0.31 & 0.83 \\
\hline & Ground Cover & $\begin{array}{l}\text { Green }(+47.5 \%), \text { Woody } \\
\text { Debris }(+17.5 \%)\end{array}$ & 0.07 & 0.28 & 0.75 \\
\hline & Stem Density & $\begin{array}{l}\text { Residual Trees }(-7.5) \\
\text { Pole Trees }(+12.5)\end{array}$ & 0.11 & 0.31 & 0.83 \\
\hline & Combined & $\begin{array}{l}\text { Residual Trees }(-7.5 \\
\text { trees }), \text { Green }(+52.5 \%)\end{array}$ & 0.19 & 0.47 & 1.27 \\
\hline \multirow{2}{*}{\multicolumn{6}{|c|}{$\begin{array}{l}\text { Success vs. Failure } \\
\text { Microhabitat }\end{array}$}} \\
\hline & & & & & \\
\hline & Canopy Cover & $\begin{array}{l}\text { Cover 3-6m }(+57.5 \%), \\
\text { Vertical Diversity }(-24.5)\end{array}$ & 0.16 & 0.45 & 1.02 \\
\hline & Ground Cover & Woody Debris $(+12.5 \%)$ & 0.30 & 0.62 & 1.52 \\
\hline & Stem Density & $\begin{array}{l}\text { Residual Trees }(-6.5) \text {, } \\
\text { Pole Trees }(-11.5) \\
\text { Saplings }(-1,+342.5)\end{array}$ & 0.19 & 0.68 & 1.66 \\
\hline & Combined & $\begin{array}{l}\text { Cover } 3-6 \mathrm{~m}(+57.5 \%) \\
\text { Vertical Diversity }(-24.5)\end{array}$ & 0.15 & 0.57 & 1.39 \\
\hline \multicolumn{6}{|c|}{ Landcover and Metrics } \\
\hline & Landscape & None & - & - & - \\
\hline & Local & CWED (+61.6 m/ha) & 0.22 & 0.44 & 1.13 \\
\hline
\end{tabular}

${ }^{a}$ Variables are listed in order with the first variable explaining the most variation, + and - indicate the direction of the relationship in relation to later nests and successful nests while number is the branching value. 
TABLE 4. Mean (\#/pt/yr) and SE for landcover and landscape metrics at point count stations ( $n=1000)$, stations with Canada Warblers present $(n=266)$, and nest sites $(n=19)$ at the Wildlife and Ecosystem Research Forest, 1996-2009.

\begin{tabular}{|c|c|c|c|c|c|c|c|c|c|c|c|c|c|c|}
\hline \multirow[b]{2}{*}{ Variable } & \multicolumn{4}{|c|}{ Point Count $^{\mathrm{a}}$} & \multicolumn{4}{|c|}{ Presence $^{\mathrm{a}}$} & \multicolumn{4}{|c|}{ Nest $^{\mathrm{a}}$} & \multicolumn{2}{|c|}{ Kruskal-Wallis } \\
\hline & $n$ & Mean & SE & & $n$ & Mean & SE & & $n$ & Mean & SE & & $\chi^{2}$ & $P$ \\
\hline \multicolumn{15}{|l|}{ Landcover } \\
\hline Mature Deciduous & 1000 & 9.0 & 0.3 & A & 266 & 8.3 & 0.5 & $\mathrm{AB}$ & 19 & 3.9 & 1.3 & $\mathrm{~B}$ & 8.70 & 0.013 \\
\hline Mature Mixed & 1000 & 8.9 & 0.3 & A & 266 & 9.8 & 0.5 & $\mathrm{~A}$ & 19 & 3.6 & 1.0 & $\mathrm{~B}$ & 14.60 & $<0.001$ \\
\hline Clear-cut & 1000 & 2.8 & 0.1 & A & 266 & 2.4 & 0.3 & A & 19 & 8.7 & 1.6 & $\mathrm{~B}$ & 22.92 & $<0.001$ \\
\hline Heavy Partial Harvest & 1000 & 1.0 & 0.1 & A & 266 & 0.6 & 0.1 & $\mathrm{~B}$ & 19 & 0.6 & 0.3 & $\mathrm{AB}$ & 6.15 & 0.046 \\
\hline \multicolumn{15}{|l|}{ Light Partial Harvest ${ }^{b}$} \\
\hline 1996-1998 & 352 & 1.6 & 0.2 & A & 150 & 1.8 & 0.4 & A & - & & & & $25031^{d}$ & 0.196 \\
\hline 2001-2003 & 324 & 5.9 & 0.5 & A & 63 & 9.1 & 1.3 & $\mathrm{~A}$ & - & & & & $8905^{\mathrm{d}}$ & 0.092 \\
\hline 2007-2009 & 324 & 8.5 & 0.5 & A & 53 & 13.9 & 1.3 & $\mathrm{~B}$ & 17 & 9.6 & 2.2 & $\mathrm{AB}$ & 13.82 & $<0.001$ \\
\hline \multicolumn{15}{|l|}{ Landscape Metrics ${ }^{c}$} \\
\hline AWMSI & 1000 & 1.81 & 0.01 & A & 266 & 1.84 & 0.02 & A & 19 & 1.92 & 0.06 & A & 6.10 & 0.047 \\
\hline CWED & 1000 & 84.7 & 1.4 & A & 266 & 88.9 & 2.7 & $\mathrm{~A}$ & 19 & 98.2 & 8.6 & A & 2.93 & 0.231 \\
\hline IJI & 1000 & 65.4 & 0.3 & A & 266 & 66.2 & 0.5 & $\mathrm{~A}$ & 19 & 62.9 & 2.8 & A & 3.05 & 0.218 \\
\hline \multicolumn{15}{|l|}{ SHDI $^{b}$} \\
\hline 1996-1998 & 352 & 0.71 & 0.02 & A & 150 & 0.77 & 0.02 & B & - & & & & $22932^{d}$ & 0.028 \\
\hline 2001-2003 & 324 & 0.90 & 0.02 & $\mathrm{~A}$ & 63 & 0.91 & 0.05 & A & - & & & & $9847^{\mathrm{d}}$ & 0.659 \\
\hline 2007-2009 & 324 & 1.07 & 0.02 & A & 53 & 0.99 & 0.06 & $A$ & 17 & 0.99 & 0.09 & A & 2.33 & 0.313 \\
\hline Distance to Road & 1000 & 130.2 & 3.8 & A & 266 & 100.4 & 6.2 & $\mathrm{~B}$ & 19 & 107.3 & 29.1 & $\mathrm{AB}$ & 14.20 & $<0.001$ \\
\hline $\begin{array}{l}{ }^{a} \text { Means with different letters } \\
\text { alpha }=0.05 \text {. } \\
\text { a Each 3-year period was test } \\
\text { c } \\
\text { cAWMSI = Area-weighted n } \\
\text { diversity index. }\end{array}$ & $\begin{array}{l}\text { ed separ } \\
\text { lean sha }\end{array}$ & $\begin{array}{l}\text { tely for } \\
\text { e index }\end{array}$ & $\begin{array}{l}\text { ariable } \\
\text { CWED }\end{array}$ & $=\mathrm{C}$ & $\begin{array}{l}\text { gnifica } \\
\text { ast-we }\end{array}$ & $\begin{array}{l}\text { int interac } \\
\text { ighted ed }\end{array}$ & $\begin{array}{l}\text { ctions } \\
\text { ge de }\end{array}$ & yea & $\begin{array}{l}\text { grou } \\
\text { nters }\end{array}$ & $\begin{array}{l}\text { p. } \\
\text { persio }\end{array}$ & & & $\mathrm{I}=\mathrm{Sh}$ & \\
\hline
\end{tabular}



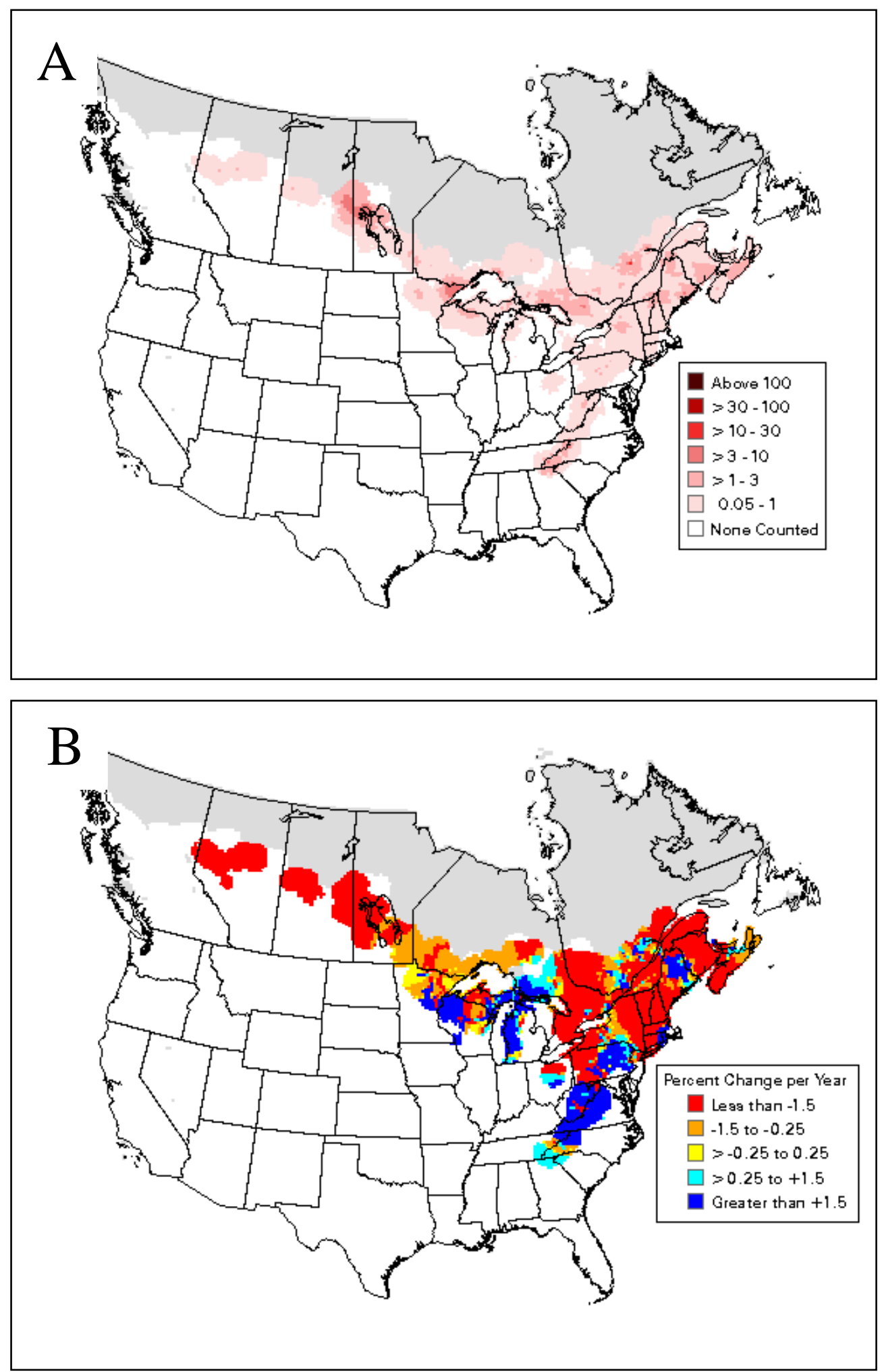

Appendix I. Canada Warbler breeding bird survey A) distribution map from 1994-2003 and B) trend map from 1966-2003 (Sauer et al. 2008). 
APPENDIX II. Weights assigned to each habitat combination for contrast-weighted edge density

\begin{tabular}{|l|l|l|l|l|l|l|l|l|l|l|}
\hline Habitats $^{\mathrm{a}}$ & 1 & 2 & 3 & 4 & 5 & 6 & 7 & 8 & 9 & 10 \\
\hline 1 & 0 & 1 & 0 & 1 & 1 & 0.5 & 1 & 1 & 0.25 & 0.75 \\
\hline 2 & 1 & 0 & 1 & 0 & 1 & 0.5 & 0 & 0.25 & 0.25 & 0.25 \\
\hline 3 & 0 & 1 & 0 & 1 & 1 & 0.5 & 1 & 1 & 0.25 & 0.75 \\
\hline 4 & 1 & 1 & 1 & 1 & 0 & 1 & 1 & 1 & 1 & 1 \\
\hline 5 & 1 & 0.25 & 1 & 0 & 1 & 0.5 & 0 & 0 & 0.25 & 0.35 \\
\hline 6 & 0.5 & 0.5 & 0.5 & 0.5 & 1 & 0 & 0.5 & 0.5 & 0.25 & 0.25 \\
\hline 7 & 1 & 0 & 1 & 0 & 1 & 0.5 & 0 & 0 & 0.25 & 0.25 \\
\hline 8 & 1 & 0.25 & 1 & 0 & 1 & 0.5 & 0 & 0 & 0.25 & 0.5 \\
\hline 9 & 0.25 & 0.25 & 0.25 & 0.25 & 1 & 0.25 & 0.25 & 0.25 & 0 & 0.25 \\
\hline 10 & 0.75 & 0.25 & 0.75 & 0.25 & 1 & 0.25 & 0.25 & 0.5 & 0.25 & 0 \\
\hline
\end{tabular}

${ }^{\mathrm{a}} 1$ = Mature Deciduous, 2 = Clear-cut, 3 = Mature Mixed, 4 = Grass, 5 = Road, 6 = Light Partial

Harvest, $7=$ Early Succession, $8=$ Developed, $9=$ Water, $10=$ Heavy Partial Harvest. 
APPENDIX III. Canada Warbler relative abundance regression tree models created using landscape metrics at the landscape, local, and combined scales at the Wildlife and Ecosystem Research Forest for each 3-year period of the study during 1996-2009.

1996-1998 Models

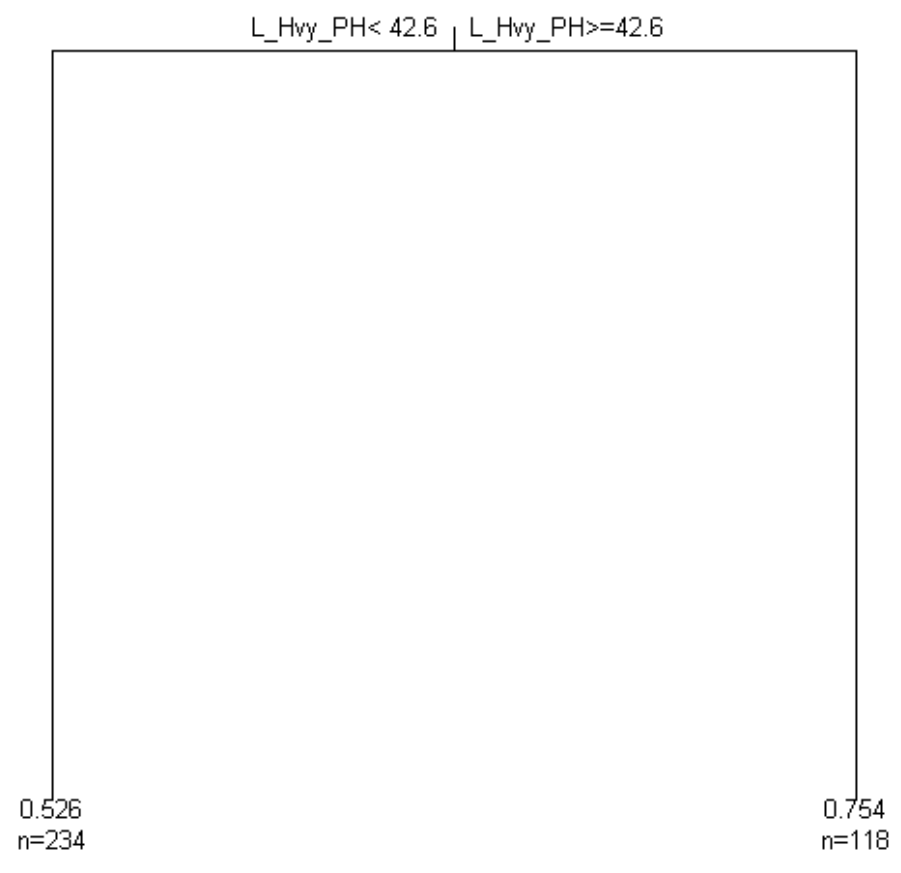

Error: 0.982 CV Error: 1.01 SE : 0.0873

Landscape Scale

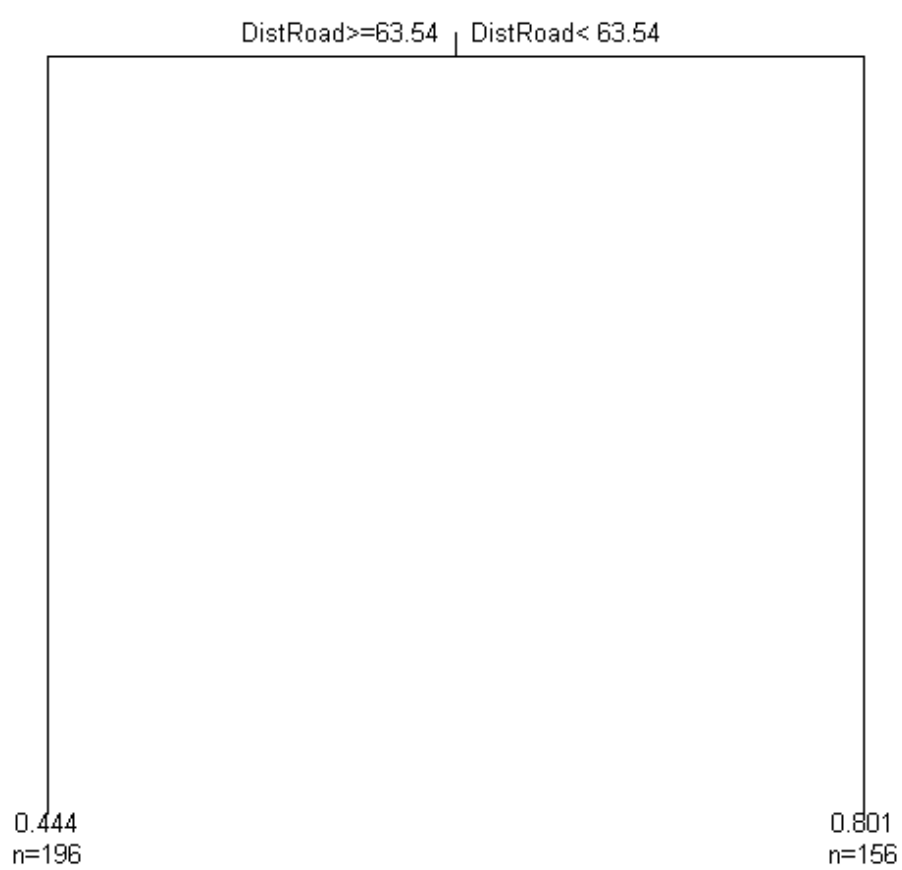

Error : 0.952 CV Error: 1.05 SE : 0.093

Local and Combined Scales 
APPENDIX III. Continued

2001-2003 Models

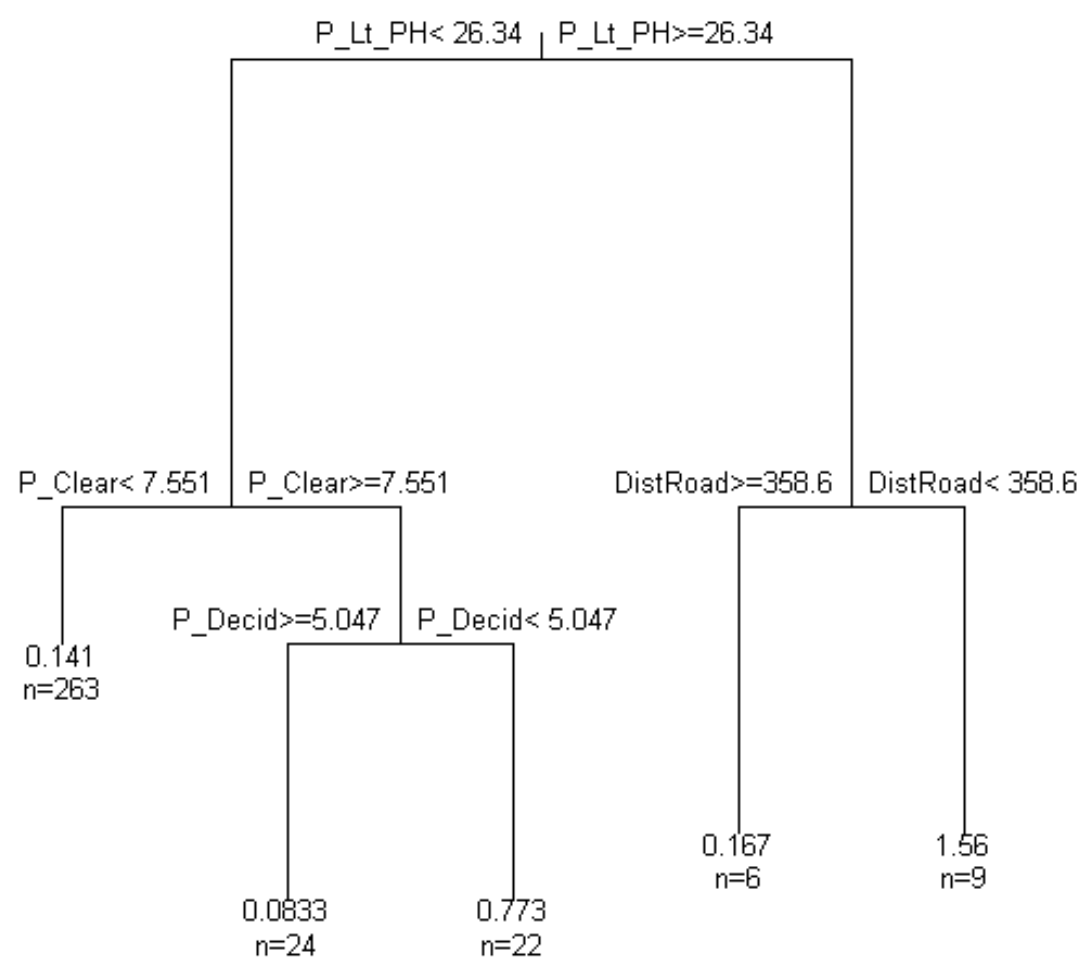

Error: 0.781 CV Error: 0.925 SE : 0.158

Local and Combined Scales 
APPENDIX III. Continued

2007-2009 Models

L $M i x>=617.2$ L $M i x<617.2$

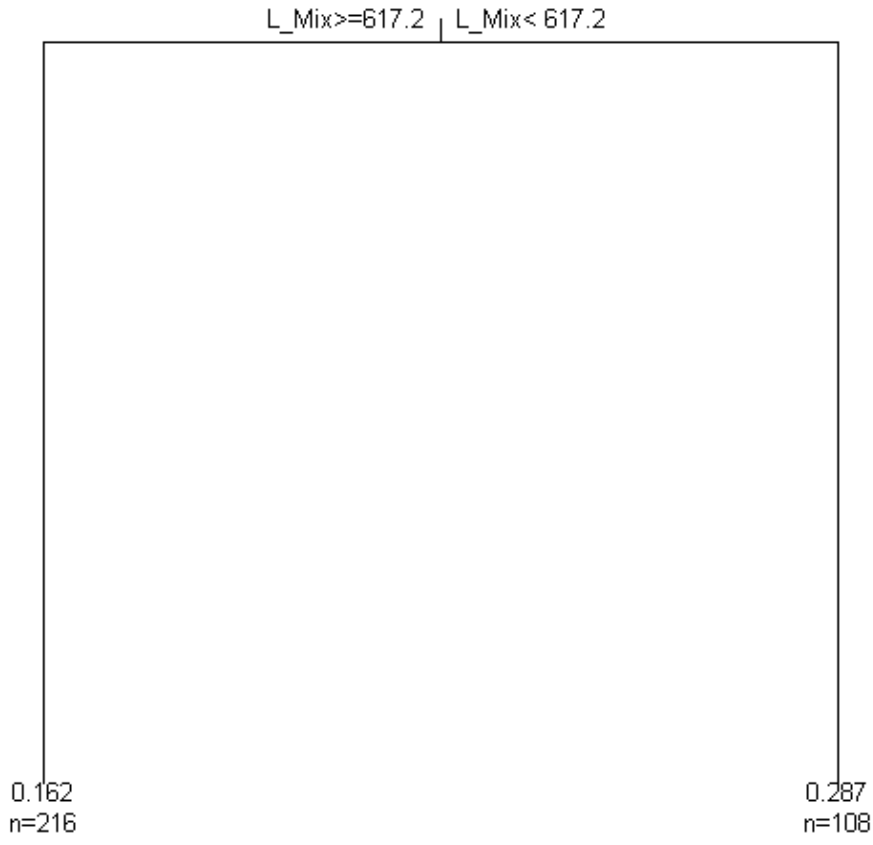

Error: 0.986 CV Error: 1.02 SE : 0.166

Landscape Scale
P_Lt_PH $<15.84$ P_Lt_PH $>=15.84$

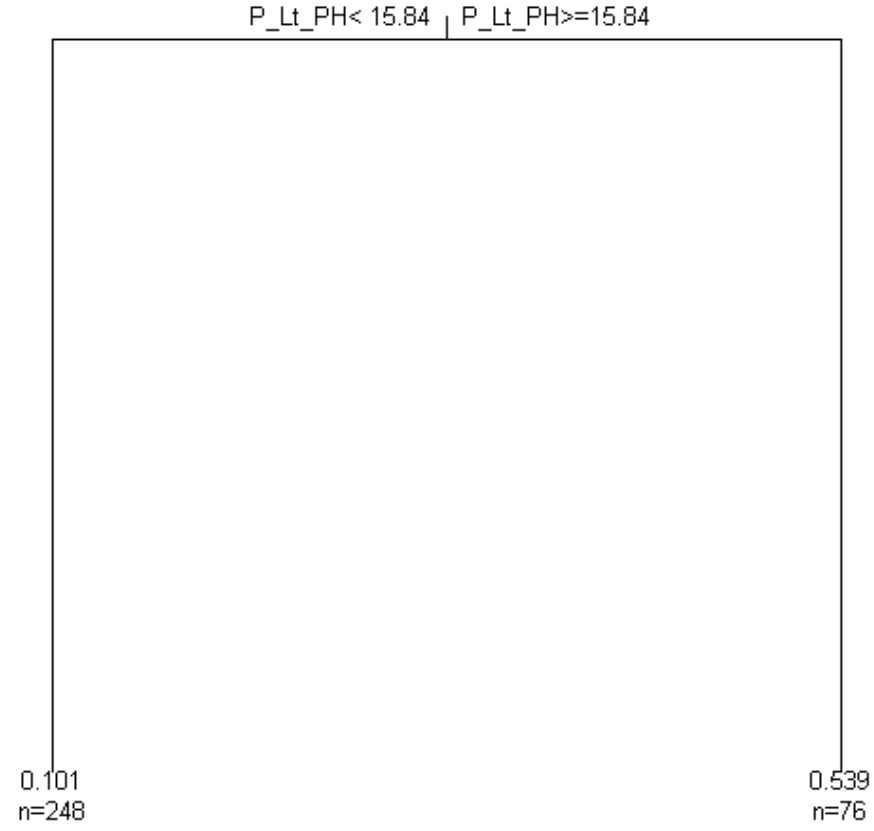

Error : 0.861 CV Error : 0.93 SE : 0.147

Local and Combined Scales 
APPENDIX IV. Canada Warbler classification tree models created comparing nests found in 1996-1998 to those in 20012003 and successful and unsuccessful nests at the Wildlife and Ecosystem Research Forest in 1996-2009

Early (E; 1996-1998) vs. Late (L; 2007-2009) Nests
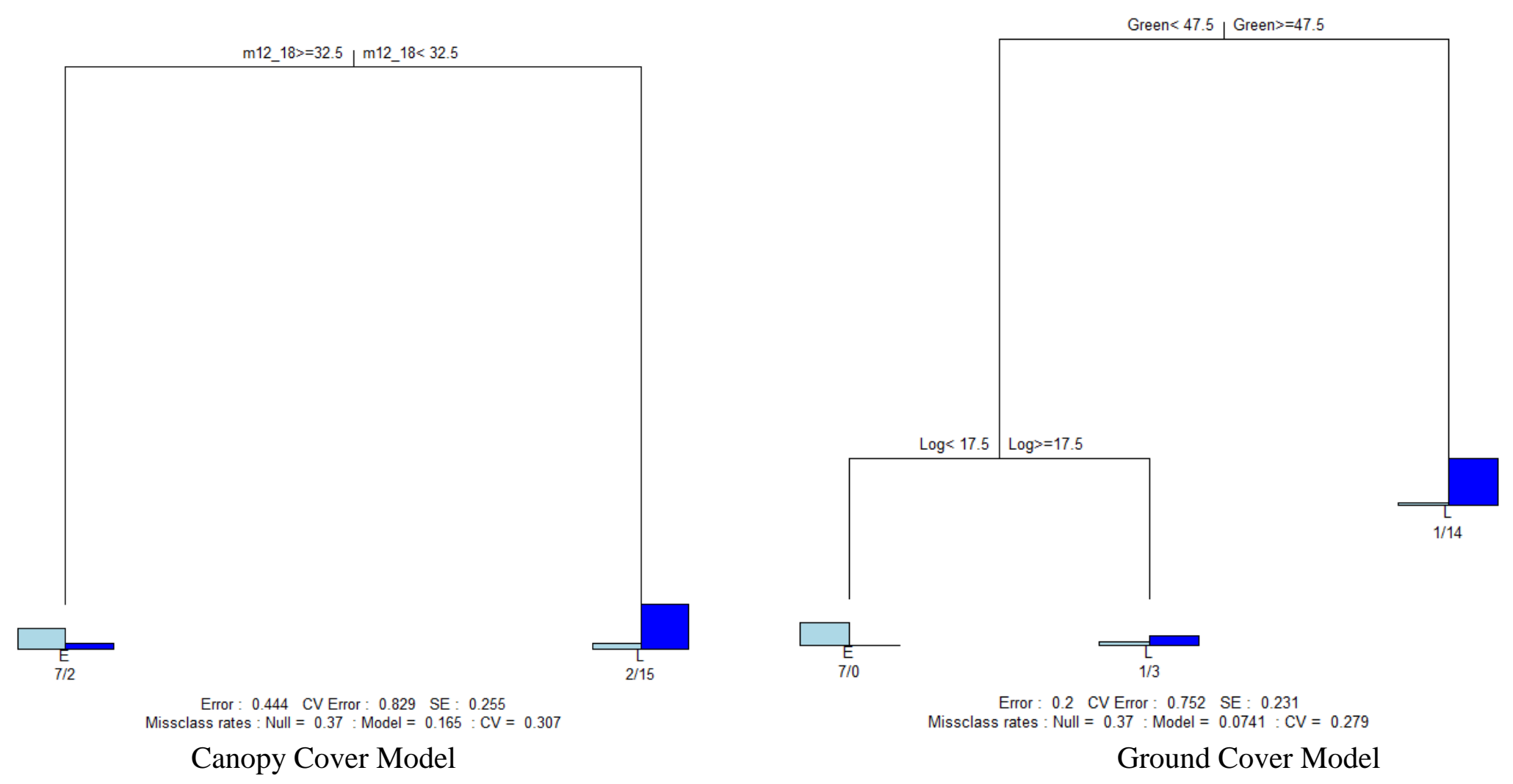
APPENDIX IV. Continued

Early (E; 1996-1998) vs. Late (L; 2007-2009) Nests
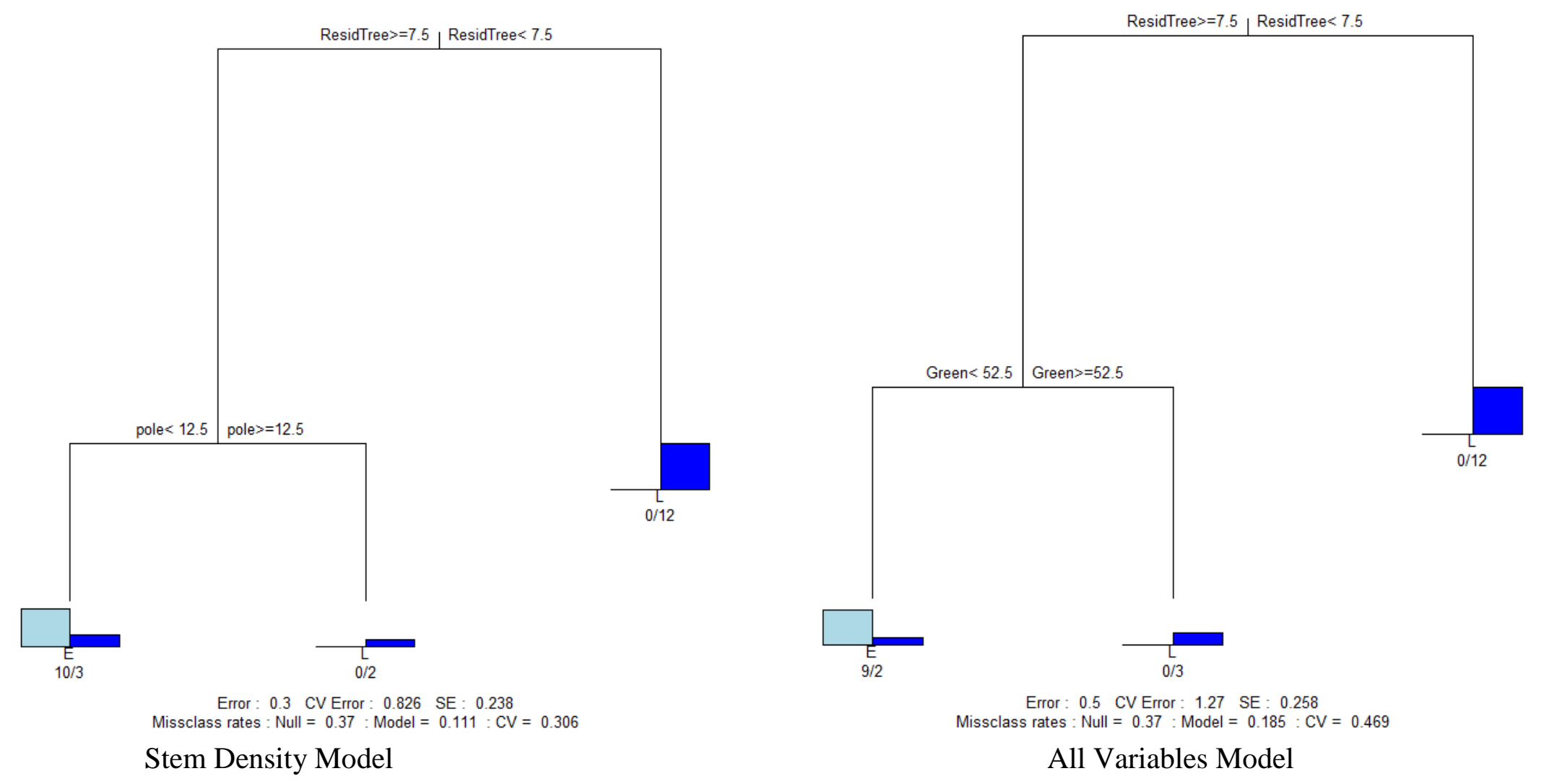


\section{APPENDIX IV. Continued}

Microhabitat at Successful (S) vs. Unsuccessful (F) Nests

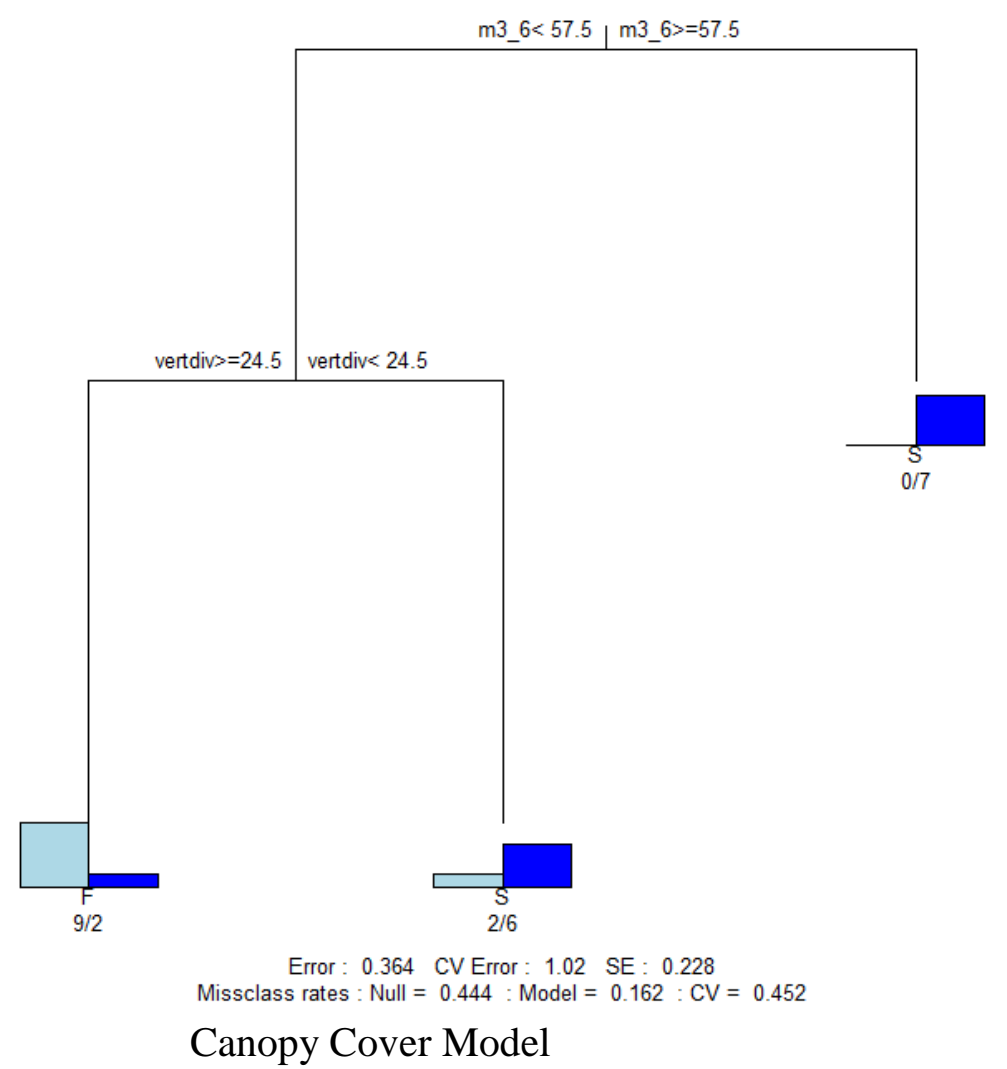

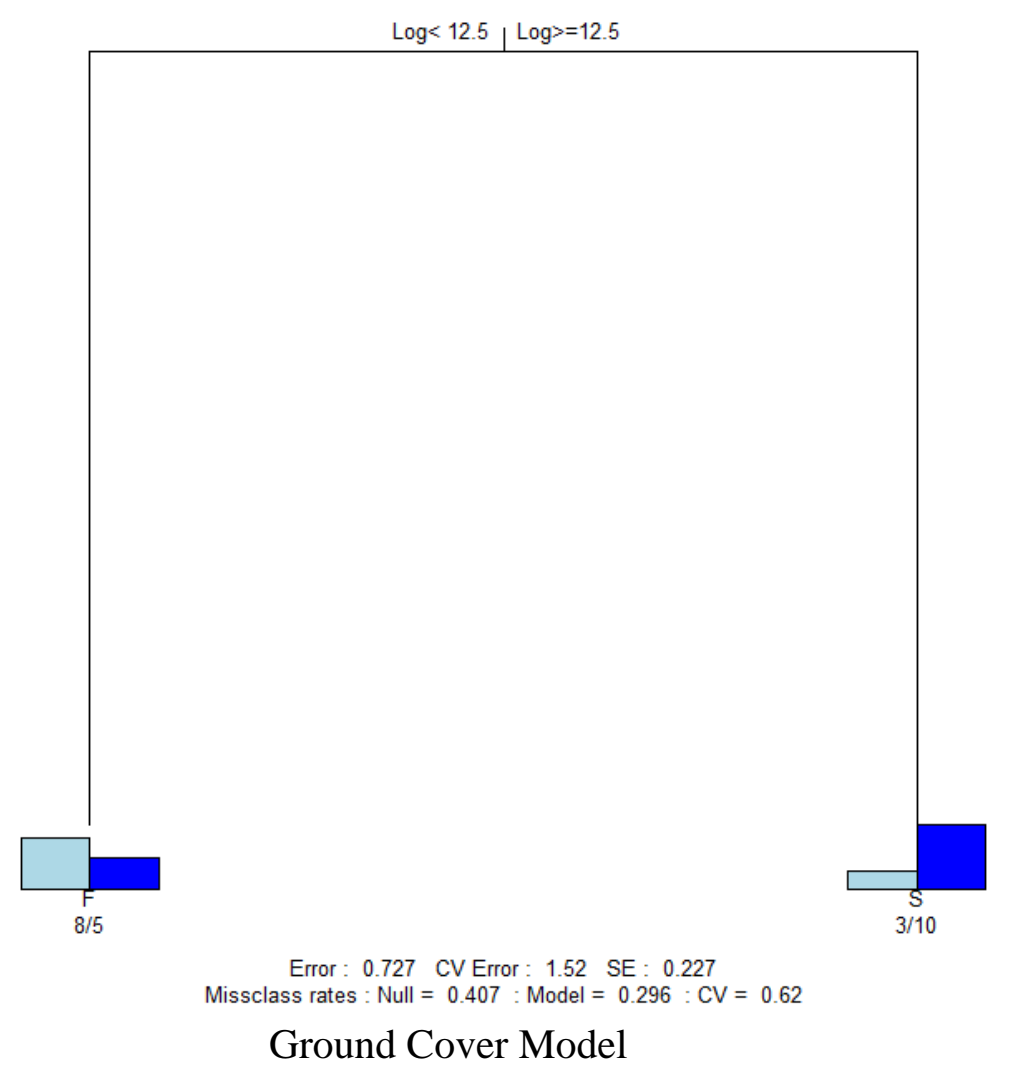




\section{APPENDIX IV. Continued}

Microhabitat Successful (S) vs. Unsuccessful (F) Nests
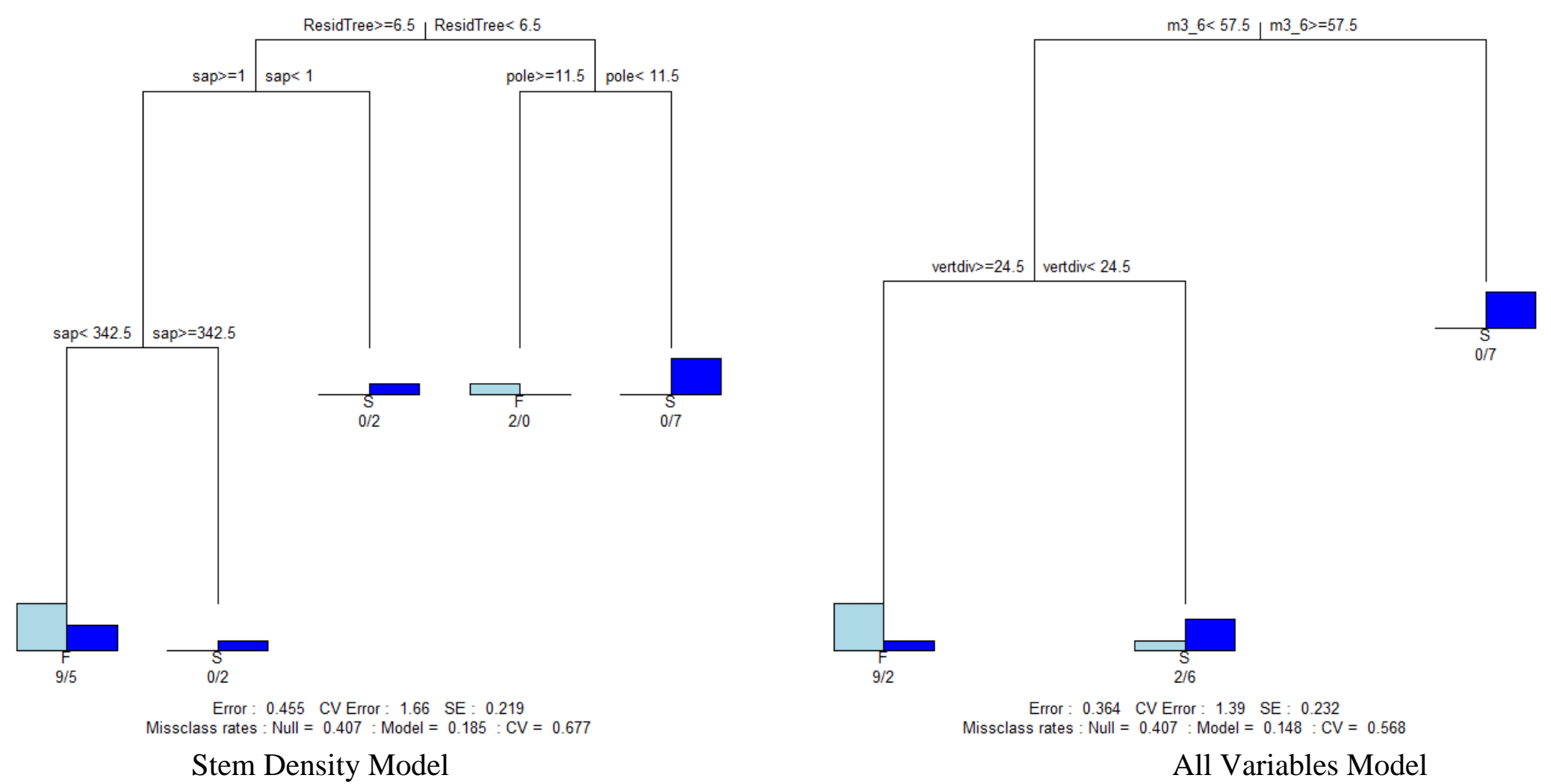


\section{APPENDIX IV. Continued}

Landscape Metrics at Successful (S) vs. Unsuccessful (F) Nests

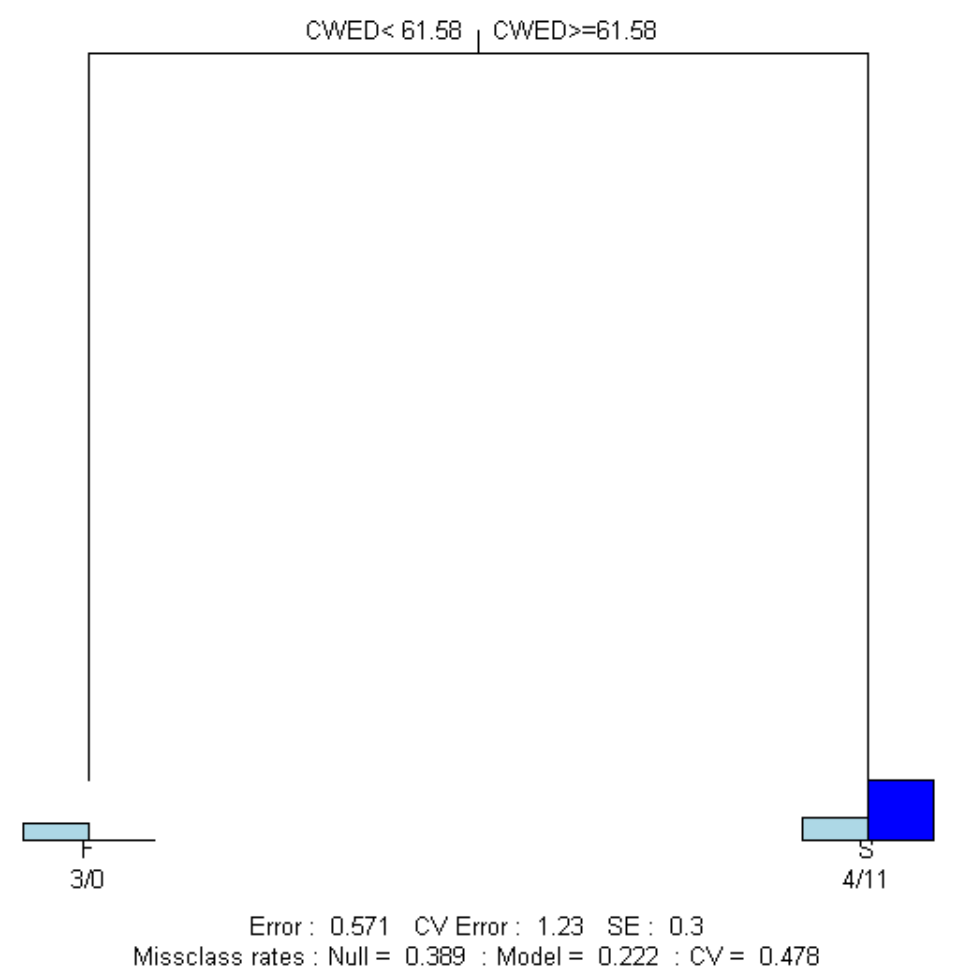

Local Scale Model 
Appendix V. Canada Warbler nest microhabitat variable summary

\begin{tabular}{|c|c|c|c|}
\hline Variable & Mean & Max & Min \\
\hline \multicolumn{4}{|l|}{ Canopy cover $(\%)$} \\
\hline$<3 \mathrm{~m}$ & 37.7 & 85 & 0 \\
\hline $3-6 m$ & 39.4 & 95 & 5 \\
\hline$>6-12 \mathrm{~m}$ & 33.1 & 75 & 0 \\
\hline$>12-18 \mathrm{~m}$ & 26.9 & 80 & 0 \\
\hline$>18-24 m$ & 21.3 & 80 & 0 \\
\hline$>24 \mathrm{~m}$ & 12.7 & 80 & 0 \\
\hline Vertical Diversity & 34.2 & 66 & 5 \\
\hline \multicolumn{4}{|l|}{ Ground Cover (\%) } \\
\hline Green & 48.7 & 90 & 0 \\
\hline Grass & 5.2 & 20 & 0 \\
\hline Shrub & 26.0 & 75 & 0 \\
\hline Herb & 5.8 & 35 & 0 \\
\hline Fern & 12.9 & 40 & 0 \\
\hline Leaf litter & 23.8 & 70 & 0 \\
\hline Woody debris & 13.3 & 60 & 0 \\
\hline Moss & 3.9 & 35 & 0 \\
\hline Bare & 9.2 & 30 & 0 \\
\hline Residual trees (\#) & 11.1 & 28 & 1 \\
\hline Pole trees $(\#)$ & 6.4 & 45 & 0 \\
\hline Saplings (\#) & 163 & 467 & 0 \\
\hline \multicolumn{4}{|l|}{ Concealment (\%) } \\
\hline Average & 72.3 & 100 & 25 \\
\hline Overhead & 70.6 & 100 & 0 \\
\hline North & 80.2 & 100 & 0 \\
\hline East & 78.9 & 100 & 10 \\
\hline South & 76.7 & 100 & 0 \\
\hline West & 53.2 & 100 & 0 \\
\hline
\end{tabular}

